UNITED STATES DEPARTMENT OF COMMERCE

R. P. LAMONT, Secretary

BUREAU OF MINES

SCOTT TURNER, Director

Bulletin 307

\title{
FLOW OF GASES \\ THROUGH BEDS OF BROKEN SOLIDS
}

BY

C. C. FURNAS

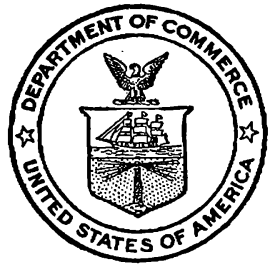

UNITED STATES

GOVERNMENT PRINTING OFFICE

WASHINGTON : 1929 



\section{CONTENTS}

Introduction

Complexity of problem

Scope of present work

Work of previous investigators

Acknowledgments

Summary of findings

Variables studied

Accuracy

Gases used

Apparatus, experimental method, and theoretical considerations

Air supply

Manometers

Calibration of meter

Details of equipment and procedure

Experimental analysis of tortuous flow

"Synthetic fuel bed".......

Variables involved........

Opportunity for expansion and its effect upon $A$...

Effect of size of passage upon $B$

Probable mechanism of flow

Objections to explanation of mechanism of flow....

Pressure drop through layered beds

Hypothetical system Approximate law of flow.--

Concept of size..........

Equivalent spherical diameter.

Shape factor.

Normal packing

Concept of resistence

Experimental work on sized materials _................

Résumé of materials used...

Effective free area and lifting velocity
Page
Experimental work on sized materials-Continued.

Change of $B$ with size of particle

Detailed study of important variables

Effect of container surface. Effect of depth of bed..

Variation of pressure drop with total pressure........

Standardization of pressure drop.

Packing . . . 30

Wall effect.................. 35

Mathematical analysis for circular containers.......

Voids next to wall . ........-

Area affected by wall .....

Extent of packing to restore original average voids _. . . . . . . . . . . .

Use of equations........-

Computation of the value of $d$

Evaluation of $M$

Error in assumptions.......

Utility of values of $A_{t} \ldots \ldots$...

Standardization of succeeding data

Variation of $A$ with particle size

General disc

Relation of resistance and lifting velocity .........

Choice of point for comparison of sizes...........

Point of reference.......

Systems studied...........

Summary ................

Factors that influence $J_{-.-}$

Relative influence of two phases...............

Variation of resistance with shape of particle

Factors that influence $\bar{K}$.-.

Definition of terms ........ 
Experimental work on sized materials-Continued.

Variation of resistance with shape of particle--Con.

Quantities that influence $K_{1}$ and $K_{1 \infty \ldots} \ldots \ldots$

Quantitative law of variation of $K_{1 \infty} \ldots \ldots$

Significance of specific resistance ..............

Equation for specific resistance.................

Relation between shape factor $F$ and normal voids $V_{n--}$

Utility of relation.......

Prediction of pressure drop for sized materials........

Sample computation.......

Mixtures of sizes: Two-component systems. ............

General considerations

Former work

Materials of this investigation........................

Experimental method .......

Effect of size composition on pressure drop at a specified rate of flow .......

Basis of comparison of systems.

Experimental data.........

Law of the maximum ........

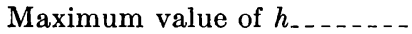

Lowering resistance by using more than two components.

Rule of mixtures...........

Positions of resistance maxima

Generalization of data...... -

Effect of separation of constituent sizes.

Variation of exponent $B$ with cemposition in binary systems

Application of $B$ relation. - -

Computation of wall-effect factor ..................

Voids in binary systems: Normal packing. ............

Specific volume relations.....

Law for specific volumes of binary mixtures........

Errors in observation.....

Applications ...........

Systems of more than two components...........

Systems involving a iiquid_
Page

Gas flow through systems of more than two component sizes....................

Experimental method.......

Apparatus..............

Experimental procedure.....

Consideration of typical data Variability of transition stage

Materials studied

Prediction of pressure drop in systems of many component sizes.

Size of materials blown from bed.

Sample computation......

Degree of reliability of predictions.................

Method of prediction for special case -

Effect of moisture

101

Effect of temperature........

Apparatus..........................

Operation...

101

102

102

104

Data obtained............. 104

General discussion of results_- 104

Effect of varying density and viscosity of gas.

106

General discussion........

Evidence of applicability of Fanning's equation.....

Variation of $B$ with $\frac{s}{z}$-...--

Effect of specific gravity and viscosity of gas on values of $A$

106

107

108

Temperature effect on air -

Variation of $A$ with gas composition

Effect of molecular weight of gases.

Mixtures of gases

Sample computation of effect of changing temperature and gas composition......

\section{6}

\section{4} 6

07

Effective temperature of a system................... 125

Pressure drop in long columns_. $\quad 125$

Example................. 126

Magnitude of error for smaller pressure drops........... 127

Conclusions_................ 127

Future work _............ 128 
Appendix I. Summary of equations

Sized material

Two component sizes

Systems of many component sizes.

Means of approximation.....

Change of units..........

Pressure drop in columns of more than unit length ..... -

Pressure drop in long columns.

Total pressure drop if temperature or gas composition varies in the column

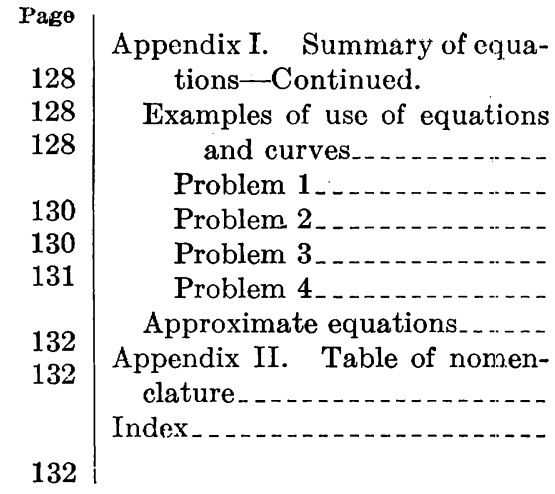
132

132

134

135

136

137

137

141

\section{ILLUSTRATIONS}

Fig.

1. Qualitative relations between friction factor in gas-flow equation and modulus $\frac{d u s}{z}$

2. Sketch of apparatus for determining pressure drop in beds of broken solids.

3. Apparatus for determining pressure drop in beds of broken solids....

4. Apparatus for determining pressure drop in beds of broken solids....-

5. Synthetic fuel bed

6. Variation of $\frac{\operatorname{total} A}{\text { number of plates }}$ with length of expansion chamber in synthetic fuel bed.

7. Variation of exponent $B$ for synthetic fuel bed with cross-sectional area of passages

8. Pressure drop in layered beds of lead shot in a 3-inch pipe

9. Hypothetical systems of broken solids; resistance in parallel and in series.

10. Cross sections of beds of Cuyuna iron ore (full size) : $a, 0.525$ to 0.371 inch; $b, 2$ to 3 mesh

11. Cross sections of beds of Cuyuna iron ore (full size): $a, 3$ to 4 mesh; $b$, 4 to 6 mesh.

12. Cross sections of beds of Cuyuna iron ore (full size): $a, 6$ to 8 mesh; $b, 14$ to 20 mesh

13. Cross sections of beds of iron ore (full size) : $a, 28$ to 35 mesh Cuyuna ore; $b, 3$ to 4 mesh Mesabi ore . . . .

14. Cross sections of beds of Mesabi iron ore (full size): $a, 4$ to 6 mesh; $b, 8$ to 10 mesh.

15. Cross sections of beds of broken solids (full size): $a, 4$ to 6 mesh coke; $b, 3$ to 4 mesh Vermilion iron ore ...

16. Cross sections of beds of broken solids (full size): $a, 3$ to 4 mesh roll scale; $b$, No. 000 shot.

17. Cross sections of beds of broken solids (full size) : $a$, No. 000 shot; $b, 4$ to 6 mesh limestone.

18. Cross sections of beds of Cuyuna iron ore (full size): $a, 70$ per cent 0.525 to $0.3 \% 1$ inch plus 30 per cent 10 to 14 mesh; $b, 70$ per cent 0.525 to 0.371 inch plus 30 per cent 10 to 14 mesh.

19. Cross section of bed of 1.050 to 0.742 inch limestone (full size) . ..... 
Fig.

20. Variation of $B$ (exponent of equation) with sizes of particles . . ........

21. Variation of standard pressure drop with rate of gas flow ..............

22. Variation of $B$ with average cross-sectional areas of particles. ..........

23. Comparison of pressure drops in columns of broken solids in brass and iron 2-inch pipes, using 1,874 grams of 2 to 3 mesh Cuyuna ore 73.35 centimeters deep and having 63.6 per cent voids.................

24. Effect of depth of bed of 2 to 3 mesh Cuyuna ore with 63.8 per cent voids on unit resistance to gas flow through beds of broken solids. -

25. Variation of pressure drop with total over-all pressure for 2 to 3 mesh Cuyuna ore having 63.8 per cent voids ..........................

26. Variation of pressure drop with total over-all pressure for 2 to 3 mesh

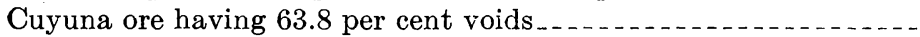

27. Correction of pressure drop to standard gas density for 10 to 14 mesh Cuyuna ore, runs 234 and 235

28. Variation of unit pressure drop with packing of Cuyuna iron ore No. 1, 10 to 14 mesh.

29. Variation of pressure drop with packing of 14 to 20 mesh Cuyuna ore -

30. Effect of packing on value of $A$

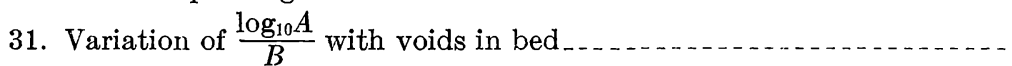

32. Relation between $A$ and $d / D$

33. Computed relation between $A_{t}$ and $d / D$

34. Computed relation between $A_{t}$ and $d / D \ldots \ldots$

35. Large-scale plot of $\log _{{ }_{10}} \Delta P P_{S} v \cdot \log _{10} R$ for Cuyuna ore

36. Relation between pressure drop and size of particle for Cuyuna ore, runs 16 to $22,30,33$ to 35,38 to 43 , and for lead shot, runs 51 to 53 , 56 to 58 , and 65 , with normal voids and Ray and Kreisinger data_

37. Relation between pressure drop and size of particle for Mesabi ore, runs 73, 78, and 82 to 85 . Anthracite data of Brooks, Nicholls, and others.

38. Relation between average normal voids and exponent of cquation (30).

39. Relation between $K_{1 \infty}\left(=\Delta P_{S \infty}\right.$ when $R=0.1, d=1$, and $\left.V_{n}=0.50\right)$ and $F$ $\overrightarrow{V_{x}}$

40. Relation between shape factor and normal voids . . . .

41. Comparison of predicted and observed pressure drops

42. Components of resistance in a bed of mixed sizes . . . . .

43. Pressure drop at a flow of 0.1 liter per second per square centimeter for various binary systems

44. Relation between maximum pressure drop and pressure drop through small constituent in two-component systems

45. Relative pressure drops in two-component systems when normal voids in the large constituent $=0.40$ and $R=0.1$

46. Relative pressure drops in two-component systems when normal voids in the large constituent $=0.50$ and $R=0.1 \ldots$

47. Relative pressure drops in two-component systems when normal voids in the large constituent $=0.60$ and $R=0.1 \ldots$

48. Variations of $B$ with composition in binary mixtures

49. Relative values of $B$ in two-component systems; all values relative to $B$ for the large constituent. . . . .

50. Voids in two-component systems . . . . . . .

51. Relation between voids and size composition in two-component systems of broken solids when voids of single components $=0.40 \ldots$ 
Fig.

52. Relation between voids and size composition in two-component systems of broken solids when voids of single components $=0.50$

Page

3. Relation between voids and size composition in two-component systems of broken solids when voids of single components $=0.60$

54. Speific volume relations in two-component lead-shot systems

55. Specific volume relations in two-component systems of lead shot and Cuyuna ore

56. Approximate specific volumes for different size ratios in two-component systems in which true gravity of each component $=1$ and normal voids for each component $=0.50$

57. Theoretical specific volume of a mixture of water and Cuyuna ore for various concentrations.

58. Views of apparatus for determining pressure drop through systemis of mixed sizes .

59. Apparatus for determining pressure drop through beds of mixed sizes_

60. Typical data for a bed of material in which fine particles are lifted ...-

61. Pressure drop in a bed containing a great deal of fine material; run 208.

62. Size analyses of some systems of many components

63. Relation between resistance factor and $B$ for systems of mixed sizes.-

64. Relation between resistance factor in systems of many sizes and pressure drop at a constant rate of flow of 0.1 liter per second per square centimeter.

65. Apparatus for study of gas flow at elevated temperatures

66. View of apparatus for determining pressure drop at elevated temperatures.

67. Pressure drop for air at various temperatures

68. Variation of viscosities of gases with temperature

69. Relation between $n$, specific gravity, and viscosity of gas for various initial values of $n$

70. Relation between $B$, gaseous viscosity, and specific gravity for various initial values of $B$

71. Relation between $B$ and temperature for air at various initial values of $B$.

72. Standard pressure drop against rate of flow for various temperatures.

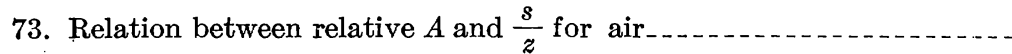

74. Relation between relative $A$ and $T$ for air

75. Relation between $A$ and $T$ for air for a particular system

76. Pressure drop for various rates of flow for different gases

77. Pressure drop for various rates of flow for different gases . . . . . .....

78. Observed and computed relations between $A$ and $\frac{s}{z}$ with changing gas composition for two different systems

79. Viscosity of gaseous mixtures 



\title{
FLOW OF GASES THROUGH BEDS OF BROKEN SOLIDS ${ }^{1}$
}

\author{
By C. C. Furnas
}

\section{INTRODUCTION}

Although a number of the most important industrial processes depend upon efficient contact between a bed of broken solids and a stream of moving gas or vapor, up to the present time very little work has been done on the laws that govern the flow of fluids through such beds. If new apparatus is built, old apparatus changed, or the mechanism of a process involving the above system altered, there are no means whereby a designer or engineer can predict the amount of pressure that will be necessary to force a given amount of gas through a given bed of broken material. Further, he has no definite means of ascertaining what arrangement of materials in the bed will give him the greatest efficiency of contact between gas and solid.

Information of this type is especially applicable to the detailed study of the physical and chemical reactions taking place within the iron blast furnace.

The North Central Experiment Station of the Bureau of Mines has undertaken a laboratory study of blast-furnace phenomena with the intention of eventually formulating a more or less complete quantitative theory of the physical and chemical reactions within the furnace. The first phase of this work has been the laboratory study of the flow of gases through beds of broken solids. In so far as possible the results of the work have been formulated into general laws, but special attention has been paid to the particular materials entering into the blast-furnace processes.

The data presented in this report are to be correlated in a later publication with data obtained for gas flow in commercial furnaces, thus affording a means of intelligently criticizing present blast-furnace practice and of suggesting and criticizing innovations.

The author does not wish to convey any false impressions as to the fundamental character of the work. It has not been fundamental from the viewpoint of the physicist and may not be pleasing to him in that Bernoulli's theorem or some such generalization has not been employed. The reason is evident as soon as a slight excursion is

1 Work on manuscript completed July, 1928. 
made into the study of the problem-it is too complex to lend itself readily to complete analysis. To explain all of the phenomena completely, no doubt, would take a great deal of experimental work, and the results probably would serve the purpose no better than those now attained.

The basis of the work has been purely empirical, but wherever possible the relations between variables have been generalized so that the field of application is not limited to the materials and conditions of the experiment. This, of course, involves considerable mathematical development, and the results may not all be considered as grossly empirical. It depends upon the point of view.

Throughout the text the word "law" occurs frequently. This is a misnomer and is used only for want of a better word. The proper phrase would be "apparent relation between variables," but this is awkward, and "hypothesis" is inapplicable in that nothing has been hypothesized. So the word "law" in this report really implies that as far as the author can perceive the given statement is the best explanation of the data.

Too much can not be expected of the accuracy of the work. The estimated accuracy is indicated in the different sections.

\section{COMPLEXITY OF PROBLEM}

This problem is one involving several variables; the development of the theory as presented in this report is necessarily quite complex, and all of the principles involved can not be understood without careful reading and thought.

As far as possible the physical laws have been formulated into mathematical equations, which are summarized at the end of this report. The characteristic constants of the materials and systems studied have been tabulated throughout the work in the form of tables and curves. With these data it should be possible for any operator or engineer without further knowledge to compute the pressure drops and gas distributions for beds of broken solids of uniform size and for most systems of mixed sizes. It would be desirable, however, for anyone interested in this subject to acquaint himself with the development of the theory as presented in detail in this bulletin.

\section{SCOPE OF PRESENT WORK}

Two hundred and fifty-eight separate sets of data have been obtained and correlated in this work. In all instances the data have taken the form of the pressure required to force gas through a given system under given conditions.

Definite laws have been formulated that make it possible to predict with a reasonable degree of accuracy the resistance to gaseous flow of a bed of broken solids of sized material. It has not been possiblo 
to formulate general laws for systems involving all mixtures of sizes, but many data have been taken and recorded for such systems and compiled into rules of somewhat limited application.

The materials used have ranged in size from minus 100-mesh dust to pieces 25 centimeters in diameter. Data have been taken on lead shot, various iron ores, limestone, coke, and roll scale. Most runs have been made with air; a few data have been taken on hydrogen and carbon dioxide. Temperatures have ranged from $20^{\circ}$ to $660^{\circ} \mathrm{C}$. A résumé of the constants for most of the different materials and conditions will be found in Table 1 .

TABLE 1.-Physical constants of materials

\begin{tabular}{|c|c|c|c|c|c|c|c|}
\hline Material & $\begin{array}{l}\text { Screen size, square } \\
\text { mesh }\end{array}$ & $\begin{array}{l}\text { Specific } \\
\text { gravity, } \\
\text { average }\end{array}$ & $\left|\begin{array}{c}\text { Weight } \\
\text { per } \\
\text { piece, } \\
\text { average } \\
\text { in grams } \\
\text { of } 500 \\
\text { pieces }\end{array}\right|$ & $\begin{array}{l}\text { Equiv- } \\
\text { alent } \\
\text { spher- } \\
\text { ical } \\
\text { diam- } \\
\text { eter } 1\end{array}$ & $\begin{array}{l}\text { Aver- } \\
\text { age } \\
\text { screen- } \\
\text { size } \\
\text { open- } \\
\text { ings }\end{array}$ & $\begin{array}{l}\text { Shape } \\
\text { factor }{ }^{2}\end{array}$ & $\begin{array}{c}\% \text { voids } \\
100 \\
\text { for } \\
\text { nor- } \\
\text { mal } 3 \\
\text { packing }\end{array}$ \\
\hline $\begin{array}{l}\text { Cuyuna ore No. } 1_{--} \\
\text {Cuyuna ore No. } 2 .\end{array}$ & $\left\{\begin{array}{l}0.525-0.371 \text { inch } \\
2 \text { to } 3 \text { to } 4 \\
4 \text { to } 6 \\
10 \text { to } 14 \\
6 \text { to } 8 \\
14 \text { to } 20\end{array}\right.$ & $\begin{array}{l}\text { 3. } 34 \\
\text { 3. } 32 \\
\text { 3. } 25 \\
\text { 3. } 17 \\
\text { 3. } 18 \\
\text { 3. } 58 \\
\text { 3. } 56\end{array}$ & $\begin{array}{l}1.173 \\
.481 \\
.165 \\
.0602 \\
.00249 \\
.0375\end{array}$ & $\begin{array}{r}\text { Centi- } \\
\text { meters } \\
0.876 \\
.652 \\
.460 \\
.331 \\
.114 \\
.271\end{array}$ & $\begin{array}{l}\text { Centi- } \\
\text { meters } \\
1.138 \\
.805 \\
.569 \\
.401 \\
.141 \\
.285 \\
.100\end{array}$ & $\begin{array}{l}0.77 \\
.81 \\
.81 \\
.81 \\
.81 \\
.95 \\
-.9\end{array}$ & $\begin{array}{l}0.638 \\
.638 \\
.638 \\
.638 \\
.638 \\
.488 \\
.551\end{array}$ \\
\hline $\begin{array}{l}\text { Cuyuna ore No. } 3 \\
\text { Mesabi ore No. } 1 \text {, run of } \\
\text { mine. }\end{array}$ & $\begin{array}{l}28 \text { to } 35 \\
4 \text { to } 6\end{array}$ & $\begin{array}{l}3.30 \\
4.02\end{array}$ & .0944 & .358 & $\begin{array}{l}.0503 \\
.401\end{array}$ & .89 & $\begin{array}{l}.651 \\
.568\end{array}$ \\
\hline $\begin{array}{l}\text { Mesabi ore No. 2, crushed } \\
\text { and washed. } \\
\text { Vermilion ore } \\
\text { Roll scale. }\end{array}$ & 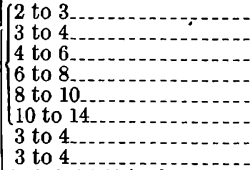 & $\begin{array}{l}3.94 \\
3.98 \\
3.97 \\
4.01 \\
4.04 \\
4.06 \\
4.98 \\
5.19\end{array}$ & $\begin{array}{l}.876 \\
.300 \\
.107 \\
.0402 \\
.0140 \\
.00460 \\
.407 \\
.166\end{array}$ & $\begin{array}{l}.750 \\
.524 \\
.372 \\
.267 \\
.188 \\
.129 \\
.539 \\
.394\end{array}$ & $\begin{array}{l}.805 \\
.569 \\
.401 \\
.284 \\
.201 \\
.141 \\
.569 \\
.569\end{array}$ & $\begin{array}{l}.93 \\
.92 \\
.93 \\
.94 \\
.94 \\
.92 \\
.95 \\
.69\end{array}$ & $\begin{array}{l}.520 \\
.523 \\
.540 \\
.540 \\
.530 \\
.528 \\
.519 \\
.588\end{array}$ \\
\hline Limestone. & $\left\{\begin{array}{l}1.050-0.742 \text { inc } \\
4 \text { to } 6\end{array}\right.$ & $\begin{array}{l}2.59 \\
2.59\end{array}$ & 19. 0 & $\begin{array}{l}2.41 \\
367\end{array}$ & 2. 28 & 1.06 & .541 \\
\hline Lead shot_. & $\left\{\begin{array}{l}4 \text { to } 6 \\
\text { Size, No. 000 } \\
\text { Size, No. TT T } \\
\text { Size, No. B } \\
\text { Size, No. } 8 \\
\text { Size, No. 12 }\end{array}\right.$ & \begin{tabular}{r|}
1.24 \\
11.33 \\
11.30 \\
11.22 \\
11.61 \\
11.44
\end{tabular} & 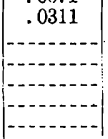 & $\begin{array}{l}.363 \\
.905 \\
.544 \\
.450 \\
.227 \\
.138\end{array}$ & \begin{tabular}{c}
.401 \\
\hdashline-4 \\
\\
\hdashline
\end{tabular} & $\begin{array}{l}.91 \\
1.00 \\
1.00 \\
1.00 \\
1.00 \\
1.00\end{array}$ & $\begin{array}{l}. .565 \\
.414 \\
.384 \\
.394 \\
.380 \\
.414\end{array}$ \\
\hline
\end{tabular}

${ }^{3}$ Defined on p. 18.

\section{WORK OF PREVIOUS INVESTIGATORS}

Despite the importance of this study, very little organized effort has been centered on the problem. Considerable attention has been paid to related subjects, such as the slow diffusion of gases through metal plates, the seepage of water through ground strata, and the flow of water through filter beds, but data from these studies have but little bearing on the subject at hand.

Storrow ${ }^{2}$ collected a few data on the subject, but they were not properly correlated or interpreted. Zeisberg ${ }^{3}$ determined some con-

2 Storrow, J. T., The Flow of Air Through Small Coals and Other Broken Material: Trans. Inst. Min. Eng., vol. 55, 1917-18, pp. 313-317.

${ }^{3}$ Zeisberg, F. C., Resistance of Absorption Tower Packing to Gas Flow: Chem. and Met. Eng., vol. 21,1919, p. 765 . 
stants which would apply to packed still columns but formulated no general laws. Royster and Hartgen ${ }^{4}$ have obtained some scattered data but not enough to be used in the formulation of definite laws. Cotton ${ }^{5}$ gives a few data on the pressure required to force given amounts of air through specified fuel beds. Ray and Kreisinger ${ }^{6}$ have obtained some data on two sizes of lead shot, Nos. 4 and 8 .

Blake ${ }^{7}$ working with a limited number of data on glass and earthenware rings and on crushed pumice stone generalized on the subject with the aid of the methods of dimensional analysis such as are used for the treatment of fluid flow through conduits.

Burke and Plummer ${ }^{8}$ enlarged somewhat on the theory presented by Blake and obtained data on several three component mixtures of lead shot.

The most complete work to date is that of Brooks, Nicholls, Augustine, and Orr, ${ }^{9}$ of the Pittsburgh Experiment Station of the Bureau of Mines. They gathered data for nine different sizes of anthracite and worked with two component mixtures of sizes. They analyzed the problem carefully and found that 17 different variables were involved. It is unfortunate that this wori was not carried to the point at which definite general laws could be formulated, as many valuable data were collected in the course of the investigation. The data presented by these various authors are given in appropriate places in this bulletin.

\section{ACKNOWLEDGMENTS}

The author wishes to acknowledge the aid and suggestions throughout the progress of the work of T. L. Joseph, supervising engineer of the North Central Experiment Station of the Bureau of Mines; O. C. Ralston, former supervising engineer of the Pacific Experiment Station of the bureau at Berkeley, Calif., and assistant chief metallurgist of the bureau; S. P. Kinney and C. G. Maier, metallurgists, and W. F. Holbrook, assistant chemist, of the bureau; M. D. Hersey, physicist, United States Bureau of Standards; and W. B. Plummer, of the Combustion Utilities Corporation.

\section{SUMMARY OF FINDINGS}

The flow of gases through beds of broken solids has very appropriately been referred to as "tortuous" flow because of the very irregular character of the path followed by any portion of the gas

\footnotetext{
4 Royster, P. H., and Hartgen, F. A., Resistance of Solids to Fluid Flow: Bureau of Mines unpublished work.

5 Cotton, A., Determination of Chimney Sizes: Mech. Eng., vol. 45, 1923, pp. 531-537.

- Ray, W. T., and Kreisinger, Henry, The Significance of Drafts in Steam-Boiler Practice: Bull. 21, Bureau of Mines, 1911, $64 \mathrm{pp.}$

7 Blake, F. C., The Resistance of Packing to Fluid Flow: Trans. Am. Inst. Chem. Eng., vol. 14, 1922, pp. 415-421.

${ }^{8}$ Burke, S. P., and Plummer, W. B., Gas Flow Through Packed Columns: Ind. and Eng. Chem, vol. 20, 1928 , p. 1196.

${ }^{\circ}$ Brooks, H. W, Nicholls, P., Augustine, C. E., and Orr, M. L., Pressures Required to Force Air Through Sized Anthracite: Bureau of Mines, February, 1926 (unpublished).
} 
stream. As might be expected, the laws governing the flow of gases under these conditions are somewhat different from those governing the flow through straight conduits of uniform cross section.

The general equation for turbulent flow in conduits is usually written in some such form as

$$
\Delta P=\frac{K s u^{2}}{d}\left(\frac{z}{d u s}\right)^{n},
$$

where $s=$ specific gravity of the fluid,

$u=$ linear velocity of the fluid,

$z=$ viscosity,

$d=$ diameter of the passage, and

$\Delta P=$ pressure drop.

$\left(\frac{z}{d u s}\right)^{n}$ is often called the "friction factor."

The exponent $n$ is usually a variable, depending upon the modulus $\frac{z}{d u s}$. This equation is derivable by means of dimensional analysis.

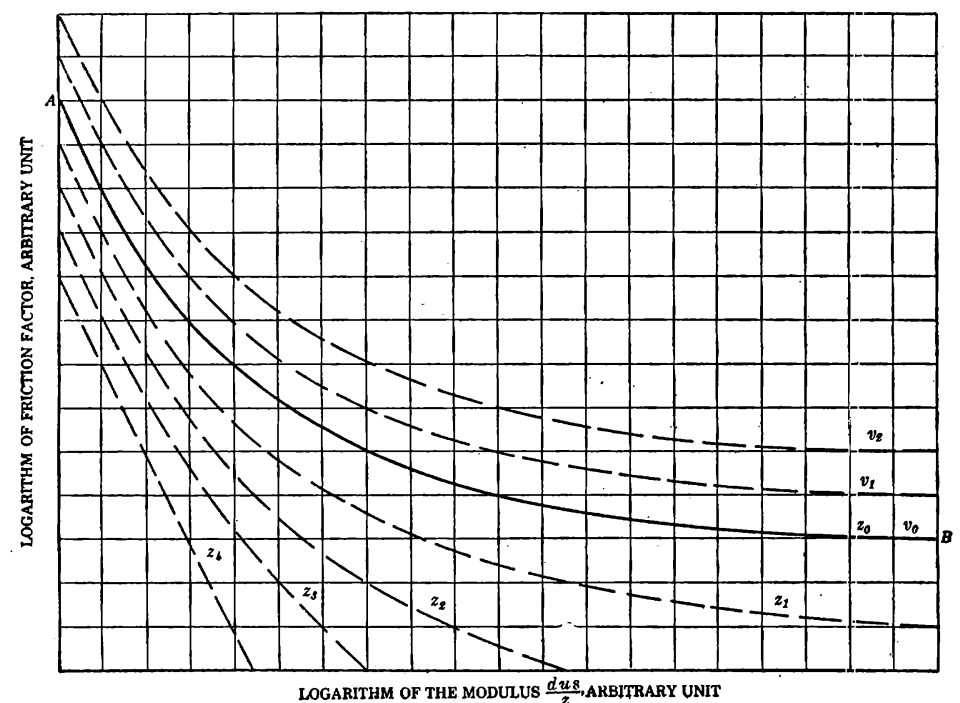

FIGURE 1.-Qualitative relations between friction factor in gas-flow equation and modulus $\frac{d u s}{2}$

However, when gas flow becomes tortuous, as in a bed of broken solids, new variables are introduced, and instead of the plot $\left(\frac{z}{d u s}\right)^{n}$ being one simple curve it becomes a series of curves affected by a number of factors and the situation becomes quite complex. This idea is qualitatively portrayed in Figure 1, where the logarithm of the reciprocal of this modulus is plotted against the logarithm of the 
friction factor. This reciprocal function is used in order to be consistent with previous literature. The solid line $A B$ represents the shape of curve usually encountered by experimenters at room temperature. However, if the viscosity of the fluid is increased, the curves of the friction factor tend to take the form of the dotted lines $z_{1}, z_{2}$, etc., so that a single line no longer defines the problem, but a 3-dimensional plot is necessary.

Further, as the voids in the bed are decreased, the friction modulus curve shifts to some such position as $v_{1}, v_{2}$, etc.; thus another variable has been introduced, and the plot becomes 4-dimensional. Another factor that affects the function in tortuous flow is the molecular weight of the gas as distinguished from its density. Besides this an arbitrary shape factor is important. The plot of the friction factor function then becomes 6-dimensional, which is the equivalent of saying it is hopelessly complicated.

Consequently, to simplify the treatment of this very complex problem the author has set up a general law for all systems that holds within the range of experimental error. It should be kept in mind that this law is not theoretically exact but that it is convenient.

The general law which has been found to apply with sufficient accuracy to all cases of tortuous flow for isothermal conditions is expressed by the equation:

$$
\Delta P_{S}=A R^{B},
$$

where $\Delta P_{S}=$ the pressure drop under some standard conditions necessary to force a given amount of gas through the system,

$$
\begin{aligned}
& A=\text { a constant, } \\
& R=\text { rate of flow in appropriate units, and } \\
& B=\text { a constant. }
\end{aligned}
$$

This law has been found to apply to all systems tested. In some cases the pressure drop was as much as 50 per cent of the total pressure. Some of the data gathered at low rates of flow have shown deviations from the law, but deviations are not consistent. The critical study of the low rates of flow is outside the scope of this investigation. The rates considered have been between 0.005 and 0.15 liter per second per square centimeter $\left(0^{\circ} \mathrm{C}\right.$. and 76 centimeters of mercury). Therefore, it is not known how much error is introduced by applying this law to higher or lower rates of flow.

It should be noted carefully that $\Delta P_{S}$ is not an observed pressure drop but is the pressure drop referred to a standard density of gas. The pressure drop in a system with a constant mass rate of flow has been found to vary inversely as the absolute over-all pressure of the gas flowing, or it may be said to vary inversely as the density of 
a given gas. If the rates of flow are high, the pressure drop may be a quantity large enough to change the average absolute over-all pressure by several per cent. If the pressure drop varies inversely as the absolute pressure, the drop at high rates of flow should not be compared with the drop at low rates of flow, as the systems are different in each case in that the gas densities are different.

Following this criterion, unless otherwise designated, all pressure drops are computed to the basis of a gas of constant and standard density. The author has chosen as his standard $0^{\circ} \mathrm{C}$. and 76 centimeters of mercury absolute pressure, and all pressure drops have been so computed. $\Delta P_{S}$ then is a hypothetical pressure drop which would be the value if the average absolute pressure on the system were 76 centimeters of mercury and the temperature $0^{\circ} \mathrm{C}$.

The unit of pressure drop has been chosen as centimeters of water per centimeter of column height. The units for $R$ have been chosen as liters of gas flowing per second per square centimeter of crosssectional area of the bed, volume at standard conditions of $0^{\circ} \mathrm{C}$. and 76 centimeters of mercury. The weight of a given gas per square centimeter of cross-sectional area could have been used, but it is not as universal a unit as volume under standard conditions.

If the units of $\Delta P_{S}$ and $R$ are chosen for standard conditions as heretofore designated, then $A$ and $B$ of equation (1) are constants for any given system. There are a number of variables, such as particle size, that may affect $A$ or $B$ or both, and the rest of this bulletin deals with the effect of various variables on the values of $A$ and $B$.

$B$ has been found to vary appreciably only with particle size, viscosity, and molecular weight of gas.

\section{VARIABLES STUDIED}

The experimentation has been confined to the following independent variables: (1) Density of gas, (2) size of particles in bed, (3) degree of packing, (4) size of container, (5) shape of particles, (6) size composition of beds of mixed sizes, (7) viscosity of the gas, (8) molecular weight of gas, and (9) moisture in the bed.

It has been found that the laws of gaseous flow through beds of broken solids can be completely expressed with the desired degree of accuracy by means of these variables.

\section{ACCURACY}

All readings were accurate to 5 per cent. However, an inaccuracy of 5 per cent in a reading of rate of gas flow might make an error of 10 per cent in the corresponding pressure-drop reading. Some of the empirical laws propounded are liable to greater errors in prediction than this. The degree of accuracy is indicated for the different cases. 


\section{GASES USED}

As already stated, most of the experimental work has been done with air, but a few data have been taken on hydrogen and carbon dioxide. The laws derived from these latter data are general and applicable to all gases.

\section{APPARATUS, EXPERIMENTAL METHOD, AND THEORETICAL CONSIDERATIONS}

The apparatus used for most of the experimental work is shown diagrammatically in Figure 2. Photographs of the apparatus are shown in Figures 3 and 4.

\section{- aIR SUPPLY}

As shown, the apparatus had three sources of air supply which could be operated independently. The first was by displacement of

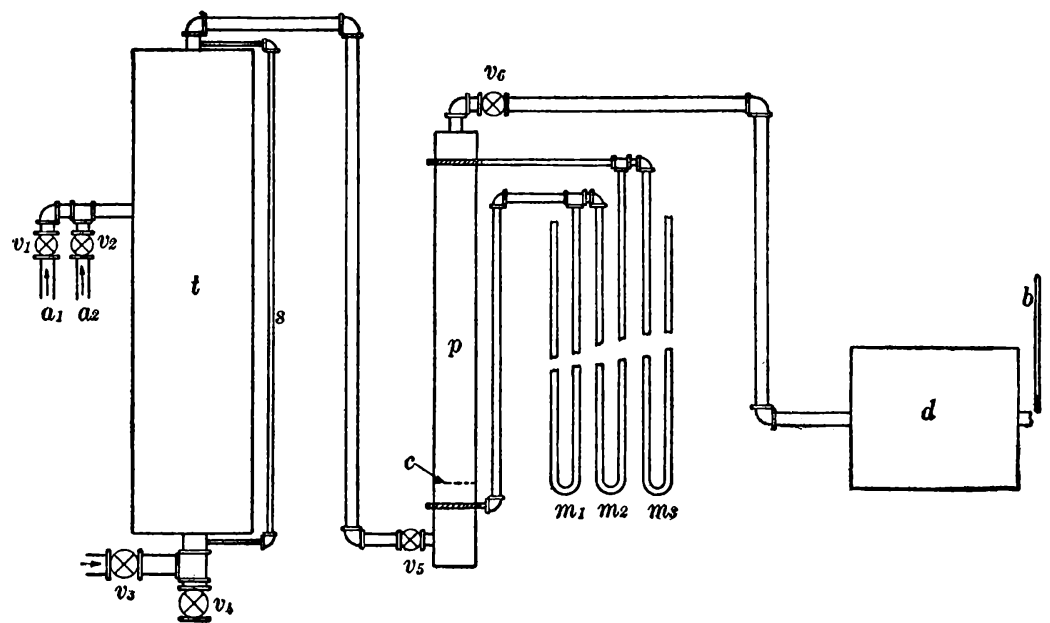

Figure 2.-Sketch of apparatus for determining pressure drop in beds of broken solids

air by water in the 200-liter tank $t$, which was accomplished by opening the valve $v_{3}$ in the water line. The second source was the high-pressure air line $a_{1}$, which delivered pressures up to 25 pounds per square inch. The third source was the low-pressure air line $a_{2}$, which was connected to a blower capable of developing 5 pounds pressure.

After leaving the tank $t$ the air passed through the valve $v_{5}$, through the upright column of broken material being tested in the tube $p$, through the valve $v_{6}$, and finally through gas meter $d$.

\section{MANOMETERS}

Testing tube $p$ was equipped with piezometer rings at both top and bottom. Manometer $m_{1}$ was filled with mercury and indicated the pressure at the bottom of the column as measured against atmospheric 


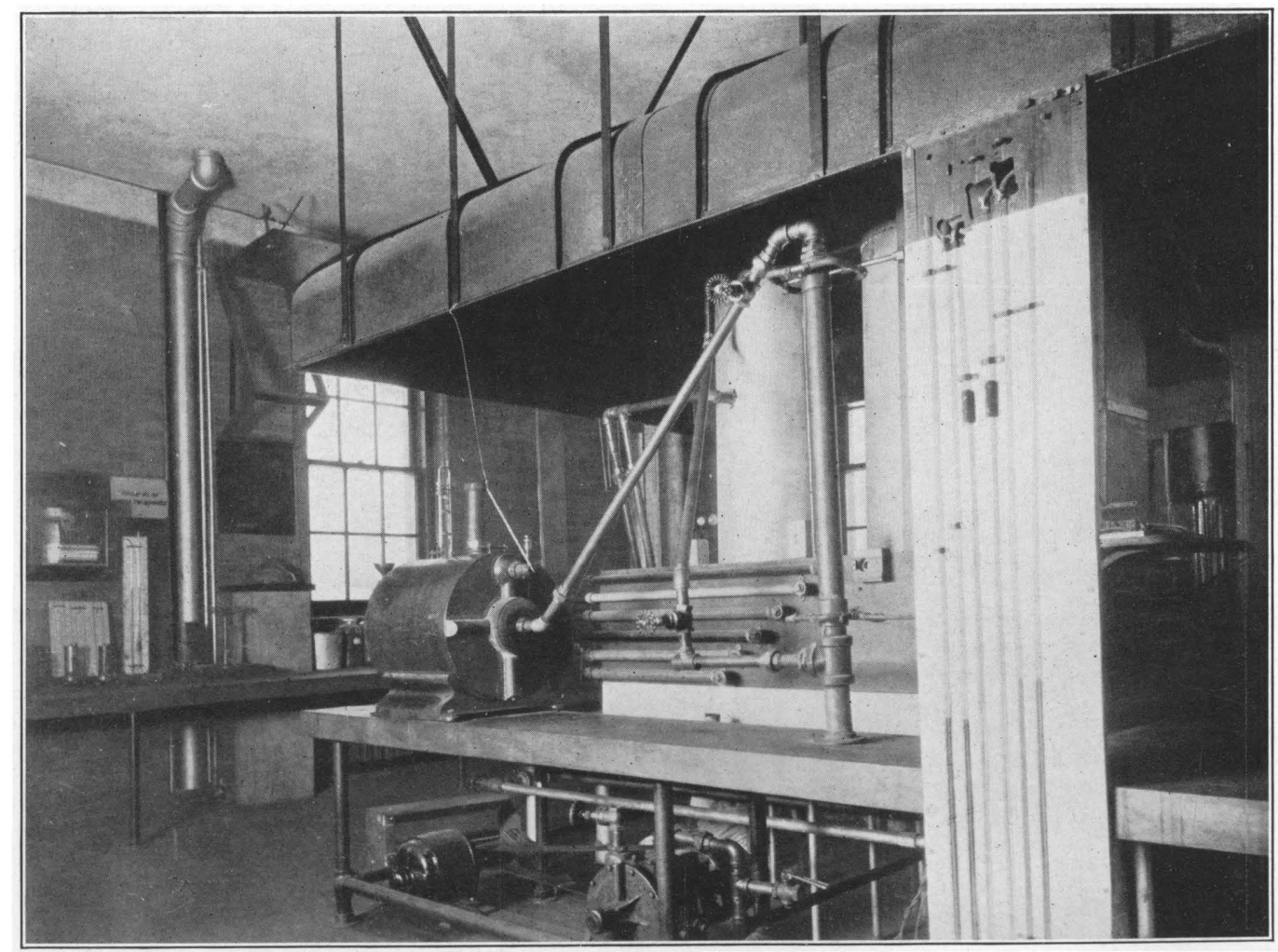

Fiqube 3.-Apparatus for determining pressure drop in beds of broken solids 


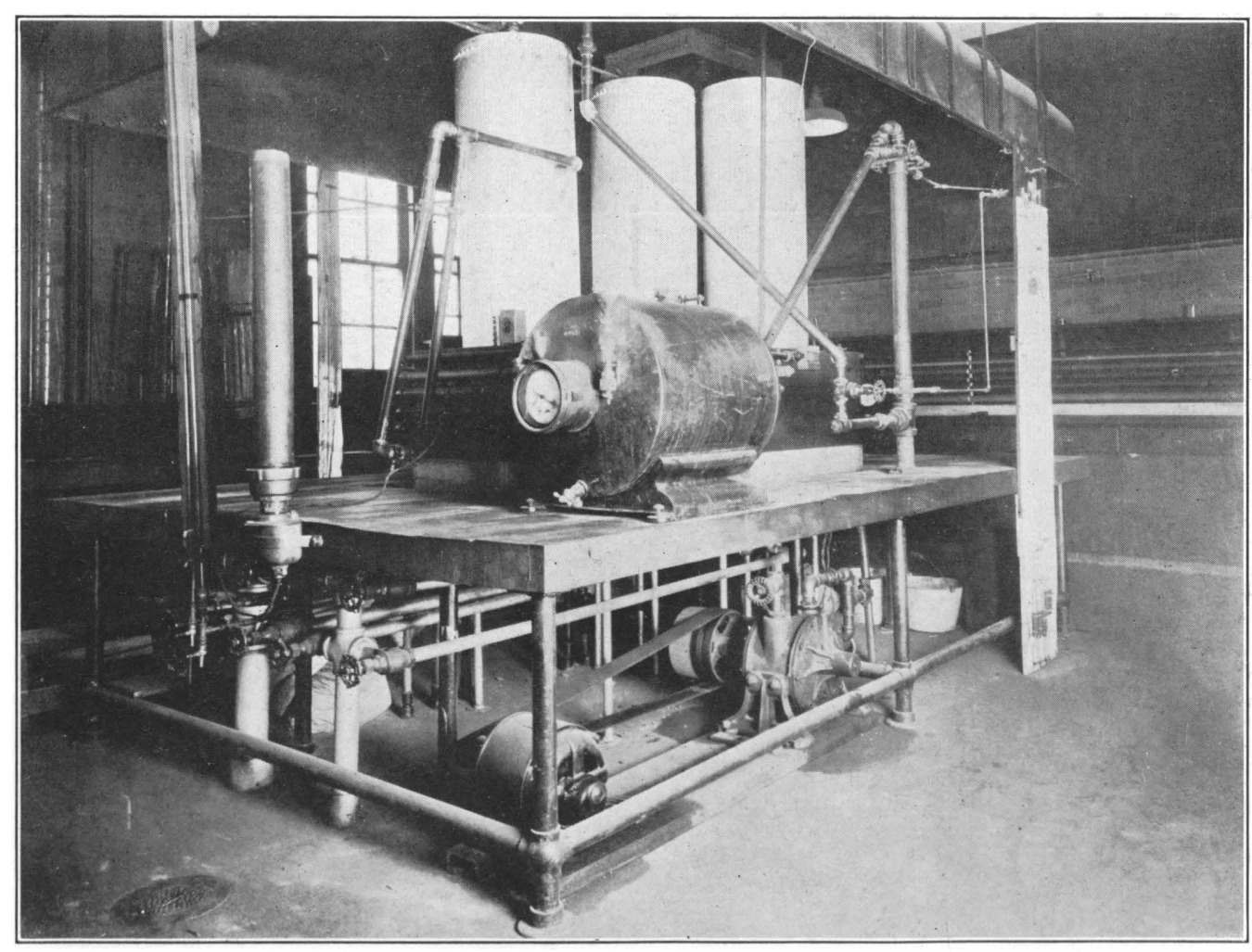

Fioure 4.-Apparatus for determining pressure drop in beds of broken solids 
pressure. Manometer $m_{2}$ was filled with water and indicated the pressure drop between the top and bottom of the bed of material. Manometer $m_{3}$ was filled with mercury and indicated the pressure at the top of the column.

\section{CALIBRATION OF METER}

Tank $t$ was calibrated for liquid capacity by means of volumetric flasks, and the scale $s$ was constructed accordingly. Meter $d$ was calibrated by forcing air through it by means of the water-supply line and measuring the volume of air displaced by observing the water level as indicated on scale $s$. The meter was calibrated for various rates of flow throughout its range.

The water-displacement method of supplying air was not used after the meter was calibrated. The low-pressure air line $a_{2}$ was used if the desired operating pressures were below 5 pounds and the highpressure line for high-pressure runs. Tank $t$ acted similarly to a capacity in electrical circuits to smooth out the fluctuationis in pressure. This arrangement worked very satisfactorily with the lowpressure blower, but the fluctuations in the high-pressure lines were always quite troublesome.

\section{DETAILS OF EQUIPMENT AND PROCEDURE}

Manometers $m_{1}, m_{2}$, and $m_{3}$ were backed by cross-section paper graduated in 0.1 inch. Meter $d$ was calibrated to read in cubic feet; and had a maximum capacity of about 12 cubic feet per minute.

Uniform and easily duplicated packing was obtained by means of an electric foundry vibrator, such as is used in packing sand molds. A 2-inch floor plate was bolted onto the vibrator so that the iron pipo containing the material to be tested could be screwed onto the vibrator in a vertical position and vibrated until the surface of the charge had descended to the desired level. An upright 3-inch pipe is shown in position on the vibrator in the left foreground of Figure 4.

Standard pipe and fittings were used throughout the set-up, except for the glass manometer tubes and the rubber connections thereto.

The air lines were of 1-inch pipe. Tube $p$ (fig. 2) represents several different pipes, varying from 1 to 6 inches in diameter but all 30 inches long and covered with a screen, $c$, at the bottom to hold the charge.

The piezometer rings were made by setting the ends of $1 / 8$-inch pipe nipples flush with the inner surface of the 2-inch pipe coupling. Four such openings were made for each ring.

The tube containing the material to be tested was screwed into the 2 -inch coupling. If tubes larger than 2 inches were used suitable reducers were employed to bring them down to that size. Thus, the bottom screen $c$ in the pipe was always between the two pressure leads.

Tests were made by placing the desired weight of broken: material in tube $p$, packing it to the desired density by means of the foundry vibrator, placing it in position in the apparatus as indicated by $43318^{\circ}-29-2$ 
Figure 2, then forcing air through the column at various rates and determining the attending pressure conditions by reading manometers $m_{1}, m_{2}$, and $m_{3}$. Rates of flow were determined by timing one or more complete revolutions of the meter hand by means of a stop watch graduated in one-fifth seconds. It was found that the personal error in this observation was great enough to require a minimum time limit of 15 seconds in determining the rate. By regulating the various valves any desired rate of flow could be obtained with satisfactory constancy.

Specific gravities of materials were determined by means of liquid displacement. For large pieces a volumeter was used. Small pieces were dropped into a burette half filled with liquid. From 50 to 500

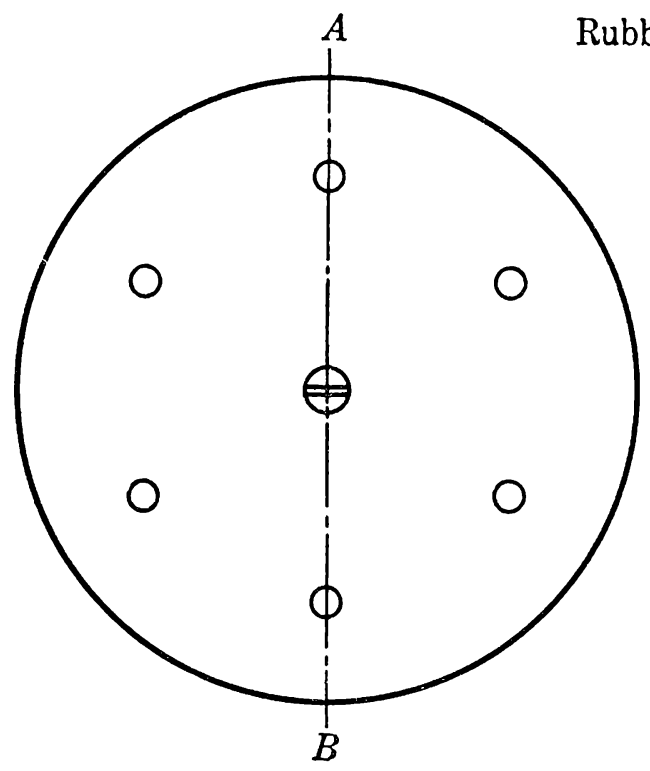

Figtre 5.-Synthetic fuel bed

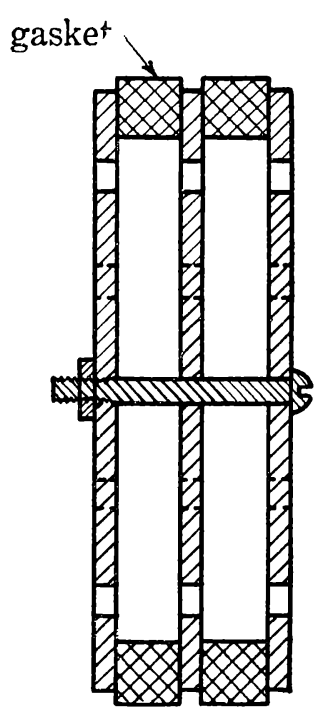

Section $A B$

grams of material were used for each determination. Water or kerosene was used as : liquid of displacement. Both liquids gave the same results, except for coke. The values of the specific gravity of coke as obtained by displacement of kerosene were approximately 25 per cent greater than those obtained with water.

\section{EXPERIMENTAL ANALYSIS OF TORTUOUS FLOW}

\section{"SYNTHETIC FUEL BED"}

"Tortuous flow" is much too complicated to be analyzed completely by any mathematical methods, so an analysis of such flow was made by a device in which variables could be changed singly. The device was termed a "synthetic fuel bed," and it is shown in Figure 5. It consisted simply of a series of plates with a number of holes in each plate. The plates were separated by annular rubber gaskets, and the series of plates and gaskets were held together tightly by a small central bolt. The device was made of suitable size to fit tightly into a section of E.ir.ch pipe ground with an inside taper. The edge was sealed to the pipe with 
molten paraffin. Tests were made with this synthetic fuel bed in just the same manner as with beds of broken solids.

The experimental work with this device was not completed until after most of the other data presented in this bulletin were taken, but logically the data of this analysis should be presented at this point.

\section{VARIABLES INVOLVED}

This synthetic fuel bed makes it possible to isolate the effects of the following variables: (1) Size of constricted portion of the passage, (2) size of expansion chamber between each constriction in passage, (3) angle through which each gas stream must turn in going from one constriction to the next, (4) relative arrangement of the constricted openings across any plane in the bed, $(5)$ nonuniformity

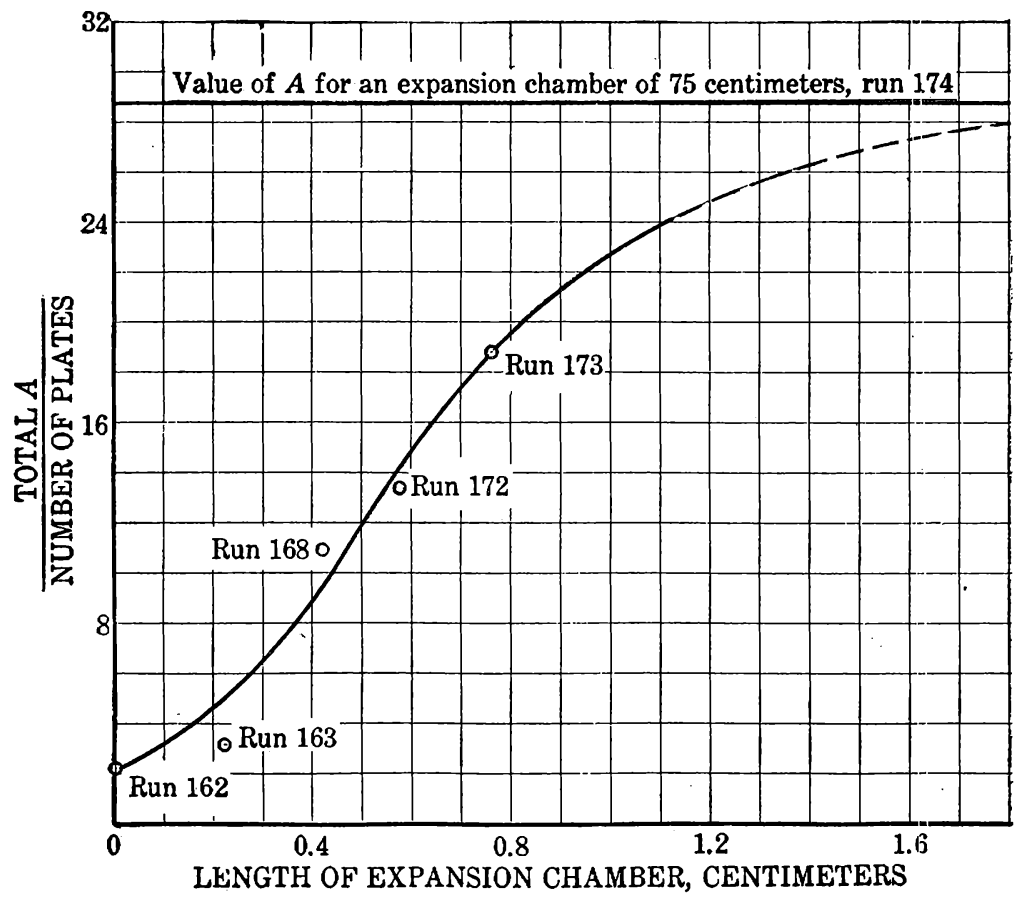

FIGURE 6.-Variation of $\frac{\text { total } A}{\text { number of plates }}$ with length of expansion chamber in synthetic fuel bed

in sizes of passages across any particular plane, and (6) proximity of adjacent openings in the bed. In an or dinary bed of broken solids it is impossible to change one of these variables without affecting some of the others.

The possibilities of this device were by no means exhausted by the author, and only a few sets of data were obtained.

\section{OPPORTUNITY FOR EXPANSION AND ITS EFFECT UPON $A$}

In all tests the pressure drop followed the law given by the equation

$$
\Delta P_{S}=A R^{B} \text {. }
$$

As might be expected, every change in one of the six variables caused a change in the value of the coefficient $A$, but most of the changes were not considered important in this problem and were not studied in detail.

The one variable whose effect on $A$ was evaluated was (2), the effect of the size of the expansion chamber between the constrictions in the passage, (See fig. 6.) 
In this figure the value of $A$ for the synthetic fuel bed is divided by 1,000 times the number of plates in the bed, and the values are plotted against the length of the expansion chamber between plates.

In these experiments the plates used for the synthetic fuel beds were made of disks of galvanized sheet iron 0.060 centimeter thick, with six holes 0.297 centimeter in diameter bored through each plate on a concentric radius of 2.5 centimeters.

The curve of Figure 6 is drawn to approach asymptotically an ordinate value of 28,900 . This number was the value of $A$ for a single plate at the bottom of a 30 -inch length of 3 -inch pipe. This was considerd as maximum opportunity for expansion.

Curiously, the actual total pressure drop for a given flow through the single plate was greater than the total pressure drop through a bed of 10 plates in which the holes were all in line, with no opportunity for expansion between plates.

The value of $B$ was approximately 2.05 for all of these experiments. The significance of these data is touched upon later.

\section{EFFECT OF SIZE OF PASSAGE UPON $B$}

The only thing that was found to affect the value of exponent $B$ was the size of the passage. The value of $B$ is practically constant for systems in which the diameter of the passage is slightly more than 1 millimeter. If the size of the passage is less than 1 millimeter, the value of exponent $B$ falls off very sharply. In Figure 7 the value of exponent $B$ is plotted against the cross-sectional area of a single opening.

Three of the values shown on the curve of Figure 7 were obtained by passing air through small screens. In the tests in which screens were used in the synthetic fuel beds the central portion of the plates would be cut out and the screen soldered in. Three bolts through the several annular metal rings and gaskets along the outer edge of the screen would hold the apparatus together.

\section{PROBABLE MECHANISM OF FLOW}

As was mentioned in the introduction, it is impossible with the data at hand to ascertain the exact details of the mechanics of tortuous flow, but something can be determined by the effect of size of passage on exponent $B$. The change of exponent $B$ with the size of the particles in a bed of broken solids is one of the most important features of this work. It is known that for fluids passing through cornduits the pressure drop varies approximately as the square of the linear velocity of flow for so-called "turbulent flow." If the velocity is low enough, "straight-line" flow occurs, and the pressure drop is directly proportional to the velocity. ${ }^{10}$

From the experimental analysis effected by means of the synthetic fuel bed it can be seen that turbulent flow probably holds until the passages are less than 1 millimeter in size, and then straight-line flow begins to enter in, for exponent $B$ becomes less than 2 .

Probably due to peculiarities of the gas film around the inner edge of the passages there is an annular ring through the passage where the gas is moving close to the wall where straight-line or viscous flow holds. The center of the stream will be in turbulent motion. The volume of gas flowing through the very thin annular ring of constant thickness which is following straight-line flow is negligible until the passage becomes very small.

In the 300 -mesh screen the opening was 0.005 centimeter square. Exponent $B$ was 1.25. Here, then, it would seem that straight-line flow was predominant

\footnotetext{
${ }^{10} \mathrm{See}$, for example, Walker, W. H., Lewis, W. K., and McAdams, W. H., Prineiples of Chemical Engi-
} neering: New York, 1923, Chap. III. 
but that there was a section in the center of each small stream where turbulent flow still occurred. The small section adjacent to the surface film where the gas was moving by straight-line flow then must be less than 0.0025 centimeter thick.

\section{OBJECTIONS TO EXPLANATION OF MECHANISM OF FLOW}

Experiment does not support the above explanation in all its details; several systems have been found in which exponent $B$ has a value less than 1 . The author is not able to explain this. If the above argument is carried to its

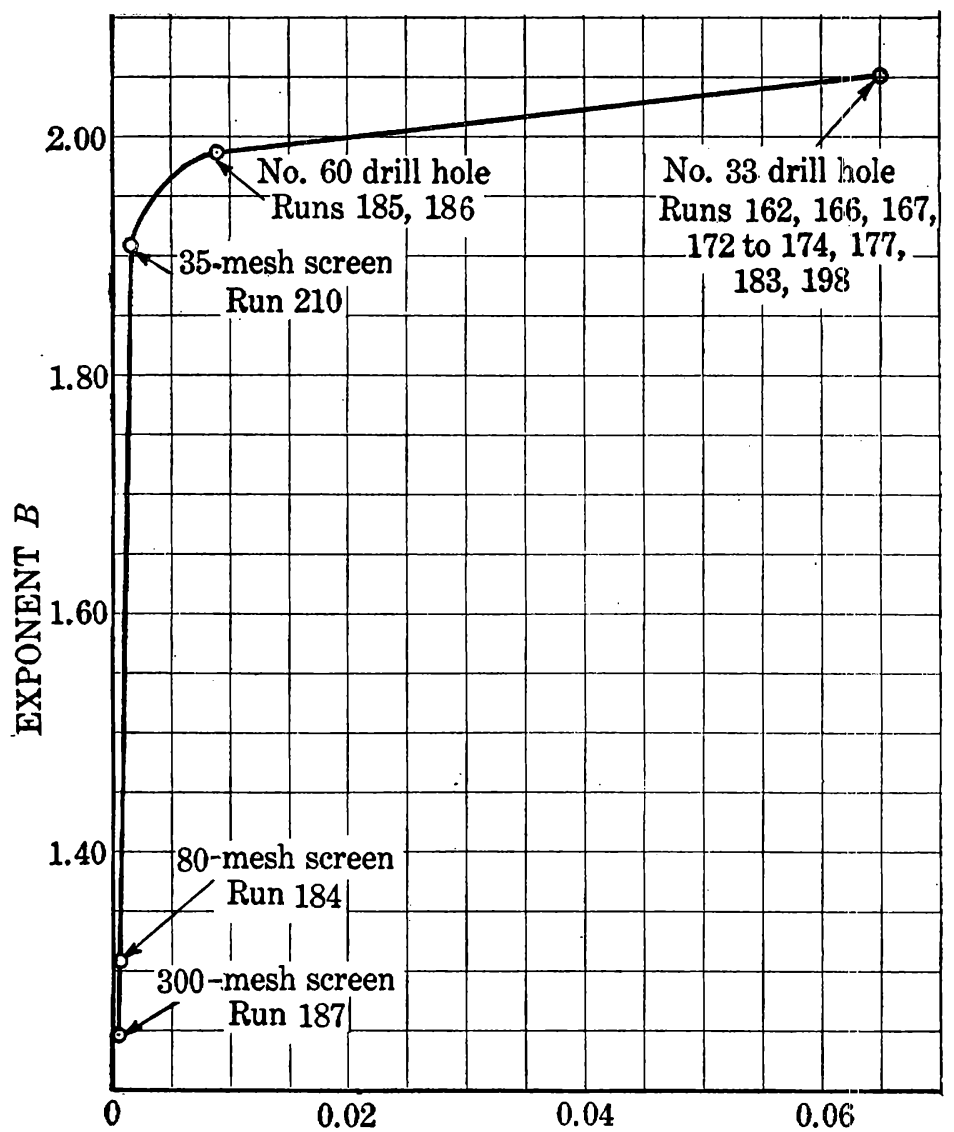

AREA OF PASSAGE, SQUARE CENTIMETER

Figure 7.-Variation of exponent $B$ for synthetic fuel bed with cross-sectional area of passages

Jogical conclusion, it would seem that fluid flow through extremely small passages, such as the diffusion of gases through metallic plates, should follow the straight-line law where the pressure drop varies directly as the rate of flow. However, such is not the case, for most experimenters find that pressure drop in the diffusion of gas through solid plates varies approximately as the square of the rate of flow. ${ }^{11}$ Undoubtedly in some instances reversible chemical reactions

${ }^{11}$ See Johnson, F. M. G., and Larose, P., The Diffusion of Oxygen Through Silver: Jour. Am. Chem. Soc., vol. 49, 1927, p. 312. Borelius, G., and Lindblom, S., The Diffusion of Hydrogen 'Through Metals: Teknisk. Tids., vol. 56 (Kemafd), 1926, p. 41; Chem. Abs., vol. 20, 1926, p. 2926. Kossonogov, K. M., and Kossonogov, I. I.: Ber. Polyteck. Iwanowo-Wosniessensk, 6, 57-71, and 406: Chem. Zentralb., 1922, Bd, III, p. 326; Chem. Abs., vol. 17, 1926, p. 17. 
enter into the diffusion, but in others it must be simply straight molecular transfer through minute passages. Possibly the difference between the two cases lies in the difference of the velocities of the gas stream. The movement of the molecules through a metal plate by diffusion is very slow, whereas a stream of gas through a bed of broken solids moves rapidly enough to have considerable kinetic energy which may affect the laws of flow.

It can very correctly be argued that if tortuous flow is a combination of straightline and turbulent flow the equation will be

$$
\Delta P=a R+b R^{2}
$$

if the two components of the system are arranged in series, and

$$
\frac{\Delta P}{a}+\sqrt{\frac{\Delta P}{b}}=R
$$

if the two components of the system are arranged in parallel, and that neither of these equations can be reduced to

$$
\triangle P=A R^{B},
$$

which has been experimentally proved to hold for all of the many systems studied.

It was pointed out that the law represented by equation (1) may not exactly fit the phenomena but only be a close approximation. It can be shown that in the range of flows used in this experimental work equation (2) or (3) may be closely approximated by equation (1), if $B$ in equation (1) has some value between (1) and (2). If part of the flow under consideration follows the law of equation (2) and the rest follows the law of equation (3), then equation (1) gives a still closer approximation of the true law.

\section{PRESSURE DROP THROUGH LAYERED BEDS}

A run was made on a 2-layered bed of lead shot, the lower part of the bed being a 7-centimeter layer of shot 0.138 centimeter in diameter, covered with a 35.5-centimeter layer of shot 0.905 centimeter in diameter. The value of exponent $B$ for the smaller shot was found experimentally to be 1.41 and for the larger shot 1.79 .

Theoretically, the equation for this run should be

$$
\Delta P_{S}=532 R^{1.41}+450 R^{1.79} .
$$

The computed curve and the curve of the observed values are given in Figure 8. The data are plotted on axes which are graduated on the logarithmic scale. If the law of flow followed the general law of equation (1), these curves would be straight lines. Despite the fact that the data shown in Figure 8 are those of two quite different systems placed in series, the lines are almost straight (slightly concave upward), and the general law of equation (1) would fit quite satisfactorily.

It will be noted that the computed and observed curves do not agree. This is because the slope of the observed curve is greater than that of the computed one. No explanation has been found for this.

\section{HYPOTHETICAL SYSTEM}

Consider the case of two systems so that for one

while for the other

$$
\Delta P_{S}=50 R^{1.00},
$$

$$
\Delta P_{S}=1,000 R^{2.00} \text {. }
$$


In Figure 9 are plotted the values of the pressure drops if the systems are placed (1) in series and (2) in parallel. It will be seen that for series flow the curve is slightly concave upward, while for parallel flow the curve is slightly concave downward. Thus, any system, when there are a number of passages

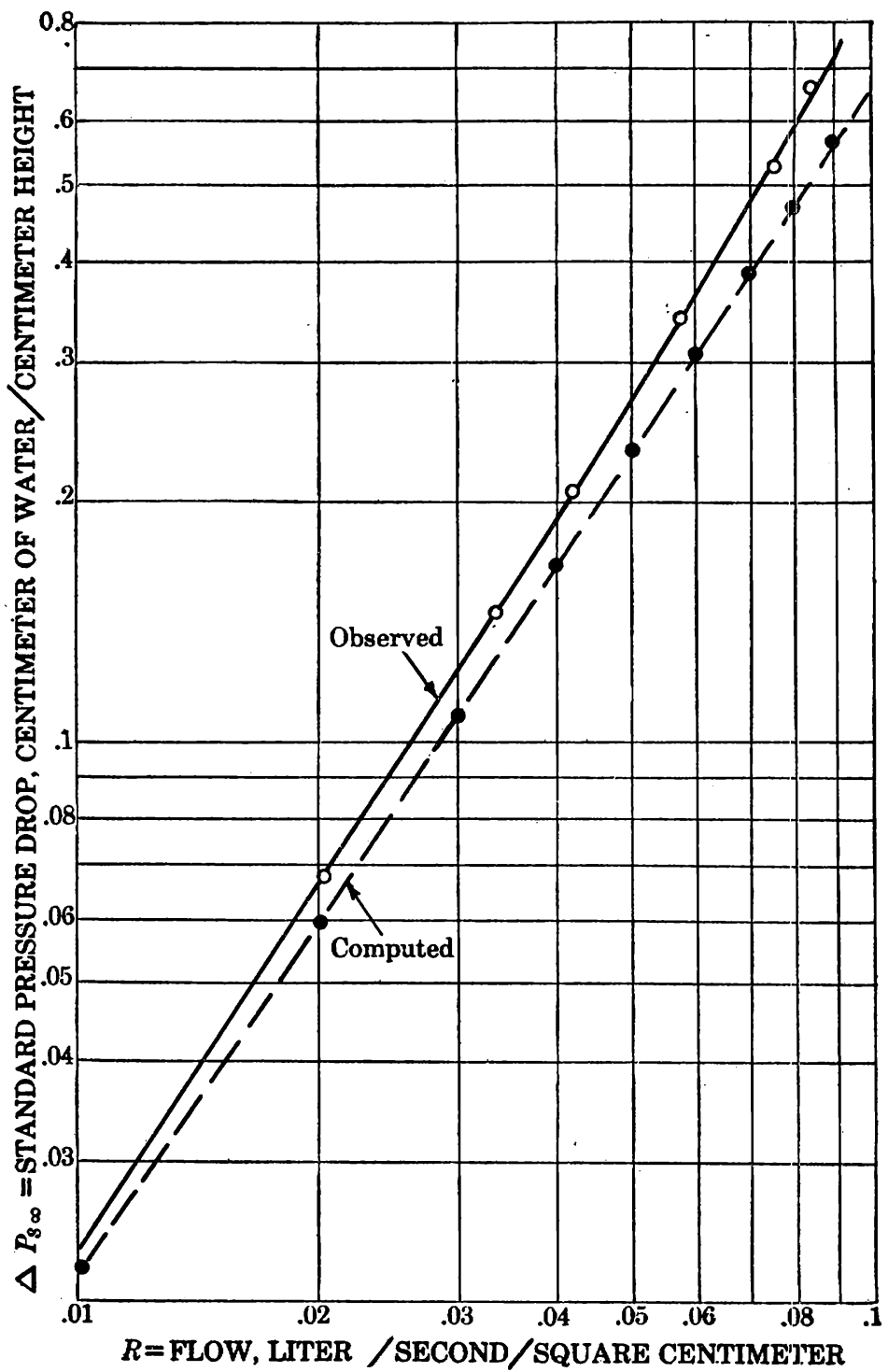

FiguRe 8.-Pressure drop in layered beds of lead shot in a 3-inch pipe; No. 12 shot 7.1 centimeters deep and No. 000 shot 35.5 centimeters deep; run 218

in both series and parallel arrangement, will have a pressure-drop curve that is a summation of the two curves of Figure 9 and will tend to be very close to a straight line on logarithmic-scale paper.

Such is the case in a bed of broken solids. Probably each small passage in the bed contains an aforementioned annular ring in which straight-line flow pre- 
vails, the rest of the passage being subject to turbulent flow where the pressure drop varies as the square of the rate of passage of the gas. The total effect, then, for each passage is a curve of the general type of the lower one of Figure 9, slightly concave downward. The slope of the line will depend upon the relative

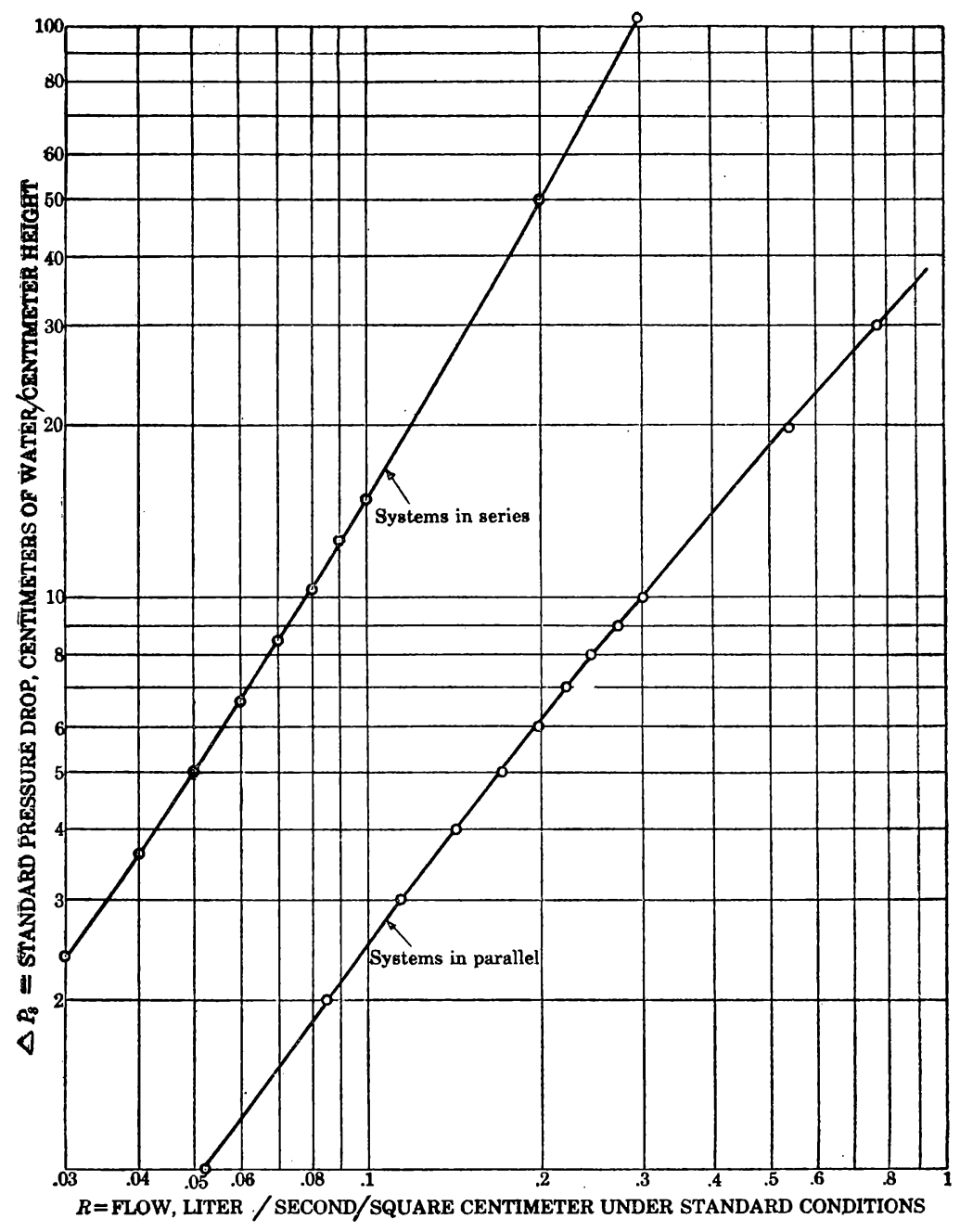

FIGURE 9.-Hypothetical systems of broken solids; resistance in parallel and in series

amounts of gas that are flowing through the passage by straight line and by turbulent flow.

In a bed of broken solids for each such constriction there will probably be another constriction in series with it which alone will give a curve of somewhat different siope from the first one. These two systems in series will give a curve slightly concave upward, such as the top curve in Figure 9. The combination of these numerous systems in parallel and in series will then tend to give a curve which closely approximates a straight line on logarithmic-scale paper. 
APPROXIMATE LAW OF FLOW

Thus, it would seem that the equation

$$
\Delta P_{S}=A R^{B}
$$

is not the equation of an exact law but only a close approximation to the true law.

It is by no means certain that the foregoing argument is absolutely correct. This would be an excellent field for some investigator who has more time to study the fundamentals of this type of fluid flow.

Experiments have indicated that for all the cases studied equation (1) holds within the range of experimental error, so throughout the rest of this bulletin it will be treated as a definite and exact law.

\section{CONCEPT OF SIZE}

\section{EQUIVALENT SPHERICAL DIAMETER}

Since the size of particles is one of the variables that affects the resistance of a bed of broken solids to the flow of gases, a clear concept of the meaning of "size" is necessary. A working definition of size has ever been a much mooted question, and any system devised for irregular bodies must be more or less arbitrary.

The most common means of designating the size of irregular particles is by screen measurements. but this method is arbitrary and because of the variation in shape of different classes of material is not particularly significant, for there are a great many combinations of shape and volume that can give the same screen size. On the other hand, if the size of a particle is defined as its volume the quantity is perfectly definite; whether or not it is usable is another matter.

If all the pieces in a bed of irregular solids are considered as spheres of an average size and the diameter of this average sphere is computed, then this figure, which may be called the "equivalent spherical diameter," is a measure of particle size and absolutely fixes the average volume of the pieces. For consistency and other reasons which will be developed later, unless otherwise designated, this equivalent spherical diameter will be used as a measure of the true size of particles.

Determination of the average equivalent spherical diameter for a sample of screen-size material is quite simple. The author's method was to pick 500 pieces at random from a pile of the material and to weigh them. The arithmetical mean of the weight of the 500 pieces was taken as the true average weight, and the equivalent spherical diameter was computed from this figure and the specific gravity datum.

This method of counting and weighing pieces seems somewhat crude, but it has proved to be the most satisfactory of any tried. Further, the equivalent spherical diameter is proportional to the cube root of the volume, and the cube root of a crudity may be a refinement. The results obtained by this method are reproducible and are consistent for different sizes of one class of material. 


\section{SHAPE FACTOR}

The equivalent spherical diameter fails to make any recognition of the shape of the particles; hence, an arbitrary but quantitative shape factor has been introduced into the problem.

The shape factor will be defined as the ratio of the equivalent spherical diameter to the average screen size as measured by square-mesh screens. The shape factor for perfect spheres will then be unity, but for most bodies it will be less than 1 . Since certain classes of particles tend to be in the form of ellipsoids or prolate spheroids or are egg-shaped, their shape factors may well be greater than unity. However, in such cases as the last mentioned the shape factor should be considered as the reciprocal of the factor as determined, as the factor is intended to be an index of symmetry with unity representing perfect symmetry, and spheroids are not as symmetrical as spheres.

There is a lower limit to the size of particles for which the equivalent spherical diameter and the shape factor can be determined satisfactorily. The author has found that for particles of screen size smaller than 14-mesh the method is not dependable. However, if the character of the fracture is the same for large as well as for small pieces of a certain material the shape factor will be the same for all sizes. In Table 1 it will be noted that for Cuyuna ore No. 1 the shape factor is identical for all sizes except the coarsest; hence, it should be possible to evaluate the shape factor of fine particles by means of somewhat larger pieces.

\section{- NORMAL PACKING}

Before developing the theory of fluid flow through beds of broken solids it will be necessary to define a third more or less arbitrary entity designated as "normal packing."

If a number of pieces of broken material are allowed to drop singly into their positions in a bed, the bed tends to form with a definite percentage of voids that is characteristic of the system. It is necessary that the particles be allowed to fall into place individually, thus eliminating the possibility of "bridging." Such an arrangement of material is characterized as having "normal packing," and the percentage of voids of the bed in such a state will be designated as the "normal voids."

The above conditions for normal packing are complied with if the material is poured into place quite slowly and from a short distance above the bed, that is to say, from a few centimeters to a few meters. Normal packing is quite definite and reproducible.

The ratio of the shape factor $F$ to the voids of normal packing $V_{n}$ is an important quantity in the present study. This factor will be used for several purposes. 


\section{CONCEPT OF RESISTANCE}

In any system that is subject to change the rate of change may be considered as the driving force divided by the resistance. In the case of the passage of the gas through the system the rate of change is the rate of flow, and the driving force is the pressure drop. It has been found, in all cases, that

$$
\Delta P_{S}=A R^{B},
$$

where $\Delta P_{S}$ is the driving force of the system and $R$ is the rate of flow.

It is desired to determine the resistance. Following the criterion of the above definition of resistance, the unit of resistance will be the reciprocal of the rate of flow when the pressure drop is unity. In such a case

$$
\begin{gathered}
R=\sqrt[B]{\frac{1}{A}}=\frac{1}{\sqrt[B]{A}} \\
\text { Resistance }=\frac{1}{R}=\sqrt[B]{A} .
\end{gathered}
$$

Hence, the quantity $\sqrt[B]{A}$ might be expected to be more fundamental and more susceptible to mathematical manipulation than the quantity $A$, which is sometimes considered as the unit of resistance in such systems as this.

However, either definition of resistance is arbitrary. $A$ is the pressure drop necessary to cause unit flow; $\sqrt[B]{A}$ is the rate of flow when the pressure drop is unity. Because of the variabjlity of exponent $B$ with size and with conditions of the system there is no fundamental basis for comparison of different systems. The term "resistance" is used in a general sense, and the mathematical definition of the term will have to be stated in each case.

\section{EXPERIMENTAL WORK ON SIZED MATERIAIS}

\section{RÉSUMÉ OF MATERIALS USED}

The materials used to determine the laws governing the flow of gases through beds of broken solids are listed in Table 1 , with the important constants for each system. In order that a reader may visualize the condition of a bed of broken solids, photographs have been taken of the cross sections of a number of beds of different materials and are shown in Figures 10 to 19.

To make specimens for these pictures broken material of the desired size was poured into a cardboard or iron tube. After the material was in place a thin slurry of plaster of Paris or quick-setting cement made from high-alumina blast-furnace slag was poured into the bed and allowed to set for 24 hours. By that time the matrix 
was hardened, and a section was cut off with carborundum dividing disks, leaving a clean cross section of the bed.

For soft materials a matrix of plaster of Paris was strong enough to hold the pieces in place for cutting. For the harder minerals it was necessary to use cement.

\section{EFFECTIVE FREE AREA AND LIFTING VELOCITY}

The material of this section does not add to the quantitative theory of this report, but it does aid materially in forming the proper concepts concerning the true conditions in a bed of broken solids.

The term "effective free area" has been coined to express the cross-sectional area in any plane across a bed of broken solids that is effective in allowing the passage of air. Naturally there are a great many dead spaces or hollows in the bed that are not used for the passage of air. Usual practice seems to be to consider the percentage of effective free cross-sectional area the same as the percentage of the voids in the bed. This is merely a guess and is far from the truth.

Brooks, Nicholls, Augustine, and Orr ${ }^{12}$ have assumed

$$
1-\frac{\text { Free area, per cent }}{100}=\left(1-\frac{\text { voids, per cent }}{100}\right)^{273} \text {. }
$$

Probably this equation was derived from considerations of the relation between the volume and cross-sectional area of a sphere, but the analogy is imperfect in this case. The solid volume of a sphere (or the volume of the voids, if that is the quantity being considered) is concentrated in one body, and the amount of that entity present affects the size of the body.

Circumstances are entirely different when a bed is made up of a large number of broken pieces uniformly mixed with a certain percentage of voids. The fitting analogy here is that of a two-component solution made up of solids and voids. An infinitesimally thin layer of this solution will still contain the original ratio of solids and voids; and in the limit this layer will be 2-dimensional-that is, an area containing the same ratio of solids to voids. Two-dimensional voids can be called "free area," so in reality free area is proportional to the voids rather than the two-thirds power of the voids.

Neither line of argument is pertinent to the case in hand, for "free area" is by no means all effective in allowing the passage of gas as the bulk of the area is blocked by overlying pieces of solid material.

A geometrical study was made of perfect spheres of uniform size packed uniformly. In the most loosely packed condition possible still retaining uniformity, a pile of spheres will have a void of 52.36 per cent and an effective free area of 21.46 per cent. In the most

- 12 See footnote 9. 

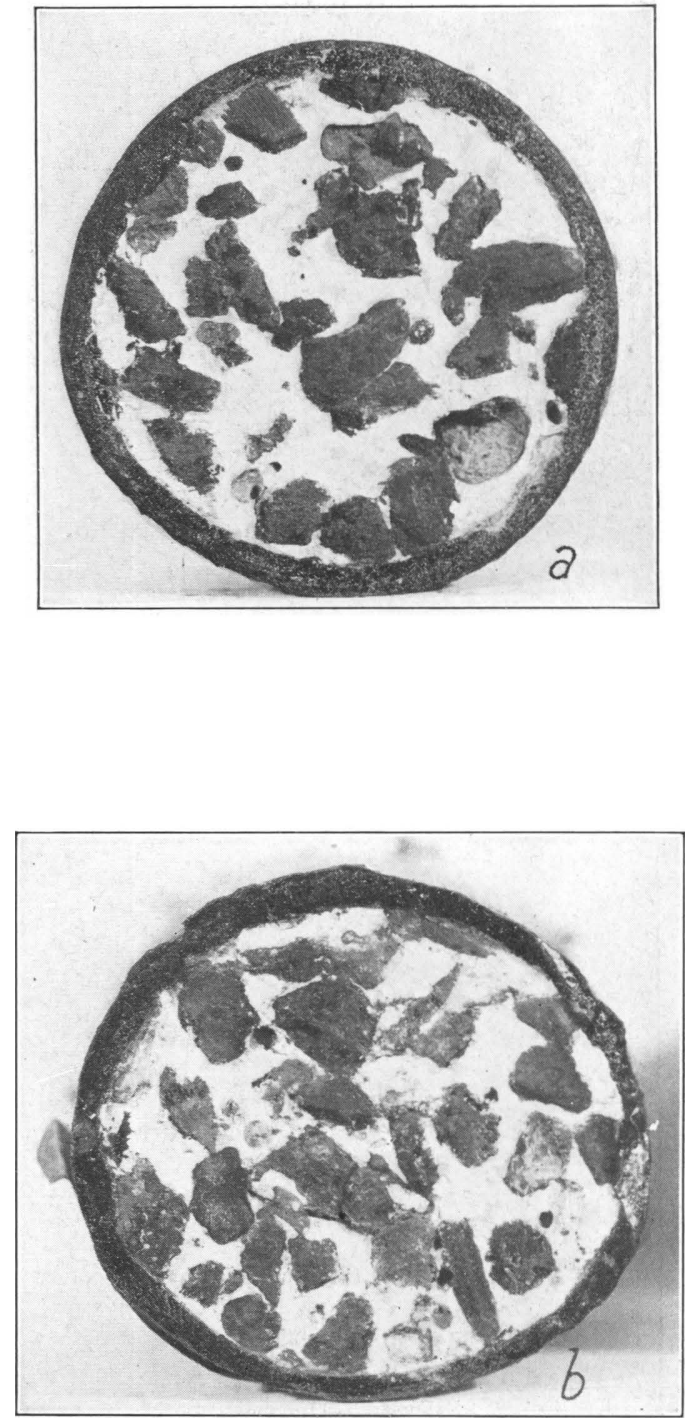

Figure 10.-Cross sections of beds of Cuyuna iron ore (full size): $a, 0.525$ to 0.371 inch; $b, 2$ to 3 mesh 

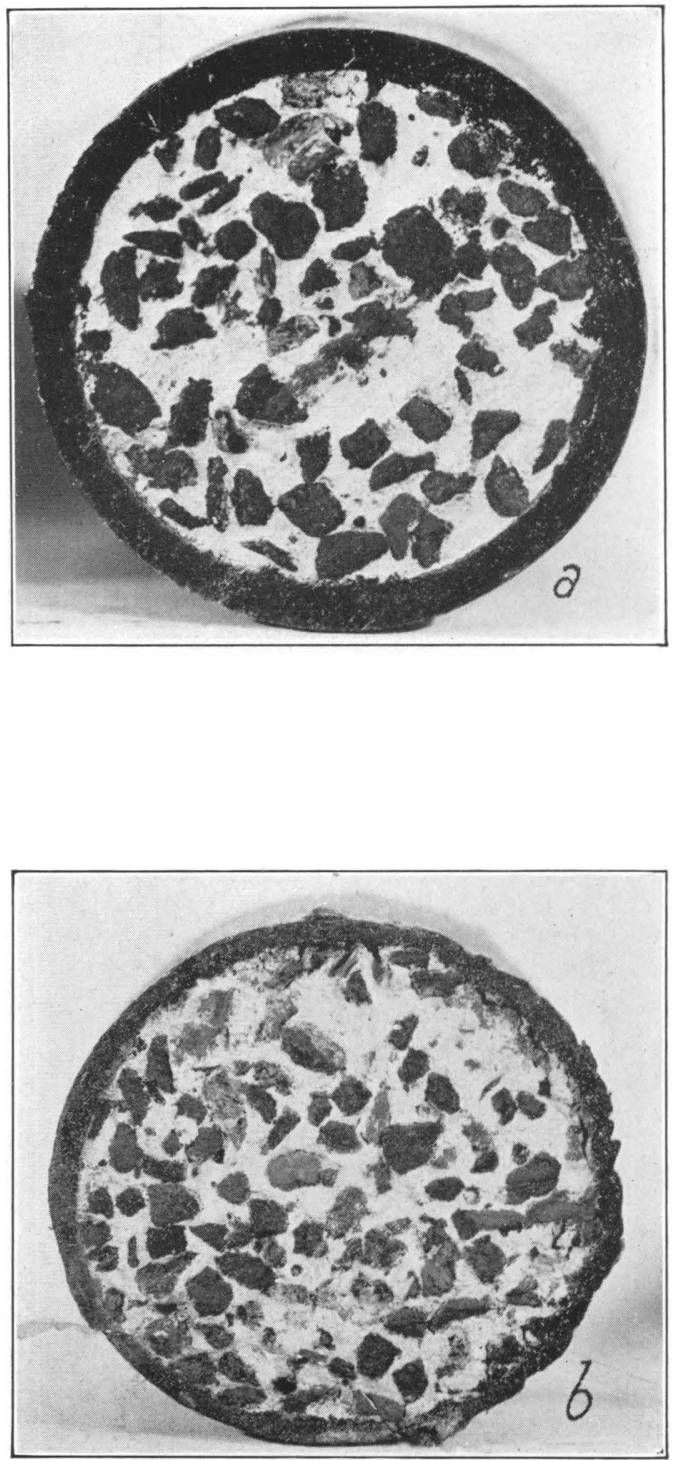

Figure 11.-Cross sections of beds of Cuyuna iron ore (full size): $a, 3$ to 4 mesh; $b, 4$ to 6 mesh 

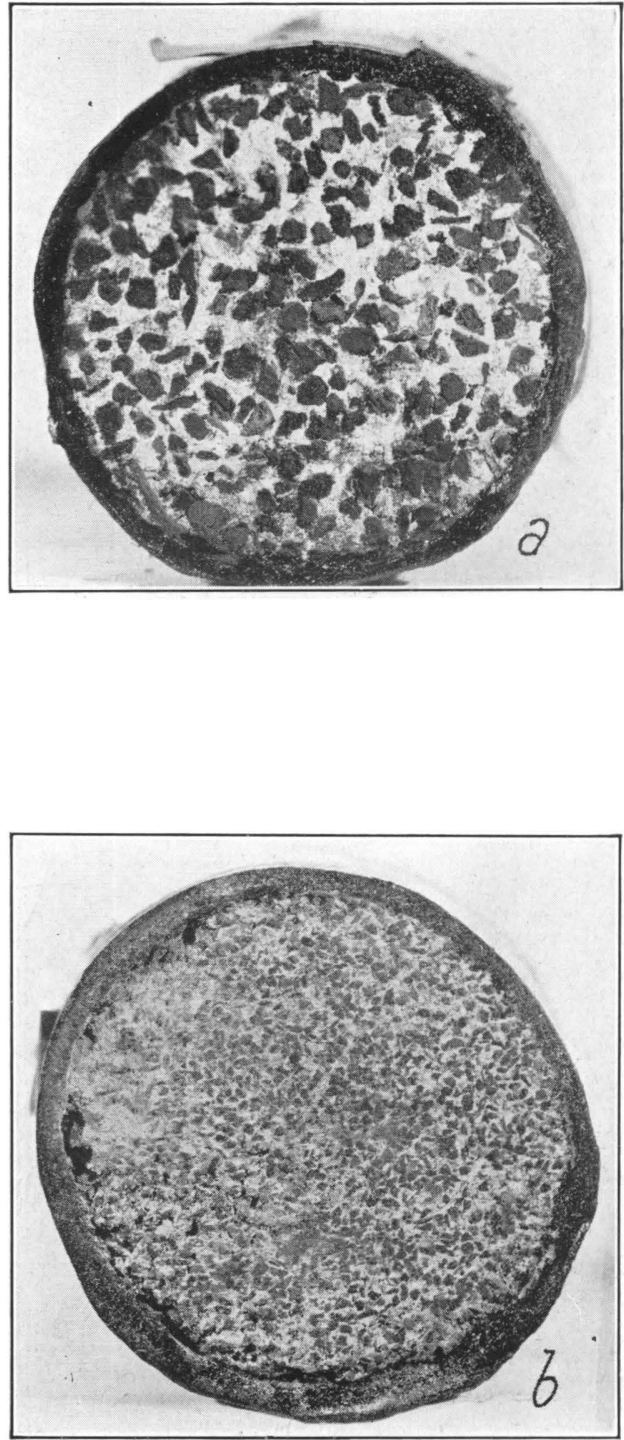

Figure 12.-Cross sections of beds of Cuyuna iron ore (full size): a, 6 to 8 mesh; $b, 14$ to 20 mesh 

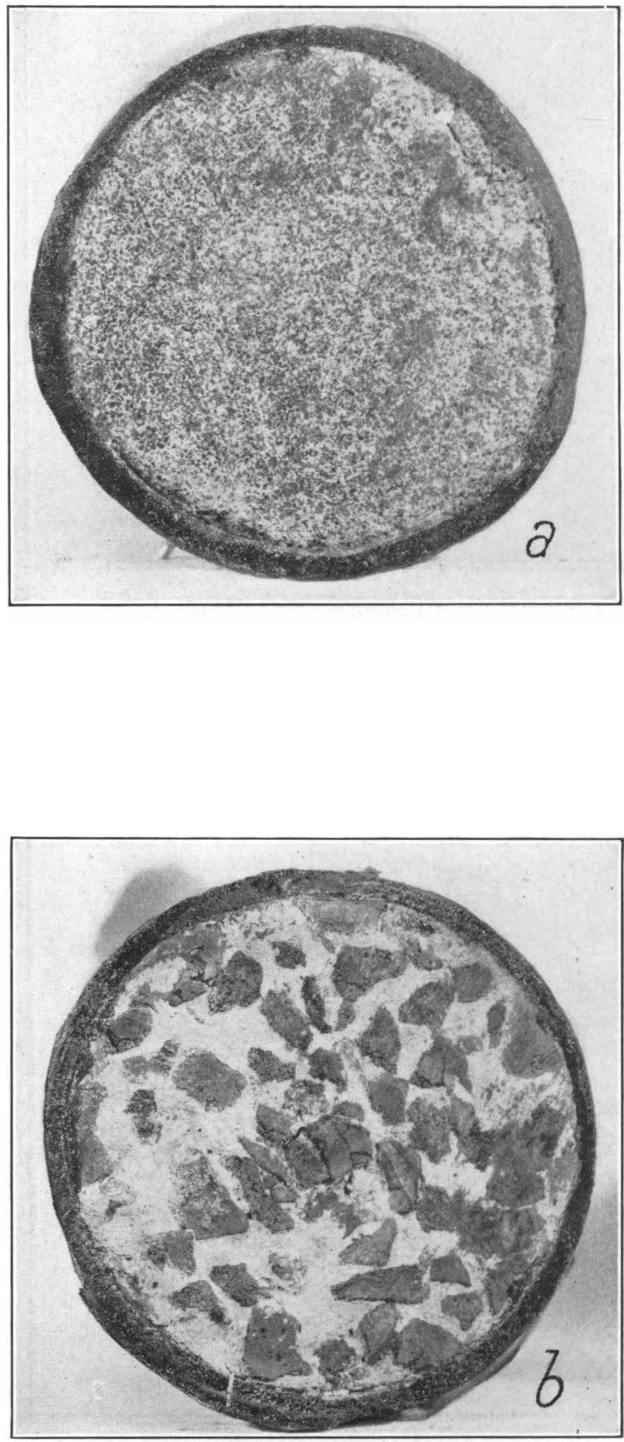

Figure 13.-Cross sections of beds of iron ore (full size): a 28 to 35 mesh Cuyuns ore; $b, 3$ to 4 mesh Mesabi ore 

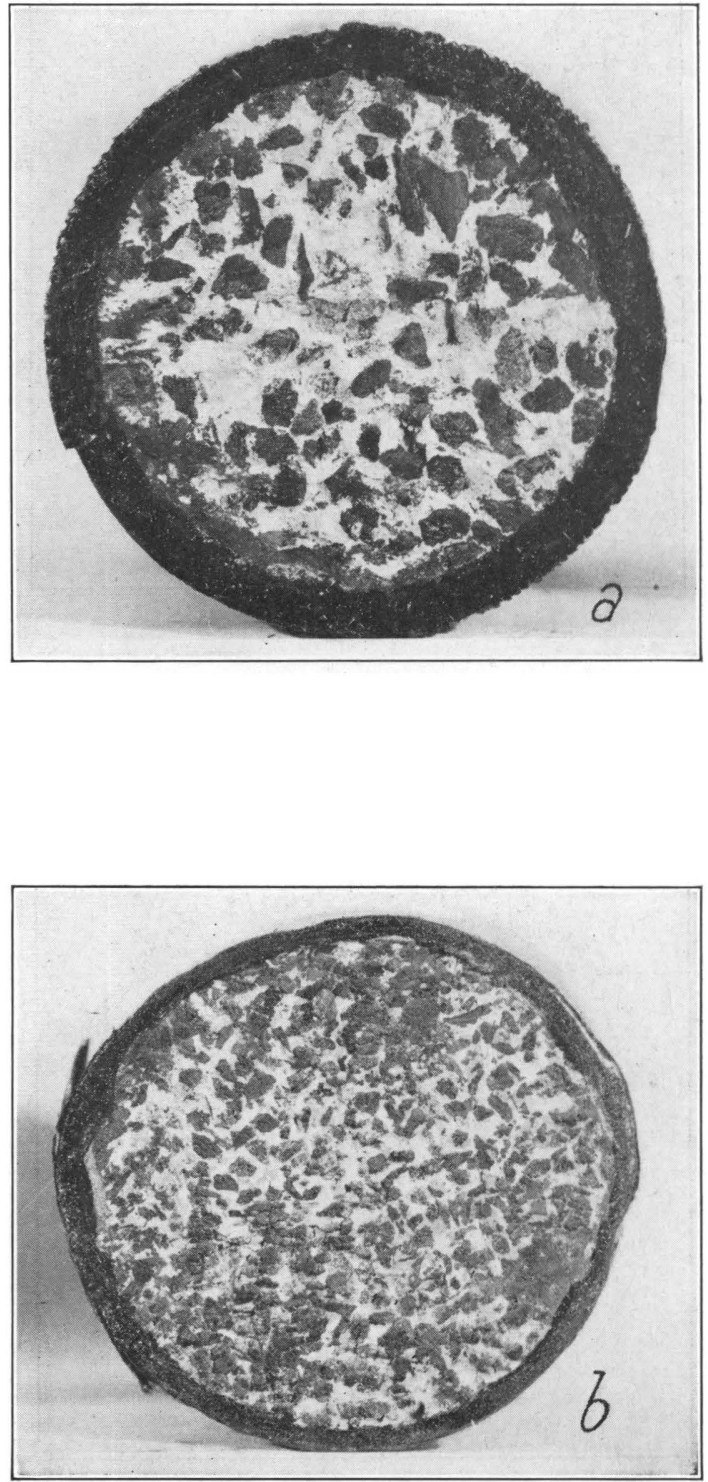

Figure 14,-Cross sections of beds of Mesabi iron ore (full size): $a, 4$ to 6 mesh; $b, 8$ to 10 mesh 

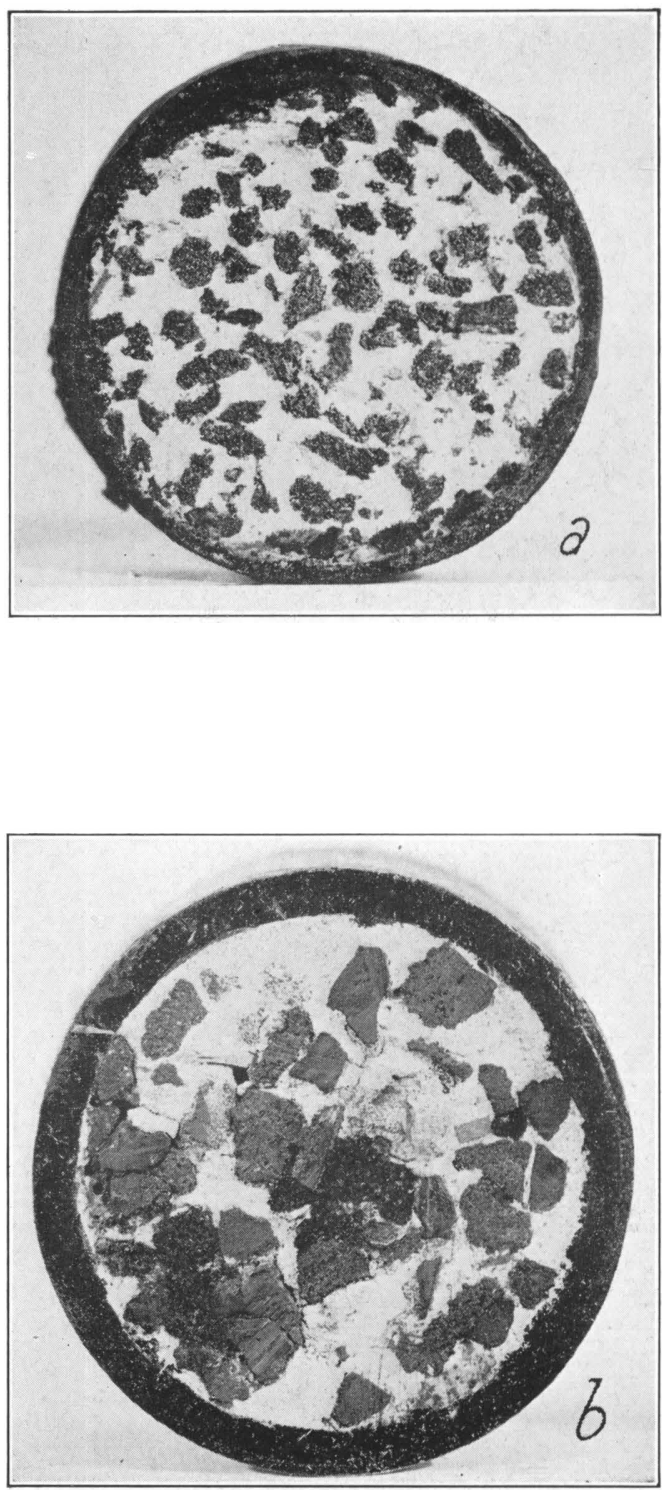

Figure 15.-Cross sections of beds of broken solids (full size): $a, 4$ to 6 mcsh coke; $b, 3$ to 4 mesh Vermilion iron ore 

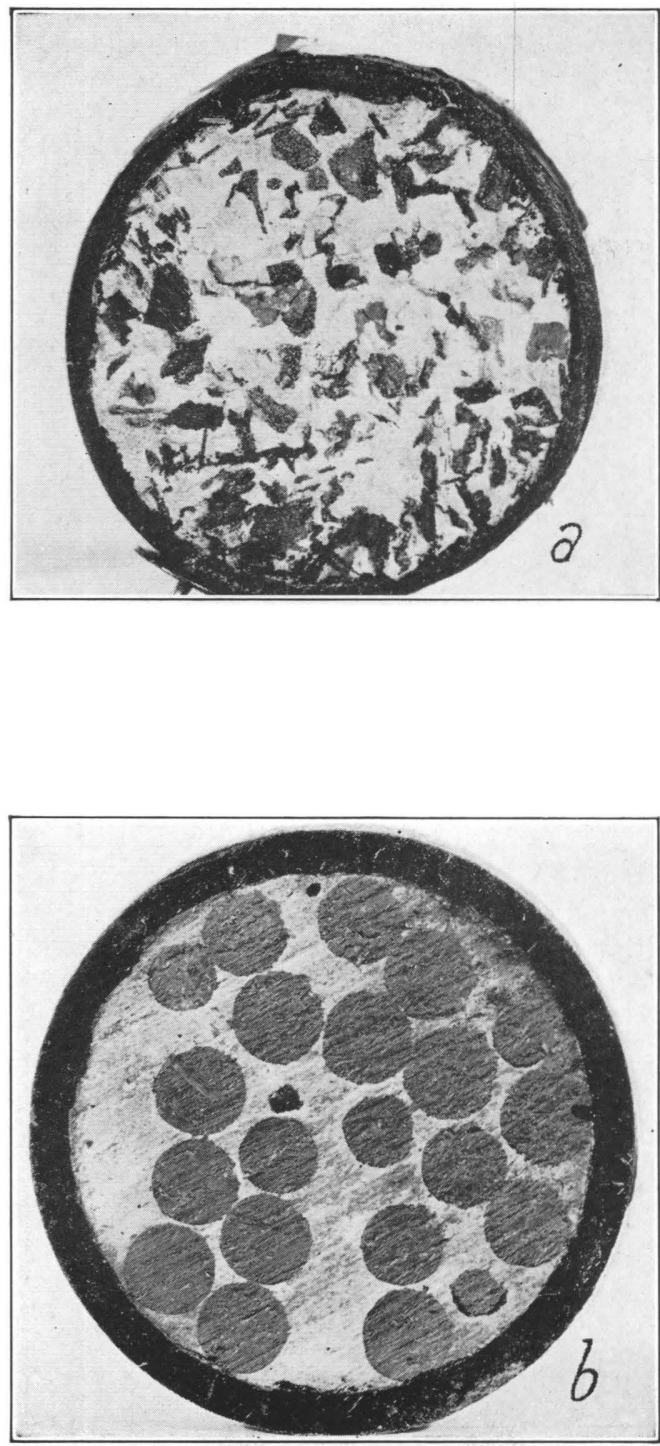

FigURE 16.-Cross sections of beds of broken solids (full size): $a, 3$ to 4 mesh roll scale; $b$, No. 000 shot 

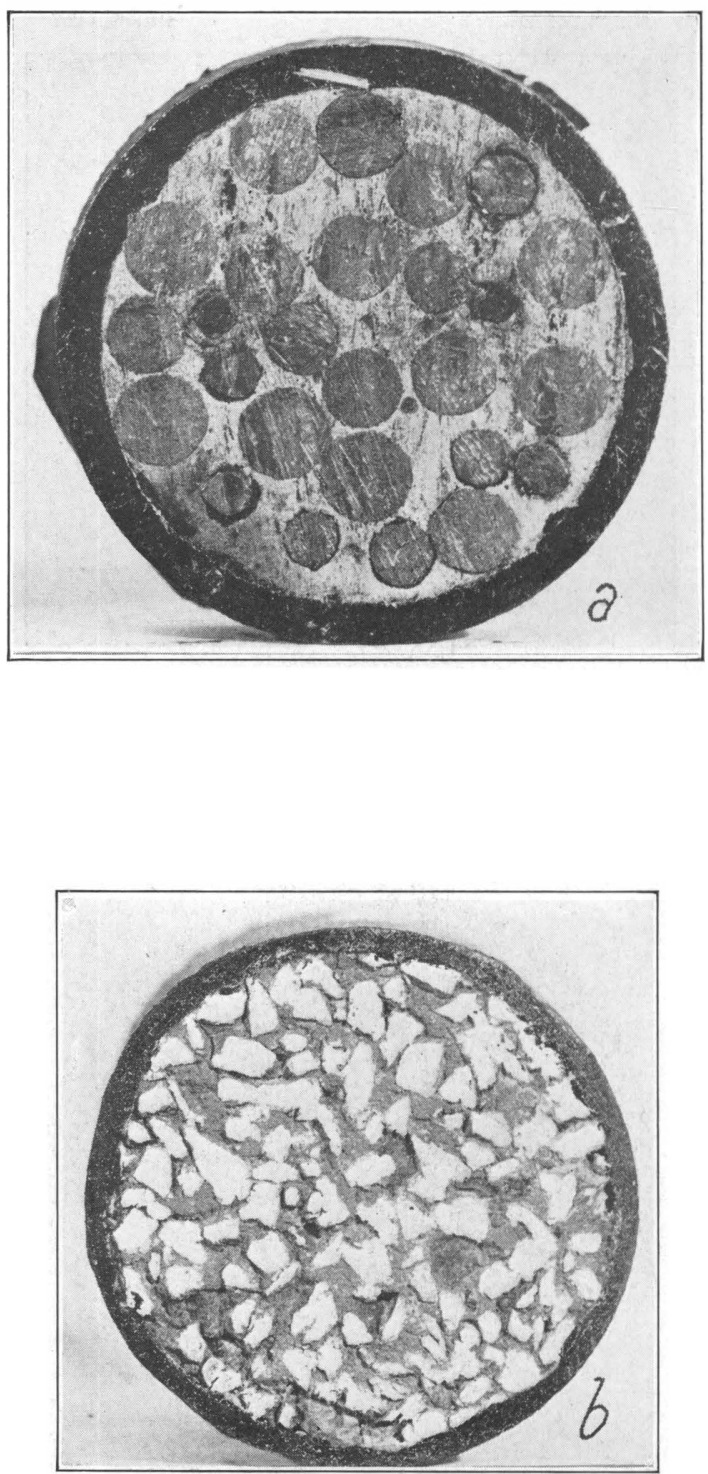

Figure 17.-Cross sections of beds of broken solids (full size): $a$, No. 000 shot; $b, 4$ to 6 mesh limestone 

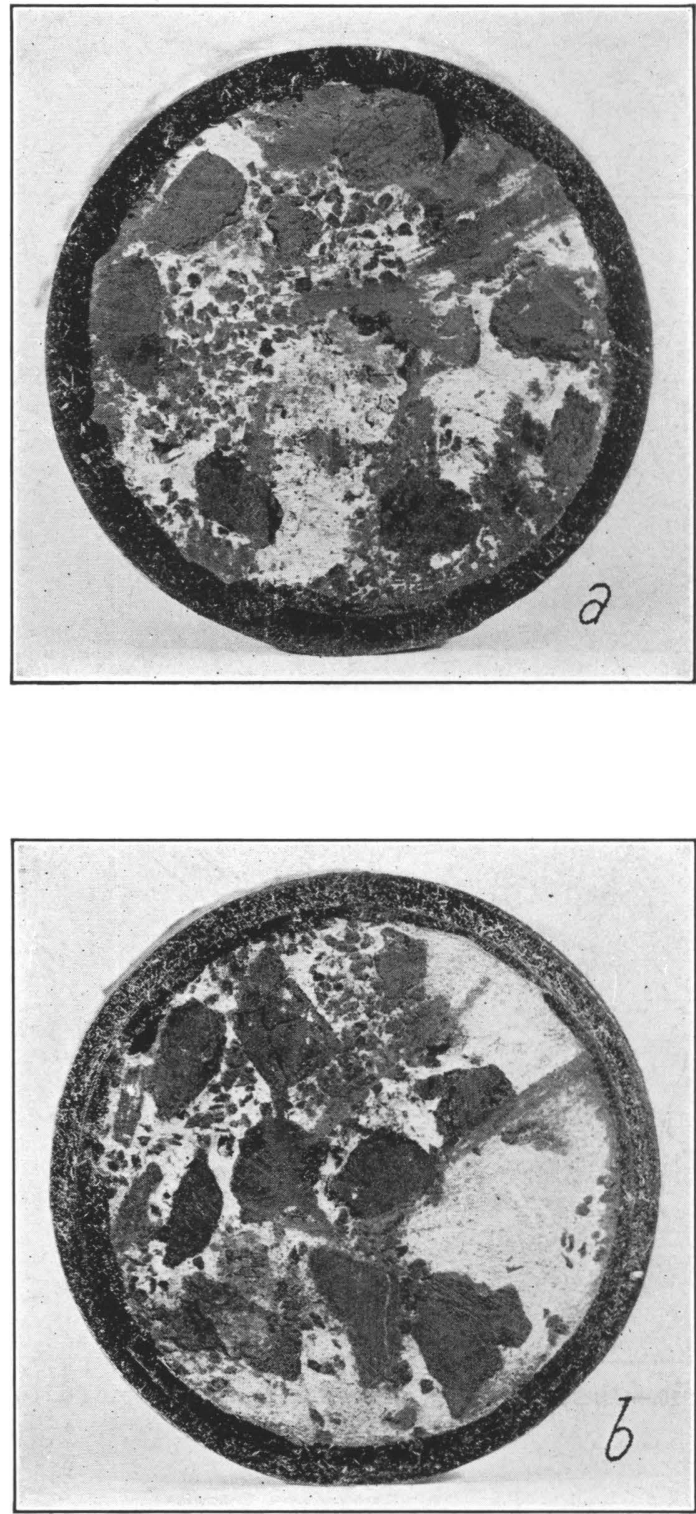

Figure 18.-Cross sections of beds of Cuyuna iron ore (full size): $a, 70$ per cent 0.525 to 0.371 inch plus 30 per cent 10 to 14 mesh; $b, 70$ per cent 0.525 to 0.371 inch plus 30 per cent 10 to 14 mesh 


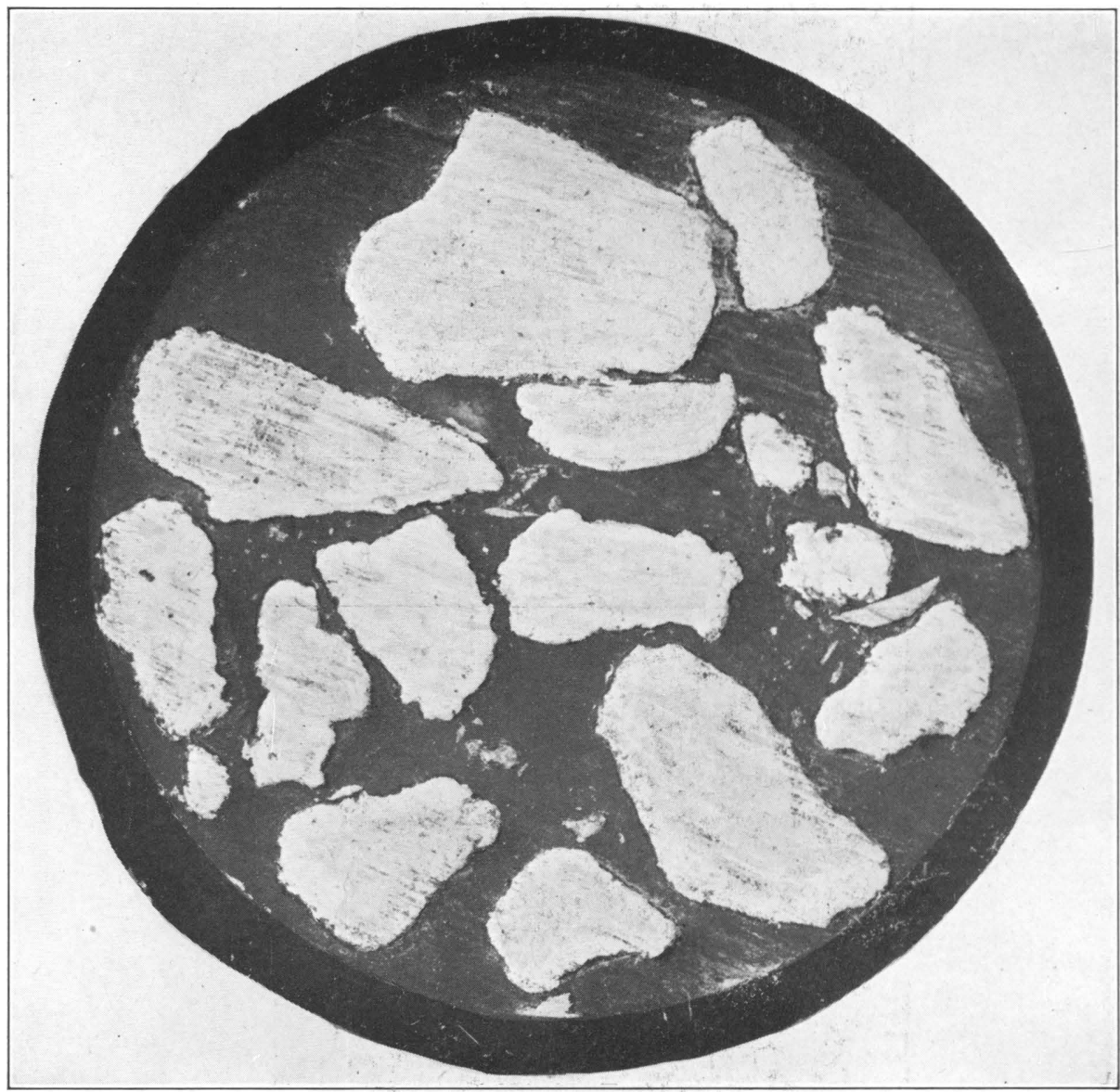

Figune 19.-Cross section of bed of 1.050 to 0.742 inch limestone (full size) 
closely packed condition possible without distortion a pile of spheres will have a void of 25.95 per cent and a probable effective free area of 9.31 per cent. These figures are independent of the size of the spheres.

Probably the most complete work on the support of solid particles by gas streams is that of Audibert, ${ }^{13}$ but his treatment has no particular significance in the case under consideration.

The "lifting velocity" or velocity of the gas stream that will just support the particles in the bed against the force of gravity gives a method for rough evaluation of the effective free area.

In a constricted passageway the linear velocity of the gas passing is equal to $\frac{\text { volume passing per unit of time }}{\text { effective free area }}$. The volume passing per unit of time is one of the determined factors of the experiment. The velocity of the gas can be computed when it is sufficient to raise the particles of a uniform bed of solids against the force of gravity. The approximate value of this velocity is given by the equation

$$
u=\sqrt{\frac{8 g r_{p} S_{s}}{3 S_{g}}}
$$

where $u=$ gaseous velocity,

$g=$ acceleration due to gravity,

$r_{P}=$ average radius of the solid particles,

$S_{s}=$ density of the solid, and

$S_{g}=$ density of the gas.

This equation is derivable by consideration of the kinetic energy of the gas stream. The particles are assumed to be spheres.

In the experimental work, when the gas velocity becomes great enough to lift the charge the pressure suddenly drops and becomes very unsteady. The lifting point can easily be determined by watching the manometers and noting at what flow the pressure begins to oscillate. The data on the lifting velocity experiments are given in Table 2.

The lifting velocity for a uniform bed of loosely packed material has been found to be independent of the depth of the bed. Tests were made of three different materials of six different sizes on beds ranging from 5 to 60 centimeters in depth, but this rule always held as long as the material was loosely packed. If the material was packed tightly, it tended to form a plug which required an abnormally high pressure to start lifting.

1s Audibert, M. E., Etude de l'entrainement du poussierde heule par l'air: Rev. Soc. ind. min., vol. 2, 1922, pp. 22-26; Ann. mines, 12th ser., vol. 1, 1922, pp. 153-190. 
TABLE 2.--Effective free areas of beds of broken solids

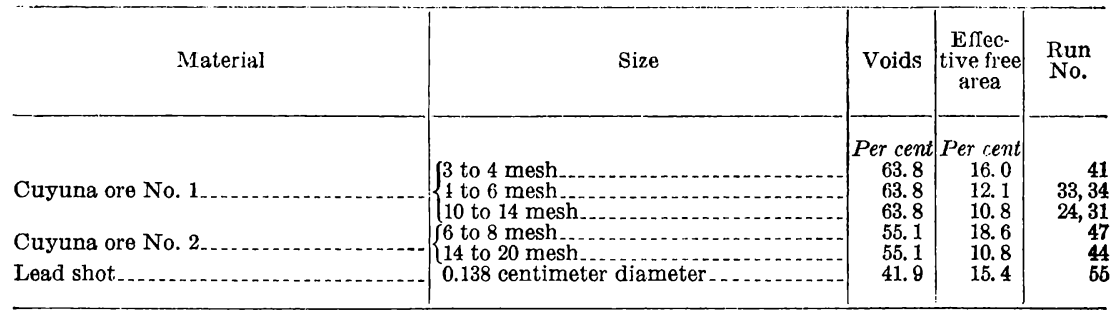

After the lifting velocity has been computed for a given size of material the rate of flow of gas at the lifting point can be determined by experiment; hence, the effective free area can be computed. The values obtained are for a loosely packed condition. If the value for a closer packing is desired, it can be approximately computed by the equation: Free area, per cent $=K$ voids, per cent, where $K$ is a constant determined by the value of the effective free area for the loose condition.

The equation for the percentage of voids in the charge is

$$
\text { Voids }=100\left(1-\frac{\text { apparent density of solids }}{\text { true density of solids }}\right) \text {. }
$$

Some of the values obtained for effective free area are given in Table 2.

Table 2 shows that 3 to 4 mesh Cuyuna ore has an effective free area of 16 and 4 to 6 mesh Cuyuna ore an effective free area of 12.1 per cent. The photographs of the cross sections of these beds are shown in Figure 11, $a$ and $b$. It can be seen that the free crosssectional area of these beds is much higher than the above figures, but only a small percentage of this free area is "effective" in allowing the passage of the gas.

By use of a planimeter it was found that the free area for 1.05 to 0.742 inch limestone (fig. 19) was 43 per cent. Probably about onethird of this figure is the value for effective free area.

Unfortunately the results found are not accurate enough to permit their use in the formulation of a theory of tortuous flow, but they do show that the fractional part of the cross-sectional area that is effective in allowing the gas to pass is quite small, being only 10 to 20 per cent instead of 40 to 60 per cent, as commonly assumed.

These data are directly applicable to all processes in which contact between gas and beds of broken solids is important, for it can be seen that the actual time of contact is much shorter than is generally assumed to be the case.

Analysis of the phenomena of lifting leads to some interesting corollaries. The upward pressure exerted by a stream of air is equal to the pressure difference at the two ends of the column. The pressure difference necessary to lift the column then depends only upon the 
density of the column as a whole, and since the density of a column is practically independent of the size of the material the lifting pressure for a given column is independent of the size of material. As the lifting velocity varies as the square root of the radius of the particle, the above statement might afford a means of correlating pressure drop and particle size. This item is discussed later.

\section{CHANGE OF B WITH SIZE OF PARTICLE}

Only three variables have been found to affect the value of $B-$ particle size, viscosity, and molecular weight of the gas. The effects of gaseous viscosity and molecular weight are considered later. The data of $B$ for various values of equivalent spherical diameter of particles and for several different materials are plotted in Figure 20.

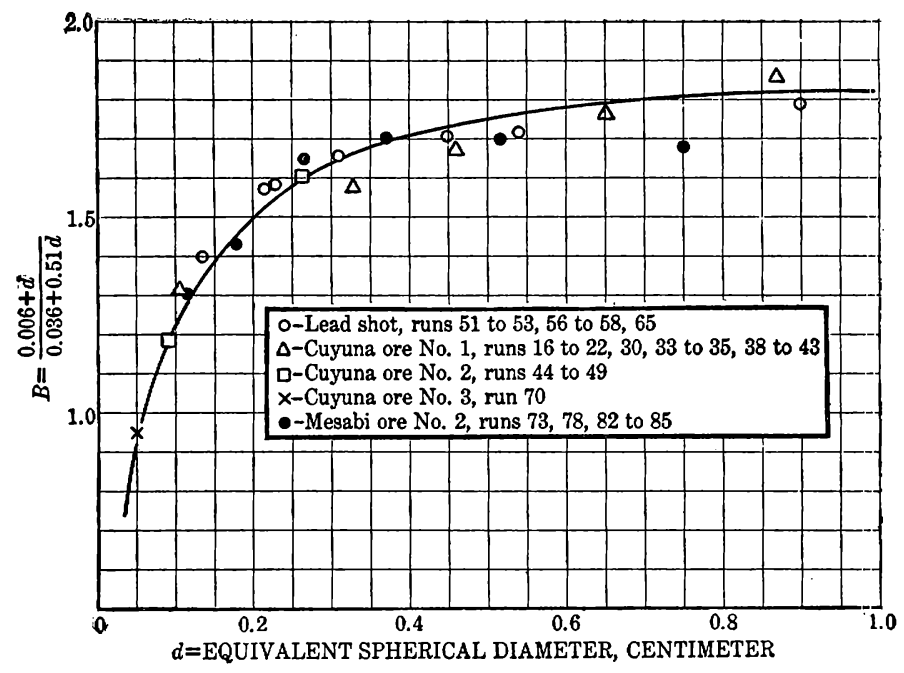

FiguRE 20.--Variation of $B$ (exponent of equation) with sizes of particles

There are several inconsistencies in the data, but it has not been possible to isolate the variation in terms of any other variables.

If the data for the pressure drop through a system of broken solids are plotted against the rate of flow on paper graduated in the logarithmic scale on both axes, the curve is a straight line, the numerical slope of the line being the value of exponent $B$ of equation (1).

If a series of such data on different sizes of material is plotted on one set of axes, the points will lie on a series of straight lines of varying slope. The curves of such a series of systems of Cuyuna ore of different sizes are given in Figure 21. The smaller the material the less the slope. The ordinate is pressure drop under standard conditions. The definition of this quantity is given on page 14 . The curves for the other materials whose data are plotted in Figure 20 are not given, 
The equation for the curve as plotted in Figure 20 is

$$
B=\frac{0.006+d}{0.036+0.51 d}
$$

where $B$ is the exponent of equation (1) and $d$ is the equivalent spherical diameter of the particle in centimeters.

In Figure 22 the curve of Figure 20 has been plotted against the average cross-sectional area of the particles rather than their diameter.

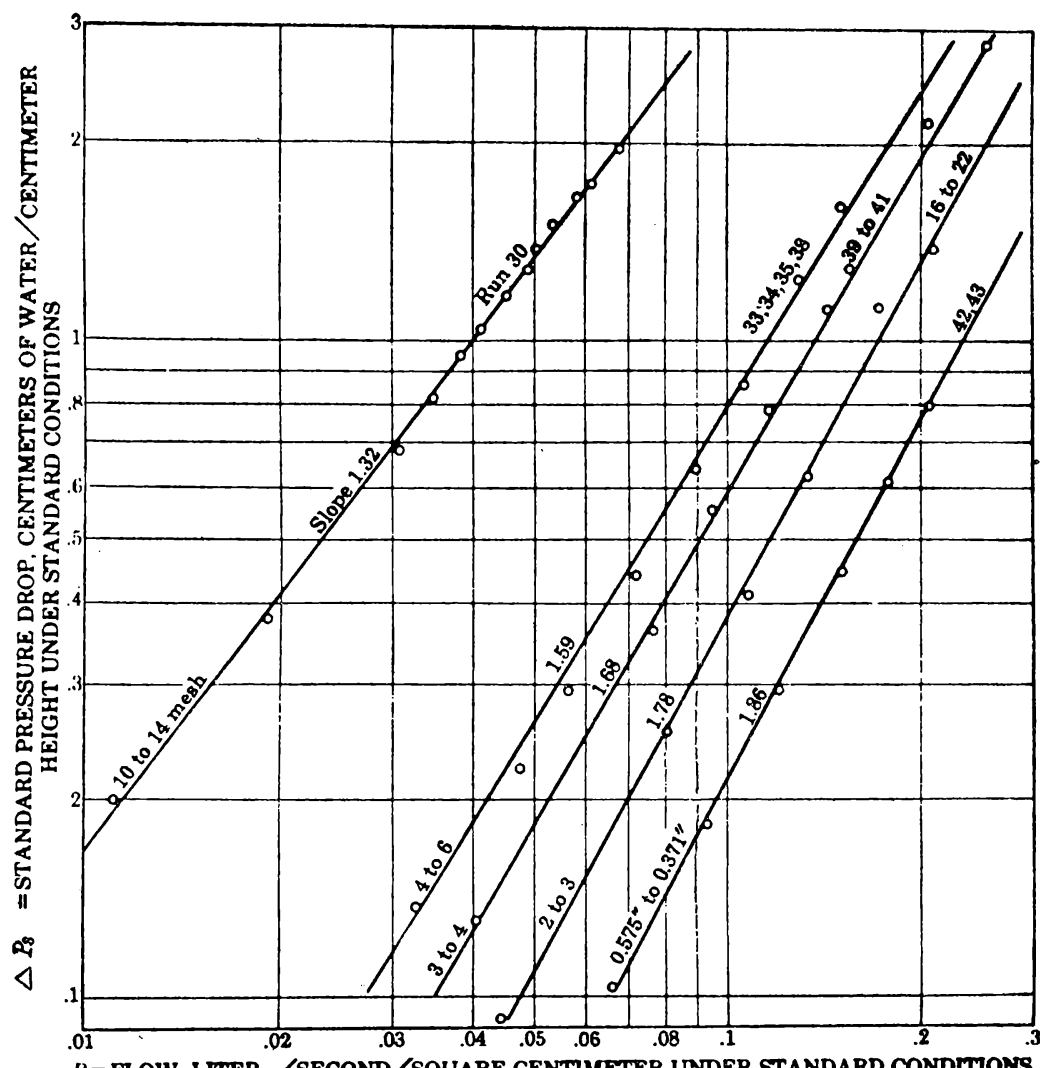

Figure 21.-Variation of standard pressure drop with rate of gas flow; sized Cuyuna iron ore, lot 1 , voids 63.8 per cent

This furnishes a basis for comparison of Figure 7 (variation of $B$ with size of passage in synthetic fuel beds) with Figure 20 . The abscissa of Figure 22 is the cross-sectional area of the particles obstructing the passage itself, so Figures 22 and 7 can not be compared directly, but it is evident, if passage size is approximately proportional to particle size, that the rate of change of $B$ with size of passage is much greater for small openings in thin plates than it is for small openings in beds of broken solids. 
This decrease of exponent with decrease of size introduces a paradoxical condition. It can be seen that values of $\Delta P$ as computed from equation (1) at high rates of flow will be greatest for the highest values of $B$. Since small particles have the smaller values of $B$, the computed pressure drop through large material at high enough rates of flow will be greater than for small material of the same claaracter. Therefore, it should be possible to reach a point of flow at which beds of large-size material would offer more resistance to the passage of gas than a body of small material. However, it is to be expected that

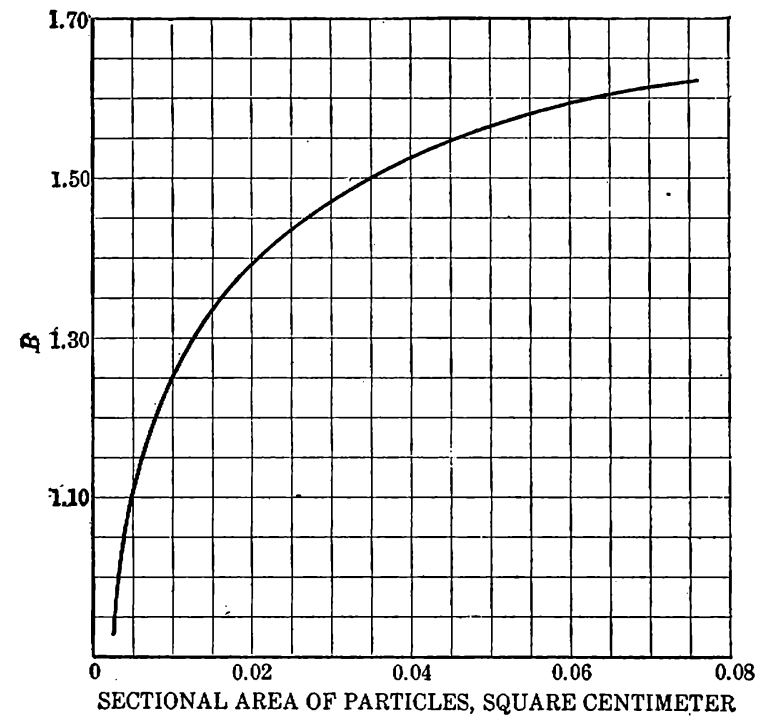

Figurw 22.-Variation of $B$ with average cross-sectional areas of particles

these laws do not hold at high rates of flow and that such extrapolation probably leads to faulty conclusions.

\section{DETAILED STUDY OF IMPORTANT VARIABLES}

\section{EFFECT OF CONTAINER SURFACE}

The next variable to be considered is that of container surface. (See fig. 23.) It is evident from the figure that this variable is eliminated as far as brass and iron pipes are concerned. The two runs represented by this figure were made under conditions that were identical in every respect except that one was made in a brass pipe and the other in an iron pipe. The differences in the two sets of points are smaller than the experimental errors.

In fluid flow through unobstructed pipes the wall surface is of prime importance, but when the passageway is plugged with a bed of broken solids the wall becomes unimportant, 


\section{EFFECT OF DEPTH OF BED}

It does not seem unreasonable to suppose that the resistance to gas flow per unit length of column of broken solids might vary with the height of column of broken solids, because of high resistances at the entrance and exit surfaces of the column. The data of Figure 24 show such a supposition to be untrue. The data plotted are those of the pressure drop per unit length of column for columns 20 to 70 centimeters in height.

There are some discrepancies in the positions of the points, but a detailed study will show that there are almost as great variations in the data of two different runs of the same height of column (60 centimeters) as there are in the data on beds of different height; hence the variations are due to experimental error and it seems well established that the pressure drop per unit of height is independent of the height of column.

\section{VARIATION OF PRESSURE DROP WITH TOTAL PRESSURE}

According to the fundamental laws of fluid flow, the pressure drop should vary inversely as the density of the gas if the rate of flow is constant as measured in mass of gas flowing per second. It does not necessarily follow that this law will be the same for an obstructed passage, such as is afforded by a bed of broken solids. A series of three experiments was performed to determine the law of variation of pressure drop with total pressure for the case under consideration. Since the pressure in the blast furnace is usually between 1 and 2 atmospheres absolute, the tests were made in this range. Of the three runs made the total pressures were approximately $1,1 \frac{1}{2}$, and 2 atmospheres.

The desired pressure was obtained by throttling the gas stream by means of the valve $v_{6}$ (fig. 2) and using the high-pressure source of air $a$. Considerable difficulty was experienced in keeping the total pressure constant, due to variations in the compressor operation, but the tests were finally completed with fair accuracy.

The material used was Cuyuna iron ore sized to pass 2-mesh and stay on 3-mesh. Nothing was allowed to vary between runs except the total pressure. The results are shown graphically in Figure 25.

Figure 26 is a cross section of the curves of Figure 25 at the flow of 0.15 liter per second per square centimeter, the pressure drop being plotted against the reciprocal of the absolute pressure. The best curve for these points appears to be a straight line passing through the origin. This means that the pressure drop varies inversely as the total over-all pressure or inversely as the density of the gas.

This statement that the pressure drop varies inversely as the density of a given gas may be confusing upon first thought, for a denser gas is presumably harder to force through a conduit. This paradox 


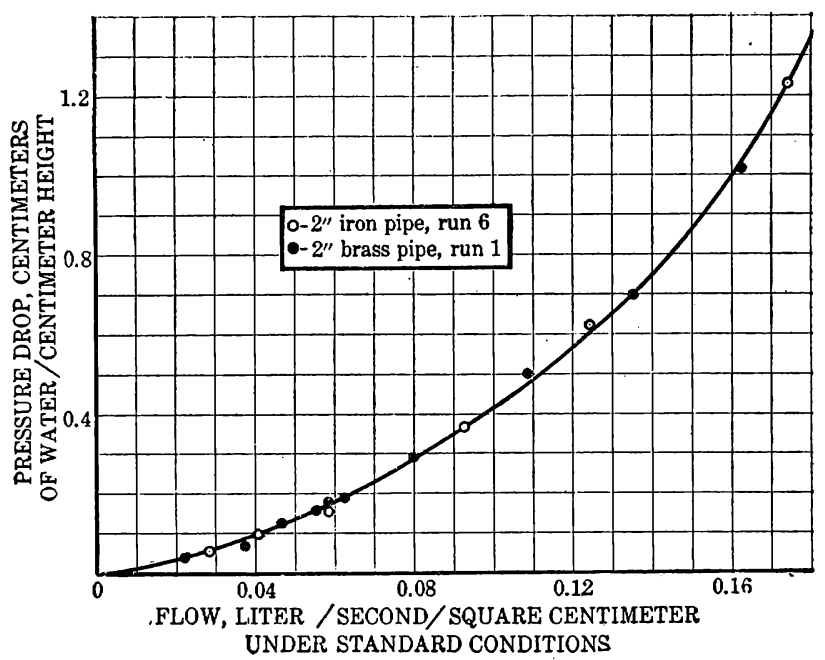

Figure 23.-Comparison of pressure drops in columns of broken solids in brass and iron 2-inch pipes, using 1,874 grams of 2 to 3 mesh Cuyuna ore 73.35 centimeters deep and having 63.6 per cent voids

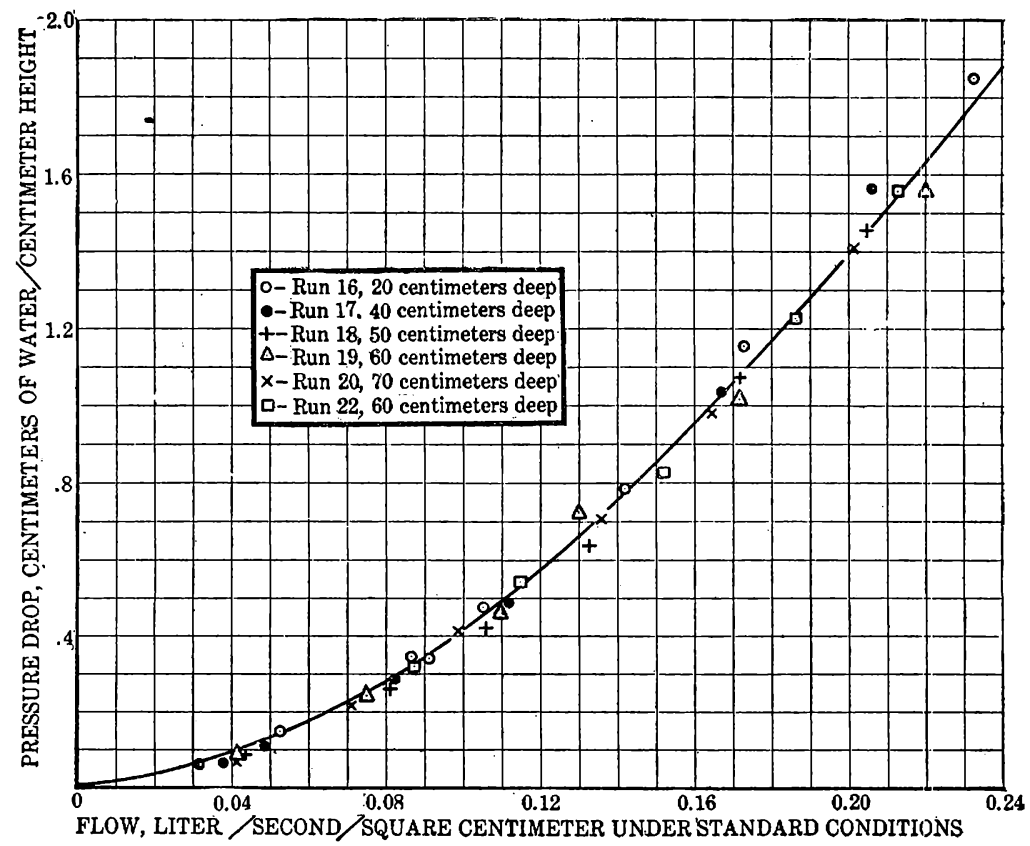

Figure 24,-Effect of depth of bed of 2 to 3 mesh Cuyuna ore with 63.8 per cent voids on unit resistance to gas flow through beds of broken solids 


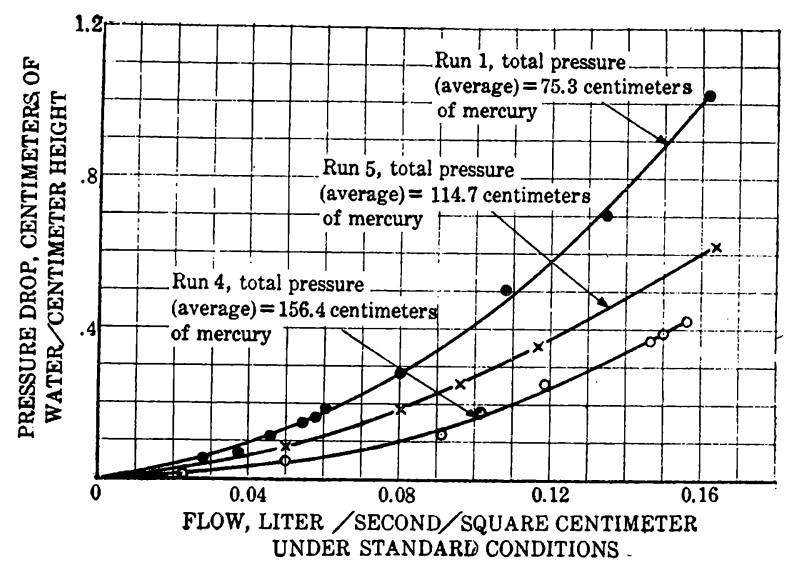

Figure 25.-Variation of pressure drop with total over-all pressure for 2 to 3 mesh Cuyuna ore having 63.8 per cent voids

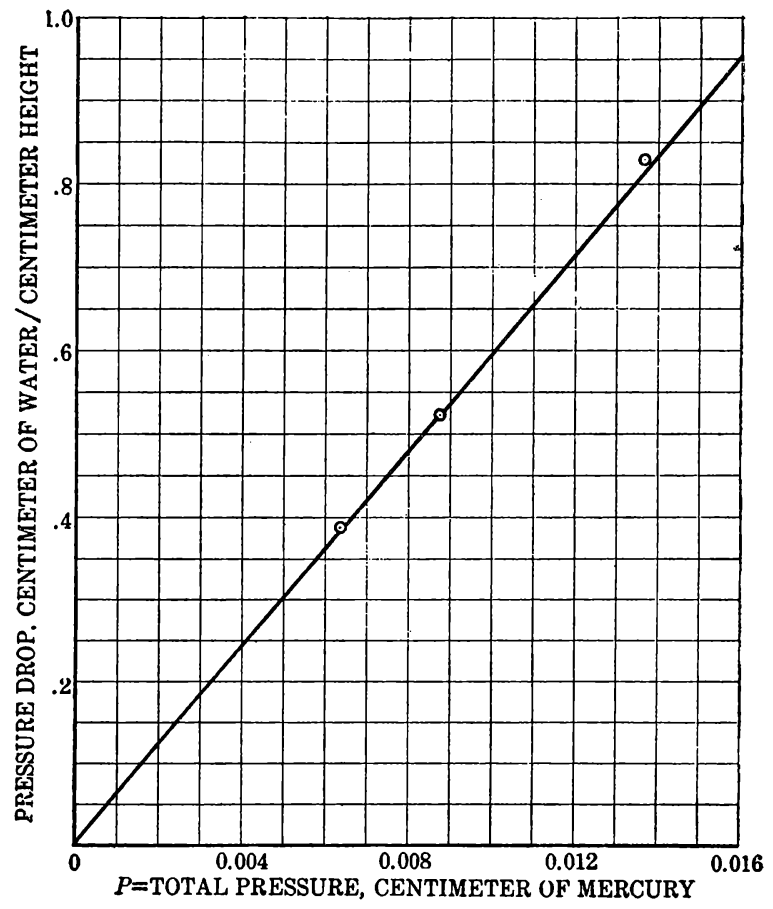

FIgURE 26.- Variation of pressure drop with total over-all pressure for 2 to 3 mesh Cuyuna ore having 63.8 per cent voids at a rate of flow of 0.15 liter per second 
disappears when it is remembered that gas flow in this bulletin is being measured in standard volume (or weight) per unit of time and not in linear velocity, as is customary in considering the flow through conduits. For a more detailed discussion of this point refer to the section of this report on "Effect of varying density and viscosity of gas" (p. 106). The above-mentioned relation is expressed by equation $(48 \mathrm{a})$ of that section.

The 2 to 3 mesh ore used for the first set of data on effect of pressure gave pressure-drop curves that conformed to the law of equation (1)

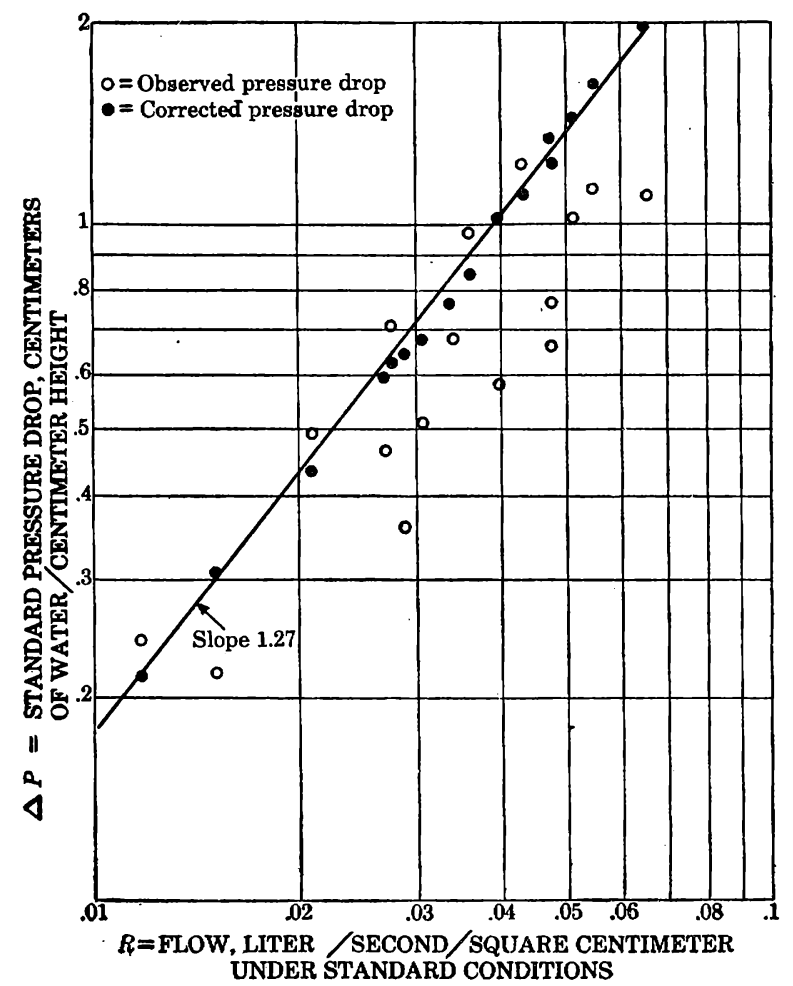

Figure 27.-Correction of pressure drop to standard gas density for 10 to 14 mesh Cuyuna ore, runs 234 and 235

if $B=1.78$. To determine whether or not the law relating to pressure drop changes with changing pressure, a second set of runs was made on a 10 to 14 mesh ore which had a $B$ value of 1.32 .

The data of these runs are plotted in Figure 27 on axes graduated in the logarithmic scale. During these runs the pressure on the system was varied at random. The open circles of Figure 27 are observed pressures plotted against the rate of flow. There is no apparent correlation between the various points.

The solid dots of the figure are the pressure drops, all corrected to a standard condition of $0^{\circ} \mathrm{C}$. and 76 centimeters of mercury, by assum- 
ing the validity of the foregoing law, namely, that the pressure drop varies inversely as the average density. The corrected points lie on a smooth curve, and there can be but little question as to the validity of the law.

\section{STANDARDIZATION OF PRESSURE DROP}

Obviously, since the pressure drop varies inversely as the over-all pressure, the pressure-drop data would lose considerable significance unless they were determined for some standard gas density. The gas densities are affected by barometric pressure, temperature, back pressure on system, and pressure drop. All values of pressure drop were corrected to that of air at $0^{\circ} \mathrm{C}$. and 76 centimeters of mercury.

When gas is flowing, the density is not uniform throughout the column, for the pressure is greater at the bottom of the column than at the top. The average pressure on the column in each case was considered as the arithmetical mean of the top and bottom pressures. In other words, it was the total pressure at the bottom of the column plus half of the pressure drop.

It can be shown that the quantity which should be employed for this particular average is the so-called root-mean-square, which is the square root of the average of the squares, but the arithmetical mean is much simpler for computation, and the error is negligible except for very long columns of material.

Owing to the magnitude of the pressure drop in some instances, the standardizing factors for the pressure drop at high rates of flow would be several per cent higher than the same factor for low rates of flow. Under some conditions the law represented by equation (1) would not hold closely for observed pressure drops but would hold almost exactly for the pressure drops in the standard state.

Throughout this report, unless an exception is noted, all pressure drops and all rates of flow are recorded as being at the standard state of $0^{\circ} \mathrm{C}$. and 76 centimeters of mercury.

\section{PACKING}

The resistance of a bed of broken solids to fluid flow varies markedly with the percentage of voids in the bed. To determine the quantitative effect of packing, a series of runs was made on two different materials, 10 to 14 mesh Cuyuna ore and 14 to 20 mesh Cuyuna ore differing somewhat in character from the first. The data for these two materials are plotted in Figures 28 and 29. For convenience of interpretation these data are plotted on paper graduated in the logarithmic scale on both axes.

The curves are all observed to be straight lines and almost exactly parallel, indicating that in all cases the pressure drop follows the law of equation (1) and that the value of $B$ does not change with a change 
in the percentage of voids. Brooks, Nicholls, Augustine, and Orr ${ }^{14}$ have noted this same invariability of the exponent in their work on similar material. The defining data for these two materials, for those used by Brooks, Nicholls, Augustine, and Orr, and for one experiment with lead shot ${ }^{15}$ are given in Table 3.

TABLE 3.-Daia on effect of packing AUTHOR'S DATA

\begin{tabular}{|c|c|c|c|c|c|}
\hline Material & $\begin{array}{c}\text { Experi- } \\
\text { mental } \\
\text { run }\end{array}$ & $\begin{array}{l}\text { Per } \\
\text { cent } \\
\text { voids } \\
\text { in bed }\end{array}$ & $\begin{array}{c}B^{1} \\
\text { aver- } \\
\text { age }\end{array}$ & $A^{12}$ & $\log _{10} A$ \\
\hline $\begin{array}{l}10 \text { to } 14 \text { mesh } \\
\text { Cuyuna ore. } \\
\text { Do } \\
\text { Do. } \\
\text { Do } 14 \text { to } 20 \text { mesh: }\end{array}$ & $\begin{array}{r}67 \\
30 \\
68 \\
233 \\
66\end{array}$ & $\begin{array}{l}62.6 \\
63.8 \\
64.5 \\
65.4 \\
67.2\end{array}$ & $\begin{array}{l}\text { 1. } 28 \\
1.28 \\
1.28 \\
1.28 \\
1.28\end{array}$ & $\begin{array}{l}75.0 \\
61.0 \\
51.8 \\
46.4 \\
34.3\end{array}$ & $\begin{array}{l}1.876 \\
1.785 \\
1.714 \\
1.656 \\
1.535\end{array}$ \\
\hline $\begin{array}{l}\text { Cuyuna ore } \\
\text { Do. } \\
\text { Do. }\end{array}$ & $\begin{array}{r}231 \\
230 \\
44-46 \\
229\end{array}$ & $\begin{array}{l}51.7 \\
54.1 \\
55.1 \\
56.9\end{array}$ & $\begin{array}{l}1.17 \\
1.17 \\
1.17 \\
1.17\end{array}$ & $\begin{array}{l}72.5 \\
62.2 \\
50.6 \\
37.9\end{array}$ & $\begin{array}{l}1.860 \\
1.794 \\
1.704 \\
1.579\end{array}$ \\
\hline
\end{tabular}

BROOKS, NICHOLLS, AUGUSTINE, AND ORR DATA ${ }^{3}$

\begin{tabular}{|c|c|c|c|c|c|}
\hline Material & Size of container & $\begin{array}{c}\text { Per } \\
\text { cent } \\
\text { voids }\end{array}$ & $B$ & $\boldsymbol{A}$ & $\log _{10} A$ \\
\hline 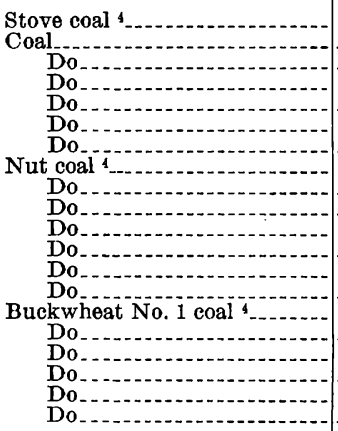 & 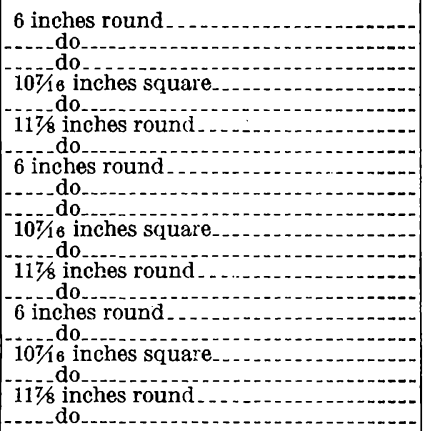 & $\begin{array}{l}44.4 \\
49.0 \\
52.3 \\
41.0 \\
52.7 \\
41.0 \\
47.7 \\
43.8 \\
49.0 \\
51.0 \\
41.6 \\
48.7 \\
40.8 \\
47.8 \\
41.3 \\
48.4 \\
41.5 \\
49.1 \\
42.0 \\
48.6\end{array}$ & $\begin{array}{l}1.79 \\
1.79 \\
1.79 \\
1.79 \\
1.79 \\
1.79 \\
1.79 \\
1.75 \\
1.75 \\
1.75 \\
1.75 \\
1.75 \\
1.75 \\
1.75 \\
1.58 \\
1.58 \\
1.58 \\
1.58 \\
1.58 \\
1.58\end{array}$ & $\begin{array}{r}4.55 \\
2.76 \\
2.01 \\
5.42 \\
2.92 \\
6.10 \\
3.25 \\
7.53 \\
4.44 \\
3.62 \\
8.31 \\
5.21 \\
10.00 \\
5.60 \\
22.3 \\
13.3 \\
29.3 \\
16.7 \\
34.4 \\
17.7\end{array}$ & $\begin{array}{r}0.658 \\
.441 \\
.303 \\
.734 \\
.465 \\
.785 \\
.512 \\
.877 \\
.647 \\
.559 \\
.920 \\
.717 \\
1.000 \\
.748 \\
1.348 \\
1.124 \\
1.467 \\
1.223 \\
1.537 \\
1.248\end{array}$ \\
\hline
\end{tabular}

RAY AND KREISINGER DATA

\begin{tabular}{|c|c|c|c|c|c|}
\hline Material & Size of tube & $\begin{array}{c}\text { Per } \\
\text { cent } \\
\text { voids } \\
\text { esti- } \\
\text { mated }\end{array}$ & $B$ & $A$ & $\log _{10} A$ \\
\hline No. 8 lead shot & $113 / 16$ inches diameter & $\begin{array}{l}38.0 \\
41.0\end{array}$ & $\begin{array}{l}1.59 \\
1.59\end{array}$ & $\begin{array}{l}67.2 \\
48.6\end{array}$ & $\begin{array}{l}1.827 \\
1.087\end{array}$ \\
\hline
\end{tabular}

1 Constants in equation (1).

2 Unit centimeter of water pressure drop per centimeter of height at standard conditions and at a rate of flow of 1 liter per second per square centimeter at standard conditions.

3 Work cited.

Approximate sizes given in Table 7.

3 Work cited.

${ }^{14}$ Brooks, H. W., Nicholls, P., Augustine, C. E., Orr, M. L., Pressures Required to Force Air Through Sized Anthracite: Bureau of Mines, February, 1926 (unpublished), p. 20.

${ }^{15}$ Ray, W. T., and Kreisinger, Henry, The Signiffcance of Drafts in. Steam-Bailer Practice: Bull. 21, Bureau of Mines, 1911, p. 27. 
A small change in the percentage of voids in a bed causes so large a change in the resistance that it is difficult to obtain data on this variable that are mutually consistent. The data of Table 3 are from different sources and on widely varying sizes and materials. If they are to be correlated for interpretation, some common basis for comparison must be found. The author has studied the data carefully

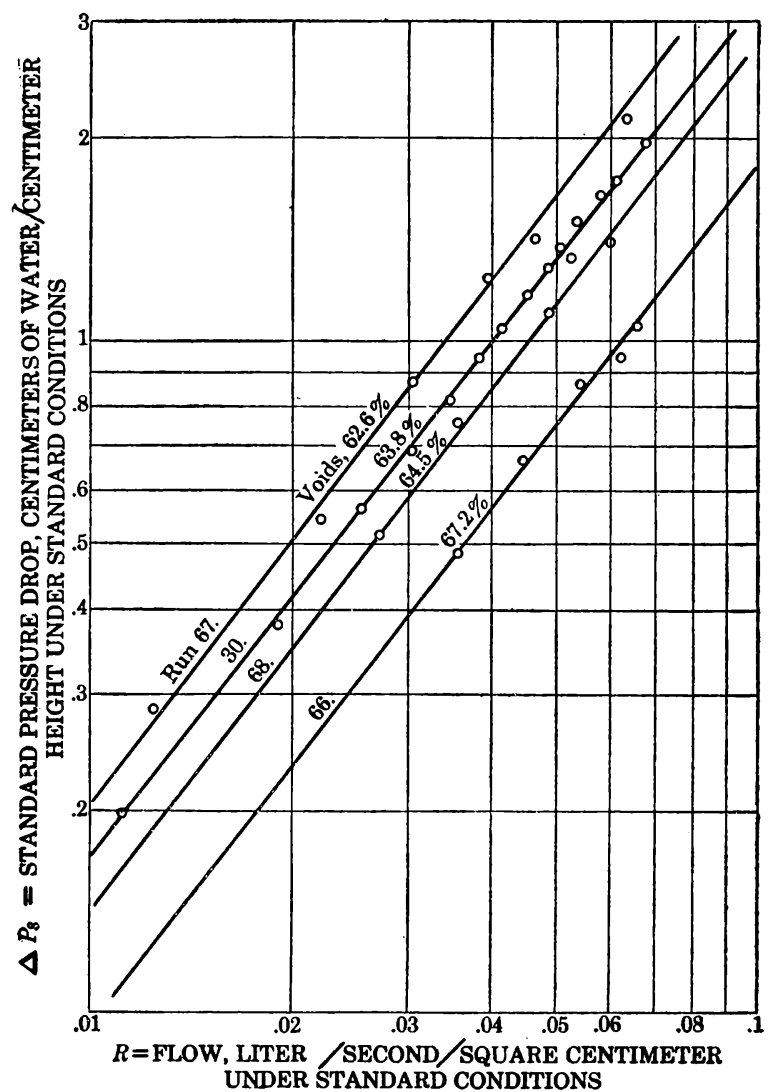

FIGURE 28.-Variation of unit pressure diop with packing of Cuyuna iron ore No. 1, 10 to 14 mesh; average slope, 1.28

and has found that of all the possible variables only the percentage of voids and the logarithm of coefficient $A$ give consistent relationships.

The data of Table 3 are plotted in Figure 30 , with $\log _{10} A$ as ordinate and the percentage of voids $V$ as abscissa. The original data points as plotted fail to lie on any sort of a smooth curve. Obviously the reason for this is that the data were obtained on different kinds and sizes of materials which necessarily have different values of $A$ for a constant void percentage. In this phase of the study the interest lies in the change of $A$ with the change of voids; hence, the absolute 
value of a point is unimportant, and only the slope of the curve need be considered. The ordinates of different groups of points may therefore be shifted until all points lie on a common curve. This has been done in Figure 30, and the resulting curve is shown at the top of the figure. One point out of each group was shifted upward by a distance that would make it fall approximately on the smooth curve drawn through the rest of the points; then the remainder of

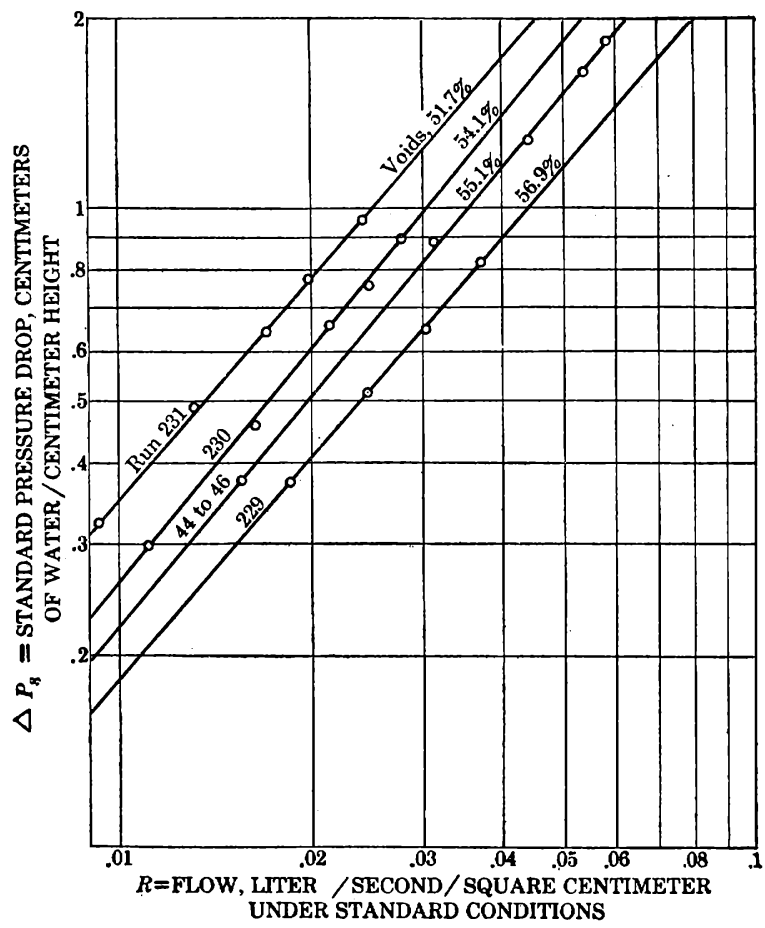

FTGORE 29.-Variation of pressure drop with packing of 14 to 20 mesh Cuyuna ore; average slope, 1.17

the points of that group would be shifted upward by the same amount. Each group of points was handled in the same way. After a few trials the different groups were closely correlated on the graph, and the smooth curve drawn through the points is thought to be the best interpretation of the data.

This method of dealing with the data is open to criticisna. To be mathematically rigorous, the data should be correlated by determining the slope along the integral curve of each group of points, averaging the values for the slopes of the different curves at each of several ordinate values, plotting these average values, and integrating that curve to obtain the true integral curve of the relationship. However, in this case there are small discrepancies in all of the groups of data, which make widely divergent values in the slopes of the short sections 
of the curves for each group of points. The averages so obtained for the values of the slopes are quite inconsistent. If there were a large number of data the average would acquire significance in the statistical sense, but with the small number of data which gives widely varying slopes the arithmetical average is of doubtful value.

On the other hand, it is apparent by inspection that the average rate of change of the logarithm of $A$ with change of $V$ is considerably

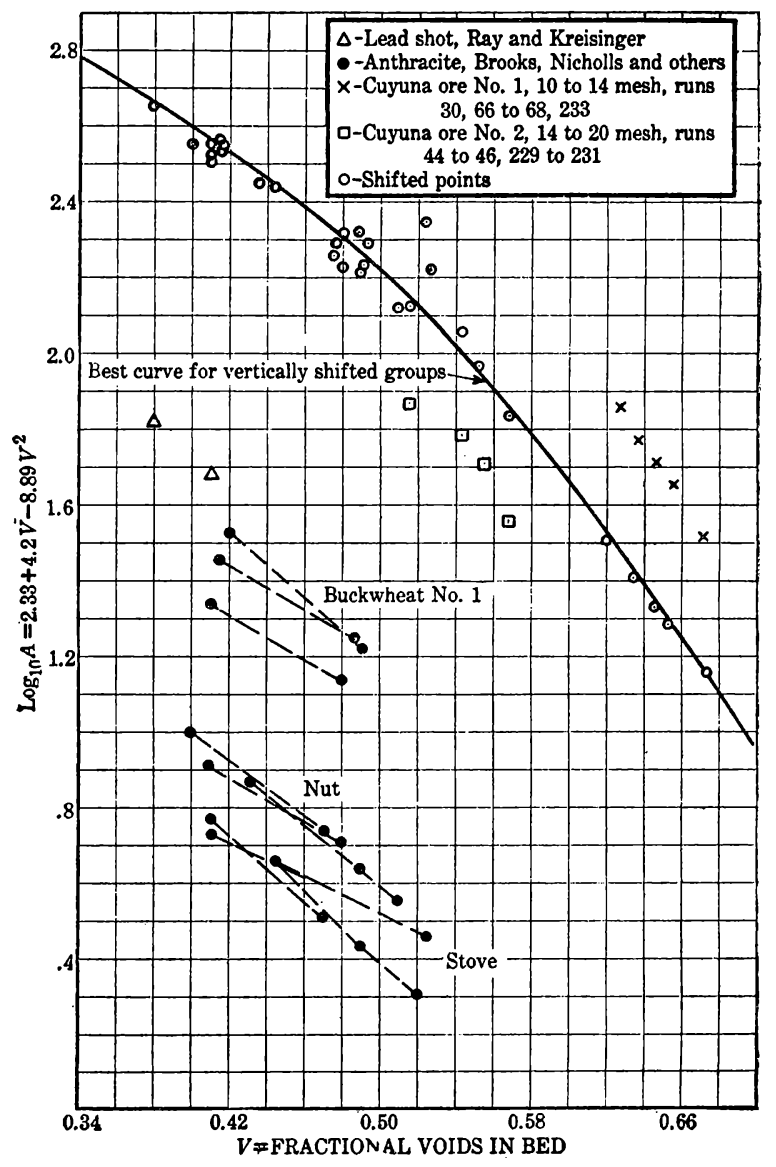

Figure 30.-Effect of packing on value of $A$

less for small values of $V$ than for the larger ones. It is felt that in this case personal judgment and the trial-and-error method of shifting groups of points to gain consistency give the best interpretation of the data.

There is an additional "wall effect" that is neglected here but is considered later. The wall effect can be neglected here, as it is practically constant for a given size of material, so will not affect appreciably the relative values of resistance for any one system with varying voids. 
The approximate equation of the curve is

$$
\log _{10} A=K+4.2 V-8.9 V^{2} .
$$

The value of constant $\dot{K}$ depends upon the size and character of the material.

The differential equation is

$$
\frac{d \log _{10} A}{d V}=4.2-17.8 \mathrm{~V} \text {. }
$$

The value of the true resistance of beds of solids to the passage of gas has been shown (p. 19) to be better represented by $\sqrt[B]{A}$ than by $A$. It would seem, then, that the foregoing data should be correlated into a curve for the variation of the logarithm of $\sqrt[B]{A}$ with voids rather than the variation of the logarithm of $A$ with voids. On the other hand, since exponent $B$ does not change with packing the converse may be true and the effect of packing may be unchanged by changes in $B$.

The data are not accurate enough to tell which of these two relations is correct; therefore either or both relations may be used, and the results of computation will be within the range of accuracy of the data.

For most conditions equations (8) and (9) are the simplest and are recommended for general use. In work on the "wall effect," which is presented later, the alternative relation is used because of convenience and mathematical consistency. If the data of logarithm of $A$ divided by $B$ are plotted against the percentage of roids and the points shifted to a common curve as explained heretofore, Figure 31 is obtained.

The general equations of the curve are

$$
\log _{10} \sqrt[B]{A}=\frac{\log _{10} A}{B}=K+2.84 V-5.88 V^{2},
$$

and

$$
\frac{d \log \sqrt[B]{A}}{d V}=2.84-11.76 V
$$

The utility of these equations will be explained in the section on wall effect.

\section{WALL EFFECT}

Although variation in the character of the wall surface may have only a negligible effect (see p. 25) on resistance to gaseous flow, there still remains the possibility that the particles lying next to the wall will not be as closely packed as the rest because of the presence of the wall and that there may be a consequent lowering of resistance for small containers. With the help of some simple assumptions this wall effect is susceptible to mathematical analysis. 


\section{MATHEMATICAL ANALYSIS FOR CIRCULAR CONTAINERS}

Consider the change in the resistance of a bed of material of average voids $V_{1}$ when a circular container wall is introduced, thus increasing the voids along the wall and increasing the average voids throughout the bed, if after the container

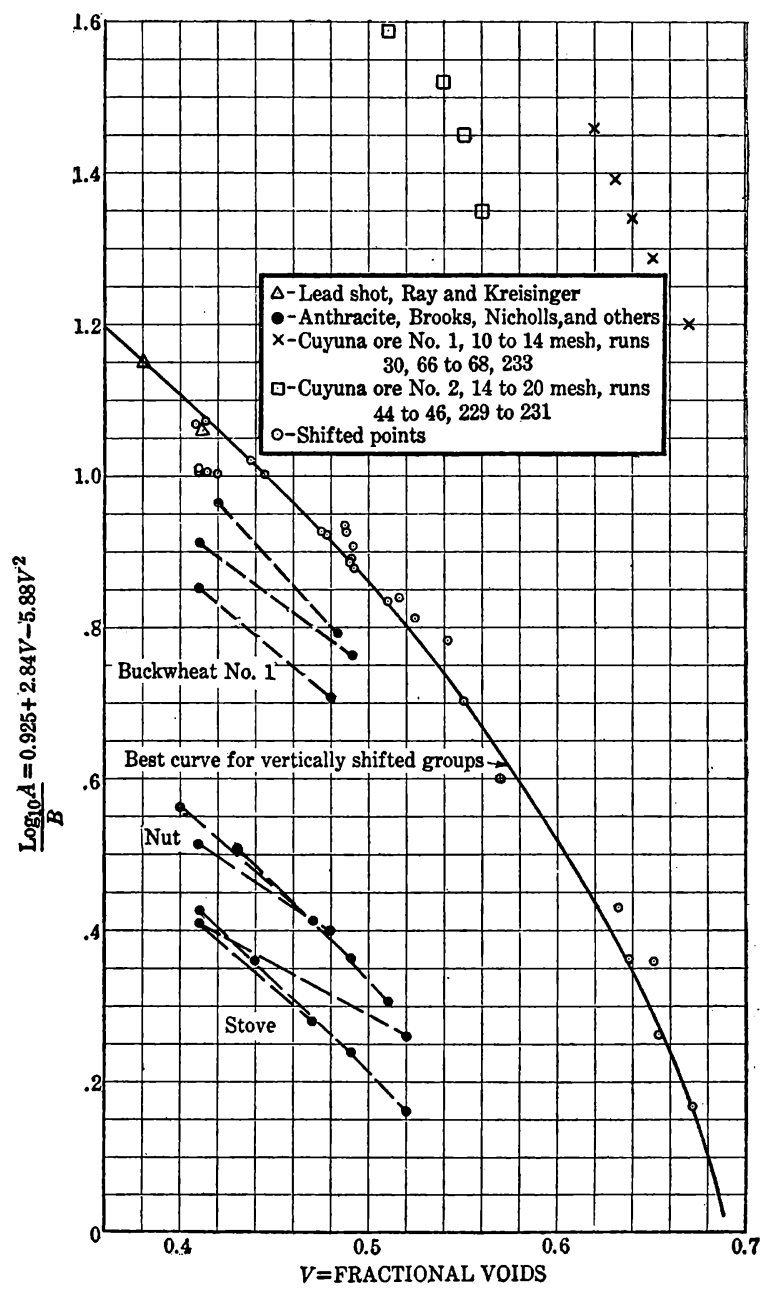

Figure 31.-Variation of $\frac{\log _{10} A}{B}$ with voids in bed. Equation of curve, $\frac{\log _{10} A}{B}=0.925+2.84 V-5.88 V^{2}$

wall is introduced the bed of material is packed so that its average percentage of voids has the same value as before the introduction of the container wall.

\section{VOIDS NEXT TO WALL}

Consider a cube of broken solid material. The material in the cube may be considered as having been pushed into place through the different faces of the cube. If the entrance through one of the faces is cut off, less material will be 
in the cube; hence the voids will be greater. This condition prevails at the wall where the outer row of broken particles will rest against the wall but will not have its interstices filled by adjoining particles. Hence, the voids along the wall will be greater than in the body of the bed, and the resistance will be correspondingly lowered.

If the voids in the interior of a bed of the material are $V_{1}$, the voids in a unit volume of the strip affected by the wall will be

$$
V_{w}=V_{1}+M\left(1-V_{1}\right) \text {. }
$$

The value of $M$ must be determined by experiment.

\section{AREA AFFECTED BY WALL}

Consider the strip of particles lying next to the wall of a container. The approximate area occupied by such a strip is $\pi d D$ if $d$ is small compared to $D$; $d$ is the diameter of the particles; $D$ is the diameter of the container. The crosssectional area of the container is $\frac{\pi D^{2}}{4}$, The ratio of the cross-sectional area covered by the strip next to the wall to the cross-sectional area of the container is

$$
\frac{\pi d D}{\frac{\pi D^{2}}{4}}=4 d / D \text {. }
$$

Each particle acts as a partial boundary for an opening on each side of itself. Since only passages through the bed that lie on the side of the particle next to the container are affected by the presence of the wall, only one-half of the area of the above-mentioned strip will be affected. Hence,

$$
\text { Affected cross-sectional area }=2 d / D \text {. }
$$

\section{EXTENT OF PACKING TO RESTORE ORIGINAL AVERAGE VOIDS}

Consider a unit length of the tube of material. Specify the cross-sectional area of the container $\frac{\pi D^{2}}{4}$ as unity. This specification involves a conflict between the units of height and of area, but if the units are not used interchangeably it will not matter. Unit volume then becomes the volume of a cylinder 1 unit high, with the diameter of the container being considered. With this assumption the volume affected by the presence of the wall is always $2 d / D \times 1$.

When a wall is introduced into an otherwise uniform bed the amount of solid material in each unit of volume of the strip next to the wall will be decreased by the quantity $M\left(1-V_{1}\right)$. (See equation (12).) Throughout the cylindrical section of unit length the volume of solid material decreases according to the equation

$$
\text { Volume change }=\frac{2 M d}{D}\left(1-V_{1}\right) .
$$

The quantity $2 M d\left(1-V_{1}\right) / D$ is the actual volume of the solid particles that are held out of the bed by the presence of the wall.

Consider that these particles are placed on top of the bed of unit height and that this bed plus the increment of height is to be packed so that the height of the bed will again be unity. Then the average voids in the bed will be the same as the original voids $V_{1}$. The difference from the original condition will lie in the fact that the central portion of the bed of volume $1-2 d / D$ will be packed to less voids than $V_{1}$, while the outer portion of the bed of volume $2 d / D$ will contain a greater void proportion than $V_{1}$. 
Assume that the increment of broken material piled on top of the bed of unit height is packed with the voids of $V_{1}$. This introduces a slight error, for that portion of the increment bed which lies next to the wall will have greater voids than $V_{1}$, but the increment will be quite small relative to the total volume so the error introduced by this assumption is negligible.

The volume occupied by a bed of broken solids is equal to the actual volume of the solid pieces divided by the volume percentage of solids in the bed, or

From equation (14),

$$
\text { Volume of bed }=\frac{\text { Volume of solids }}{1-V_{1}}
$$

$$
\text { Volume of increment }=\frac{2 M d\left(1-V_{1}\right)}{D\left(1-V_{1}\right)}=\frac{2 M d}{D} .
$$

Since the bed is of unit cross section, the increment of height added to the original bed is $2 M d / D$. Therefore, for the average voids to be $V_{1}$ a column of height $1+2 M d / D$ must be packed to a height of 1 .

When the voids in a bed of solids are changed, the contraction in volume must all come from the original voids, as the volume occupied by the solid material does not change. Therefore, if $V_{2}$ is the fractional voids in the central section of the bed, after packing

$$
V_{2}=(1+2 M d / D) V_{1}-\frac{2 M d}{D}=V_{1}+\frac{2 M d}{D}\left(V_{1}-1\right) .
$$

If $V_{3}$ is the fractional voids in the strip next to the wall, after packing

$$
V_{3}=\left[V_{1}+M\left(1-V_{1}\right)\right]\left(\frac{1+2 M d}{D}\right)-\frac{2 M d}{D} .
$$

The bed has now been restored to unit length after the wall of the container is introduced and may be considered as a resistance unit consisting of two different resistances in parallel. This case may be treated exactly as electrical resistances are treated-that is, by defining the reciprocal of the resistance as the conductance and postulating that the total conductance of a system is equal to the sum of the conductances of the individual parts.

The resistance to the flow of gases of a unit cross section of a bed of broken solids is $\sqrt[B]{A}$, as explained on page 19. If the bed is not of unit cross section, the resistance is $\frac{\sqrt[B]{A}}{\text { area }}$.

Since the cross-sectional area of the container has been defined as unity in all cases,

$$
\frac{1}{\sqrt[B]{A_{C}}}=\frac{1}{\frac{\sqrt[B]{A_{2}}}{a_{2}}}+\frac{1}{\frac{\sqrt[B]{A_{3}}}{a_{3}}}=-\frac{a_{2}}{\sqrt[B]{A_{2}}}+\frac{a_{3}}{\sqrt[B]{A_{3}}},
$$

where $A_{C}=$ the average value of $A$ for the total system,

$A_{2}=$ the value of $A$ for the central section of the bed which is unaffected by the wall,

$A_{3}=$ the value of $A$ for section of the bed next to the wall,

$a_{2}=$ the cross-sectional area of the central section of the bed, and

$a_{3}=$ the cross-sectional area of the strip next to the wall. 
According to the conventions of this development the cross-sectional area of the whole bed is unity and

and

$$
a_{2}=1-2 d / D
$$

$$
a_{3}=2 d / D \text {. }
$$

\section{USE OF EQUATIONS}

All observations are taken in a container of finite size. It is desired to know what the resistance of a unit cross section of a particular bed would be if the container were of infinite size. It is only under the condition of the infinite or boundless container that proper correlation can be made between systems of different sizes of material. $A_{1}$ will be designated as the value of $A$ for the bed of material under consideration when no container wall is present.

Equation (18) makes no mention of the quantity $A_{1}$, although that is the quantity desired. $A_{C}$ is a figure determined by laboratory experiment. $A_{2}$ and $A_{3}$ are quantities that are, respectively, greater and less than $A_{1}$ and can not be measured separately.

However, it is known from equation (11) that

and

$$
\log _{10} \sqrt[B]{A_{2}}=\log _{10} \sqrt[B]{A_{1}}+K_{2}
$$

$$
\log _{10} \sqrt[B]{A_{3}}=\log _{10} \sqrt[B]{A_{1}}+K_{3}
$$

where $K_{2}$ and $K_{3}$ are constants determined by the values of $V_{2}$ and $V_{3}$, which in turn are determined by equations (16) and (17) and by the numerical solution of equation (11).

Expressed differently,

and

$$
\sqrt[B]{A_{2}}=\sqrt[B]{A_{1}}{ }^{K_{2}^{\prime}}
$$

$$
\sqrt[B]{A_{3}}=\sqrt[B]{A_{1}}{ }^{K_{3}^{\prime}}
$$

Fortunately, the value of exponent $B$ does not change appreciably with change in degree of packing (see p. 12), so equation (18) may be put in the form

or

$$
\frac{1}{\sqrt[B]{A_{C}}}=\frac{1}{\sqrt[B]{A_{1}}}\left(\frac{a_{2}}{10^{K_{2^{\prime}}}}+\frac{a_{3}}{10^{K_{z^{\prime}}}}\right)
$$

$$
\frac{A_{1}}{A_{C}}=\left(\frac{a_{2}}{10^{\pi_{2}^{\prime}}}+\frac{a_{3}}{10^{K_{3}^{\prime}}}\right)^{B} \text {. }
$$

Equation (23) reveals the important fact that when exponent $B$ is constant equation (18) reduces to a statement of ratio of the values of $A_{C}$, the known quantity, and $A_{1}$, the desired quantity. Therefore, either $A_{1}$ or $A_{C}$ may be arbitrarily fixed at any desired value and the equation be solved for the proportional value of the other. This could not be done if $B$ were not constant or if the quantity $\sqrt[B]{A_{1}}$ could not be factored out of the right member of the equation.

It has been found that the easiest method of computation has been to assume that $A_{1}$ is unity in all cases and to solve for $A_{C}$. The value of $A_{C}$ is a number less than 1 , and it represents the ratio of the observed value of $A$ to the value $A$ would have if the testing tube were of infinite diameter. The reciprocal of this number is the correction factor that must be applied to observed values to 
give the values for $A$ for the standard basis of comparison, that is, in a container of infinite size. As the container becomes large or as the particles in the tube become small the correction factor approaches 1 and in many cases can be neglected. The terms of equations (18) or (23) may be manipulated into a number of different forms, but none of them are as advantageous for computation as equation (18).

\section{COMPUTATION OF THE VALUE OF $d$}

Before accurate computations can be made on the wall effect it is necessary to know the value of $d$, which will be called the displacement diameter. The quantity $d_{d}$ is not exactly the average diameter of the particles, but it is the average linear distance that is accounted for by an average particle in the bed. In a unit volume of a bed of broken solids, if $V_{1}$ is the fractional voids the volume of solid material in the bed is $1-V_{1}$. If the equivalent spherical diameter of the pieces is $d$, the volume of each piece is $1 / 6 \pi d^{3}$. Therefore, if $N$ is the number of pieces of solid material in the average unit cube in the bed,

$$
N=\frac{1-V_{1}}{1 / 6 \pi d^{3}}=\frac{1-V_{1}}{0.524 d^{3}} .
$$

Therefore, the equivalent volume of each piece-that is, the volume accounted for by each-is given by the equation

$$
\text { Equivalent volume }=\frac{0.524 d^{3}}{1-V_{1}} \text {. }
$$

If this is the average volume occupied by each piece, then the average piece is resting in a cube of a volume given by equation (25), and all of these hypothetical cubes are packed tightly in the bed. This is an arbitrary condition which by definition must hold, as all of the volume in the bed must be accounted for by the pieces present, and the cube is the only solid that is symmetrical in all three dimensions and can be piled to fill the entire space in a given volume. For instance, spheres can not possibly be piled to occupy more than about $\mathbf{7 0}$ per cent of a given volume. Then, the average linear distance accounted for by the average piece in each of the three dimensions is the cube root of the cube defined by equation (25). That is.

$$
d_{d}=\sqrt[8]{\frac{0.524 d^{3}}{1-V_{1}}}=\frac{0.806 d}{\sqrt[8]{1-V_{1}}},
$$

where $d$ is the equivalent spherical diameter, as defined on page 17, and $d_{d}$ is linear distance in each dimension accounted for by each particle and is the quantity used in computing the wall effect. It will be spoken of as the "displacement diameter."

Examples: In a bed of 0.525 to 0.371 inch Cuyuna ore which has voids of 0.618 the value of the displacement diameter $d_{d}$ is 1.11 times the equivalent spherical diameter.

In a bed of lead shot that is packed as closely as possible and thus has voids of 0.302 the value of displacement diameter $d$ is 0.909 times the equivalent spherical diameter.

The foregoing argument does not hold if the particles have a directional tendency in packing, for instance, if the particles were elongated on the average and if they tended to pack with their long axes perpendicular to the walls of the container. Such a container might occur with small plates or short needles. The difference between $d_{d}$ and $d$ is usually small and may be neglected. 


\section{MIXTURES OF SIZES: TWO-COMPONENT SYSTEMS}

When a bed of broken solids consists of more than one size of material, one of the major factors in determining the resistance of the bed is the relative proportion of the different sizes of particles. If a bed consists of more than two component sizes, the system becomes quite complex and the analysis very difficult. In view of the fact that any exact theory that might be developed for systems of many components apparently would be very complex, unwieldy, and uncertain, for practical use the analytical study has been confined to systemus of two components. Empirical data have been obtained for systems which were mixtures of many sizes and arbitrary rules used for the interpolation and prediction of those data.

Equation (1)

\section{GENERAL CONSIDERATIONS}

$$
\Delta P_{S}=A R^{B}
$$

has been found to express a law that holds within the range of experimental error no matter what the size composition of the bed may be. Variation in the size composition of the bed affects both $A$ and $B$. An analysis and consideration of the experimental data of these variations will now be given.

Assume a bed of uniformly sized particles in a container with a stream of gas flowing through the bed. Assume the rate of flow to be constant and the size composition of the bed varied by introducing particles of a larger size into the bed. As the larger pieces are introduced into the bed the pressure drop per unit length of column (the rate of gas flow remaining constant) may be expected to change.

Introduction of the larger particles may influence the resistance of the bed in three ways:

1. When a small number of the larger pieces are distributed at random throughout the bed, they tend to be well separated and to act as individual solid obstructions in the bed of small particles; this will tend to increase the pressure drop.

2. When the number of large particles become great enough, they will tend to nest together. Wherever two or more pieces come together there will be a void between the large pieces. Frequently, this void will be filled with the finer particles, but when there are not enough smaller particles at hand to fill the void there will often be enough to form a layer at the bottom of the cavity. This gives the same effect as a nozzle pointing into an expansion chamber, the layer of small particles at the bottom of the cavity being the nozzle and the void between the large particles being the expansion chamber. It has been shown (p. 12) that the larger the expansion chamber the greater the pressure drop, so as the percentage of large material 


\begin{tabular}{|c|c|c|c|c|c|c|c|c|c|c|c|c|c|c|c|c|}
\hline $\begin{array}{l}\text { Bituminous } \\
\text { size. }\end{array}$ & cosl, 1316 & $\begin{array}{l}3 / 4 \text { to } 1 / 2 \text { inch } \\
16 \text { to } 1 / 4 \text { inch } \\
1 / 4 \text { to } 1 / 10 \text { inch } \\
1 / 10 \text { to } 1 / 30 \text { inch }\end{array}$ & 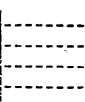 & 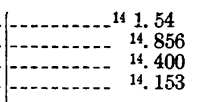 & $\begin{array}{l}15.900 \\
15.900 \\
15.900 \\
15.900\end{array}$ & & $\mid$ & $\begin{array}{l}4.6 \\
4.6 \\
4.6 \\
4.6\end{array}$ & $\begin{array}{l}.335 \\
.19 \\
.09 \\
.03\end{array}$ & $\begin{array}{l}1.87 \\
1.74 \\
1.10 \\
1.02\end{array}$ & $\begin{array}{r}13.6 \\
10.0 \\
9.8 \\
28.9\end{array}$ & $\begin{array}{l}.82 \\
.60 \\
.83 \\
.93\end{array}$ & $\begin{array}{l}16.6 \\
16.7 \\
11.8 \\
30.1\end{array}$ & $\begin{array}{l}4.50 \\
5.07 \\
9.42 \\
28.2\end{array}$ & $\left|\begin{array}{c}-\cdots \\
\hdashline-\cdots\end{array}\right|$ & $\begin{array}{l}.40 \\
.40 \\
.40 \\
.40\end{array}$ \\
\hline
\end{tabular}

1 Defined on p. 18

3 Original data in the appendix.

6 Unit: Pressure drop, centimeter of water per centimeter of height of column when air is flowing through the bed at rate of 1 liter per second per square centimeter cross-sec-

tional area, the gas being at standard conditions, $0^{\circ} \mathrm{C}$. and 76 centimeters mercury pressure.

7 Determined by the curves of Figures 21 and 22

8 Defined on p. 45.

10 Determined by kerosene displacement.

11 Data from Ray, W. T., and Kreisinger, Henry, Significance of Drafts in Steam-Boiler Practice: Bull. 21, Bureau of Mines, 1911, pp. 27-28.

12 Data from Brooks, H. W., Nicholls, 'P., Augustine, C. E., and Orr, M. L., Pressures Required to Force Air Through Sized Anthracite: Rep. of Investigations, Bureau of

Mines, February, 1926 (not 13 actor, $A_{\infty} \sqrt[B]{A_{\infty}}$, and $K_{1 \infty}$, computed by aid of the assumption that $F=0.90$

${ }_{14}^{13}$ Data of wall-effect factor, $A_{\infty} \sqrt[B]{A_{\infty}}$, and $K_{1 \infty}$, com

${ }_{10}$ Assumed value. Data necessary for determination not given by authors.

${ }^{16}$ Data from Storrow, J. T., The Flow of Air Through Small Coal and Other Broken Material: Trans. Am. Inst. Min. and Met. Eng., vol. 55, 1918, pp. 313-317. 
TABLE 7.-Summary of data on air flowing through sized materials

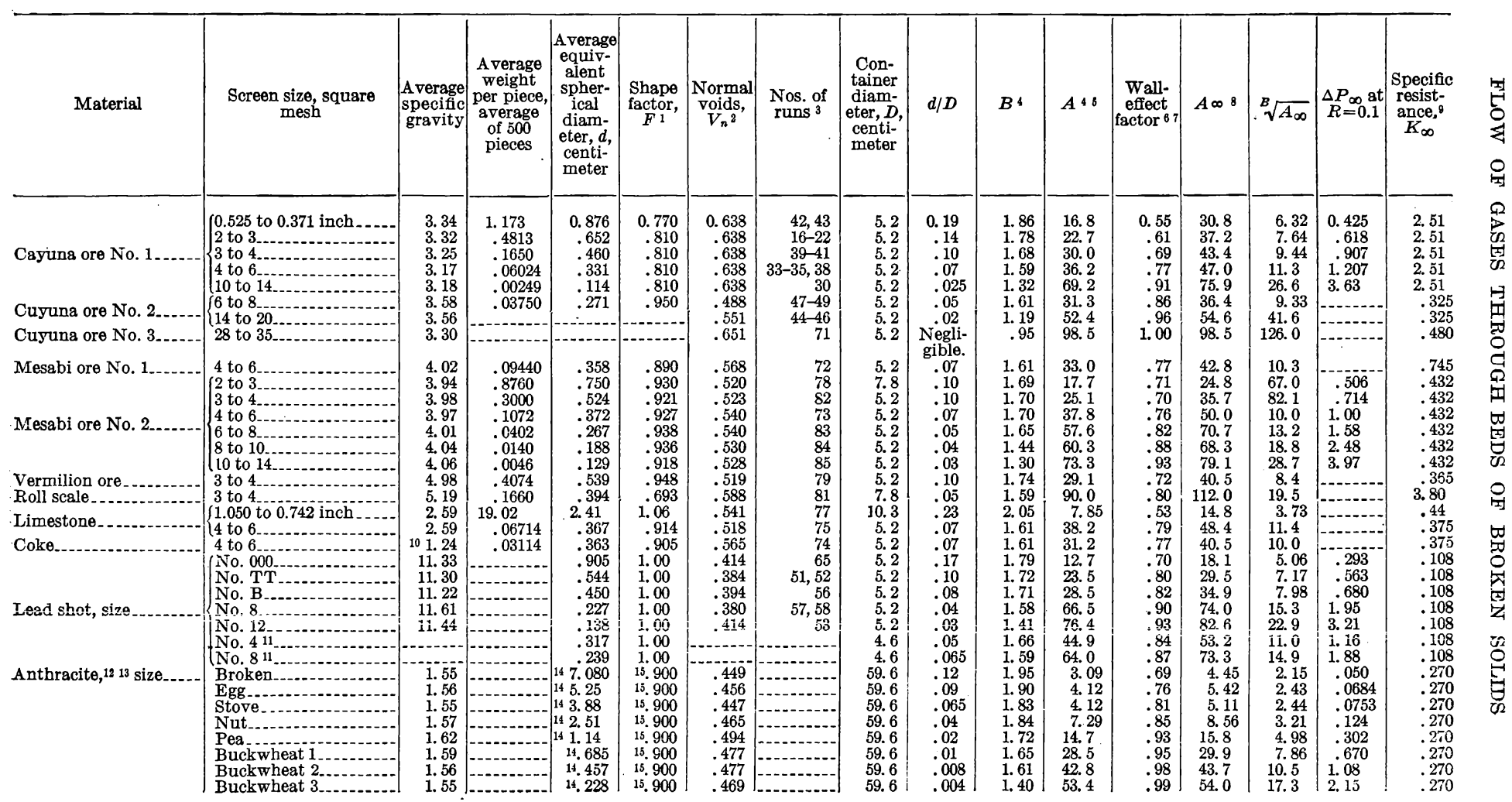


TABLE 6.-Properties of test systems of broken solids

\begin{tabular}{|c|c|c|c|c|c|c|c|c|c|c|}
\hline Substance & \multicolumn{2}{|c|}{ Screen size } & $\begin{array}{l}d \text { (equiv- } \\
\text { alent } \\
\text { spherical } \\
\text { diameter) }\end{array}$ & $\begin{array}{l}D \text { (diam- } \\
\text { eter of } \\
\text { test con- } \\
\text { tainer) }\end{array}$ & $d / D$ & $F$ & \multicolumn{2}{|c|}{$V_{n}$} & $E / V_{n}$ & $K_{1}$ \\
\hline $\begin{array}{l}\text { Roll scale (lami- } \\
\text { nated). } \\
\text { Vermilion iron ore.- } \\
\text { Limestone. }\end{array}$ & \multicolumn{2}{|c|}{3 to 4 mesh } & $\begin{array}{c}\text { Centi- } \\
\text { meters } \\
0.394 \\
\\
.539 \\
2.41\end{array}$ & $\begin{array}{r}\text { Centi- } \\
\text { meters } \\
7.8 \\
\\
5.2 \\
10.3\end{array}$ & $\begin{array}{r}0.05 \\
.10 \\
.23\end{array}$ & $\begin{array}{r}0.693 \\
.948 \\
1.945\end{array}$ & \multicolumn{2}{|c|}{0.588} & 1.18 & $\begin{array}{l}3.9 \\
.35 \\
.425\end{array}$ \\
\hline Substance & $K$ & $\begin{array}{l}\text { Wall- } \\
\text { effect } \\
\text { factor }\end{array}$ & $\begin{array}{c}\text { Com- } \\
\text { puted } \triangle P \\
\text { at } R=0.1\end{array}$ & $\begin{array}{c}\text { Observed } \\
\triangle P \text { at } \\
R=0.1\end{array}$ & $\begin{array}{l}\text { Com- } \\
\text { puted } B\end{array}$ & $\underset{B}{O}$ & & & $\begin{array}{l}\text { rror in } \\
\text { nputed } \\
\text { essure } \\
\text { drop }\end{array}$ & $\begin{array}{c}\text { Error in } \\
\text { computed } \\
B_{B}\end{array}$ \\
\hline $\begin{array}{l}\text { Roll scale (lami- } \\
\text { nated). }\end{array}$ & 1.35 & 0.80 & 2. 90 & 2.3 & 1. 69 & & 59 & & $\begin{array}{r}\text { er cent } \\
10-26\end{array}$ & $\begin{array}{r}\text { Per cent } \\
6.0\end{array}$ \\
\hline $\begin{array}{l}\text { Vermilion iron ore } \\
\text { Limestone. }\end{array}$ & $\begin{array}{l}.291 \\
.268\end{array}$ & $\begin{array}{l}.72 \\
.53\end{array}$ & .45 & $\begin{array}{l}.53 \\
.07\end{array}$ & $\begin{array}{l}1.75 \\
1.87\end{array}$ & & .74 & & $\begin{array}{r}12-15 \\
5-21\end{array}$ & $\begin{array}{r}.5 \\
9.0\end{array}$ \\
\hline
\end{tabular}

1 The shape factor as determined was 1.06. As explained on p. 18, a shape factor greater than 1 has no significance except as it is used in its reciprocal form; therefore the shape factor is $\frac{1}{1.06}=0.945$.

$43318^{\circ}-20-5$ 
The predictions are not perfect, but the results are accurate enough to substantiate the theory as developed.

At a flow of 0.1 liter per second per square centimeter the observed pressure drop of the roll scale was approximately 3,300 per cent higher than that of the limestone, yet the theory predicted the pressure drop with a maximum error of 26 per cent for the roll scale.

The roll scale and the Vermilion iron ore make an interesting comparison. The two materials were of the same screen size (3 to 4 mesh) but because of the platelike structure of the roll scale $\Delta P_{S_{\infty}}$ at $R=0.1$ was 435 per cent greater than for the Vermilion ore. This theory, predicated on the basis of screen size allone, might in making a prediction for these systems be in error by 435 per cent on one of them, but the theory as developed predicted a pressure drop within 26 per cent for one and within 15 per cent for the other. The theory as developed is believed to be dependable for predicting the pressure drop in a bed of any sort of sized material with an accuracy of 25 per cent.

\section{SAMPLE COMPUTATION}

Computation for the prediction of pressure drop in a bed of roll scale

It is desired to predict the pressure drop per unit length of column in a bed of 3 to 4 mesh roll scale in a 3-inch pipe, normal packing, for a flow of 0.1 liter per second per square centimeter. The properties of the material are listed in Table 6.

\section{Computations}

$d=0.394, D=7.8, F=0.693, V_{n}=0.588$, and $F / V_{n}=1.18$.

From Figure 39, $K_{1 \infty}=3.80$.

This value is for $V=0.50 ; V_{n}=0.588$.

If voids are increased to 0.588 , from Figure 30 ,

$\Delta \log K_{\infty}=-0.46$, and

$K_{\infty}=1.318$.

$V=0.588$.

From Figure 21, $B=1.69$, and

$d / D=0.05$.

From Figures 33 and 34, the correction factor for wall effect $=0.80$.

$K=1.055$. $V=0.588$.

From Figure 38, $J=1.1$.

$$
\begin{aligned}
& \Delta P_{S}=\frac{1.055}{0.394^{1.1}}=\frac{1.055}{0.359}=2.94 . \\
& R=0.1 \\
& d=.394 \\
& V=.588
\end{aligned}
$$

Observed $\Delta P_{S}=2.33$.

$R=0.1$

$\begin{aligned} d= & =.394 \\ V & =.588\end{aligned}$

Error in predicting

$\Delta P_{S}=26$ per cent.

Computed $B=1.69$.

Observed $B=1.59$.

Error in predicting $B=6$ per cent. 


\section{PREDICTION OF PRESSURE DROP FOR SIZED MATERIALS}

The theory developed thus far has covered the field of air at room temperature flowing through beds of broken solids of uniform size of any size, shape, or degree of packing and in a container of any size.

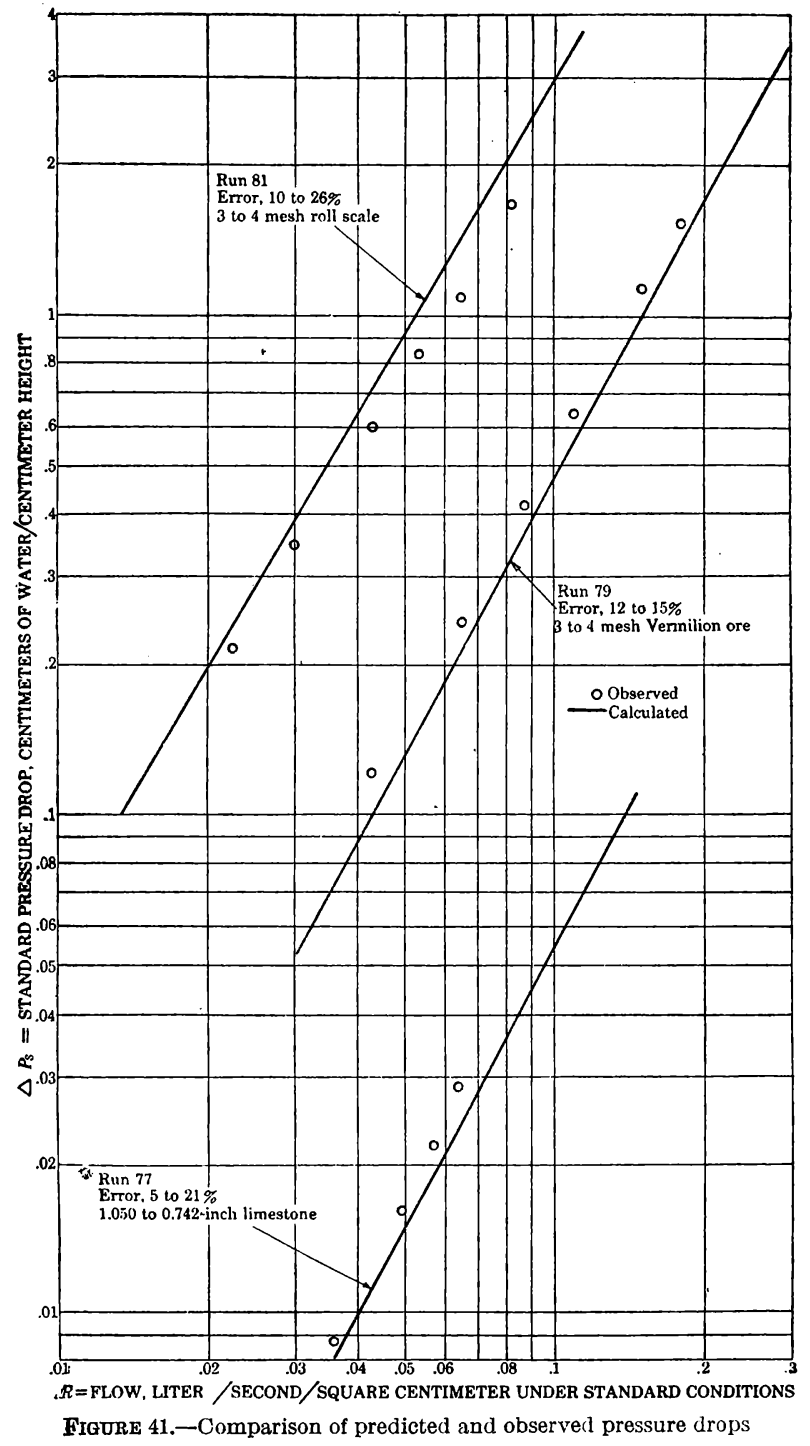

The test of a theory is to be able to predict correct results for new systems. Three different materials were chosen to test the validity of the theory as developed-laminated roll scale, Vermilion iron ore, and limestone. Their properties are given in Table 6 . The results of the predictions and their confirmations are plotted in Figure 41. 
LQUATION FOR SPECIFIC RESISTANCE

An approximate equation for the curve of Figure 39 is

$$
\log _{10} K_{1_{\infty}}=3.7843-3.4414 \frac{F}{\bar{V}_{n}}+0.6177\left(\frac{F}{V_{n}}\right)^{2}
$$

\section{RELATION BETWEEN SHAPE FACTOR F AND NORMAL VOIDS $V_{n}$}

It would seem reasonable to suppose that there is a relation between the shape of a particle as defined by the shape factor $F$ and the voids of normal packing. In Figure 40 are plotted the values of $F$ against $V_{n}$ for a number of substances. The substances are

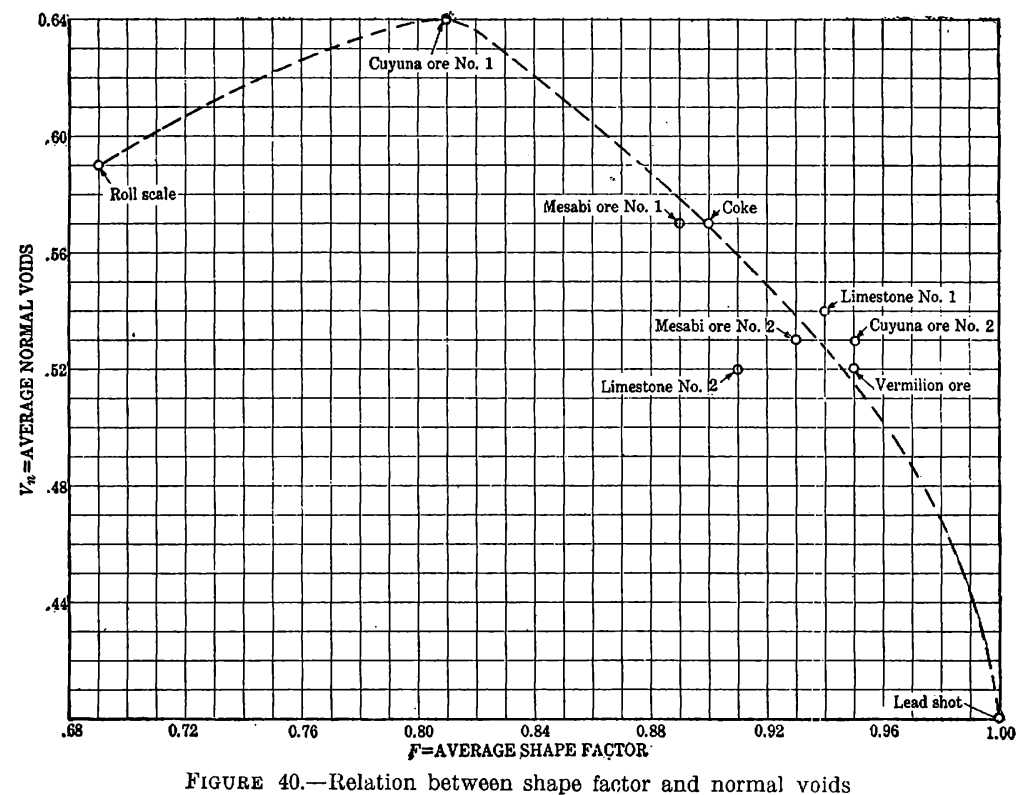

those whose properties are tabulated in Table 5 , with the addition of roll scale, a laminated scale from the surface of steel ingots. It will be noted that there is a fairly definite relation between the two quantities.

\section{UTILITY OF RELATION}

Therefore the specific resistance $K_{1_{\infty}}$ can be roughly determined by means of $F$ alone; thus, if $F$ is known the $V_{n}$ can be approximated by means of the curve of Figure $40 ; \frac{F}{V_{n}}$ can be computed, and the value of $K_{1_{\infty}}$ can then be found.on the curve of Figure 39. However, this introduces a source of considerable error because of the uncertainty of the relation between $F$ and $V_{n}$, and it is recommended that $V_{n}$ be determined experimentally for accurate prediction of pressure drop. 
is a function which shows the relation between character of materials in a bed and the resistance of the bed to fluid flow. The ordinate $K_{1_{\infty}}$ is the pressure in a bed of the material indicated, 1 centimeter high and 1 square centimeter in cross section, if $R=0.1, d=1$, and $V=0.50$, and may properly be called the specific resistance of the material.

The curve of Figure 39 is a true index to the resistance of different classes of materials. The character of materials ranged from the irregular honeycombed structure of coke to the symmetrical spheres of lead shot. This relation is the connecting link between different

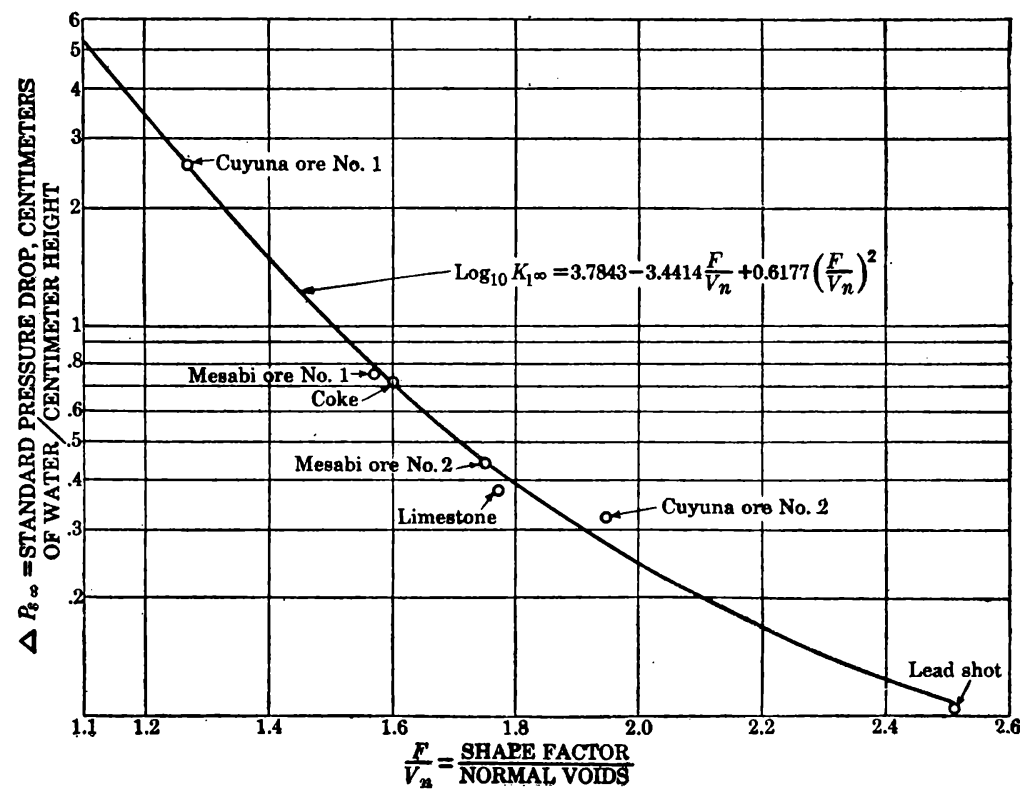

FIGURE 39.-Relation between $K_{1 \infty}\left(=\Delta P_{s \infty}\right.$ when $R=0.1, d=1$, and $\left.V_{n}=0.50\right)$ and $\frac{F}{V_{n}}$

classes of materials. It implies that the resistance to gas flow in a bed of broken solids is practically independent of the character of the surface, shape of particle being the determining factor.

It is to be noted that two different materials which are usually given the same name may vary widely in their specific resistance to gas flow; for instance, the two different Cuyuna ores that were used, although coming from the same ore deposit, varied widely in shape factor, normal voids, and specific resistance $K_{1_{\infty}}$. The same was true to a smaller degree of the two Mesabi ores.

The shape factor $F$ and the voids of normal packing $V_{n}$ depend entirely upon the shape of the pieces, which in turn depends upon the character of fracture. 
If the further condition is laid down that the different systems be compared with $d=1$, equation (30a) becomes

$$
\begin{gathered}
\Delta P_{S_{\infty}}=K_{1 \infty} . \\
R=0.1, \\
V=0.50, \\
d=1.00
\end{gathered}
$$

$K_{1 \infty}$ is now completely defined. It is a natural constant, the value of which depends solely on the nature of the particles in the bed of any system studied, for all other conditions are held constant. $K_{1_{\infty}}$ is the constant for a system in a container of infinite size and $K_{1}$ is the corresponding constant for a system of finite size. $K_{1_{\infty}}$ is the basis for comparison of different systems.

\section{QUANTITIES THAT INFLUENCE $K_{1}$ AND $K_{1 \alpha}$}

By purely empirical methods it has been found that $K_{1}$ can be satisfactorily expressed as a function of $F / V_{n}$, that is, the shape factor divided by the voids of normal packing (definitions on p. 18).

QUANTITATIVE LAW OF VARIATION OF $K_{1_{10}}$

The data used in determining this function of the variation of $K_{1_{\infty}}$ with $F / V_{n}$ are given in Table 5 . It was not possible to use the data on anthracite for this purpose, for these data were gathered from another source, ${ }^{17}$ and there was no way of telling the value of the shape factor $F$ for the material these investigators used.

TABLE 5.-Data on pressure drop, shape factor, and normal voids

\begin{tabular}{|c|c|c|c|c|c|c|c|}
\hline Material & $\begin{array}{c}V_{n} \text { aver- } \\
\text { age }\end{array}$ & $F$ average & $F / V_{n}$ & $K_{\infty}$ & $\begin{array}{l}\Delta \log _{10} K \\
\text { for } \\
V=0.501\end{array}$ & Factor & $\boldsymbol{K}_{1_{\infty}}$ \\
\hline $\begin{array}{l}\text { Cuyuna ore No. 1 } \\
\text { Cuyuna ore No. 2 } \\
\text { Mesabi ore No. 1 } \\
\text { Mesabi ore No. 2- } \\
\text { Coke } \\
\text { Limestone } \\
\text { Lead shot }\end{array}$ & $\begin{array}{r}0.638 \\
.488 \\
.568 \\
.530 \\
.565 \\
.518 \\
.397\end{array}$ & $\begin{array}{c}0.81 \\
.95 \\
.89 \\
.93 \\
.905 \\
.914 \\
1.00\end{array}$ & $\begin{array}{l}1.27 \\
1.95 \\
1.57 \\
1.75 \\
1.60 \\
1.77 \\
2.52\end{array}$ & $\begin{array}{l}0.380 \\
2.373 \\
2.341 \\
.320 \\
.325 \\
2.313 \\
.265\end{array}$ & $\begin{array}{r}+0.82 \\
-.06 \\
+.34 \\
+.13 \\
+.33 \\
+.08 \\
-.39\end{array}$ & $\begin{array}{l}0.61 \\
.871 \\
2.19 \\
1.35 \\
2.14 \\
1.20 \\
.408\end{array}$ & $\begin{array}{l}2.51 \\
.325 \\
.745 \\
.432 \\
.706 \\
.375 \\
.108\end{array}$ \\
\hline
\end{tabular}

Four of the systems of materials tabulated (Cuyuna ore No. 2, Mesabi ore No. 1, coke, and limestone) did not have enough data to determine the pressure drop for $d=1$, so the values $\Delta P$ for $d=1$ were computed by means of equations (30) and (31) and the known value of $\Delta P$ for the particular value of $d$. The data showing the relation between $F / V_{n}$ and $K_{1_{\infty}}$ are plotted in Figure 39. The ordinate axis $\left(K_{1 \infty}\right)$ is graduated in the logarithmic scale.

\section{SIGNIFICANCE OF SPECIFIC RESISTANCE:}

The points do not all lie on a smooth curve, but considering the diversity of the sources of data the agreement is remarkable. This 
In general, then, the systems under consideration may be thought of as having two phases, solids and voids. Changes which are wrought in either of these phases have influences on the resistance of the system as a whole commensurate with the amount of that phase present.

\section{VARIATION OF RESISTANCE WITH SHAPE OF PARTICLE}

FACTORS THAT INFLUENCE $K$

General considerations.-Equations (30) and (31) define the variation of the pressure drop with size for a particular system for which $K$ is known. For the work to have any particular utility some means must be devised for determining the value of $K$ without resorting to experiment.

Apparent paradox.-Considering the very large effect that the voids in a bed have on the resistance (see figs. 30 and 31 and equations 10 and 11), it would be expected that if systems of two different materials-one with a small fraction of voids and the other with large voids-are compared, the system having the smallest voids would have much the higher resistance.

Surprisingly, this does not seem to be the case. Figure 36 indicates that a bed of Cuyuna ore particles 1 centimeter in diameter with voids $=0.638$ has a much greater pressure drop when $R=0.1$ than does a similar bed of shot with voids $=0.397$.

This paradox may be explained as follows: "Normal voids" is a property of a bed of broken solids which depends upon the shape of the particles. The more nearly symmetrical the particles the more order in their piling; hence, the less voids. The more order there is in the piling of a bed of material the more passages are left unblocked by the random arrangement of particles and the less the resistance to gaseous flow. Hence, other things being equal, the resistance of a bed of small normal voids will be less than a bed with high normal voids.

DEFINITION OF TERMS

To attack the problem systematically, equation (30) will be changed to

$$
\begin{aligned}
\Delta P_{S_{\infty}} & =\frac{K_{1_{\infty}}}{d^{J}} . \\
R & =0.1 \\
\text { voids } & =0.50
\end{aligned}
$$

$K_{1_{\infty}}$ is a constant for a given system whose variation with different systems will now be studied. The value of fractional voids has been changed from that of normal packing to a constant value of 0.50 for all systems. This figure is arbitrarily chosen for convenience. 
of $1 / d$ would not be a straight line. The only quantity that has been found which consistently affects the value of $J$ is the average normal voids, $V_{n}$.

The data of $J$ for the four systems considered are plotted against $V_{n}$ in Figure 38. The values of $V_{n}$ are the averages for the different sizes in each system. Three of the points lie on a straight line; the fourth-that for Mesabi ore-is off the curve. There are not suffi-

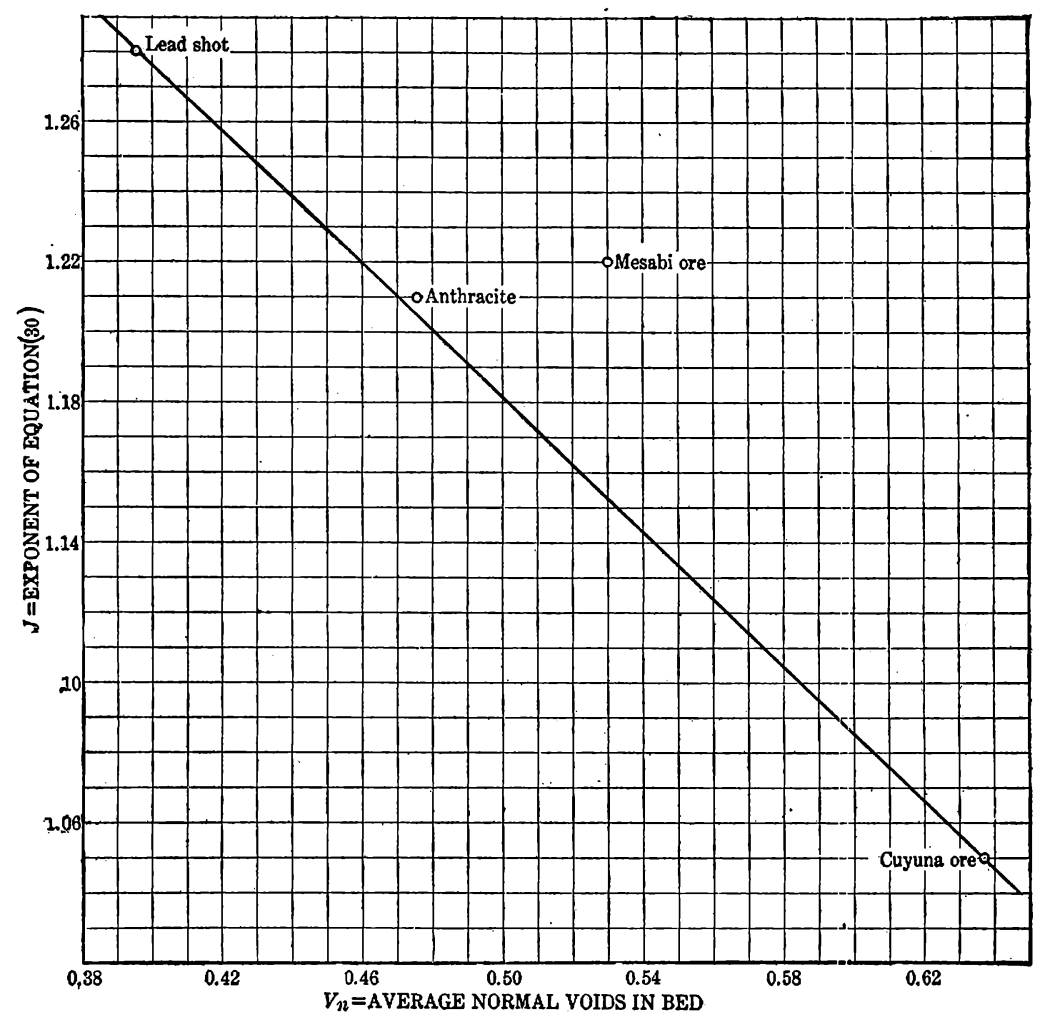

Figure 38.-Relation between average normal voids and exponent of equation (30)

cient data and they are not sufficiently accurate to justify any refinements in the determination of the curvature so the curve is interpreted as a straight line with the equation

$$
J=-V_{n}+1.68 \text {. }
$$

\section{RELATIVE INFLUENCE OF TWO PHASES}

It will be noticed that the larger the percentage of voids the smaller the value of $J$; that is, when the voids are large a change of the size of the particles has less influence than if the voids are small. On the other hand, equations (10) and (11) show that the larger the voids the greater the change of resistance with change of voids. 
SUMMARY

It will be observed that the curves for all of these sets of data are straight lines.

Therefore,

$$
\Delta P_{S_{\infty}}=\frac{K}{d^{J}},
$$

$R=0.1$

voids normal

where $K$ is a constant depending on the material, and

$J$ is a constant whose dependence will be established later.

FACTORS THAT INFLUENCE $J$

$J$ is the numerical slope of the straight lines in Figures 36 and 37. It will be seen that it varies with the different materials. Empirical

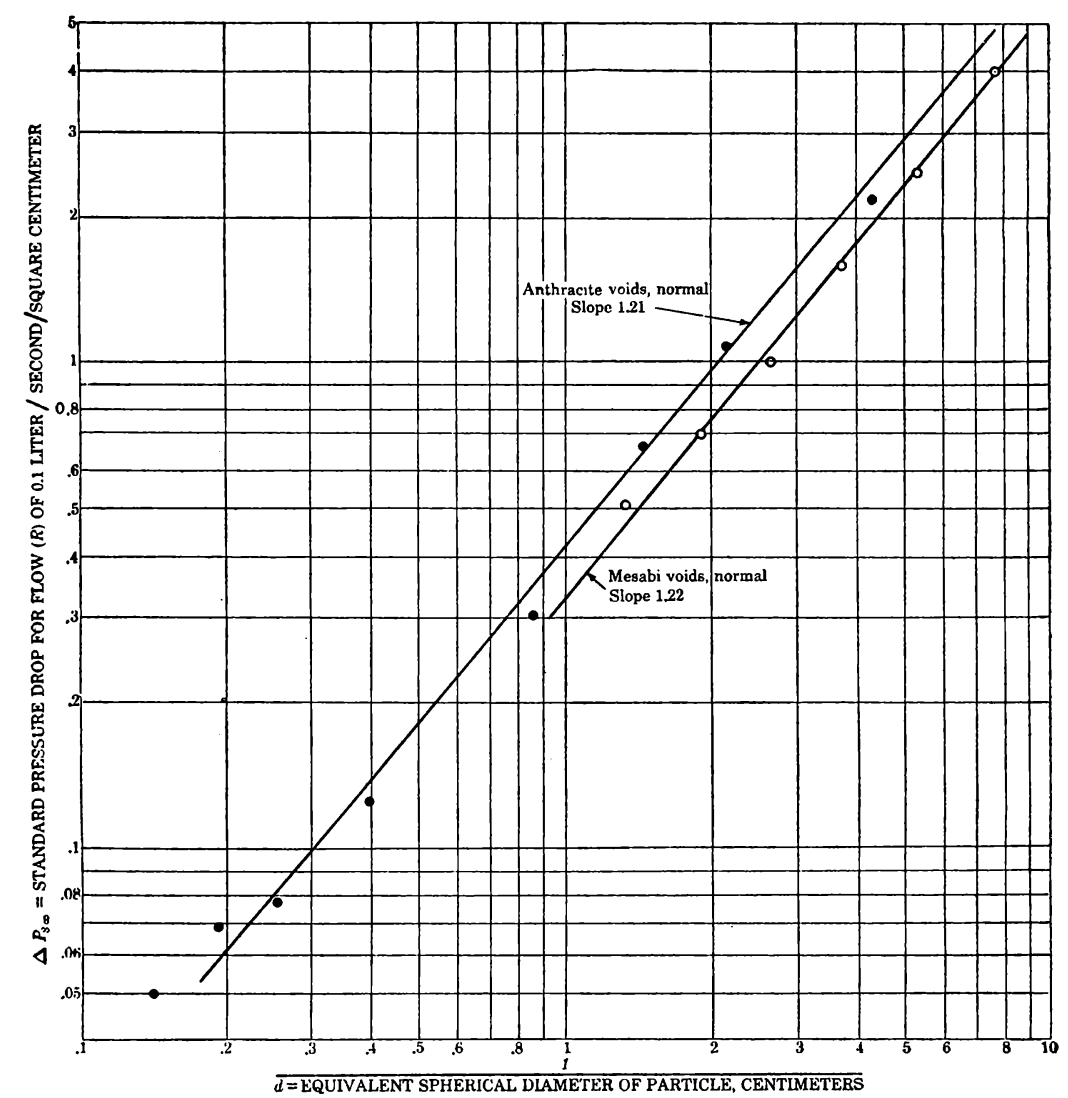

FigURE 37.-Relation between pressure drop and size of particle for Mesabi ore, runs 73, 78, and 82 to 85 . Anthracite data of Brooks, Nicholls, and others

study is the only way of determining the influencing factor. Evidently $J$ does not vary with $B$, as might be expected from equation (29); for $B$ varies with size, and if exponent $J$ were not constant for different sizes the plot of the logarithm of $\Delta P_{\infty}$ against the logarithm 


\section{POINT OF REFERENCE}

The point of reference will therefore be taken in the observed range of flow and $\Delta P_{S_{\infty}}$ at a rate of flow of 0.1 liter per second per square centimeter will be correlated against particle size.

\section{SYSTEMS STUDIED}

Four different systems of material have been chosen for this studyCuyuna ore, Mesabi ore, lead shot, and anthracite. The particles range in size from approximately 0.1 to 7 centimeters. The per-

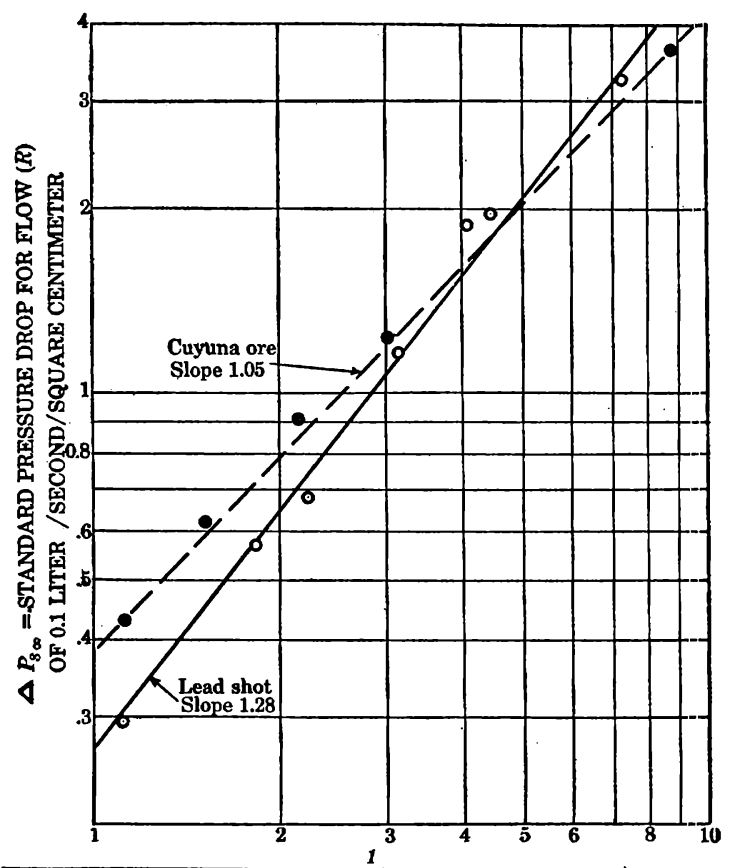

$d=$ EQUIVALENT SPHERICAL DIAMETER OF PARTICLE, CENTIMETERS

Figure 36.-Relation between pressure drop and size of particlo for Cuyuna ore, runs 16 to $22,30,33$ to 35 , and 38 to 43 , and for lead shot, runs 51 to 53,56 to 58 , and 65 , with normal voids and Ray and Kreisinger data

centage of voids in the bed ranged from approximately 38 to 64 per cent. The data on anthracite were taken from the report of investigation of Brooks, Nicholls, Augustine, and Orr. ${ }^{16}$ All of the data are compiled in Table 7.

The data are plotted in Figures 36 and 37. In these figures $\Delta P_{S_{\infty}}$ for $R=0.1$ is plotted against the reciprocal of the equivalent spherical diameter. Both axes are graduated in the logarithmic scale. In all cases the voids are normal (see p. 18) and are not quite constant for the different sizes. A number of probable relations have been studied, but this is the only one that is even approximately consistent. 
In general, it will be seen that the curves for the different sizes of material uend to converge at a common point. In all probability the convergence does not hold for very large materials. To the right of this common point the resistance of large materials is greater than the resistance of small materials. As has been explained on page 25, this inversion is probably artificial and arises from extrapolation. Other groups of a material of different sizes give similar families of intersecting curves, although the coincidence is not always as sharp as that shown.

A careful and detailed study of the mathematics of the family of curves shown and of a number of others of similar nature might reveal the fundamental laws

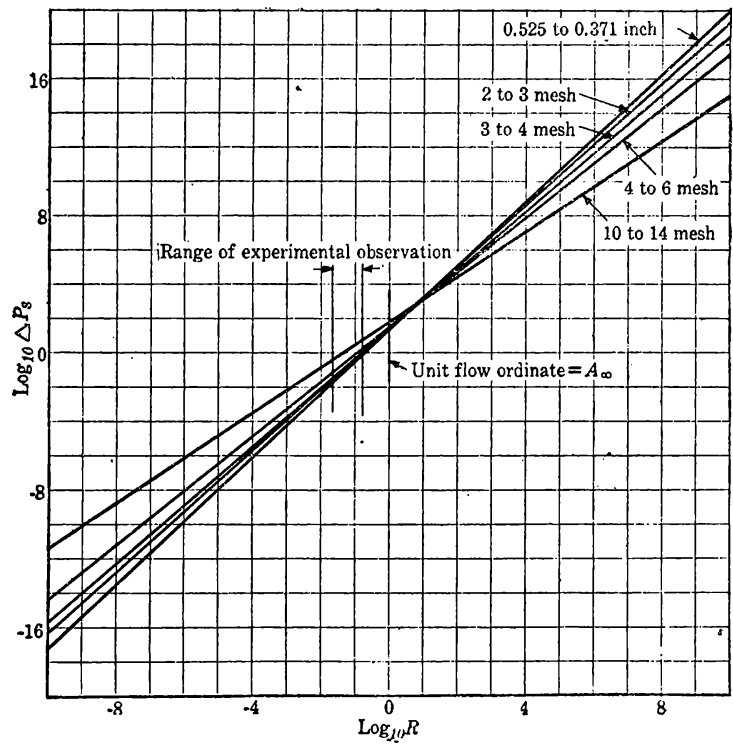

FiguRE 35.-Large-scale plot of $\log _{10} \Delta P_{S} v . \log _{10} R$ for Cuyuna ore: $R$, rate of air flow, liters per second per square centimeter; $\Delta P_{S}$, standard pressure drop, centimeter of water per centimeter of height

of the mechanism of tortuous flow, but such a study is outside the field of this investigation.

When an equation is formed for the relation between pressure drop and size of particles, it is equivalent to setting up a vertical line at some constant rate of flow and correlating the intercept values of $\Delta P_{S}$ with the diameter of the particles corresponding to the intercepted curve. Obviously, the relation between the intercepts depends on the point of constant flow chosen for the comparison. If the point of coincidence of the different members of the family of curves is exact, there will be a general law covering the intercepts; if it is not exact the governing intercepts may depend upon the point chosen for reference.

If unit flow is chosen for a point of reference, the correlation of intercepts will be a correlation of the value of $A_{\infty}$ against particle size. However, unit flow is approximately ten times greater than the highest observed rates of flow, so any small errors in the observed range will be greatly magnified when extrapolated so far, and the true law of the relation between pressure drop and particle size may be masked by magnified errors. 


\section{RELATION OF RESISTANCE AND LIFTING VELOCITY}

In the section on lifting velocity it was stated that the lifting pressure depended only on the density of the column as a whole and not on the size of the particles. Further, it was shown that

$$
u=K_{1} \sqrt{r_{S}}=K_{1}^{\prime} \sqrt{d_{S}}
$$

where $u$ is the lifting velocity, and $d_{S}$ is equivalent spherical diameter of the particle.

With $\Delta P_{S}$ constant

$$
\text { Therefore, } R=K_{1}^{\prime} \sqrt{d_{s}} \text {. }
$$

$u$ may be used as a measure of rate of flow.

$$
\Delta P_{\mathrm{s}}=A R^{B} \text {. }
$$

For a given system if $\Delta P_{S}$ is chosen as the lifting pressure it is a constant independent of the size of material. The argument may now be generalized, and the rate of flow for any constant value of $\Delta P$ will be considered. Therefore, substituting equation (28) in equation

$$
A=\frac{K_{2}}{d^{B / 2}}
$$

(1) where $K_{2}$ is a constant depending on the material.

It will be seen that if $B=2.00$ equation (29) is the law of the variation of resistance in conduits.

The foregoing argument is based on statements that are only approximately true, and hence equation (29) may not be exactly true. However, it is only reasonable to suppose that $A$ will vary according to some such general law.

\section{CHOICE OF POINT FOR COMPARISON OF SIZES}

Greatly extended curves for the relation between pressure clrop and rate of flow for several sizes of Cuyuna ore have been plotted in Figure 35. The logarithm of pressure drop has been plotted against the logarithm of the rate of flow. All curves have been drawn as straight lines in accordance with the law

$$
\Delta P_{S \infty}=A_{\infty} R^{B},
$$

where $A_{\infty}$ is the value of $A$ in a container of infinite size.

The values of $A_{\infty}$ and $B$ used in making this figure are given in Table 7, page 58. The scale has been condensed a great deal, so that the general tendencies of the curves may be observed. This means that the observed data have been extrapolated a great deal; thus in the figure the lower limit of $R$ as plotted is $10^{-10}$ liters per square centimeter per second and the upper limit is $10^{10}$ liters per square centimeter per second. Relatively the range of flow in which it has been possible to make observations is very small, indeed, and is indicated in the figure. If a vertical cross section is drawn through the group of curves at the point of unit flow, the value of $\Delta P_{S}$ at each curve is the value of $A_{\infty}$ for that size of that material. 
terial in a container and it is desirable to know what the value of $A$ would be in a column unhindered by boundary walls, it is only necessary to divide the observed value of $A$ by the value of $A_{t}$, as given in Figures 33 and 34.

If the datum is available for the value of $A$ in one size of circular container and it is desired to know the value of $A$ for another size of container, the ratio of the values of $A_{t}$ for the two cases may be obtained from Figures 33 and 34 and the observed datum multiplied by this figure.

If the value of $A$ for a given system of material in an infinite container is available or may be calculated, the value of $A$ for the same system in a container of finite size may be obtained by multiplying the known datum by the value of $A_{t}$, as given in Figure 33 or 34 .

Interpolation may be employed for values of $V_{1}$ and $B$, not given by the curves. The value of $B$ does not change appreciably with degree of packing or presence of a wall. $A$ and $B$ are defined by equation (1).

\section{STANDARDIZATION OF SUCCEEDING DATA}

Since, in the experimental work, it has not been possible to keep the value of $d / D$ constant, it will be necessary to standardize all observed values of $A$ according to some common basis.

All succeeding values of $A$, unless otherwise stated, will be given as the value of $A$ when $d / D$ is 0 , that is, in a container of infinite size and will be designated by $A_{\infty}$. The suffix $\infty$ will have the same significance when used with $\Delta P$. Thus, $\Delta P_{\infty}$ means the pressure drop that the specified system would have at the specified rate of flow if the container were infinitely large. $\Delta P_{S}$ designates the pressure drop under standard conditions in a container of infinite size.

\section{VARIATION OF A WITH PARTICLE SIZE}

GENERAL DISCUSSION

The resistance of a bed of broken material to the flow of gas is determined by the size and number of the openings between the particles rather than by the size of the particles themselves, but since there is no way of measuring the size of the openings dependence must be placed on the particle size as a measure of the openings and hence indirectly a measure of the resistance of the bed. For fluids flowing through conduits the resistance varies inversely as the diameter of the conduit. 


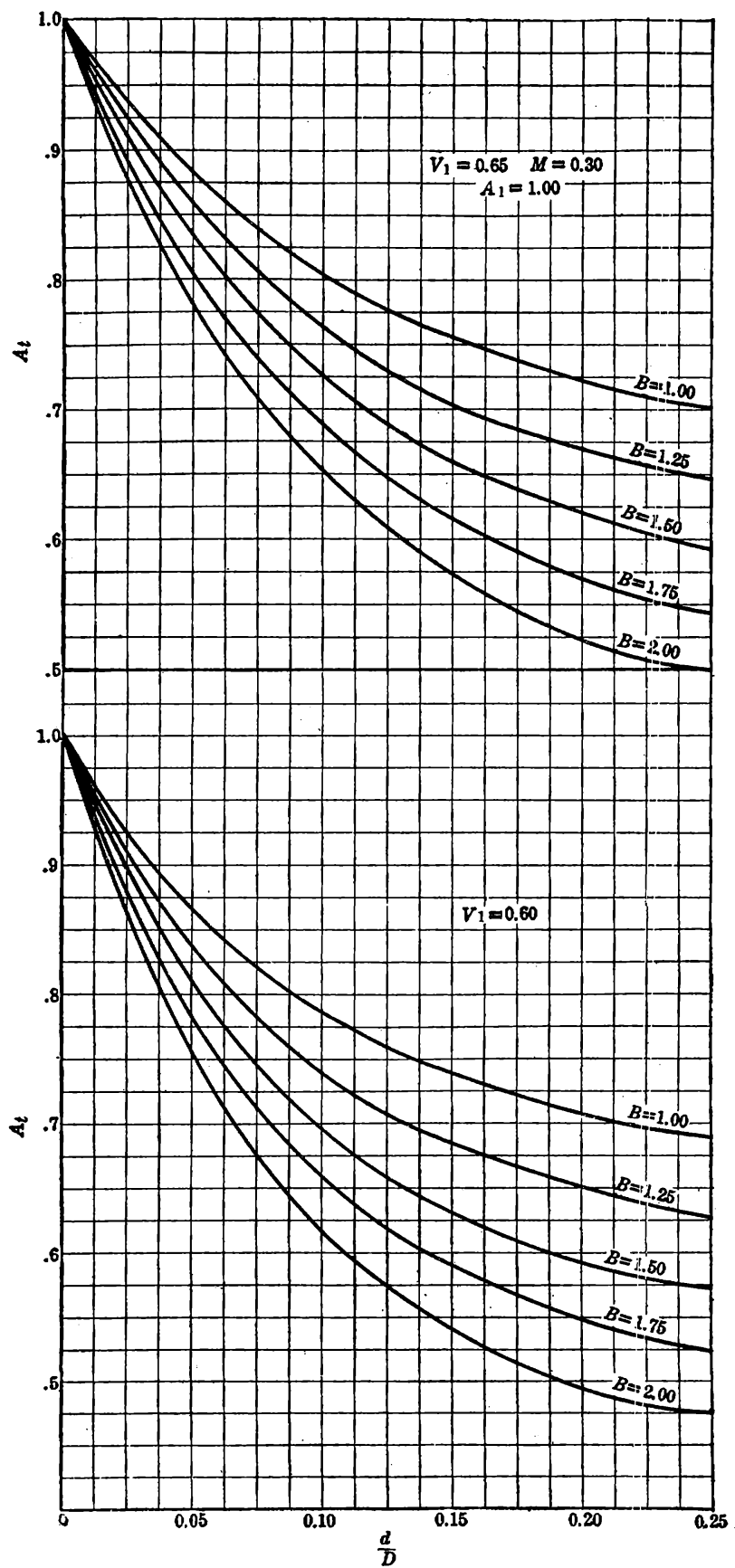

Figure 34.-Computed relation. between $A_{t}$ and $d / D: d$, displacement diameter of average particle; $D$, diameter of circular container; $A_{t}$, computed $A ; A_{1}$, relative value of $A$ in an inflnitely large container 
The largest value of $d / D$ considered is 0.25 . If $d / D=0.25$ the error in assuming that the area is $2 d / D$ instead of the quantity given in equation (27) is 12.5 per cent. From Figures 33 and 34 it can be seen that this causes an error in the

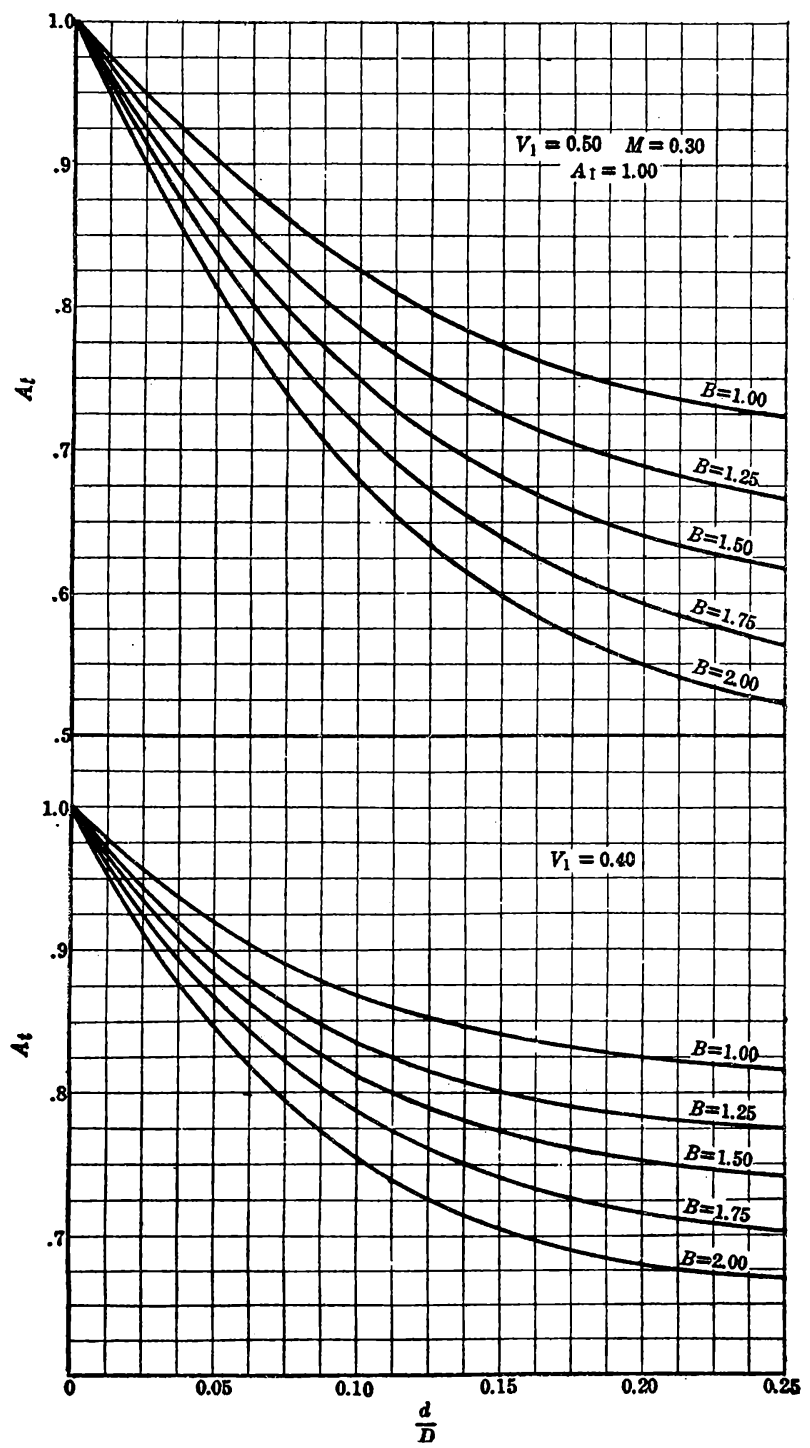

FIGURE 33.-Computed relation between $A_{t}$ and $d / D: d$, displacement diametor of average particle; $D$, diameter of circular container; $A_{\ell}$, computed $A$; $A_{1}$, relative value of $A$ in an infinitely large container

values of $A_{C}$ of 2 to 3 per cent. That error is too small to be of any consequence, considering inconsistencies in experimental data; hence, it will be neglected.

$$
\text { UTILITY OF VALUES OF } A_{\ell}
$$

The values of $A_{t}$, as given in Figures 33 and 34, are really correction factors. If a datum is available for value of $A$ of a column of ma- 
TABLe 4.-Data on wall effect

\begin{tabular}{|c|c|c|c|c|c|c|c|c|c|}
\hline Material & $\begin{array}{l}\text { Equiv- } \\
\text { alent } \\
\text { spheri- } \\
\text { cal } \\
\text { diam- } \\
\text { eter, } d_{\theta}\end{array}$ & $\begin{array}{c}\text { Voids } \\
\text { in } \\
\text { bed, } \\
V_{1}\end{array}$ & $\begin{array}{l}\text { Dis- } \\
\text { place- } \\
\text { ment } \\
\text { diam- } \\
\text { eter }\end{array}$ & $\begin{array}{l}\text { Diam- } \\
\text { eter of } \\
\text { con- } \\
\text { tainer }\end{array}$ & $\begin{array}{l}\text { Run } \\
\text { No. }\end{array}$ & $d / D$ & $A$ & $B$ & $\log _{10} \sqrt[B]{A}$ \\
\hline & $C m$. & & $C m$. & $C_{5.19}$ & & & & & \\
\hline No. 12 lead shot. & .138 & $\begin{array}{r}.419 \\
.419\end{array}$ & .133 & 7.80 & 64 & .017 & 82.0 & 1. 41 & 1. 356 \\
\hline & $\begin{array}{r}138 \\
\cdot 138\end{array}$ & $\begin{array}{r}.419 \\
.419\end{array}$ & .133 & 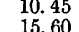 & & $\begin{array}{l}.0127 \\
0085\end{array}$ & & $\begin{array}{l}1.41 \\
1.41\end{array}$ & 1.380 \\
\hline & .876 & .618 & .974 & 5.19 & 238,242 & .188 & 13.6 & 1.2 . & $\begin{array}{l}1.391 \\
.637\end{array}$ \\
\hline .525 to 0.371 inch Cuyuna & .876 & .618 & .974 & 7.80 & 240,241 & .125 & 16.9 & 1.7 & .637 \\
\hline ore & 876 & .618 & .974 & 15.6 & & .06 & 19. & 1.78 & . .730 \\
\hline & 460 & .630 & .518 & 2. 59 & 249 & .200 & 26 & 1. 69 & .848 \\
\hline 3 to 4 mesh Cuyuna ore... & 0 & .630 & .518 & 5.19 & $39-41$ & .100 & 29.9 & 1. 69 & .873 \\
\hline & & . 6300 & 518 & 7.80 & 248 & .066 & 36.5 & 1.69 & .924 \\
\hline
\end{tabular}

None of the sets of data are mutually comparable as they stand, for they cover three different systems which have entirely different values of $\sqrt[B]{A}$. However, the material of this section involves only the rate of change of $\sqrt[B]{A}$ with changing $d / D$. The value of the logarithm of each group of points may then be shifted as much as desired, and the relative values of the points within the group will remain unchanged. By the method of trial and error the ordinates of the different groups were shifted until all the points lay on a fairly smooth curve. (See the lower section of fig. 32.) This was the method employed in interpreting the data on the variation of $A$ with packing.

A number of curves were computed for the variation of the $\log _{10} \sqrt[B]{A}$ with $d_{d} / D$ by means of equations (10), (16), (17), and (18), using different values of $M$. It was found that the value of $M=0.30$ gave the best curve for these data. (See curve in fig. 32.) This means that when a container wall is introduced into a bed of material 30 per cent of the solid material in the section next to the wall is removed, leaving the voids in that section correspondingly larger.

Using the value $M=0.30$, the values of $A_{t}$ (the actual value of $A$ for a column of stock in a container) have been computed for a number of conditions. The results are shown in Figures 33 and 34 . The data are presented as the value that $A_{C}$ would have when plotted against $d_{d} / D$, if $A_{1}$ (the value for a bed of material in a container of infinite size) were unity. $A_{t}$ in all cases is less than 1 ; this means that observed resistance is always less than actual resistance for an unbounded bed of the same degree of packing.

\section{ERROR IN ASSUMPTIONS}

For simplicity in the foregoing development it was assumed that the crosssectional area of the strip of outer particles next to a circular container wall was $\pi D d$. Since only the voids of the outer half of this strip were affected by the container wall the cross-sectional area, whose resistance was changed by the wall, was assumed to be $\frac{\pi D d}{2}$.

When the unit of cross-sectional area was chosen as $\frac{\pi D^{2}}{4}$, the affected area became $2 d / D$.

The true cross-sectional area of the strip is as follows:

$$
\text { Affected area }=\frac{\pi D^{2}}{4}-\frac{\pi}{4}(D-d)^{2}=\frac{\pi}{4}\left(2 d D-d^{2}\right) .
$$

When the unit of area is chosen as $\frac{\pi D^{2}}{4}$, the affected area $=2 d / D-(d / D)^{2}$. 


\section{EVALUATION OF $M$}

Equations (16) and (17) contain the constant $M$, which must be evaluated experimentally. It is not possible to do this by direct means. The direct method of obtaining this constant would necessitate solution of equations (16) and (17) by means of equation (10) and the substitution of these two solutions in equation (18). The equations are of such forms that the final equation would be very complicated and it would be practically impossible to solve for $M$. The only usable method is that of trial and error.

Careful study has been made of the relations between the different variables of these equations. Using equations (10), (16), (17), and (18) and assuming $A_{1}$ (the value of $A$ for the case in which there is no interfering container wall)

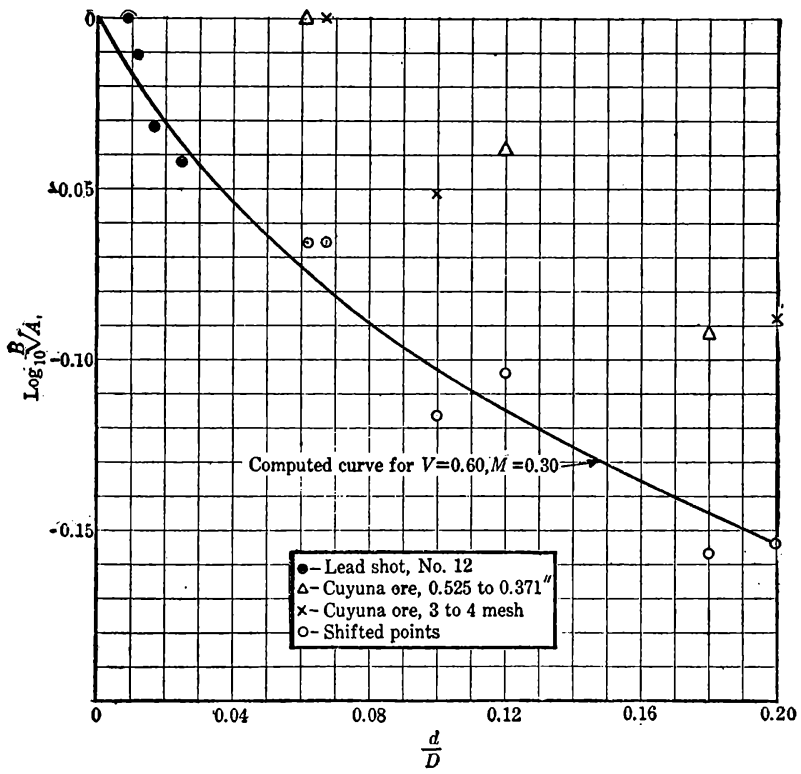

Figure 32.-Relation between $A$ and $d / D$; comparison of observed and computed values with $M=0.30$

to have a value of 1 , it is possible to determine $A_{C}$ (the average value of $A$ in a bed in a finite container) as a function of $d_{d} / D$. It has been found that the value of $A_{C}$ varies very rapidly with small changes in the value of $M$, varies considerably with the value of exponent $B$ (see equation 1 ), and varies some with the percentage of voids in the bed. If $\sqrt[B]{A_{C}}$ is solved for as a function of $d / D$, the only variables that will affect it will be $M$ and the percentage of voids. If the variations with the percentage of voids are disregarded, experimentally obtained values of $\sqrt[B]{A_{C}}$ can be plotted against $d / D$, different curves for different values of $M$ can be computed, and the value of $M$, which gives a curve that fits the data best, can be considered the best value of $M$.

The data that were used in this determination are given in Table 4. The containers used in these experiments were all standard wrought-iron pipe of $1,2,3,4$, or 6 inch sizes. Their volumes per unit length were carefully measured by means of their water capacity and their diameters computed from these data. The data of Table 4 are plotted in the upper part of Figure 32.

$43318^{\circ}-29-4$ 


\section{LAW FOR SPECIFIC VOLUMES OF BINARY MIXTURES}

If a straight line is drawn from the point of the specific volume of the small component (point $C$, fig. 54) to the vertical abscissa of 100 , intersecting it at an ordinate value equal to the reciprocal of the true specific gravity of the large component (point $D$, fig. 54), the line $C D$ intersects $A B$ at $B$ and the triangle $A B C$ is the field of possible existence of the specific volume of the binary system in question.

Proof.-Consider a bed of large particles containing a certain fraction of voids, $V_{1}$. If very small particles are introduced into the bed, they will not ncrease the volume of the bed as a whole until all of the voids of the large pieces are filled. Therefore, if infinitely small particles are introduced into a bed of large pieces the plot of specific volume against per cent composition by weight will follow the straight line $A B$ (of fig. 54) until such a composition that all of the voids of the large pieces are filled with the small constituent. But the small constituent itself has voids, no matter how small the particless. Call this fraction of voids $V_{2}$.

Therefore, at the point at which all of the large voids are filled with the small particles, in unit volume of the system,

$$
W_{2}=V_{1} \times\left(1-V_{2}\right) S_{2},
$$

where $W_{2}=$ weight of the small constituent, and

$S_{2}=$ true specific gravity of the small constituent.

In the same unit volume,

$$
W_{1}=\left(1-V_{1}\right) S_{1},
$$

where $W_{1}=$ weight of the large constituent, and

$S_{\mathrm{i}}=$ true specific gravity of the large constituent.

Therefore, the per cent composition in which the large particles are "saturated" with the small is given by the equation,

$$
\begin{aligned}
& \text { Saturation per cent of large component }=\frac{\left(1-V_{1}\right) S_{1}}{\left(1-V_{1}\right) S_{1}+V_{1}\left(1-V_{2}\right) S_{2}} . \\
& \text { If } S_{1}=S_{2} \text {, saturation per cent }=\frac{1-V_{1}}{\left(1-V_{1}\right)+V_{1}\left(1-V_{2}\right)} .
\end{aligned}
$$

$$
\text { If } V_{1}=V_{2} \text {, saturation per cent }=\frac{S_{1}}{S_{1}+V S_{2}}
$$

$$
\text { If } V_{1}=V_{2} \text {, and } S_{1}=S_{2} \text {, saturation per cent }=\frac{1}{1+V} .
$$

Thus, in Figure 54, if infinitely small particles are introduced into a bed of broken solids the specific volume when plotted against per cent composition by weight will follow the line $A B$ until the saturation point $B$ is reached.

Now, consider a system at the other end of the diagram, a bed of very fine particles of true specific gravity $S_{2}$ and voids $V_{2}$.

$$
\text { Specific volume }=\frac{1}{S_{2}\left(1-V_{2}\right)} .
$$

Suppose a weight fraction, $X$, of large particles is introduced and distributed at random through the bed without leaving any voids between adjacent large pieces. Then for a unit weight of the system

$$
\text { Specific volume }=\frac{1-X}{S_{2}\left(1-V_{2}\right)}+\underset{S_{1}}{X}
$$


the origin (point 0.0 therefore 0 partial specific volume) that line represents the lowest possible specific volume which that system can have. Such a line is $A B$, Figure 54 .

Obviously the highest partial specific volume that any constituent may have is the value of the specific volume of that constituent, for in the systems considered it would not be possible for any added material to increase the total volume of the system by an amount greater than

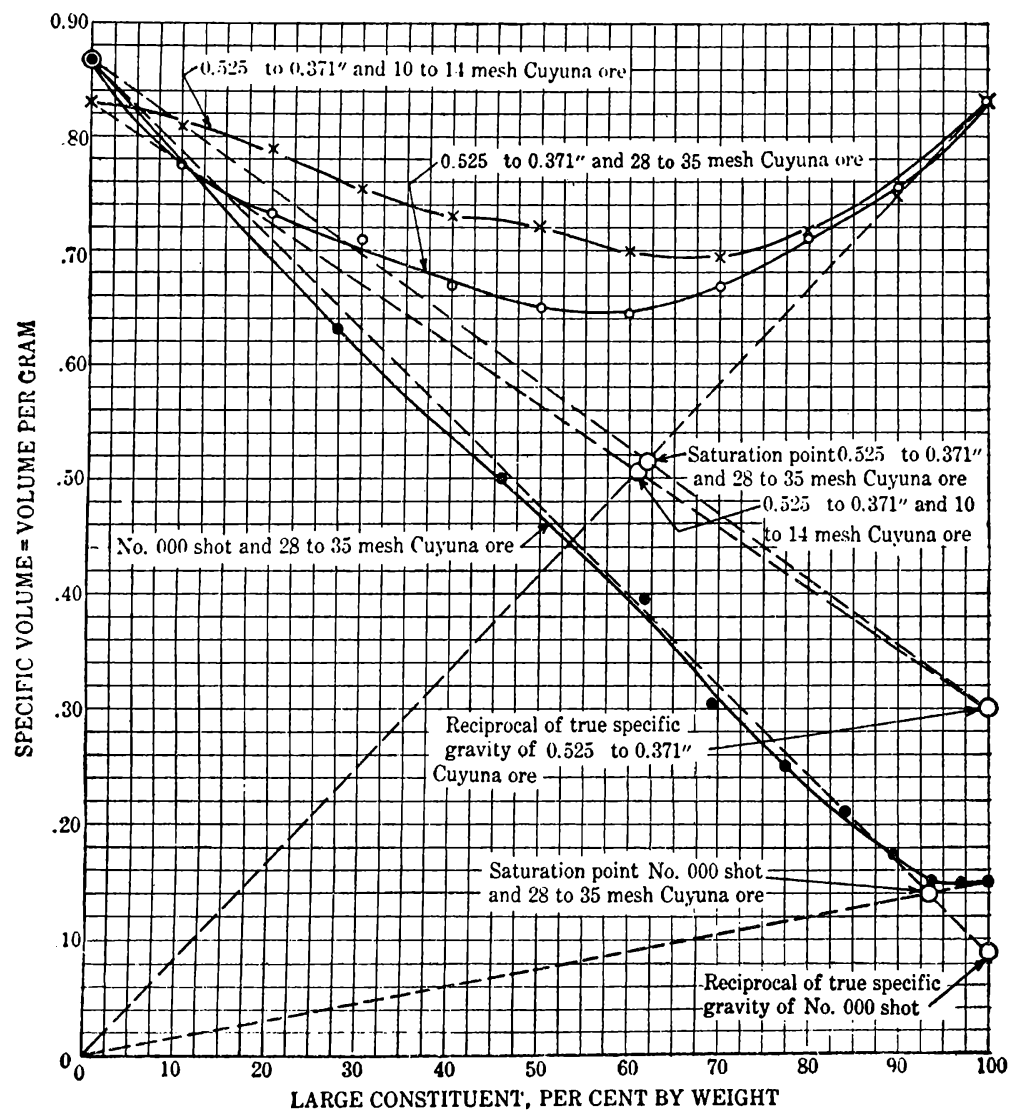

Figure 55.--Specific volume relations in 2-component systems of lead shot and Cuyuna ore

the volume added. Therefore, the line $A C$ of Figure 54 represents the highest specific volume such a system may have. It is to be understood that in speaking of specific volume and partial specific volume reference is made to the over-all volume occupied by a bed of the specified component and not to the actual volume of the particles themselves. Data of a system of mixtures of Cuyuna ore and lead shot are plotted in Figure 55. 
position is zero for the rate of change of volume with the change of weight. This represents the smallest possible partial molal volume that this constituent can have, for obviously the addition of the small particles can not decrease the volume of the system as a whole. In true chemical solutions there are systems in which the addition of a

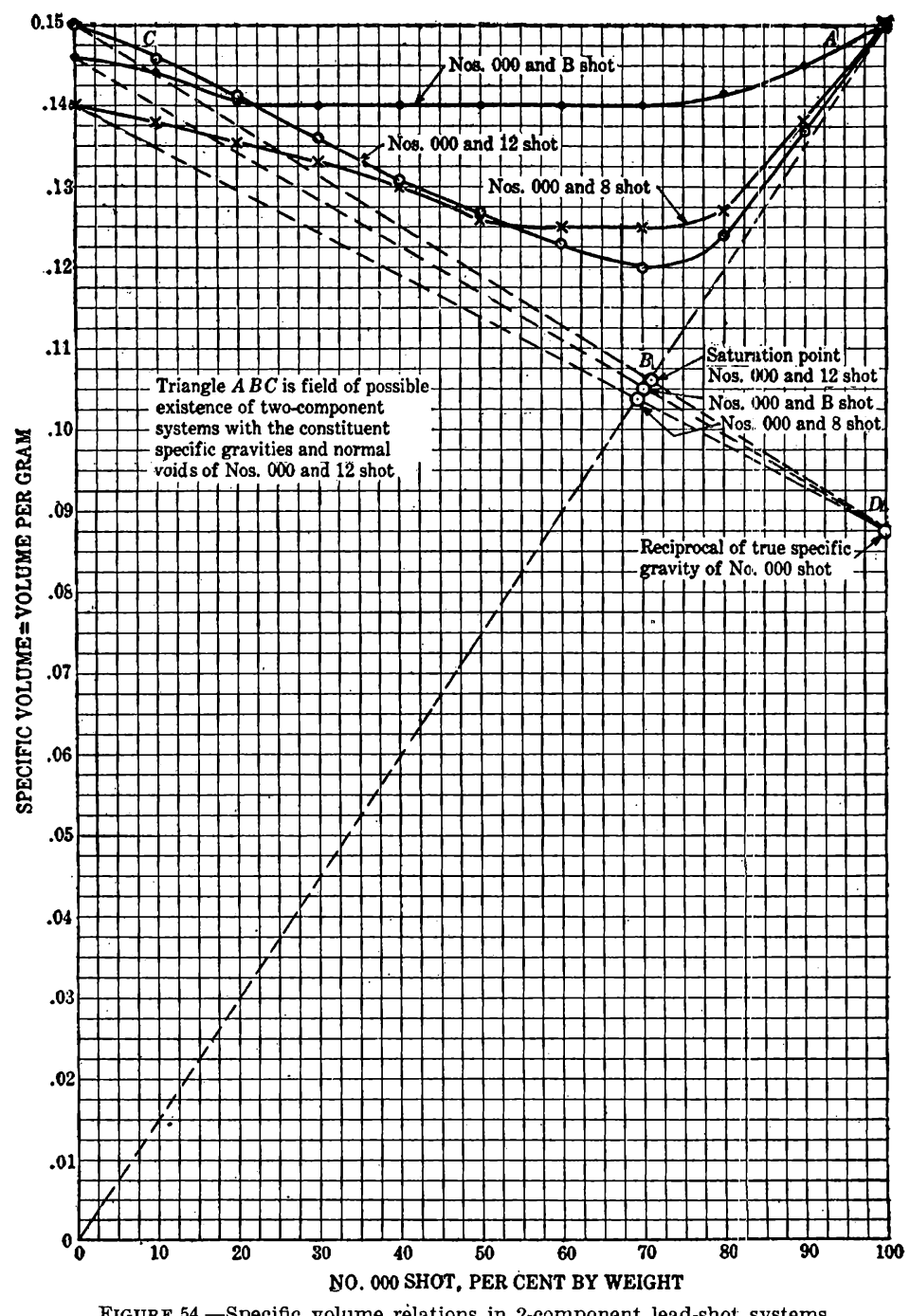

Figure 54.-Specific volume rèlations in 2-component lead-shot, systems

second component actually decreases the total volune, but such can not be the case here.

Since the intercept of the tangent of the curve with the $y$ axis represents the partial specific volume, if a straight line is drawn from the value of the specific volume at 100 per cent of the large constituent to 
may be developed that tells the maximum variation possible in any bed.

$$
\text { Specific volume }=\frac{1}{\text { True specific gravity of solids } \times(1-\mathrm{V})}
$$

In such a case a binary system may be considered as strictly analogous to a system of liquid solutions of two components. The theoretical treatment of such systems can be found elsewhere. ${ }^{19}$ Plot specific volume of the bed as ordinate against the per cent composition by weight as abscissa. (See fig. 54.) If a tangent is drawn to the curve at any point, the value of intercept of that tangent with the $y$ axis is, in solution parlance, the partial specific volume of the small constituent of the system. The intersection of this same tangent with the

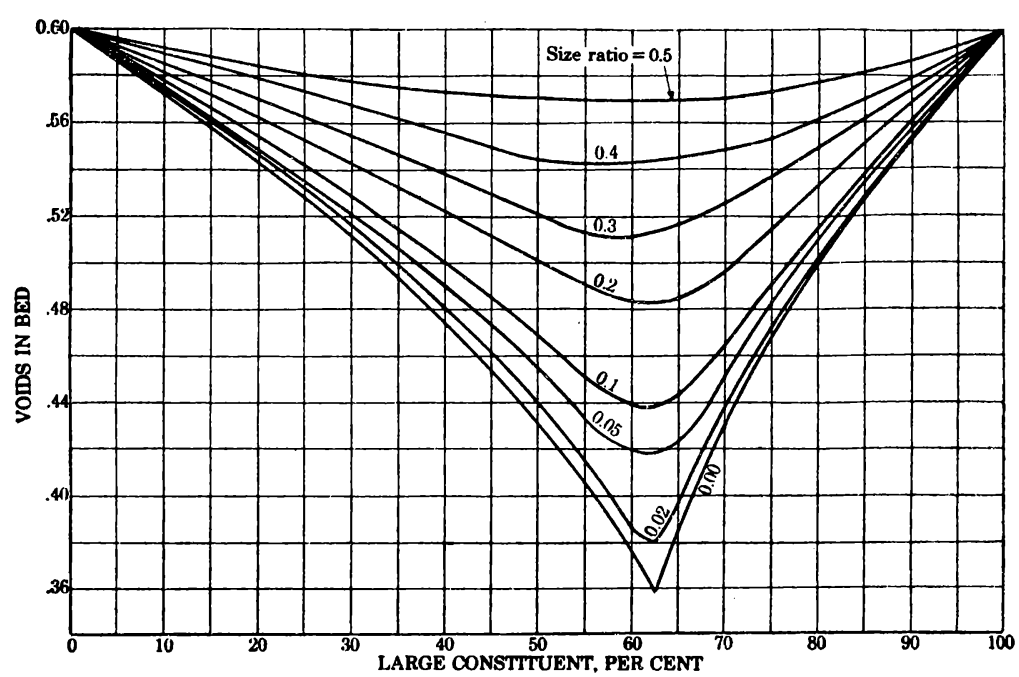

Figure 53.-Relation between voids and size composition in 2-component systems of broken solids when voids of single components $=0.60$

vertical line at abscissa $=100$ per cent is the partial volume of the large constituent.

"Partial specific volume" means the rate of change in the volume of the system as a whole if a unit of weight is added to the system of constant and specified composition.

Consider a single component system of large pieces. Suppose some very small particles are dropped into the bed. The small particles will drop into the voids between the large pieces, filling them up but not increasing the volume of the system as a whole. Thus, weight has been added to the system but the volume is unchanged. Therefore, the partial specific volume of the small constituent at that com-

${ }^{10}$ Sce Lewis, G. N., and Randall, Merle, Thermodynamics and the Free Energy of Chemical Substunces: New York, 1923, pp. 36-40. 
smallest percentage of voids that the author has found in practice was 26.6 per cent in a system containing 70 per cent No. 000 shot and 30 per cent No. 12 shot.

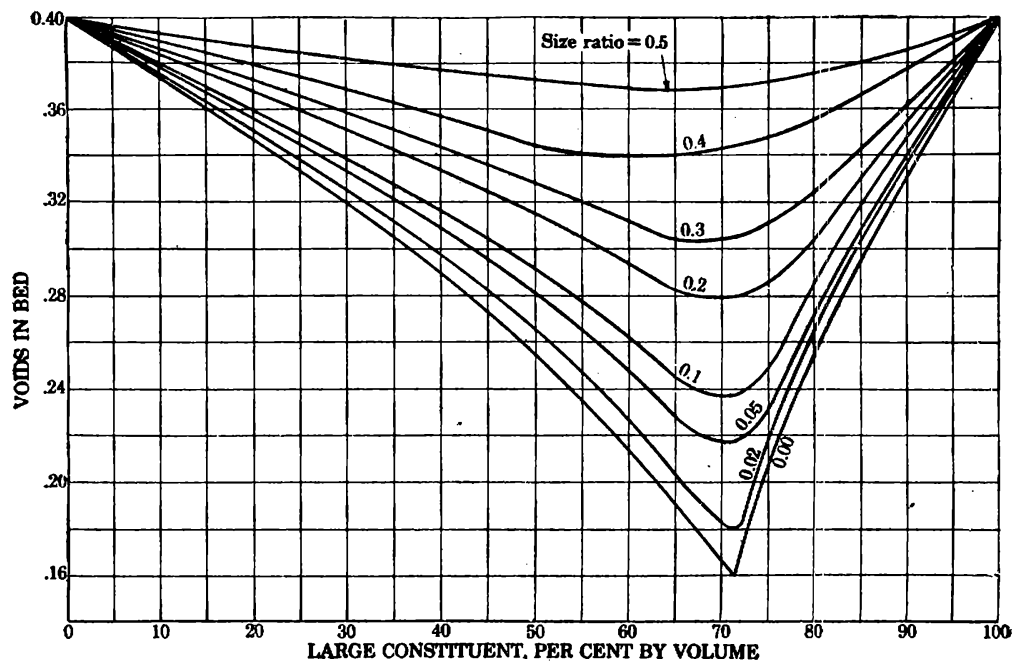

FIGURE 51.-Relation between voids and size composition in 2-component systems of broken solids when voids of single components $=0.40$

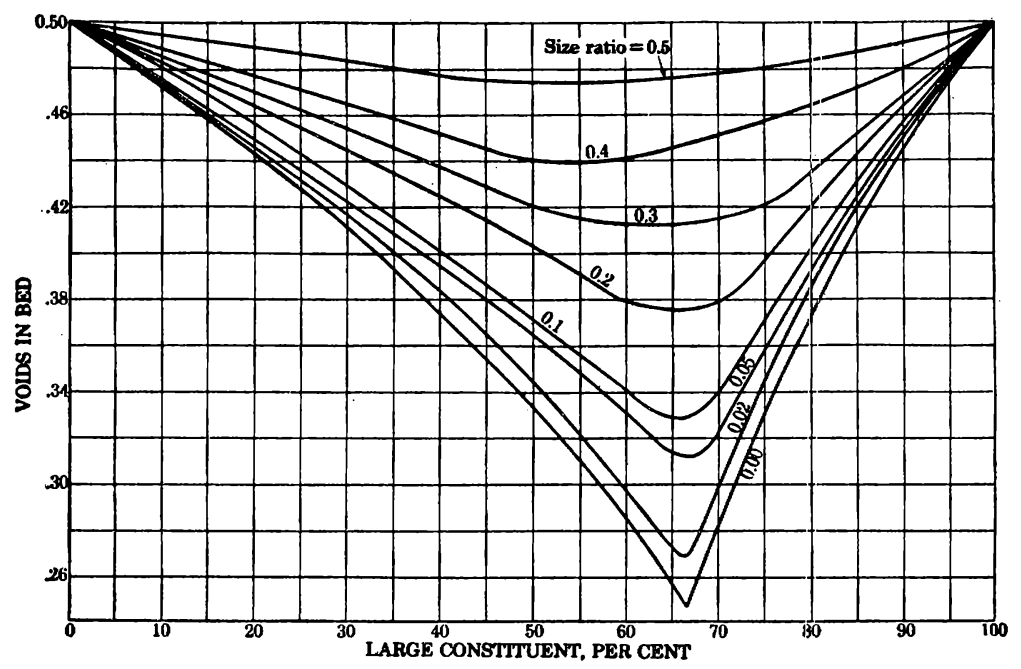

Figdre 52.-Relation between voids and size composition in 2-component systems of broken solids when voids of single components $=0.50$

\section{SPECIFIC VOLUME RELATIONS}

If the data on voids in the bed and the specific gravity of the solid are combined in such a manner as to give the corresponding specific volumes of the bed (reciprocal of the specific gravity of the bed as a whole or the apparent specific gravity as it may be called), a theory 
voids in the beds of pure components, or, if the normal voids of the two constituents are not the same, less than the weighted average of the two. This is caused by the nesting of the small particles between the large ones. As the percentage of large material in the bed is increased from 0 to 100 , the voids decrease to a minimum and then rise to the value of the pure large constituent.

If the normal voids of the two constituents are very different, the actual value of voids might not pass through a minimum, but the value relative to the weighted mean of the two constituents would pass through such a point.

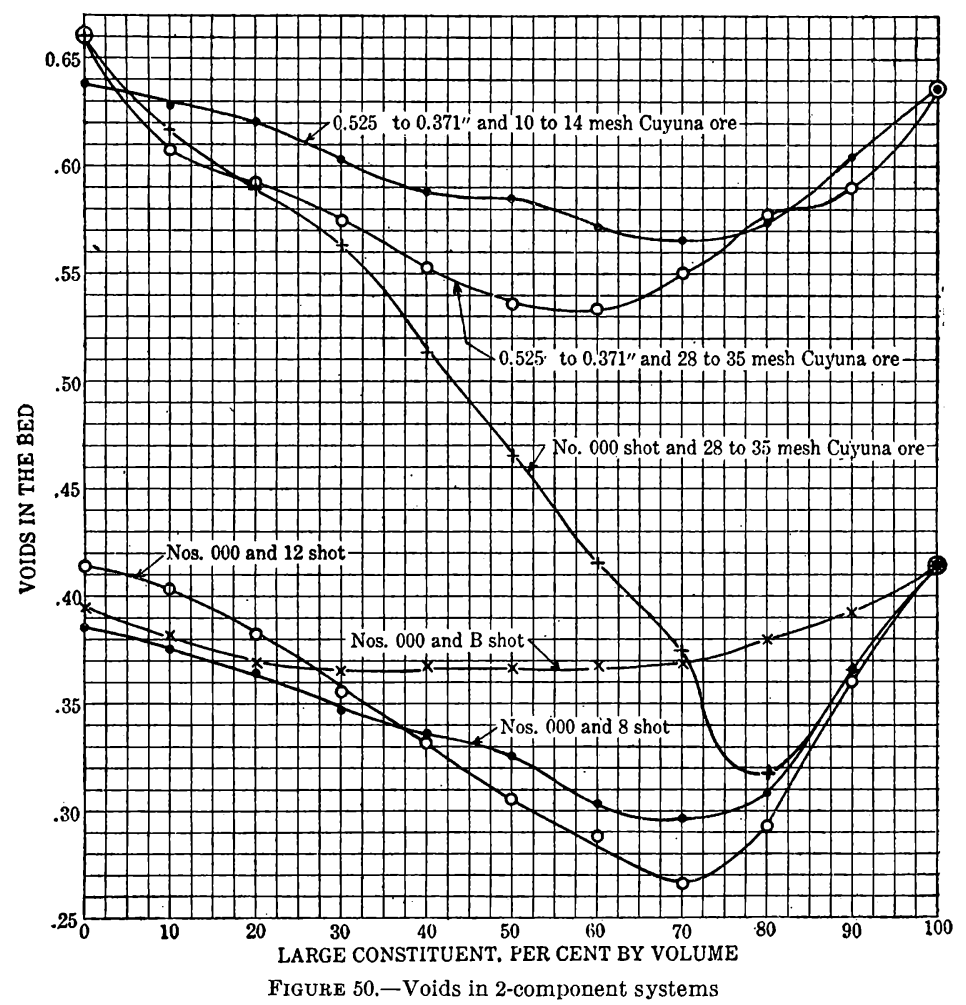

The data of the voids of the six binary systems studied are given in Figure 50. These same data have been generalized and plotted in Figures 51, 52, and 53 for component voids of 40,50 , and 60 per cent, respectively.

It can be shown geometrically that the smallest percentage of voids possible in a bed of closely packed, uniformly sized spheres is 25.95 per cent. As was explained in the section on wall effect, the actual voids in a container are always greater than this. The smallest amount of voids observed by the author in beds of uniformly sized shot has been 38.4 per cent. The largest percentage of voids in any normally packed bed has been 65.1 per cent for 28 to 35 mesh Cuyuna ore. The 
constituent which is considered as unity. These curves are general, are applicable to any binary system, and should be accurate to within a few per cent. Linear interpolation may be used for intermediate values.

\section{APPLICATION OF B RELATION}

If the $\Delta P_{S \infty}$ has been determined for $R=0.1$ from the data of preceding sections and it is desired to obtain the value of $\Delta P_{S \infty}$ for some other rate of flow, it is necessary to use the $B$ relations of Figure 49 . Divide $\Delta P_{S \infty}$ by $0.1^{B}, B$ being determined by Figure 4:9. This gives the value of $A_{\infty}$. Multiply the value so obtained by $R^{B}$, where $R$ is the rate of flow in question. The product is the value of $\Delta P_{S \infty}$ at the desired rate of flow.

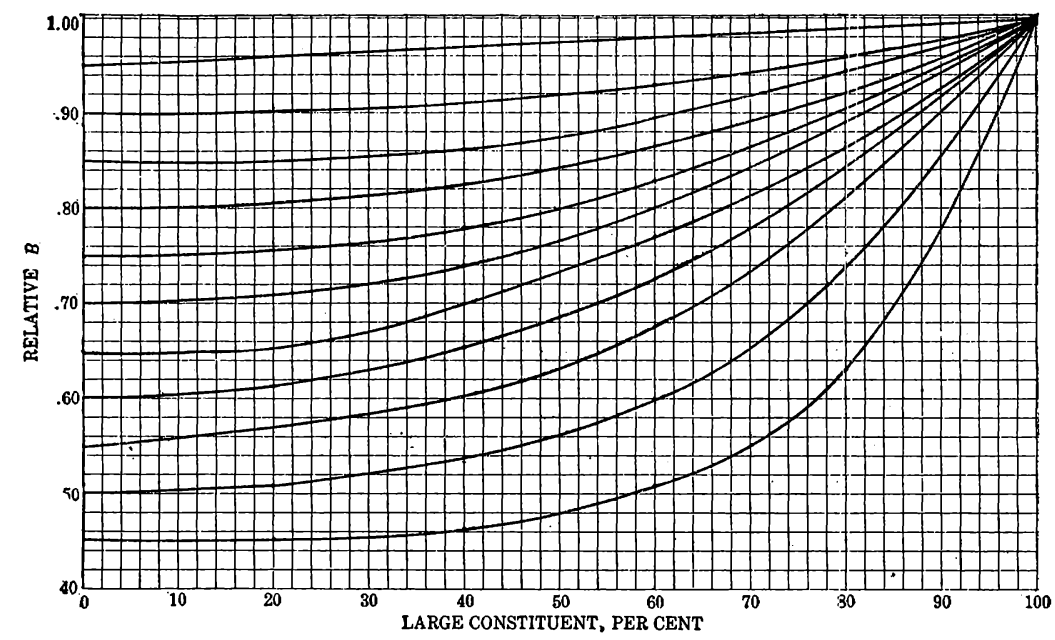

Figure 49.-Relative values of $B$ in 2-component systems; all values relative to $B$ for the large constituent

\section{COMPUTATION OF WALL-EFFECT FACTOR}

$\Delta P_{S \infty}$ is the standard pressure drop in a container of infinite size. The pressure drop in a finite container is less. This wall-effect factor can be determined by Figures 33 and 34 , if $d / D$ is known. The $d / D$ may be considered as a linear function of the composition. The $d / D$ for each pure component may be determined by means of equation (26).

\section{VOIDS IN BINARY SYSTEMS: NORMAL PACKING}

In connection with the resistance of binary systems a more or less thorough study has been made of the voids and specific volumes of the different systems. Several attempts have been made to relate the voids in the bed to the resistance, but no satisfactory relation has been found. When two different sizes of materials are uniformly mixed, the percentage of voids in the bed is less than the normal 
VARIATION OF EXPONENT B WITH COMPOSITION IN BINARY SYSTEMS

All of the foregoing relations have been based on a rate of flow of 0.1 liter per second per square centimeter. The pressure drop for any other flow must be computed by means of equation (1),

$$
\Delta P_{S}=A R^{B} .
$$

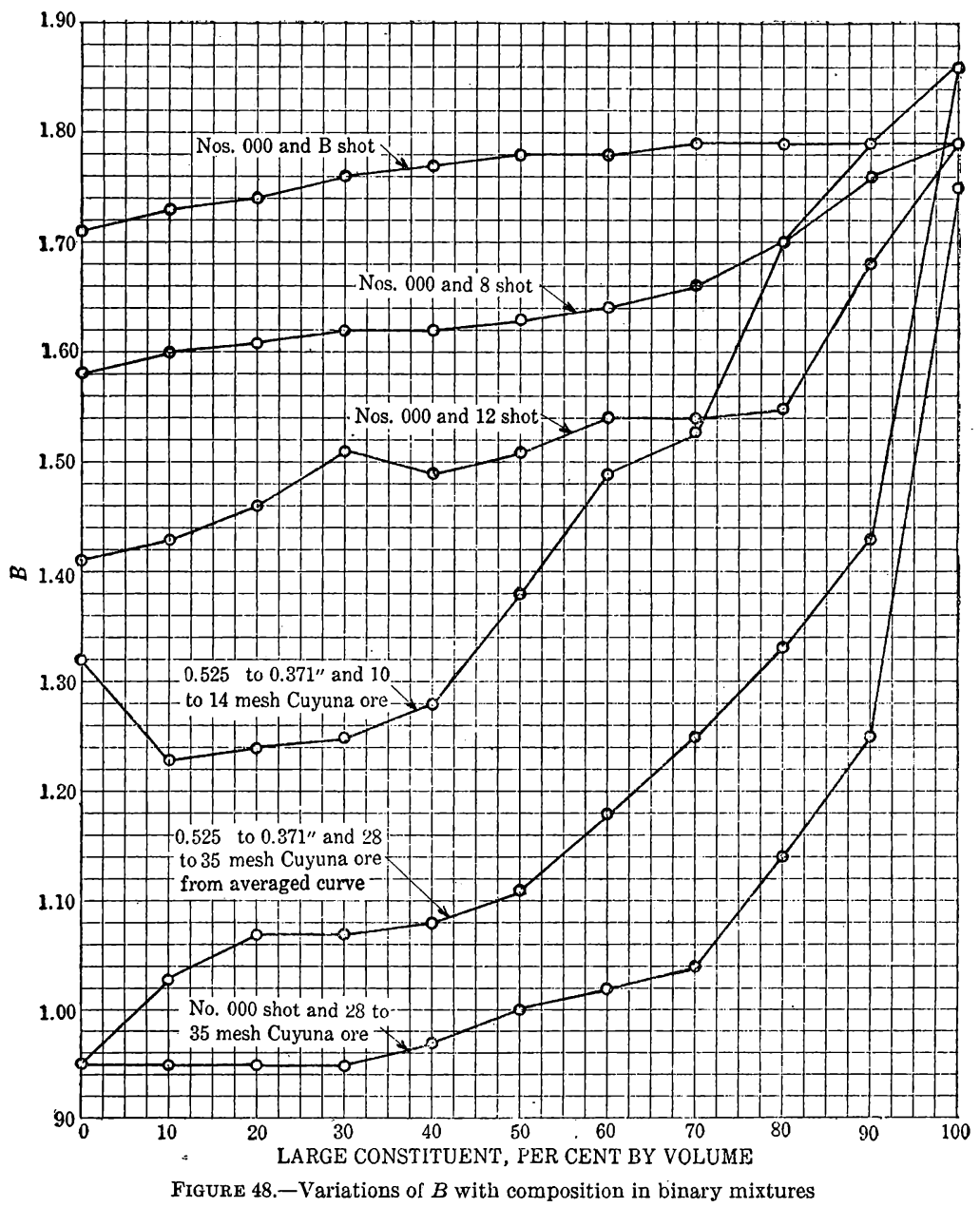

The relation between composition and the value of $B$ must be known before equation (1) may be used. The values of $B$ for the six binary systems studied have been plotted in Figure 48 with percintage composition as abscissa and $B$ as ordinate. These data have been generalized into curves of relative values of $B$ in Figure 49 . The ordinate is given in values of $B$ relative to the value for the large $43318^{\circ}-29-6$ 
per cent and that considerable confidence may be placed in the curves of Figures 45,46 , and 47 .

The curves are plotted with volume per cent of large constituent as abscissa and relative $\underset{R=0.1}{\Delta P_{S \infty}}$ as ordinate. The pressure drop of the smaller constituent has been taken as unity and constant, and the pressure drop of the larger constituent has been taken as a variable having values between 1 and 0 . This makes the figures applicable to any ratio of resistances and is therefore perfectly general. Interpolation or extrapolation may be used for values of voids of the large constituent other than those given in the three figures.

The curves apparently are modified forms of the so-called probability curve, which has the general equation

$$
y=K e^{-h^{2} x^{2}},
$$

but owing to the unsymmetrical tendencies of the systems a general mathematical theory would be quite complicated, cumbersome, and of no particular utility, so the results are best left in the graphic form.

However, it seems reasonable to suppose that the resistance is in some way connected with the probable distribution of small particles among large ones, and that some modification of the probability law might be expected to apply. This would be a very interesting line of research.

The data as shown in Figures 45 to 47 do not give any relations directly involving sizes of materials. It was necessery to form the relations on the basis of relative resistances of the components of a binary system rather than sizes of materials, so that the argument might be perfectly general. The relation between size and resistance for various substances has been given in previous sections.

It is to be noted that if the resistance of the large constituent is half or more of the resistance of the small one the curve of the change of resistance with composition of the system is almost a straight line. Thus, if a system is composed of a mixture of sizes but the smallest is not less than half of the largest the system may roughly be considered as having one component, the effective size of which is the average size of the mixture. This statement is based on the supposition that resistance is inversely proportional to the size, which is only true in a qualitative way.

\section{EFFECT OF SEPARATION OF CONSTITUENT SIZES}

In general, it may be seen from the foregoing data that if a system of a mixture of two sizes has the constituent sizes separated into separate layers, the combined resistance of the two layers will be less than the resistance of the mixed bed.

This rule will always hold for binary systems but is not necessarily true for systems of many sizes. 
The element of personal choice enters into this treatment, for there are a number of variations and inconsistencies in Figure 43. It has been necessary to study the data as a whole to determine the general

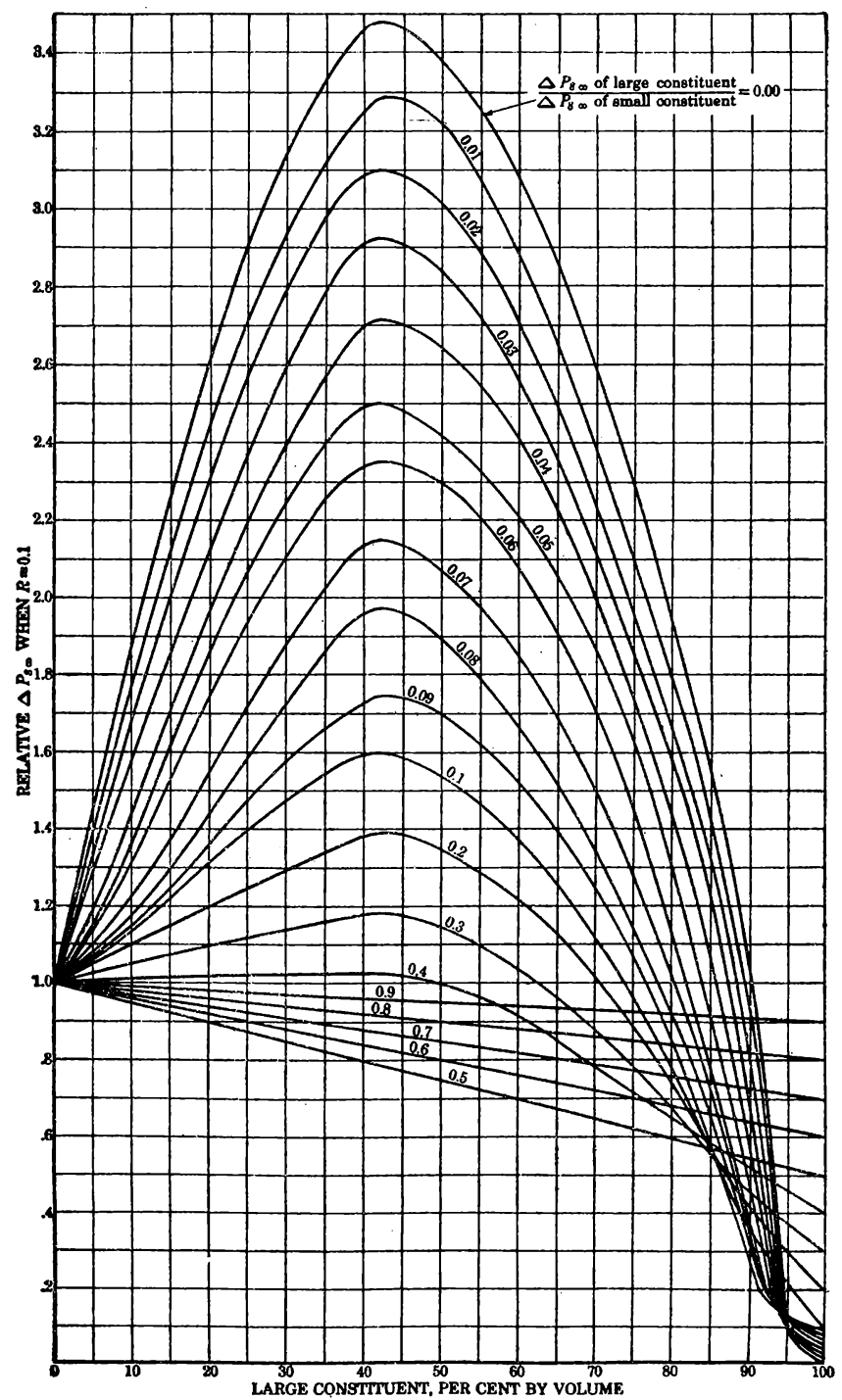

FIgURE 47.-Relative pressure drops in 2-component systems when normal voids in the large constituent $=0.60$ and $R=0.1$; all values relative to pressure drop of the small constituent

tendencies and not become lost in consideration of minor inconsistencies and attempts to correlate minutiæ. Other investigators might be justified in interpreting the data somewhat differently, but the author feels that variation could not reasonably be more than a few 
This means that the maximum occurs when the voids formed by the large constituent are approximately equal to one-fourth.

\section{GENERALIZATION OF DATA}

By aid of the foregoing rule the law of the maximum as expressed by equation (33), Figure 44, and the general tendency of the curves

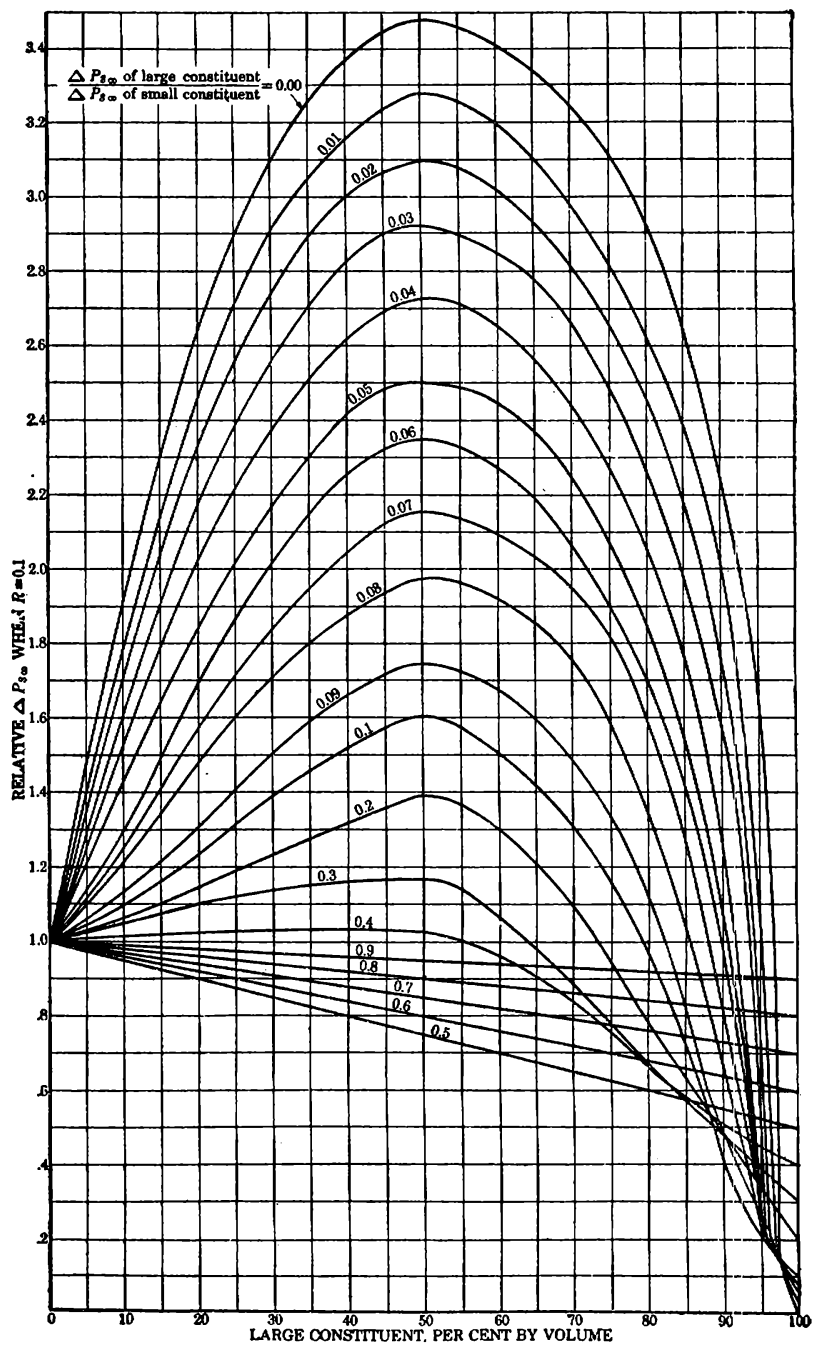

Figure 46.-Relative pressure drops in 2-component systems when normal voids in the large constituent $=0.50$ and $R=0.1$; all values relative to the pressure drop of the small constituent

of Figure 43, the data as presented may be generalized to fit any desired binary system. The results of such a generalization are given in Figures 45, 46, and 47 for 40, 50, and 60 per cent normal voids, respectively, in the large constituent. 
small. Thus, the system No. 000 shot and 28 to 35 mesh Cuyuna ore has a maximum at 65 per cent and the normal voids of the No. 000 shot are 0.414. The corresponding system of 0.525 to 0.371 inch and 28 to 35 mesh Cuyuna ore have a maximum at 30 per cent and the normal voids of the large ore are 0.638 . If the value of normal voids

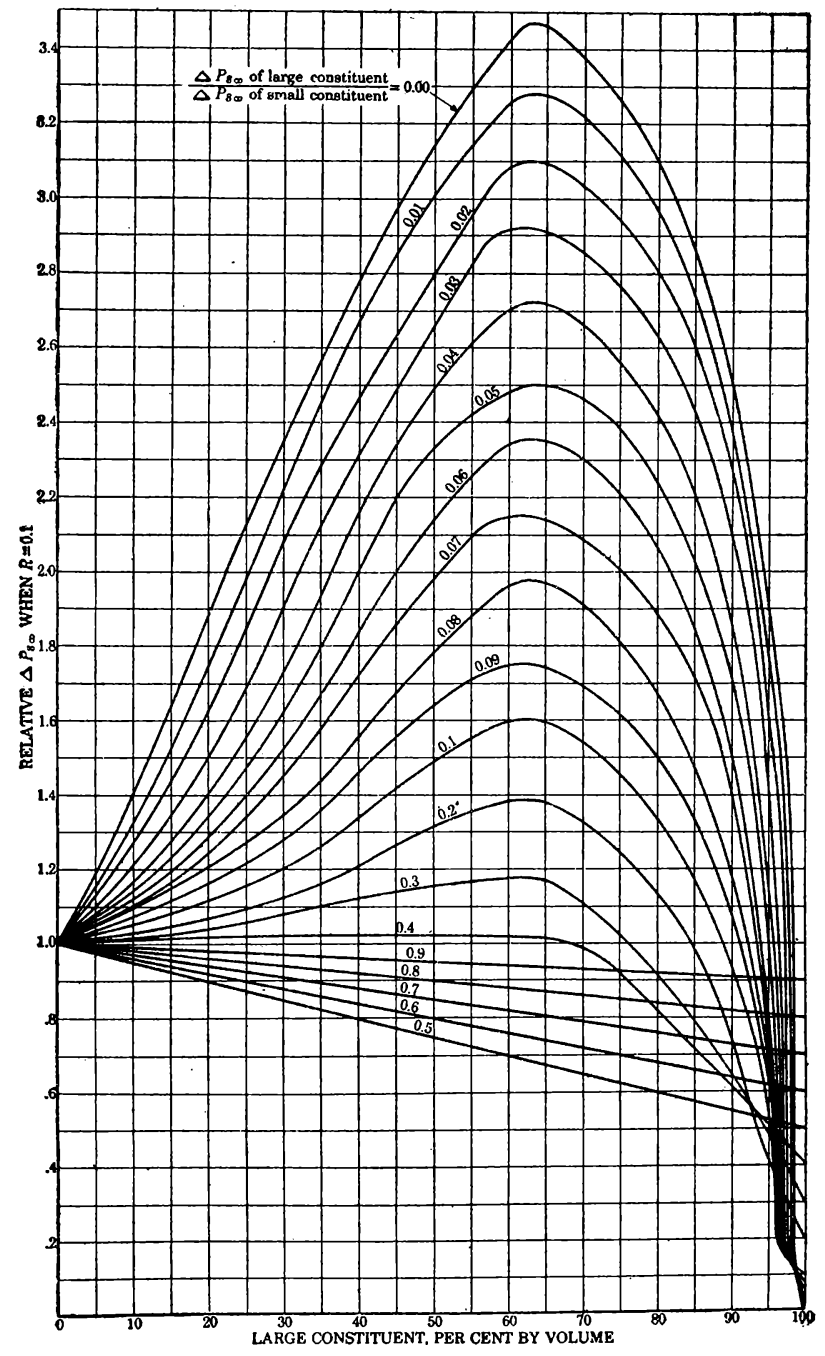

FIGURY 45.--Relative pressure drops in 2-component systems when normal voids in the large constituent $=0.40$ and $R=0.1$; all values relative to pressure drop of the small constituent

of the large constituent of the upper five systems of Figure 43 (the lowest curve does not have a well-defined maximum) is multiplied by the percentage of the large constituent at the point at which the maximum occurs, the following values are obtained: $27,19,29,29,25$ per cent. The average value is 26 per cent or roughly one-fourth. 
Proof.-Consider a binary system of materials of resistance $A$ and $C$. Suppose the proportions of $A$ and $C$ are such that the resistance is a maximum. Introduce a third component of intermediate resistance $B$, keeping the amount of the constituent of the resistance $A$ the same proportion of the whole. Consider $B$ and $C$ as a binary system. From the general shape of the curves of Figure 43 it will be seen that the resistance of the $B-C$ is greater than of $C$ alone. Consider the system as a whole as a binary system. Now, with $A$ as one constituent and the $B-C$ system as the other the $B-C$ value will now correspond to $L$ of equation (33). From equation (33) or a similar equation, since the value corresponding to $L$ is larger in the second case (ternary) than in the first (binary), the value of $h$ (maximum resistance) will be larger for the binary system. This argument may be extended to as many constituents as desired.

Stated in generalized language, if the value of the maximum is greater the smaller the resistance of the large component. Any intermediate components introduced tend to raise the resistance of the larger constituent and thus reduce the value of the maximum.

From the general shape of the curves of Figure 43 the author feels justified in extending this argument concerning the maximum to cover the resistance at any size composition. This makes the rule general for all resistances.

\section{RULE OF MIXTURES}

'Therefore, the resistance of a system of two component sizes may be lowered by displacing part of the large constituent with particles of smaller size but larger than the small constituent.

This rule may be generalized and extended to cover as many constituent sizes as desired.

Mlustration.-A binary system of lead shot containing 70 per cent of No. 000 size $(d=0.905$ centimeter) and 30 per cent of No. 12 size $\left(d=0.138\right.$ centimeter) had a value of $\underset{R=0.1}{\Delta P_{S \infty}}=5.13$ (run 100). Part of the large constituent was displaced by smaller No. B shot, giving a system of 48 per cent No. 000 size $(d=0.905$ centimeter $)$, 22 per cent of No. B size $(d=0.450$ centjmeter), and 30 per cent of No. 12 size ( $d=0.138$ centimeter), which had a value of $\underset{R=0.1}{\Delta P_{S \infty}=4.19}$ (run 252). Thus, by introducing 22 per cent of a component of intermediate size into the bed the resistance was decreased 19 per cent.

It is not known how far the rule, as stated above, holds. It is based upon generalizations of data of a rather limited character, so the extent of its exact validity is problematical. However, it may be held in mind as a general rule with possible limitations.

\section{POSITIONS OF RESISTANCE MAXIMA}

The maxima in the curves of Figure 43 do not fall at any one composition of the bed; neither do they seem superficially to follow any single law of variation. However, it will be observed that those systems which have their maxima at the higher percentage of large material are systems in which voids of normal packing are relatively 
$h==$ maximum resistance for each curve,

$x=\frac{G}{L}$,

$y=\frac{h}{L}$, and

$\bar{L}=3.47 \frac{G}{L}-18.7$.

$$
h=3.47 G-18.7 L \text {. }
$$

This equation expresses the relation between the value of the maximum resistance in a binary system made up of resistance $G$ and resistance $L$. It may be spoken of as the law of the maximum.

\section{MAXIMUM VALUE OF $h$}

Suppose $G$ to be constant. Then, since negative values of $L$ have no meaning in this case the maximum value of $h$ occurs when $L$ is zero, that is, for particles of infinite size. Therefore, the greater the difference between the sizes of the particles in a binary system (more strictly speaking, the greater the difference in resistance of the two constituents) the higher will be the point of maximum resistance of the system.

Since the maximum value of $h$ occurs when $L$ is zero,

$$
h_{(\max )}=3.47 G .
$$

This means that no matter how large the particles of the large constituent may be the value of the maximum can never be greater than 3.47 times the resistance of the small constituent.

Equation (33) applies only if $\frac{G}{L}$ is greater than 10 .

From a study of Figure 38 the following rule of resistance of binary systems may be deduced: The resistance of a system of a mixture of two component sizes is greater than if the different-size materials are separated and put into layers.

Instances may be found in which this rule will not hold where there is nonuniformity in the beds. The rule refers only to cases in which the constituent sizes are distributed uniformly relative to each other.

If the ratio between the constituent sizes is not greater than 2 to 1 , the increase of resistance upon mixing is so small as to be negligible.

\section{LOWERING RESISTANCE BY USING MORE THAN TWO COMPONENTS}

An interesting corollary results from a generalization of these considerations. It may be stated: The resistance of a binary system is greater than the resistance of a system of more than two components if the small constituent is the same in both cases and its ratio to the larger components is kept the same. 


\section{LAW OF THE MAXIMUM}

The first item to be studied will be the numerical value of the maximum in the curves. In Figure 44 observed values of the resistance of the small constituent have been divided by the observed value of the resistance of the large constituent and plotted as abscissas against the similar ratio of the value of maximum in the curve to the resistance of the large constituent, these values being plotted as ordinates. It can be seen that there is a definite relation between these two quantities. The author feels justified in drawing the upper portion of the curve as a straight line and the lower portion as indicated.

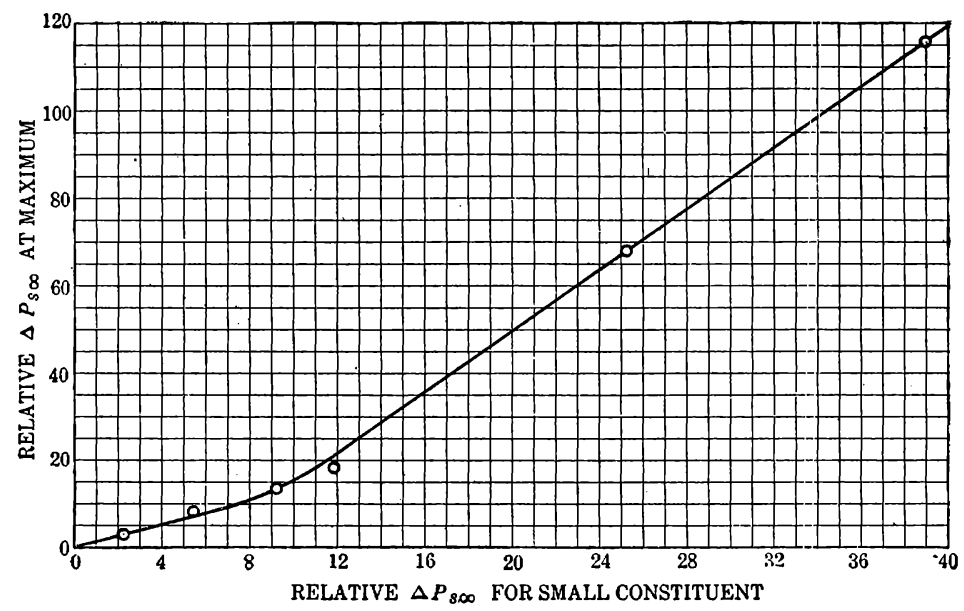

Figure 44.-Relation between maximum pressure drop and pressure drop through small constituent in 2-component systems when $R=0.1$; all values relative to pressure drop through the large constituent

The value of the resistance of the small constituent instead of the resistance of the large constituent could have been used as a common divisor of the quantities involved, but the mathematics of the former case would not be as simple as for the latter.

Consider the upper straight-line portion of the curve. The equation of the line as drawn is

$$
y=3.47 x-18.7
$$

where $x$ is the abscissa, and

$y$ is the ordinate.

$x$ and $y$ are relative values of resistance compared to the resistance of the large constituent.

If $G=$ resistance of the small constituent, as measured by pressure drop,

$L=$ resistance of the large constituent as measured by pressure drop, 
would suppose that if such a change of resistance were to occur it would be in a bed containing a much smaller percentage of large particles. Two cross sections of a typical bed of mixed sizes are shown in Figure 18, $a$ and $b$. These cross sections are for a bed containing 70 per cent of 0.525 to 0.371 inch and 30 per cent of 10 to 14 mesh Cuyuna ore. This is approximately the point of maximum resistance; that is, if the percentage of small material were either increased or decreased the resistance to gas flow would be less.

Appearances would not warrant any such conclusion, for it would seem as if a bed containing a greater percentage of fine particles would

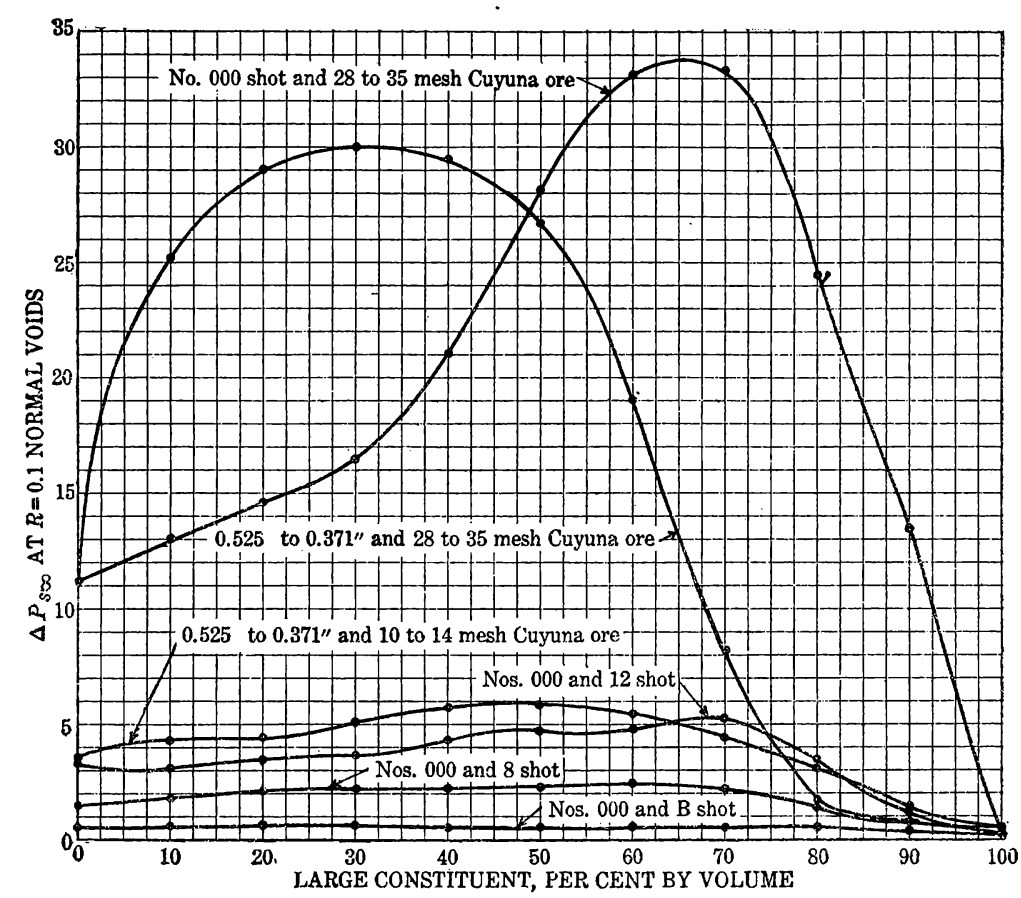

Figure 43.-Pressure drop at a flow of 0.1 liter per second per square centimeter for various binary systems

have a higher resistance, but experimental aata show that this system has the maximum resistance. Figure 18, $a$ and $b$, shows two different cross sections of the same tube of material. It will be observed that in both sections portions of the bed contain no fine material. These, then, are cross sections of the aforementioned expansion chambers, which are the major cause of the high resistance.

The correlation of these data into a workable theory is not simple. After numerous experiments it has been found that the best basis for comparison is that of the ratio of the resistance (in this case the value of $\Delta \mathrm{P}_{S_{\infty}}$ at $R=0.10$ ) of the small to the large constituent. 
might settle into place unhampered by neighboring particles, thus obtaining "normal packing." (Defined on p. 18.) The experimental method just outlined seems quite crude, but close duplication of results was always obtainable, so the method appears fairly accurate and probably gives good random distribution of the components.

\section{EFFECT OF SIZE COMPOSITION ON PRESSURE DROP AT A SPECIFIED RATE OF FLOW}

\section{BASIS OF COMPARISON OF SYSTEMS}

As has been pointed out, since exponent $B$ of equation (1) is a variable any definition of the resistance offered to the flow of gases by a bed of broken solids is arbitrary and limited in its significance to an expression of the relation between the resistances of various systems at a specified rate of flow.

As was explained on page 46 , it is better to compare resistances at a rate of flow in the range of experimental observation than in an extrapolated position. As before, a rate of flow of 0.10 liter per second per square centimeter has been chosen for a comparison of pressure drops. If values of the coefficient $A$ of equation (1) had been chosen for comparison, it would have been equivalent to studying the pressure drop at a rate of flow of 1 liter per second per square centimeter, a rate almost ten times greater than the highest used in this investigation.

This section takes up the consideration of the relation between $\underset{\mathrm{R}=0.1}{\Delta P_{S_{\infty}}}$ and the size composition of binary mixtures. $\underset{R=0.1}{\Delta P_{S_{\infty}} \text {, when }}$ completely interpreted, means the pressure drop under standard conditions measured in centimeters of water per centimeter height of column in a container of infinite diameter at a rate of flow of 0.1 liter per second per square centimeter under standard conditions.

The wall-effect factor was computed by interpolation between the two pure constituents. It was assumed that $d / D$, the relation between size of particle and size of container, varied linearly with composition between the values of the two pure components. From the values of $d / D$ thus obtained values of the wall-effect factors were taken from Figures 33 and 34.

\section{EXPERIMENTAL DATA}

The data of $\underset{R=0.1}{\Delta P_{S_{\infty}}}$ are plotted against volume percentage of size composition in Figure 43 for six binary systems. Several surprising things are shown in this figure. As the percentage of large material in a bed is increased the resistance (pressure drop) rises to a maximum, which may be several hundred per cent greater than the resistance of the small constituent. Sometimes this maximum occurs in a bed containing 60 to 70 per cent of the large particles, Intuitively, one 
TABLE 8.-Data on two-component systems-Continued SYSTEM- 0.525 to 0.371 INCH CUYUNA ORE +28 TO 35 MESH CUYUNA ORE [ 0.525 to 0.371 incl Cuyuna ore $-d=0.876$ centimeter; 28 to 35 mesh Cuyuna ore $-d=0.040$ centimeter]

\begin{tabular}{|c|c|c|c|c|c|c|c|c|}
\hline $\begin{array}{c}\text { Volume per cent large } \\
\text { constituent }\end{array}$ & $\begin{array}{l}\text { No. of } \\
\text { run }\end{array}$ & $\begin{array}{l}\text { Voids in } \\
\text { bed, } \\
\text { pormal } \\
\text { packing }\end{array}$ & $\underset{B^{\prime}}{\text { Observed }}$ & $\begin{array}{c}\text { Observed } \\
A\end{array}$ & $\begin{array}{c}d / D \\
\text { linear } \\
\text { inter- } \\
\text { polation }\end{array}$ & $A_{t}$ & $A_{\infty}$ & $\begin{array}{l}\Delta P_{s_{\infty}} \text { at } \\
2 R=0.1\end{array}$ \\
\hline $\begin{array}{l}0 \\
10 \\
20 \\
30 \\
40 \\
50 \\
60 \\
70 \\
80 \\
100\end{array}$ & $\begin{array}{r}71 \\
146 \\
147 \\
148 \\
149 \\
150 \\
152 \\
153 \\
154 \\
155 \\
42\end{array}$ & $\begin{array}{l}0.651 \\
.608 \\
.591 \\
.575 \\
.552 \\
.537 \\
.533 \\
.550 \\
.578 \\
.590 \\
.638\end{array}$ & $\begin{array}{l}0.95 \\
1.03 \\
1.07 \\
1.07 \\
1.08 \\
1.11 \\
1.18 \\
1.25 \\
1.33 \\
1.43 \\
1.86\end{array}$ & \begin{tabular}{c|}
98.5 \\
247 \\
310 \\
317 \\
308 \\
293 \\
220 \\
93.5 \\
28.8 \\
16.1 \\
16.8
\end{tabular} & $\begin{array}{r}+0.000 \\
.015 \\
.027 \\
.038 \\
.049 \\
.059 \\
.070 \\
.081 \\
.092 \\
.103 \\
.190\end{array}$ & $\begin{array}{r}-1.00 \\
.96 \\
.92 \\
.90 \\
.88 \\
.85 \\
.83 \\
.79 \\
.76 \\
.70 \\
.55\end{array}$ & $\begin{array}{c}98.5 \\
257 \\
338 \\
353 \\
350 \\
345 \\
265 \\
118 \\
37.9 \\
23.0 \\
30.5\end{array}$ & $\begin{array}{l}11.1 \\
25.1 \\
29.0 \\
30.0 \\
29.5 \\
26.8 \\
19.0 \\
8.11 \\
1.78 \\
.86 \\
.44\end{array}$ \\
\hline
\end{tabular}

SYSTEM-0.525 TO 0.371 INCH CUYUNA ORE+10 TO 14 MESH CUYUNA ORE

[0.525 to 0.371 inch Cuyuna ore $-d=0.876$ centimeter; 10 to 14 mesh Cuyuna ore $-d=0.114$ centimeter]

\begin{tabular}{|c|c|c|c|c|c|c|c|c|}
\hline $\begin{array}{l}0 \\
10 \\
20 \\
30 \\
40 \\
50 \\
60 \\
70 \\
80 \\
90\end{array}$ & $\begin{array}{r}30 \\
130 \\
132 \\
133 \\
134 \\
145 \\
144 \\
143 \\
141 \\
140 \\
42\end{array}$ & $\begin{array}{l}0.638 \\
.629 \\
.620 \\
.602 \\
.589 \\
.584 \\
.571 \\
.567 \\
.576 \\
.604 \\
.638\end{array}$ & $\begin{array}{l}1.32 \\
1.23 \\
1.24 \\
1.25 \\
1.28 \\
1.38 \\
1.49 \\
1.53 \\
1.70 \\
1.79 \\
1.86\end{array}$ & $\begin{array}{r}69.2 \\
64.5 \\
67.6 \\
77.4 \\
96.0 \\
111.0 \\
125 \\
125 \\
108 \\
56 \\
16.8\end{array}$ & $\begin{array}{l}0.017 \\
.027 \\
.038 \\
.048 \\
.059 \\
.069 \\
.080 \\
.090 \\
.101 \\
.112 \\
.190\end{array}$ & $\begin{array}{l}0.95 \\
.91 \\
.89 \\
.86 \\
.82 \\
.78 \\
.76 \\
.75 \\
.72 \\
.65 \\
.55\end{array}$ & $\begin{array}{r}75.9 \\
71.0 \\
76.0 \\
90.0 \\
117.0 \\
142 \\
165 \\
167 \\
150 \\
86.0 \\
30.5\end{array}$ & $\begin{array}{l}3.65 \\
4.18 \\
4.38 \\
5.06 \\
5.74 \\
5.07 \\
5.46 \\
4.40 \\
3.06 \\
1.39 \\
.44\end{array}$ \\
\hline
\end{tabular}

\section{EXPERIMENTAL METHOD}

The experiments for determining the resistance to flow of gases were run in exactly the same manner as for sized materials, the only new feature of the work being the methods of mixing the different sizes of materials. Since there is always a strong tendency for segregation of sizes in systems such as are now being considered, considerable care had to be exercised in getting uniform mixtures. Uniform mixing was accomplished by placing the body of materials to be tested in a thin layer on a wide pan, then slowly pouring this material into a short, wide-mouthed reagent bottle, finally pouring the material from the bottle into the tube (the bottle being kept in rotation during pouring) in which the resistance to flow of gases was determined. In each instance in which the mixture of materials was poured from the container of large cross-sectional area to one of smaller area the vertical segregation of large and small sizes of materials which tended to take place was partly neutralized by the horizontal stream-line movement of the whole stock as it was poured into the succeeding receptacle. In some instances it was necessary to repeat the cycle of pouring the material from one vessel to another several times to get a uniform distribution, but the final results appeared to be satisfactory in all instances. It was necessary to pour the mixtures of materials into the tube quite slowly, so that each particle 
(1) Pressure drop per unit length of column at a flow of 0.1 liter per second per square centimeter, (2) exponent $B$ of equation (1), (3) coefficient $A$ of equation (1) (pressure drop at unit flow), (4) voids in bed, and (5) specific volume of bed.

\section{TABLE 8.-Data on two-component systems}

SYSTEM-NO. 000+NO. 12 SHOT

[No. 000 shot $-d=0.905$ centimeter; No. 12 shot $-d=0.138$ centimeter]

\begin{tabular}{|c|c|c|c|c|c|c|c|c|}
\hline $\begin{array}{c}\text { Volume per cent large } \\
\text { constituent }\end{array}$ & $\begin{array}{l}\text { No. of } \\
\text { run }\end{array}$ & $\begin{array}{c}\text { Voids in } \\
\text { bed, } \\
\text { normal } \\
\text { packing } 1\end{array}$ & $\underset{B^{2}}{\text { Observed }}$ & $\underset{A^{2}}{\text { Observed }}$ & $\begin{array}{c}d / D^{3}, \\
\text { linear } \\
\text { inter- } \\
\text { polation }\end{array}$ & $A_{t}^{4}$ & $A_{\infty} \delta$ & $\begin{array}{l}\triangle P_{s_{\infty}} \text { at } \\
2 R=0.1\end{array}$ \\
\hline $\begin{array}{l}0 \\
10 \\
20 \\
30 \\
50 \\
60 \\
80 \\
90\end{array}$ & $\begin{array}{r}53 \\
94 \\
95 \\
96 \\
97 \\
98 \\
99 \\
100 \\
101 \\
102 \\
65\end{array}$ & $\begin{array}{l}0.414 \\
.403 \\
.382 \\
.357 \\
.332 \\
.307 \\
.289 \\
.266 \\
.291 \\
.360 \\
.414\end{array}$ & $\begin{array}{l}1.41 \\
1.43 \\
1.46 \\
1.51 \\
1.49 \\
1.51 \\
1.54 \\
1.54 \\
1.55 \\
1.68 \\
1.79\end{array}$ & $\begin{array}{r}76.0 \\
84.0 \\
85.0 \\
100.0 \\
115.0 \\
132.0 \\
139.0 \\
147.0 \\
101.0 \\
43.0 \\
13.0\end{array}$ & $\begin{array}{r}0.030 \\
.040 \\
.060 \\
.070 \\
.090 \\
.100 \\
.110 \\
.130 \\
.140 \\
.160 \\
.170\end{array}$ & $\begin{array}{l}0.93 \\
.90 \\
.87 \\
.86 \\
.84 \\
.82 \\
.81 \\
.80 \\
.79 \\
.75 \\
.70\end{array}$ & $\begin{array}{r}83 \\
82 \\
98 \\
106 \\
137 \\
161 \\
170 \\
184 \\
128 \\
57 \\
18\end{array}$ & $\begin{array}{l}\text { 3. } 34 \\
\text { 3. } 11 \\
\text { 3. } 40 \\
\text {. } 84 \\
\text {. } 35 \\
4.82 \\
4.87 \\
5.13 \\
3.30 \\
1.13 \\
.29\end{array}$ \\
\hline
\end{tabular}

SYSTEM-NO. $000+$ NO. 8 SHOT

[No. 000 shot $-d=0.905$ centimeter; No. 8 shot $-d=0.227$ centimeter]

\begin{tabular}{|c|c|c|c|c|c|c|c|c|}
\hline $\begin{array}{l}0 \\
10 \\
20 \\
40 \\
50\end{array}$ & $\begin{array}{r}58 \\
103 \\
104 \\
105 \\
106 \\
107 \\
108 \\
109 \\
110 \\
111 \\
-\quad 65\end{array}$ & $\begin{array}{r}0.384 \\
.376 \\
.364 \\
.347 \\
.335 \\
.324 \\
.301 \\
.298 \\
.309 \\
.364 \\
.414\end{array}$ & $\begin{array}{l}1.58 \\
1.60 \\
1.61 \\
1.62 \\
1.62 \\
1.63 \\
1.64 \\
1.66 \\
1.70 \\
1.76 \\
1.79\end{array}$ & $\begin{array}{l}66.5 \\
66.9 \\
70.8 \\
74.6 \\
73.8 \\
77.3 \\
83.0 \\
76.3 \\
62.8 \\
32.0 \\
13.0\end{array}$ & $\begin{array}{l}0.040 \\
.052 \\
.064 \\
.077 \\
.089 \\
.101 \\
.114 \\
.127 \\
.139 \\
.154 \\
.170\end{array}$ & $\begin{array}{l}0.90 \\
.87 \\
.86 \\
.85 \\
.83 \\
.81 \\
.78 \\
.76 \\
.74 \\
.72 \\
.70\end{array}$ & $\begin{array}{r}74.0 \\
75.0 \\
82.3 \\
87.8 \\
89.0 \\
85.5 \\
107.0 \\
100.0 \\
84.9 \\
44.5 \\
18.0\end{array}$ & $\begin{array}{l}1.57 \\
1.93 \\
2.02 \\
2.13 \\
2.12 \\
2.24 \\
2.44 \\
2.20 \\
1.69 \\
.78 \\
.29\end{array}$ \\
\hline
\end{tabular}

SYSTEM-NO. $000+$ NO. B SHOT

[No. 000 shot $-d=0.905$ centimeter; No. B shot $-d=0.450$ centimeter]

\begin{tabular}{|c|c|c|c|c|c|c|c|c|}
\hline $\begin{array}{l}0 \\
10 \\
20 \\
30 \\
50\end{array}$ & $\begin{array}{r}56 \\
112 \\
113 \\
114 \\
115 \\
116 \\
117 \\
118 \\
119 \\
120 \\
65\end{array}$ & $\begin{array}{r}0.394 \\
.381 \\
.368 \\
.365 \\
.368 \\
.366 \\
.368 \\
.369 \\
.380 \\
.392 \\
.414\end{array}$ & $\begin{array}{l}\text { 1. } 71 \\
1.73 \\
1.74 \\
1.76 \\
1.77 \\
1.78 \\
1.78 \\
1.79 \\
1.79 \\
1.79 \\
1.79\end{array}$ & $\begin{array}{l}28.5 \\
30.5 \\
30.4 \\
31.3 \\
29.9 \\
28.6 \\
27.2 \\
25.6 \\
21.0 \\
17.9 \\
13.0\end{array}$ & $\begin{array}{l}0.080 \\
.090 \\
.098 \\
.107 \\
.116 \\
.125 \\
.136 \\
.143 \\
.152 \\
.162 \\
.170\end{array}$ & $\begin{array}{l}0.82 \\
.80 \\
.79 \\
.78 \\
.77 \\
.76 \\
.75 \\
.74 \\
.73 \\
.72 \\
.70\end{array}$ & $\begin{array}{l}34.9 \\
38.2 \\
38.5 \\
40.1 \\
38.9 \\
37.6 \\
36.3 \\
34.6 \\
28.8 \\
24.9 \\
18.0\end{array}$ & $\begin{array}{l}0.68 \\
.71 \\
.70 \\
.71 \\
.66 \\
.63 \\
.60 \\
.57 \\
.59 \\
.40 \\
.29\end{array}$ \\
\hline
\end{tabular}

SYSTEM-NO. 000 SHOT+28 TO 35 MESH CUYUNA ORE

[No. 000 shot $-d=0.905$ contimeter; 28 to 35 mesh Cuyuna ore $-d=0.04$ centimeter]

\begin{tabular}{|c|c|c|c|c|c|c|c|c|}
\hline $\begin{array}{l}0 \\
10 \\
20 \\
30 \\
50\end{array}$ & $\begin{array}{r}71 \\
121 \\
122 \\
123 \\
124 \\
125 \\
126 \\
127 \\
128 \\
129 \\
65\end{array}$ & $\begin{array}{l}0.651 \\
.617 \\
.590 \\
.563 \\
.512 \\
.466 \\
.418 \\
.372 \\
.319 \\
.366 \\
.414\end{array}$ & $\begin{array}{r}0.95 \\
.95 \\
.95 \\
.95 \\
.97 \\
1.00 \\
1.02 \\
1.04 \\
1.14 \\
1.25 \\
1.79\end{array}$ & $\begin{array}{r}98.5 \\
109.0 \\
121.0 \\
133 \\
175 \\
250 \\
310 \\
327 \\
303 \\
209 \\
13\end{array}$ & $\begin{array}{r}+0.000 \\
.015 \\
.027 \\
.039 \\
.050 \\
.061 \\
.072 \\
.083 \\
.094 \\
.106 \\
.170\end{array}$ & $\begin{array}{r}-1.00 \\
.95 \\
.93 \\
.91 \\
.89 \\
.89 \\
.89 \\
.90 \\
.90 \\
.88 \\
.77\end{array}$ & $\begin{array}{l}98.5 \\
115.0 \\
130 \\
146 \\
196 \\
281 \\
348 \\
364 \\
337 \\
238 \\
18\end{array}$ & $\begin{array}{l}11.1 \\
13.0 \\
14.7 \\
16.5 \\
21.0 \\
28.1 \\
33.2 \\
33.3 \\
24.4 \\
13.4 \\
.29\end{array}$ \\
\hline
\end{tabular}

1 Defined on p. 18. Defined on p. 42.

a Defined on p. 6.
s Defined on p. 6. 
increases the layer of small particles at the bottom of each void becomes thinner, tending to make the expansion chamber larger and the pressure drop greater. $\Lambda$ s the proportion of large particles increases, the number of these nozzle-expansion chamber arrangements increases, thus making the pressure drop greater. After the percentage of the larger component becomes larger than a certain value many of: the large voids will not have a layer of small particles at the bottom to act as an entering constriction, so the expansion-chamber effect should rise to a maximum and then decrease.

3. As the proportion of the large material in the bed becomes larger there will be portions of the bed that will be made of unobstructed groups of the larger particles; consequently for these portions of the bed the pressure drop should be less than for other portions and will tend to decrease the pressure drop throughout the bed as a whole.

The author's conception of the qualitative effect of these factors is shown in Figure 42. It has not been possible to analyze data to make experimental evaluation for the effect of the separate factors, but it can be seen from Figure 42 that if the pressure drop for a constant rate of flow is plotted against the size composition for

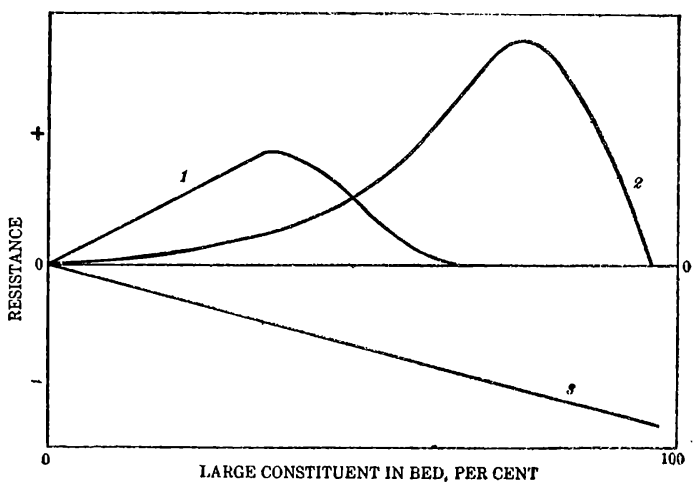

FIGURE 42.-Components of resistance in a bed of mixed sizes

a two-component system the curve should rise to a maximum and then decrease as the percentage of large particles becomes greater.

\section{FORMER WORK}

A small amount of work on analyzing the effects of mixing sizes was done at the Pittsburgh Experiment Station. of the United States Bureau of Mines. ${ }^{18}$. The data obtained at that time were very incomplete, but the authors deduced from their results that the resistance to gas flow should rise to a maximum as the percentage of large material was increased.

\section{MATERIALS OF THIS INVESTIGATION}

In the present investigation of two-component systems the materials used were Cuyuna ore and lead shot. The data on the principal systems are given in Table 8 . This report considers variations of the following quantities with change of composition of the bed:

18 Brooks, H. W., Nicholls, P., Augustine, C. E., and Orr, M. L., Pressures Required To Force Air Through Sized Anthracite: Rept. of Investigations, Bureau of Mines, February, 1926 (not published). 
Equation (40) is the equation of a straight line of specific volume as a function of $X$ where $X$ is the weight fraction of the large particles.

When $X$ is 0

$$
\text { Specific volume }=\frac{1}{S_{1}\left(1-V_{2}\right)},
$$

which is the specific volume of a bed of the small component.

When $X=1$ (or 100 per cent)

$$
\text { Specific volume }=\frac{1}{S_{1}},
$$

which is the reciprocal of the true specific gravity of the large component.

Therefore, if large particles are introduced into a bed of infinitely small ones the specific volume curve will be the straight line $C D$ of Figure 54. However, as soon as the line crosses the line $A B$ the system becomes hypothetical, for it has been shown that the line $A B$ represents the lower limit of possible specific volume. Therefore, as the composition of the system passes beyond the abscissa value of $B$ it must follow the line $A B$. Therefore the triangle $A B C$ represents the possible field of existence of the binary system.

Proof that point $B$ as determined by the intersection of the lines $A O, O$, and $C D$ is the same as the "saturation point" specified by equation (36) follows.

Equation of line $C D$.

$$
\text { Specific volume }=\frac{1-X}{\overline{S_{2}\left(1-\overline{V_{2}}\right)}}+\frac{X}{S_{1}} .
$$

Since the line $A B$ passes through the origin.

Equation of line $A B$

$$
\text { Specific volume }=\frac{X}{S_{1}\left(1-V_{1}\right)},
$$

for $\frac{1}{S_{1}\left(1-V_{1}\right)}$ is the specific volume of the system at $X=1$ (or 100 per cent).

At the point of intersection the specific volumes as expressed by equations (40) and (42) must be equal or

$$
\begin{gathered}
\frac{X}{S_{1}\left(1-V_{1}\right)}=\frac{1-X}{S_{2}\left(1-\overline{V_{2}}\right)}+\frac{X}{S_{1}} . \\
X\left[S_{2}\left(1-V_{2}\right)+S_{1}\left(1-V_{1}\right)-S_{2}\left(1-V_{2}\right)\left(1-V_{1}\right)\right]=S_{1}\left(1-V_{1}\right) .
\end{gathered}
$$

Simplifying,

$$
X=\frac{S_{1}\left(1-V_{1}\right)}{\left(1-V_{1}\right) S_{1}+V_{1}\left(1-V_{2}\right) S_{2}} .
$$

The equation is identical with equation (36); therefore the point of intersection is the true saturation point.

\section{ERRORS IN OBSERVATION}

It will be noted that a few of the observed data points in Figure 55 lie outside the field specified for their possible existence. These discrepancies are due entirely to experimental error-that is, the small variations in degree of packing that are unavoidable. The percentage error in all cases is quite small.

The data that have just been discussed have been generalized and plotted in relative values in Figure 56 fọ various size ratios. The 
curves are for binary systems of 50 per cent voids in both components with both components having the same true specific gravity. Variations from these conditions can be accounted for by computations with the preceding equations, but Figure 56 gives the approximate quantitative relations for most systems that will be met in practice.

\section{APPLICATIONS}

The foregoing discussion applies only indirectly to the resistance to gas flow through columns of broken solids, but it does have value when broken solids are to be packed with a regard to volume occupied.

Thus, Figure 54 shows that when 30 per cent of No. 12 shot was introduced into a bed of No. 000 shot the total volume of the system

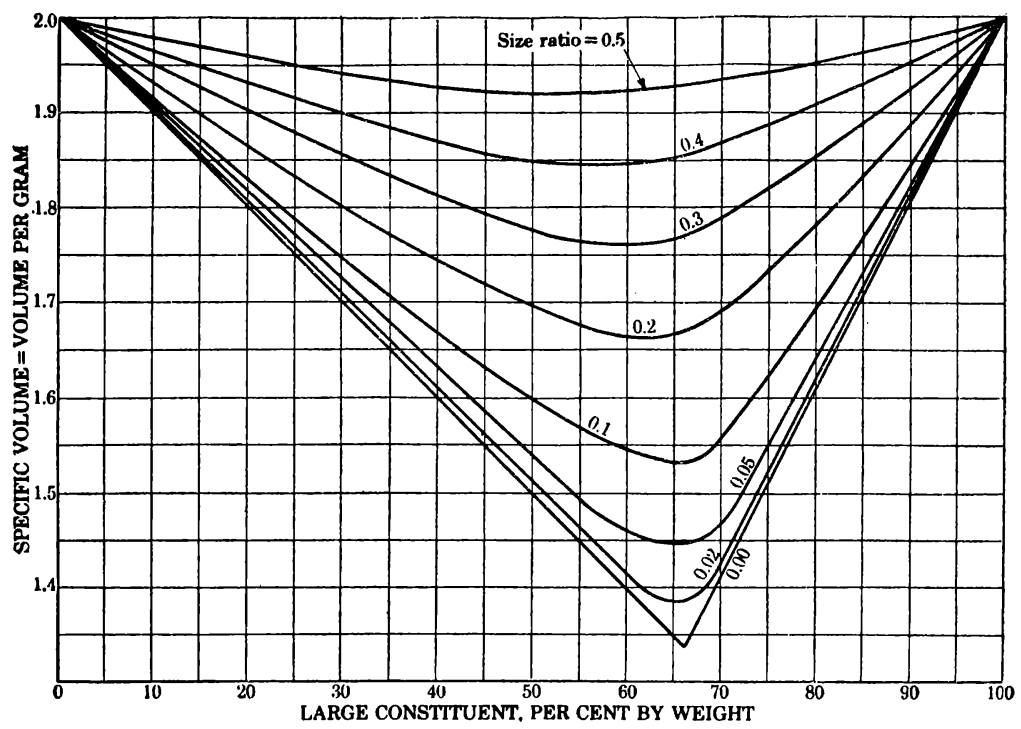

FIGURE 56.-Approximate specific volumes for different size ratios in 2-component systems in which true gravity of each component $=1$ and normal voids for each component $=0.50$

was 21 per cent less than it would have been if each material were packed separately.

For the conditions represented in Figure 56 it will be seen that if 33 per cent of very fine material was introduced into the bed of large pieces there would be a volume saving of 33.5 per cent.

These figures should have interest to coke-oven operators and persons interested in storing and shipping materials of nonuniform size. The capacity of one set of coke ovens was materially increased by making a change of a few per cent in the percentage of fine material in the charge.

SYSTEMS OF MORE THAN TWO COMPONENTS

Systems of more than two components will have greater specific volumes than binary systems except when the smallest component 
is very small and represents the bulk of the material. Under those conditions it would not make a great deal of difference about the size distribution of the large constituents.

\section{SYSTEMS INVOLVING A LIQUID}

A liquid may be considered as a component of particles of infinitely small size with no voids. In Figure 57 have been plotted the lines for the specific volume of a mixture of water and Cuyuna ore of any size but of specific gravity 3.33 and normal voids 0.638 . It will be observed that the minimum specific volume for the system occurs at 65 per cent ore by weight and that at this point the total volume is 61 per cent of what it would be if the two components were separated. Experimenters attempting to verify this curve quantitatively would

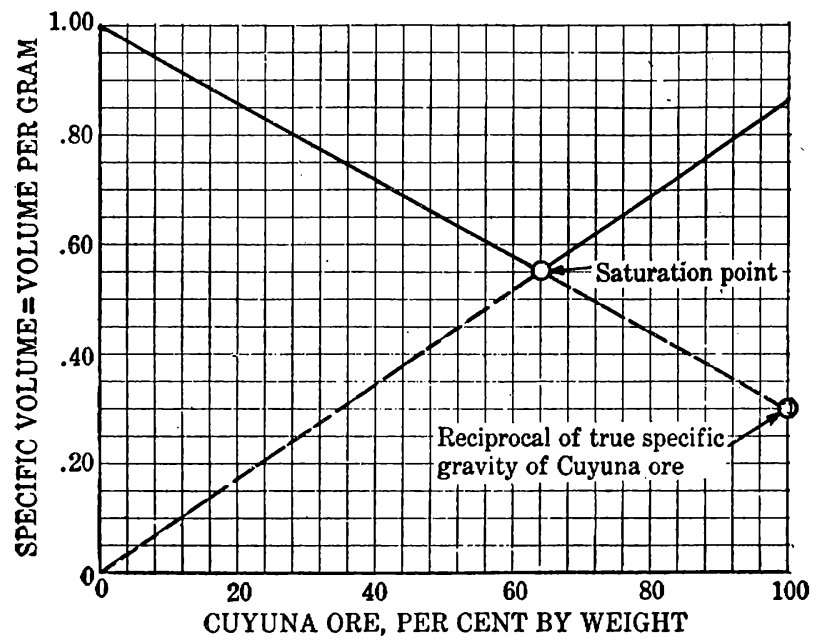

FigURE 57.-Theoretical specific volume of a mixture of water and Cuyuna ore for various concentrations

probably be harassed by wetting and adsorption phenomena. These data should be of interest when volume is an item in storing or handling sludges.

\section{GAS FLOW THROUGH SYSTEMS OF MORE THAN TWO COMPONENT SIZES}

EXPERIMENTAL METHOD

A number of data have been taken on systems that are mixtures of a number of sizes. The method of measuring resistance was essentially the same as in the foregoing experiments.

\section{APPARATUS}

Most of the experimental work was done in a cylinder approximately 38 centimeters in diameter and 93 centimeters high. Air was used in all of the experiments and was supplied by a compressor 
capable of delivering 165 liters per second. The rate of flow of the gas entering the cylinder was measured by means of a thin plate orifice. The equations used for computing the rates of flow through the orifice were those employed in standard practice..$^{20}$

The orifice was 2.08 centimeters in diameter concentrically placed in pipes 10.3 centimeters in diameter; upstream pressure lead 8 centimeters from plate, downstream pressure lead 4 centimeters from plate. At a flow of 164 liters per second it was found that the orifice coefficient was 0.80 . From characteristics of fluid flow through orifices ${ }^{21}$ it was estimated that the orifice coefficient at low rates of flow would be 0.70 .

The following equations were used for this particular orifice at a temperature of $27^{\circ} \mathrm{C}$.:

$P_{1}=$ total upstream pressure in centimeters of mercury.

$P_{2}=$ total downstream pressure in centimeters of mercury.

$R=$ rate of flow in liters per second, standard conditions.

(a) When $P_{2} / P_{1}<0.53$,

$$
R=0.655 P_{1}
$$

(b) when $P_{2} / P_{1}>0.53<0.83$,

$$
R=2.32 P_{1} \sqrt{\left(P_{2} / P_{1}\right)^{1.421}-\left(P_{2} / P_{1}\right)^{1.712}} ;
$$

(c) when $P_{2} / P_{1}>0.83<0.91$,

$$
R=139.6 \sqrt{\log _{10} P_{1}} / P_{2}
$$

(d) when $P_{2} / P_{1}>0.91<1.00$,

$$
R=0.3445 \sqrt{P_{1}-P_{2}} .
$$

For all equations $R$ varies directly as $P_{2}$ and inversely as the square root of the absolute temperature ${ }^{\circ} \mathrm{C}$.

A diagram of the apparatus is given in Figure 59. Photographs are shown in Figure 58, $A$ and $B$.

The bottom of the cylinder was covered with a 10-centimeter layer of iron balls 5 centimeters in diameter to break up the gas stream and distribute it uniformly across the bed of material. The lower pressure-drop lead was fastened into the tube above the bed of iron balls by means of a 6-hole piezometer ring. The upper pressure-drop lead was placed 66 centimeters above the lower bed.

\section{EXPERIMENTAL PROCEDURE}

The general principles of experimentation are the same as those discussed in the first part of this report. The materials are placed in the cylinder on top of the bed of iron balls, the height of the column is measured, and air is blown through the bed, the pressure drop

${ }^{20}$ See Walker, W. II., Lewis, W. K., and McAdams, W. H., Principles of Chemical Engineering: New York, 1923, p. 93.

21 Judd, Horace, Experiments on Water Flow Through Pipe Orifices: Jour. Am. Soc. Mech. Eng., vol. 38, 1916, p. 709. 
Bureau of Mines

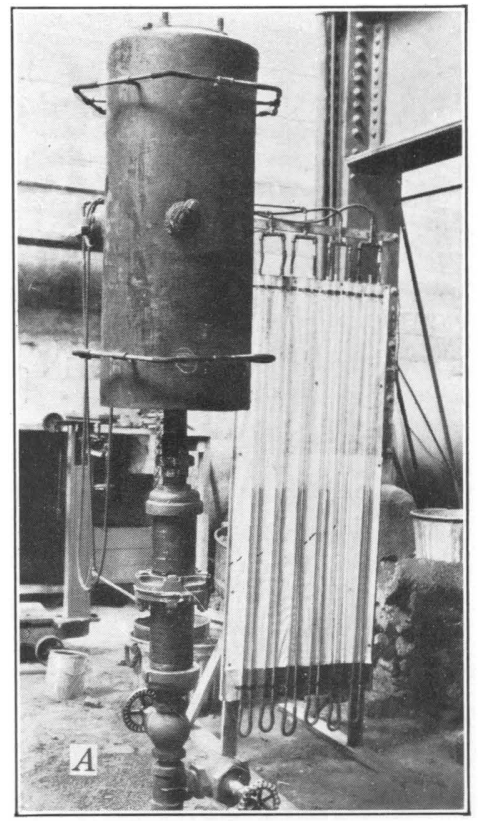

Bulletin 307

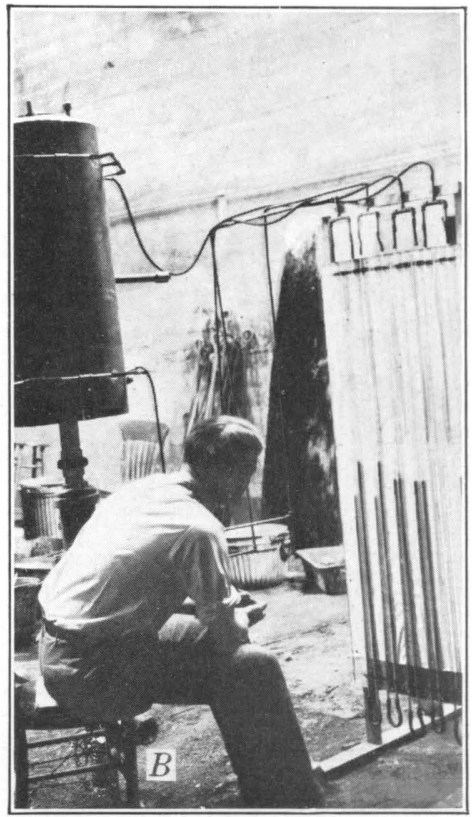

FIGURE 58.-Views of apparatus for determining pressure drop through systems of mixed sizes 

being noted for each flow. The flow is measured by means of the pressure drop through the orifice below the cylinder. As the flow is increased a point is reached at which the fine particles are lifted from the bed and dance in the air stream, some of the fine material being

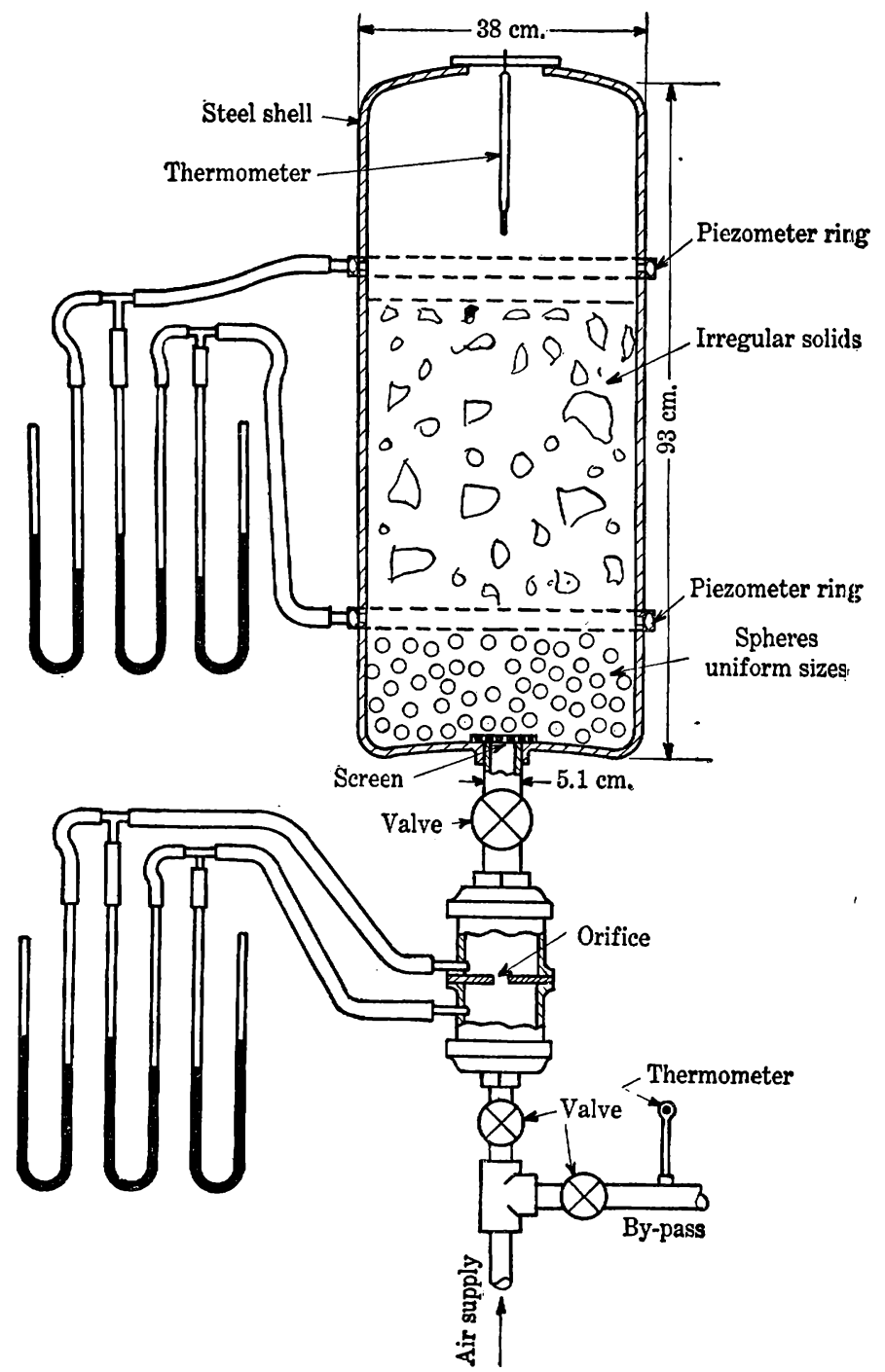

FiguRe 59.-Apparatus for determining pressure drop through beds of mixed sizes

blown out of the apparatus. At this point the pressure drops, usually to a small fraction of its original value. The rate of air flow is increased further to determine the law of flow when the fine particles were lifted. The apparatus and materials are handled with a crane. The rate of air flow is varied by by-passing some of the air 
from a line that is carrying a constant flow of 165 liters per second from the air compressor.

If the charge is a mixture of two or more different materials, the mixing done outside the apparatus on a steel floor in the same manner that concrete is hand-mixed by "cutting." The materials are

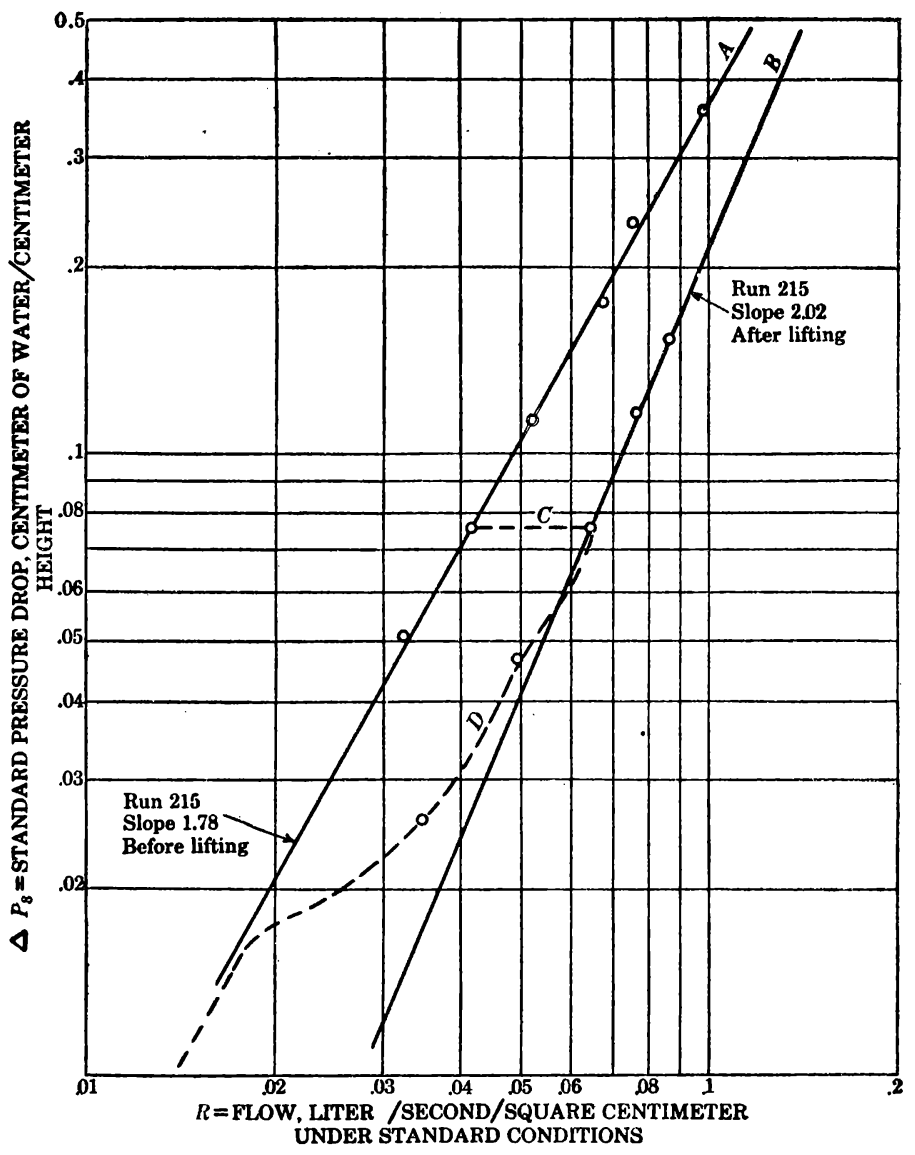

FIGURE 60.-Typical data for a bed of material in which fine particles are lifted. Charge: 63.9 per cent Illinois Steel Co.'s blast-furnace ore charge, 25.6 per cent coke, 10.5 per cent limestone, all uniformly mixed

then dropped into the cylinder slowly and carefully to give normal packing.

The temperature is recorded by a mercury thermometer suspended in the gas stream above the bed. A small error is introduced here, for the temperature at the bottom of the column might be several degrees warmer than that at the top, but this error is much smaller than others that occur in this type of experiment. 


\section{CONSIDERATION OF TYPICAL DATA}

The data obtained in this series of experiments were not as precise and clean cut as those obtained in the work on one and two component systems because of the mobility of the fine particles in the bed. Two typical sets of data are shown in Figures 60 and 61 . The pressure drops are plotted against rates of flow for both before and after the lifting of the fine particles from the bed. Both axes are graduated in the logarithmic scale. If the pressure drop follows the law of equation (1), the curves should be straight lines.

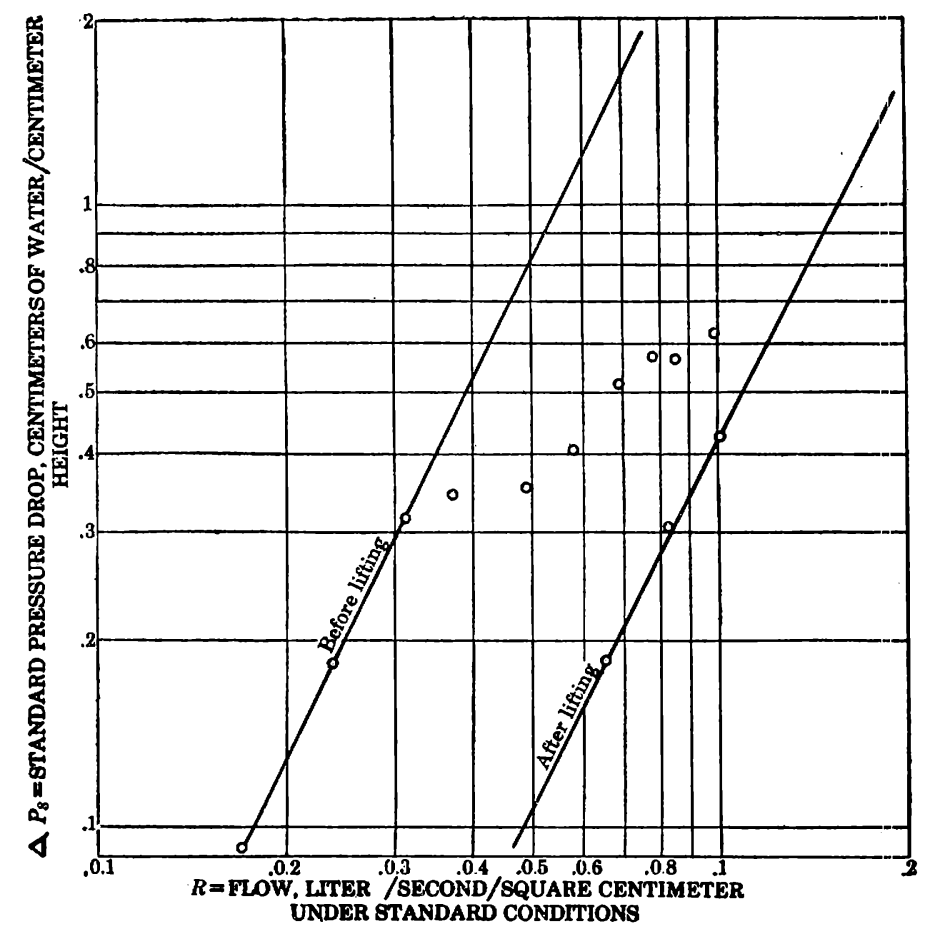

Figure 61.-Pressure drop in a bed containing a great deal of fine material; run 208

Figure 60 presents the data for a uniformly mixed Illinois Steel Co. blast-furnace charge. Curve $A$ is for a quiet bed. A straight line represents the trend of these data quite satisfactorily. Just before reaching the rate of flow $=0.1$ the fine particles lifted from the bed and the pressure dropped to about 50 per cent of its original value. The flow of 0.1 liter per second per square centimeter was almost the maximum attainable with the apparatus at hand, so the pressure drop after blowing had to be studied at rates of flow less than that required for the initial lifting of the fines.

The fine material remained lifted and danced in the gas stream until the flow was reduced to about 0.06 liter per second per square 
centimeter, then part of the fine particles began to settle back into the bed. This shows that the pressure required to cause the initial lifting was much greater than was required to maintain it, in much the same manner that water may be supercooled without freezing. Before the fines lifted when the flow was between 0.06 and 0.10 the system might be spoken of as "superblown."

Curve $B$ represents the data with the fine particles lifted. It will be noted that as the flow decreased below 0.06 liter per second per square centimeter the observed pressure-drop data were higher than the straight line $B$. These higher values were caused by the fine particles settling back in to the bed, thus increasing its resistance.

The author has drawn a dotted curve, $D$, which he believes would be the approximate course of curve $B$ if no fines had been lost in the blowing and if they were all allowed to settle back into place. However, much of the finest material was always blown out of the apparatus, so curve $D$ could never quite be realized.

The author feels that the straight line $C$ would represent the course of the pressure drop between the states represented by curves $A$ and $B$, provided there were no lag in the lifting and settling of the particles. The pressure drop at $C$ might be called the "critical pressure" for this particular system. Such a curve as $C$ is not realizable in practice because of the inevitable lag in the lifting of the particles.

The data of Figure 61 are for a system in which there is a greater percentage of fine material in the bed. The degree of superblowing is much less here than in the former case. After the particles began to lift and the data points began to drop away from the curve $A$ the pressure drop increased very little with increase in rate of flow. This might be caused by an increasing degree of lifting in the bed as flow increased. The lifting was not uniform all the way across the bed because of the inevitable occurrence of small pockets and channels in a system of such large variance in sizes (500 to 1). These can only be eliminated by having a relatively very large body of material, so that minor variations in the bed are of little consequence.

In the system represented in Figure 60, when the rate of flow became approximately 0.1 liter per second per square centimeter, all of the fines were lifted throughout the bed, and the pressure dropped to the normal variation of curve $B$.

VARIABILITY OF TRANSITION STAGE

The stage of transition between a system in which the fines are not lifted and that in which the fines are all lifted is too indefinite and variable to be subject to study, so only the conditions represented by the two limiting conditions will be studied. 


\section{MATERIALS STUDIED}

The constituent materials used in the study of systems of many components were coke, Mesabi iron ore, Cadiz iron ore, flue dust, flue-dust sinter, vessel slag, roll scale, and limestone, from the Illinois Steel Co. of South Chicago, Ill.; three different sizes of ore and one size of coke from the Columbia Steel Co. at Provo, Utah; Vermilion iron ore; and Cuyuna iron ore. Data were taken on these materials or their mixtures or both. All of the data are summarized in Table 9. This table also gives limited information on common sand, fine sand, stone dust, and dry soil, computed from the data of another investigator. $^{22}$ The table is divided into two sections, giving the data for before and after lifting of the fine particles. The physical constants of the constituent materials are given in Table 10 and the screen analyses

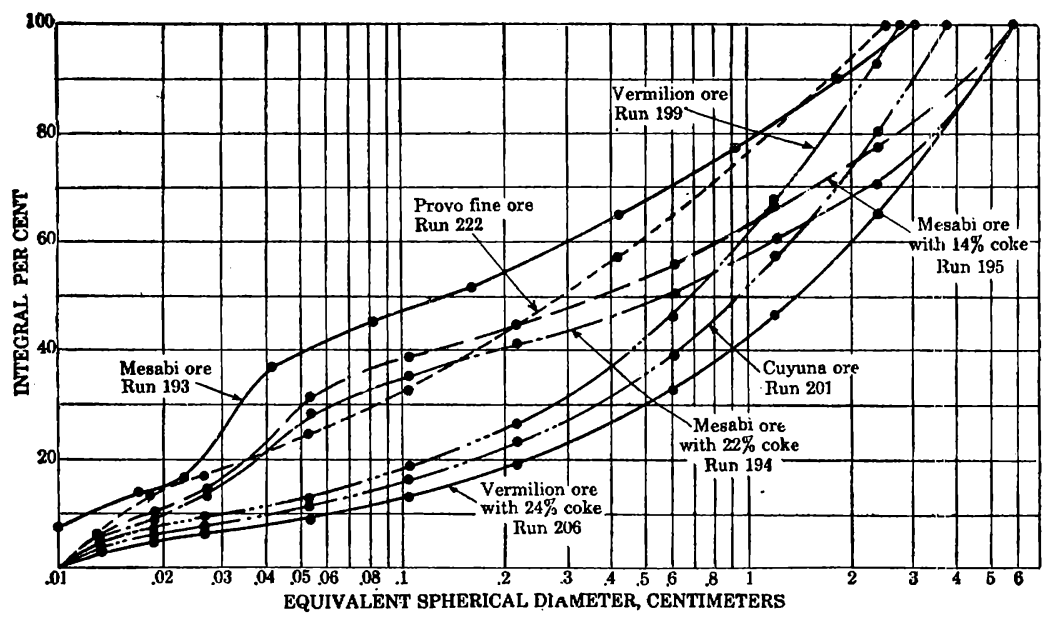

Figure 62.-Size analyses of some systems of many components

of the materials in Tables 11 and 12 . The cumulative percentages of the screen analyses are plotted in Figure 62.

Table 9 is self-explanatory with the aid of the footnotes.

The value of exponent $B$ for polycomponent systems can be obtained accurately enough from Figure 63, relating $B$ and "resistance factor," if $d$ is considered the geometrical mean of the diameters.

$$
\text { Symbolically, resistance factor }=\Sigma\left(\frac{\text { per cent }}{\sqrt{\bar{d}_{1} d_{2}}}\right)^{J},
$$

where $J$ varies between 1 and 1.25 (see fig. 38), where $d_{1}$ and $d_{2}$ are the limiting diameters in a certain size fraction of the material and per cent stands for the fraction by volume in that

${ }^{22}$ Storrow, John T., The Flow of Air Through Small Coal and Other Broken Materlal: 'Trans. Inst. Min. Eng., vol. 55, 1918, pp. 313-317.

$43318^{\circ}-29-7$ 
particular size division. It is immaterial how many size divisions are made in the evaluation except that the greater the number of terms the greater the accuracy. The symbol $\Sigma$ stands for the sum of all the different terms.

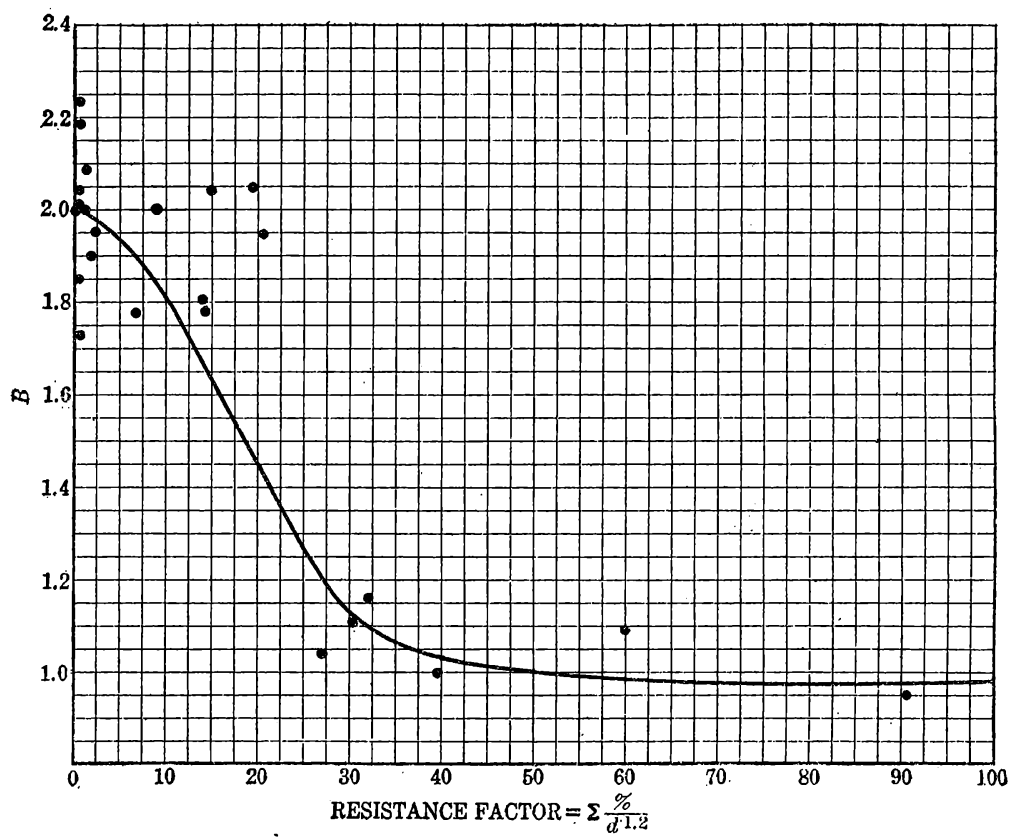

FIGURE 63.- Relation between resistance factor and $B$ for systems of mixed sizes

It is commensurate with the accuracy of the rest of the determination simply to consider the reciprocal of the diameter $d$ to be equal to the geometric mean of the reciprocal screen sizes used to analyze the materials. If the gas velocity is sufficient to lift the fine material from the bed, exponent $B$ for air at room temperature may usually be considered $=2.0$. 
TABLE. 9-Systems of mixed sizes

[Screen analyses in Table 10. Experimental cylinder 38.1 centimeters in diameter, unless otherwise stated]

\begin{tabular}{|c|c|c|c|c|c|c|c|c|c|c|}
\hline \multirow{3}{*}{ Material 1} & \multirow[b]{2}{*}{ Run No. } & \multirow[b]{2}{*}{$\begin{array}{l}\text { Approxi- } \\
\text { mate } \\
\text { voids }\end{array}$} & \multicolumn{8}{|c|}{ Static beds } \\
\hline & & & $\begin{array}{l}\text { Average } \\
d \text {, centi- } \\
\text { meters }{ }^{2}\end{array}$ & $d / D$ & $\begin{array}{l}\text { Wall- } \\
\text { effect } \\
\text { factor }{ }^{3}\end{array}$ & $\underset{B^{4}}{\text { Observed }}$ & $\begin{array}{l}\text { Com- } \\
\text { puted } \\
\Delta P_{S} \text { at } \\
R=0.1\end{array}$ & $\begin{array}{c}\text { Observed } \\
\Delta P_{s} \text { at } \\
R=0.1\end{array}$ & $\underset{R=0.1}{\triangle P_{S \infty}}$ & $A_{\infty}{ }^{6}$ \\
\hline & $\mathbf{1}$ & 2 & 3 & 4 & 5 & 6 & y & 8 & 9 & 10 \\
\hline $\begin{array}{l}\text { Illinois Steel CQ. coke. } \\
\text { Run-of-mine Mesabi ore } \\
95.7 \text { per cent Mesabi ore }+4.3 \text { per cent Illinois Steel Co. coke }\end{array}$ & $\begin{array}{l}200 \\
193 \\
195 \\
194\end{array}$ & $\begin{array}{r}0.55 \\
.43 \\
.37 \\
.38\end{array}$ & $\begin{array}{l}5.74 \\
.74 \\
1.39 \\
1.78\end{array}$ & $\begin{array}{r}0.151 \\
.048 \\
.090 \\
.116\end{array}$ & $\begin{array}{r}0.55 \\
.92 \\
.88 \\
.86\end{array}$ & $\begin{array}{l}2.00 \\
1.01 \\
1.16 \\
1.11\end{array}$ & $\begin{array}{l}0.109 \\
8.49 \\
-8.30\end{array}$ & $\begin{array}{c}0.011 \\
8.86 \\
91.36 \\
9.99\end{array}$ & $\begin{array}{r}0.020 \\
8.92 \\
81.55 \\
81.15\end{array}$ & $\begin{array}{r}2.0 \\
96.5 \\
4670 \\
190\end{array}$ \\
\hline $\begin{array}{l}\text { Typical } 10 \text { Illinois Steel Co. blast-furnace ore charge }{ }^{11} \text { without coke or lime- } \\
\text { stone }\end{array}$ & 207 & .38 & .61 & .016 & .94 & $1.90 ?$ & 16.5 & 19.0 & 20.2 & 1550 \\
\hline $\begin{array}{l}64.3 \text { per cent Illinois Steel Co. blast-furnace ore charge }+12.4 \text { per cent coket } \\
10.9 \text { per cent limestone, uniformly mixed }+12.4 \text { per cent layer of coke- } \\
63.9 \text { per cent Illinois } S \text { teel } C \text { Co. blast-furnace ore charge }+25.6 \text { per cent coke }\end{array}$ & 208 & .34 & 3.29 & .086 & .78 & 2.05 & 6.9 & 123.4 & 124.36 & 12512 \\
\hline $\begin{array}{l}\text { +10.5 per cent limestone, uniformly mixed } \\
\text { Vermilion ore }\end{array}$ & $\begin{array}{l}215 \\
199\end{array}$ & $\begin{array}{l}.33 \\
.39\end{array}$ & $\begin{array}{r}3.93 \\
.99\end{array}$ & .103 & $\begin{array}{l}.80 \\
.91\end{array}$ & $\begin{array}{l}1.78 \\
1.95\end{array}$ & 4.8 & $12.0^{36}$ & 13.2 & 1200 \\
\hline Vermilion ore saturated with water & 204 & .41 & .99 & .046 & .91 & 2.00 & & 1.80 & 1.97 & 197.0 \\
\hline $\begin{array}{l}92 \text { per cent Vermilion ore }+8 \text { per cent Illinois Steel Co. coke } \\
76 \text { per cent Vermilion ore }+24 \text { per cent coke (layered) }\end{array}$ & $\begin{array}{l}205 \\
206\end{array}$ & $\begin{array}{r}.41 \\
18.43\end{array}$ & $\begin{array}{r}1.70 \\
.99\end{array}$ & .045 & .86 & $\begin{array}{l}2.04 \\
2.00\end{array}$ & $\begin{array}{l}3.36 \\
4.8\end{array}$ & $\begin{array}{r}1.15 \\
121.90\end{array}$ & $\begin{array}{r}1.33 \\
12.09\end{array}$ & $12 \frac{148}{209}$ \\
\hline $\begin{array}{l}\text { Cuyuna ore } \\
\text { Coke of Columbia Steel Co., Provo, Utahb }\end{array}$ & $\begin{array}{l}201 \\
219\end{array}$ & $\begin{array}{r}.45 \\
.56\end{array}$ & $\begin{array}{l}1.19 \\
3.33\end{array}$ & $\begin{array}{l}.031 \\
.088\end{array}$ & $\begin{array}{l}.89 \\
.66\end{array}$ & $\begin{array}{l}1.95 \\
2.00\end{array}$ & $\begin{array}{l}4.6 \\
.03\end{array}$ & $\begin{array}{l}7.5 \\
.024\end{array}$ & $\begin{array}{l}8.43 \\
.036\end{array}$ & $\begin{array}{l}765 \\
3.6\end{array}$ \\
\hline Coarse Provo ore ${ }^{14}$ & 220 & .45 & 3.94 & .103 & .71 & 2. 19 & .034 & .035 & .049 & 7.5 \\
\hline Medium Provo ore ${ }^{14}$ & 221 & .47 & 2. 31 & .061 & .80 & 2. 27 & .072 & 077 & .096 & 19. 0 \\
\hline $\begin{array}{l}\text { Fine Provo ore } 14 \\
67 \text { per cent fine Provo ore }+16.7 \text { per cent coke uniformiy mixed }+16.6 \text { per }\end{array}$ & 222 & .40 & .49 & .013 & .98 & 1.04 & & 1.82 & 1.96 & 20.7 \\
\hline $\begin{array}{l}\text { cent coke layered above bed } \\
67 \text { per cent fine Provo ore }+33 \text { per cent coke, uniformly mixed }\end{array}$ & $\begin{array}{l}223 \\
224\end{array}$ & $\begin{array}{r}13.35 \\
.43\end{array}$ & $\begin{array}{l}1.90 \\
2.38\end{array}$ & $\begin{array}{l}.050 \\
.063\end{array}$ & .88 & $\begin{array}{l}1.80 \\
2.00\end{array}$ & & $\begin{array}{r}12.10 \\
.26\end{array}$ & $\begin{array}{ll}12 & 2.39 \\
.333\end{array}$ & $\begin{array}{r}12 \\
154 \\
33.3\end{array}$ \\
\hline $\begin{array}{l}\text { Provo ore, } 33.2 \text { per cent fine }+16.7 \text { per cent medium }+16.7 \text { per cent coarse }+ \\
16.7 \text { per cent coke, all uniformly mixed }+16.7 \text { per cent coke layered above } \\
\text { bed }\end{array}$ & 225 & ${ }^{13} .37$ & 2.57 & .068 & .83 & 1.78 & & 12.205 & 12.247 & 12150 \\
\hline $\begin{array}{l}\text { Provo ore, } 33.3 \text { per cent fine }+16.7 \text { per cent medium }+16.7 \text { per cent coarse }+ \\
33.3 \text { per cent coke, all nuiformi mixed }\end{array}$ & 226 & & 2.82 & 074 & -81 & 1.90 & & & , & - \\
\hline Common sand 15 & & No data. & .11 & .024 & .96 & 1.09 & & 9.146 & 9152 & 283. 0 \\
\hline Fine sand ${ }^{15}-$ & & No data. & .03 & .007 & .99 & .95 & & 16. 028 & 16. 028 & 176 \\
\hline $\begin{array}{l}\text { Stone dust } 15 \\
\text { Dry soil } 15\end{array}$ & & No data. & .09 & .020 & .97 & .92 & & $\begin{array}{l}16.285 \\
16\end{array}$ & 16.294 & 1400 \\
\hline Dry soil 15 & & No data. & .14 & .030 & & 1.05 & & ${ }^{16} .031$ & ${ }^{16 .} 033$ & 370 \\
\hline
\end{tabular}




\begin{tabular}{|c|c|c|c|c|c|c|c|c|c|c|}
\hline \multirow{3}{*}{ Material 1} & \multicolumn{8}{|c|}{ Particles finer than 14 mesh lifted by gas stream } & \multirow{2}{*}{$\begin{array}{c}A_{\infty}, \text { if } B \\
\text { were } \\
2.00\end{array}$} & \multirow{2}{*}{$\begin{array}{l}\text { Approxi- } \\
\text { mate } R \\
\text { for lifting } \\
\text { fines }\end{array}$} \\
\hline & $\begin{array}{l}\text { Average } \\
d \text {, centi- } \\
\text { meters }\end{array}$ & $d / D$ & $\begin{array}{l}\text { Wall- } \\
\text { effect } \\
\text { factor }{ }^{3}\end{array}$ & $\mid \underset{B^{4}}{\text { Observed }}$ & $\begin{array}{l}\text { Com- } \\
\text { puted } \\
\Delta P_{\mathcal{S}} \text { at } \\
R=0.1\end{array}$ & $\mid \begin{array}{c}\text { Observed } \\
\Delta P S \text { at } \\
R=0.1\end{array}$ & $\begin{array}{l}\Delta P_{s \infty} \\
R=0.1\end{array}$ & $A_{\infty}{ }^{6}$ & & \\
\hline & 11 & 12 & 13 & 14 & 15 & 16 & 17 & 18 & 19 & 20 \\
\hline $\begin{array}{l}\text { nlinois Steel Co. coke.... } \\
\text { Run-of-mine Mesabi ore }\end{array}$ & 5.74 & 0.151 & 0.55 & 2.0 & 0.019 & 0.011 & 0.020 & 2.0 & 2. 0 & \\
\hline $\begin{array}{l}\text { 95.7 per cent Mesabi ore }+4.3 \text { per cent Iilinois Steel Co. coke-- } \\
92.6 \text { per cent Mesabi ore }+7.4 \text { per cent Illinois Steel Co. coke }\end{array}$ & & & No data. & & & & & & & \\
\hline $\begin{array}{l}\text { Typical } 10 \text { Illinois Steel Co. blast-furnace ore charge } 11 \text { without coke or lime- } \\
\text { stone }\end{array}$ & 1.36 & .036 & .88 & (17) & .61 & .55 & .625 & & 62.5 & 0.025 \\
\hline $\begin{array}{l}\text { 64.3 per cent Illinois Steel Co. blast-furnace ore charge }+12.4 \text { per cent coke+ } \\
10.9 \text { per cent limestone, uniformly mixed }+12.4 \text { per cent layer of coke } \\
63.9 \text { per cent lllinois Steel Co. blast-furnace ore charge }+25.6 \text { per cent coke }+\end{array}$ & 3.68 & .096 & .77 & 1.85 & 12.31 & 12.42 & 12.545 & 1238.6 & 1254.5 & .03 \\
\hline $\begin{array}{l}10.5 \text { per cent limestone, uniformly mixed } \\
\text { Vermilion ore }\end{array}$ & $\begin{array}{l}4.21 \\
1.18\end{array}$ & .0311 & .76 & 2.02 & .23 & .195 & .256 & $\begin{array}{r}26.9 \\
99.5\end{array}$ & 25.6 & $\begin{array}{l}.10 \\
.06\end{array}$ \\
\hline $\begin{array}{l}\text { Vermilion ore saturated with water } \\
92 \text { per cent Vermilion ore }+8 \text { per cent Iilino is Steel Co coke }\end{array}$ & $\begin{array}{l}1.18 \\
2.56\end{array}$ & .031 & .089 & $\begin{array}{l}2.00 \\
2.09\end{array}$ & .00 & 1.80 & 1.97 & 197 & 197.5 & 07 \\
\hline 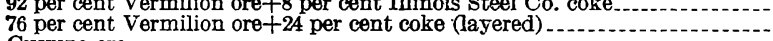 & $\begin{array}{l}2.56 \\
1.18\end{array}$ & .031 & .80 & $\begin{array}{l}2.09 \\
2.13\end{array}$ & $\begin{array}{l}\cdot .34 \\
12.50\end{array}$ & 12.86 & 12.945 & 12126 & 1294.5 & .08 \\
\hline Cuyuna ore & 1. 49 & .039 & .88 & 1.70 & .43 & .70 & .795 & 39.7 & 79.5 & .06 \\
\hline $\begin{array}{l}\text { Coke of Columbia Steel Co., Provo, Utah...- } \\
\text { Coarse Provo ore } 14\end{array}$ & 3. 33 & .087 & .66 & 2.00 & .038 & .024 & .036 & 3.6 & 3.6 & -..- \\
\hline $\begin{array}{l}\text { Coarse Provo ore } 14 \\
\text { Medium Provo ore }\end{array}$ & $\begin{array}{l}3.94 \\
2.31\end{array}$ & .060 & .81 & $\begin{array}{l}2.19 \\
2.27\end{array}$ & .037 & $\begin{array}{l}.035 \\
.077\end{array}$ & $\begin{array}{l}.049 \\
.096\end{array}$ & $\begin{array}{r}7.5 \\
19.0\end{array}$ & $\begin{array}{l}4.9 \\
9.6\end{array}$ & ---- \\
\hline $\begin{array}{l}\text { Fine Provo ore } 14 \\
67 \text { per cent fine Provo ore }+16.7 \text { per cent coke uniformly mixed }+16.6 \text { per }\end{array}$ & .70 & .018 & .98 & 1.90 & .52 & .75 & .765 & 61.0 & 76.5 & .05 \\
\hline cent coke layered above bed & 2.00 & .053 & .84 & 2.05 & 12. 28 & .443 & 12. 524 & ${ }^{12} 58.0$ & 1) 52.4 & .10 \\
\hline $\begin{array}{l}67 \text { per cent fine Provo ore }+33 \text { per cent coke, uniformly mixed } \\
\text { Provo ore, } 33.2 \text { per cent fine }+16.7 \text { per cent medium, }+16.7 \text { per cent coarse }+\end{array}$ & 2.45 & .064 & .78 & 2.00 & .18 & .26 & .333 & 33.3 & 33.3 & \\
\hline $\begin{array}{l}16.7 \text { per cent coke, all uniformly mixed }+16.7 \text { per cent coke layered above } \\
\text { bed. }\end{array}$ & 2. 87 & .076 & .81 & 1.73 & 12.155 & 12.145 & ${ }^{12} .179$ & 129.67 & 1217.9 & .10 \\
\hline $\begin{array}{l}\text { Provo ore, } 33.3 \text { per cent fine }+16.7 \text { per cent medium }+16.7 \text { per cent coarse }+ \\
33.3 \text { per cent coke, all uniformly mixed. } \\
\text { Common sand } 15\end{array}$ & 2.85 & .076 & No data. & 1.90 & .101 & .110 & .142 & 11.3 & 14.2 & \\
\hline Fine sand 15 & & & No data. & & & & & & & - \\
\hline $\begin{array}{l}\text { Stone dust } 15 . \ldots \\
\text { Dry soil } 15\end{array}$ & & & No data. & & & & & & & - \\
\hline & & & & & & & & & & \\
\hline
\end{tabular}


1 Compositions given in per cent by weight.

2 Computed by per cent by volume.

3 Determined by figs. 33 and 34

Defined by equation (1).

Defined on p. 45 . Unit - centimeter of water per centimeter of height.

Tnit-centimeter of water per centimeter of height.

${ }^{8} R=0.01$ liter per second per square contimeter.

10 Materials and second per square centimeter;

11 Composition of ore charge: Groups 3 and 7, Mesabi ores, 75.3 per cent; sinter, 4.2 per cent; Cadiz ore, 8 per cent; vessel slag, 2.1 per cent; roll scale, 2.1 per cent; flue dust, 8

per cent.

12 Figure refers to the standard pressure drop in a unit height of the bed proper, not the average with the overlying coke.

13 Figure refers to voids in the bed proper and not to the overlying coke.

16 Data of Storrow, John T., Flow of Air Through Bmall Coal and Other Broken Material: Trans. Inst. Min. Eng., vol. 55, 1918, pp. 313-317. Oontainer, 4.6 centimeters in diameter.

${ }^{18} R=0.0001$ liter per second per square centimeter.

11 Indeterminate because of inconsistencies in data. 
TABLE 10.-Constants for determining resistance to gas flow of constituent materials tabulated in Table 9

\begin{tabular}{|c|c|c|c|c|c|c|}
\hline Material & Size of fraction tested & $\begin{array}{l}\text { Average } \\
\text { specific } \\
\text { gravity }\end{array}$ & $\begin{array}{l}\text { Shape } \\
\text { factor, } 1 \\
\qquad F\end{array}$ & $\begin{array}{l}\text { Normal } \\
\text { voids, } 1 \\
V_{n}\end{array}$ & $F / V_{n}$ & $\begin{array}{c}K_{\infty}{ }^{23} \\
\text { voids } \\
\text { normal }\end{array}$ \\
\hline Wlinois Steel Co. coke. & 1.050 to $0.525 \mathrm{inch}$ & 1.00 & 0.98 & 0.55 & 1.78 & 0.235 \\
\hline $\begin{array}{l}\text { Run-of-mine Mesabi ore } \\
\text { Illinois Steel Co. blast- }\end{array}$ & $\begin{array}{l}4 \text { to } 6 \text { mesh } \\
4 \text { to } 8 \text { mesh. }\end{array}$ & $\begin{array}{l}\text { 3. } 70 \\
\text { 3. } 34\end{array}$ & $\begin{array}{r}1.00 \\
.93\end{array}$ & $\begin{array}{l}.595 \\
.51\end{array}$ & $\begin{array}{l}1.68 \\
1.83\end{array}$ & $\begin{array}{l}.270 \\
.332\end{array}$ \\
\hline Vermilion ore & 3 to 4 mesh & 4.98 & .95 & .52 & 1.83 & .205 \\
\hline Cuyuna ore & 6 to 8 & 3.58 & .9 & .4 & 1.94 & .310 \\
\hline $\begin{array}{l}\text { Coke of Columbia Steel } \\
\text { Co., Provo, Utah. }\end{array}$ & 1.050 to $0.525 \mathrm{i}$ & .90 & .97 & .62 & 1. 56 & .162 \\
\hline $\begin{array}{l}\text { Provo ore } \\
\text { Illinois Steel Co. lime- } \\
\text { stone. }\end{array}$ & $\begin{array}{l}1.050 \text { to } 0.525 \text { inch. } \\
1.050 \text { to } 0.742 \text { inch. }\end{array}$ & $\begin{array}{l}3.60 \\
2.50\end{array}$ & $\begin{array}{l}.92 \\
.94\end{array}$ & $\begin{array}{l}.575 \\
.54\end{array}$ & $\begin{array}{l}1.61 \\
1.74\end{array}$ & .215 \\
\hline
\end{tabular}

1 Defined on p. 18

2 Pressure drop when $d=1, V=$ normal, $R=0.1$.

3 Computed by means of equations (32) and (8).

TABLE 11.-Screen analyses of materials of mixed sizes

\begin{tabular}{|c|c|c|c|c|c|c|c|c|}
\hline \multicolumn{2}{|l|}{ Screen size } & $\begin{array}{l}\text { Run-of- } \\
\text { mine } \\
\text { Mesabi } \\
\text { ore }\end{array}$ & $\begin{array}{l}\text { Vermil- } \\
\text { ion ore }\end{array}$ & $\underset{\text { ore }}{\text { Cuyruna }}$ & $\begin{array}{l}\text { Provo } \\
\text { coarse } \\
\text { ore }\end{array}$ & $\begin{array}{c}\text { Provo } \\
\text { medium } \\
\text { ore }\end{array}$ & $\begin{array}{l}\text { Provo } \\
\text { fine ore }\end{array}$ & $\begin{array}{c}\text { Provo } \\
\text { coke }\end{array}$ \\
\hline & & 1 & 2 & 3 & 4 & $\boldsymbol{5}$ & 6 & $y$ \\
\hline $\begin{array}{l}\text { On } 1.050 \text { inch } \\
1.050 \text { to } 0.525 \text { inch } \\
0.525 \text {-inch to } 3 \text {-mesh } \\
3 \text { to } 8 \text { mesh. } \\
8 \text { to } 14 \text { mesh } \\
14 \text { to } 28 \text { mesh } \\
28 \text { to } 48 \text { mesh } \\
18 \text { to } 65 \text { mesh } \\
65 \text { to } 100 \text { mesh } \\
\text { Through } 100 \text {-mesh. }\end{array}$ & 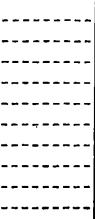 & $\begin{array}{r}9.9 \\
12.4 \\
12.6 \\
13.4 \\
6.4 \\
8.2 \\
20.4 \\
5.0 \\
4.6 \\
7.0\end{array}$ & $\begin{array}{r}7.4 \\
26.0 \\
20.5 \\
19.5 \\
8.5 \\
5.5 \\
3.5 \\
2.9 \\
1.8 \\
4.5\end{array}$ & $\begin{array}{r}19.8 \\
22.8 \\
18.1 \\
16.2 \\
7.0 \\
4.8 \\
3.7 \\
2.2 \\
1.8 \\
3.6\end{array}$ & 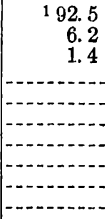 & \begin{tabular}{r}
245.8 \\
50.0 \\
4.2 \\
\hdashline 65.0 \\
\end{tabular} & $\begin{array}{r}42.5 \\
13.2 \\
11.7 \\
8.0 \\
7.8 \\
2.8 \\
13.9\end{array}$ & $\begin{array}{r}371.0 \\
17.8 \\
11.2 \\
\hdashline \\
\hdashline \\
\hdashline \\
\\
\\
\hdashline\end{array}$ \\
\hline \multirow[t]{2}{*}{ Screen size } & $\begin{array}{c}\text { Vessel } \\
\text { slag }\end{array}$ & Sinter & $\begin{array}{l}\text { Roll } \\
\text { scale }\end{array}$ & $\begin{array}{l}\text { Flue } \\
\text { dust }\end{array}$ & $\underset{\text { ore }}{\text { Cadiz }}$ & $\begin{array}{l}\text { Mixed } \\
\text { Mesabi } \\
\text { charge } \\
\text { after } \\
\text { blowing }\end{array}$ & $\begin{array}{l}\text { Vermil- } \\
\text { ion ore } \\
\text { after } \\
\text { blowing }\end{array}$ & $\begin{array}{c}\text { Provo } \\
\text { fine ore } \\
\text { after } \\
\text { blowing }\end{array}$ \\
\hline & 8 & 9 & 10 & 11 & 12 & 13 & 14 & 15 \\
\hline $\begin{array}{l}\text { On } 1.050 \text { inch } \\
1.050 \text { to } 0.525 \text { inch } \\
0.525 \text {-inch to } 3 \text {-mesh } \\
3 \text { to } 8 \text { mesh } \\
8 \text { to } 14 \text { mesh } \\
14 \text { to } 28 \text { mesh } \\
28 \text { to } 48 \text { mesh } \\
48 \text { to } 65 \text { mesh } \\
65 \text { to } 100 \text { mesh } \\
\text { Through } 100-m e s h\end{array}$ & $\begin{array}{r}7.8 \\
7.8 \\
15.6 \\
13.7 \\
9.4 \\
9.1 \\
12.6 \\
4.4 \\
4.1 \\
15.3\end{array}$ & $\begin{array}{r}1.4 \\
5.4 \\
13.6 \\
20.0 \\
13.2 \\
11.3 \\
14.4 \\
8.2 \\
6.9 \\
5.7\end{array}$ & $\begin{array}{r}17.1 \\
19.0 \\
17.6 \\
11.2 \\
16.0 \\
5.3 \\
5.0 \\
9.0\end{array}$ & $\begin{array}{r}0.7 \\
1.5 \\
6.3 \\
20.4 \\
19.2 \\
19.1 \\
32.8\end{array}$ & $\begin{array}{r}13.9 \\
19.0 \\
14.6 \\
10.8 \\
11.2 \\
3.9 \\
3.7 \\
23.1\end{array}$ & $\begin{array}{r}12.7 \\
16.6 \\
17.5 \\
13.0 \\
6.4 \\
6.5 \\
4.8 \\
7.3 \\
5.1 \\
10.1\end{array}$ & $\begin{array}{r}9.1 \\
28.3 \\
19.8 \\
18.6 \\
8.7 \\
3.5 \\
6.2 \\
1.5 \\
.6 \\
3.7\end{array}$ & $\begin{array}{r}49.4 \\
16.5 \\
11.9 \\
7.8 \\
6.5 \\
2.4 \\
5.4\end{array}$ \\
\hline
\end{tabular}

$1 d$ for pieces on 1.050 -inch screen $=4.01$ centimeters.

$2 d$ for pieces on 1.050 -inch screen $=3.04$ centimeters.

${ }^{8} d$ for pieces on 1.050 -inch screen $=4.07$ centimeters. $\boldsymbol{C}$ for Illinois Steel Co. coke $=5.74$ centimeters. $d$ for largest pieces $=10$ to 12 centimeters. $d$ for Illinois Steel Co. limestone $=4$ to 10 centimeters (approximate). 
TABLE 12.-Screen-analysis data of John T. Storrow

\begin{tabular}{|c|c|c|c|c|c|}
\hline Screen size, mesh & $\begin{array}{c}\text { Common } \\
\text { sand }\end{array}$ & $\begin{array}{l}\text { Fine } \\
\text { sand }\end{array}$ & $\begin{array}{l}\text { Stone } \\
\text { dust }\end{array}$ & Dry soil & $\begin{array}{l}\text { Geomet- } \\
\text { ric mean } \\
\text { size }\end{array}$ \\
\hline $\begin{array}{l}\text { On } 10 \\
10 \text { to } 30 \\
30 \text { to } 60.000 \\
60 \text { to } 90 \\
\text { Thro } 200\end{array}$ & $\begin{array}{r}\text { Per cent } \\
19.50 \\
8.50 \\
50.96 \\
19.56 \\
1.14 \\
.24\end{array}$ & $\begin{array}{r}\text { Per cent } \\
1.15 \\
57.35 \\
36.85 \\
3.90 \\
.75\end{array}$ & $\begin{array}{r}\text { Per cent } \\
18.7 \\
26.1 \\
12.4 \\
5.5 \\
6.5 \\
30.8\end{array}$ & $\begin{array}{r}\text { Per cent } \\
50.23 \\
16.95 \\
12.83 \\
13.13 \\
5.97 \\
10.85\end{array}$ & $\begin{array}{c}C m . \\
0.194 \\
.097 \\
.034 \\
.0183 \\
.0105 \\
.0052\end{array}$ \\
\hline
\end{tabular}

TABLE 13.-Predictions of values of $B$

\begin{tabular}{|c|c|c|c|c|c|}
\hline Natcial & $\begin{array}{l}\text { No. of } \\
\text { run }\end{array}$ & $\begin{array}{l}d \text { at } 1 / 3 \\
\text { fines } 1\end{array}$ & $\underset{B^{2}}{\text { Predicted }}$ & $\underset{B^{3}}{\operatorname{Observed}}$ & $\begin{array}{c}\text { Per cent } \\
\text { error }\end{array}$ \\
\hline $\begin{array}{l}\text { Run-of-mine Mesabi ore } \\
\text { Run-of-mine Mesabi ore }+4.3 \text { per cent coke (14 per }\end{array}$ & 193 & 0.05 & 0.94 & 1.01 & 7.0 \\
\hline $\begin{array}{l}\text { cent by volume) } \\
\text { Run-of-mine Mesabi ore }+7.4 \text { per cent coke ( } 22 \text { per }\end{array}$ & 195 & .06 & 1.00 & 1.16 & 13.8 \\
\hline 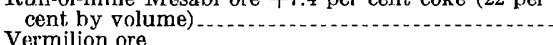 & 194 & .08 & 1. 11 & 1. 11 & 0.0 \\
\hline Cuyuna ore.... & 201 & .42 & $\begin{array}{l}1.04 \\
1.71\end{array}$ & $\begin{array}{l}1.90 \\
1.95\end{array}$ & 14.0 \\
\hline Provo fine ore. & 222 & .11 & 1.25 & 1. 04 & \\
\hline
\end{tabular}

1 From fig. 62.

3 From Table 9.

2 From fig. 16 or equation (7).

PREDICTION OF PRESSURE DROP IN SYSTEMS OF MANY COMPONENT SIZES

In Table 9 columns 7 and 15 are designated as "computed $\Delta P_{S}$ at $R=0.1$." The numbers in these columns are the values of the standard pressure drop at a rate of flow of 0.1 liter per second per square centimeter which have been computed by means of more or less arbitrary rule.

If a value of $R=1.0$ had been chosen as the reference flow the values computed would have been the $A$ of equation (1), but, as has been explained before, $R=0.1$ is within the experimental range, and extrapolation to $R=1.0$ causes discrepancies which make the data lose some of their significance.

The arbitrary rule by means of which these predictions were made is: If a bed of broken solids consists of many constituent sizes and the proportions of these sizes are fairly evenly distributed, the pressure drop of the mixed system is the same as that of a system of the same composition with the constituent sizes in separate layers.

This rule is recognized as being in opposition to the rule of resistance of binary systems, as given on page 67. However, qualitative justification for the rule as stated above may be obtained by an extension of rule of the lowering of resistance by using more than two components, as stated on page 67 . Briefly, the argument is: The greatest resistance occurs in a system of two component sizes. As the number of component sizes decreases the resistance decreases until for a system of a large number of constituent sizes the resistance is an additive property of the composition, that is, is the same whether layered or mixed. 


\section{SIZE OF MATERIALS BLOWN FROM BED}

The predictions for a quiet bed were made by considering all of the sizes as shown by the screen analysis. When the fine particles were being blown from their original position in the bed, they were left out of consideration in computing the resistance; that is, they were considered as a part of the gas stream. The results appear to justify this assumption. The question arises: What size particles are lifted? If columns 13,14 , and 15 of Table 11 are compared with columns 1, 2, and 6 of the same table, it will be seen that the screen analysis shows thet the bed contained less material finer than 14mesh after blowing than before. Therefore, 14-mesh is the division point, and any material finer than 14-mesh was not considered as part of the bed when the fines were being lifted.

\section{SAMPLE COMPUTATION}

Each computation was made by considering a mixed bed 1 centimeter high. It was considered that each constituent size was separated and packed with normal voids and that the summation of the height of all these separated layers was still 1 centimeter. This can not be realized experimentally but may be handled theoretically.

The quantities necessary to determine the specific resistance of any one kind of material are the shape factor and voids of normal packing for a single size. Both of these quantities are considered to be independent of the size of the material. The method of prediction for a particular material and size is the same as shown on page 56. After resistance of a unit length of column of one type and size of material is determined by the method cited the figure is multiplied by the fractional part (by volume) that it occupies in the bed. This is done for each constituent. The summation of all the parts is the total resistance. No recognition is paid to the change of voids upon mixing the different sizes. The computations consider that the bed is packed with normal voids for each size.

If the prediction is to be for a mixture of more than one kind of material, the resistance of a unit height of column of each particular kind of material is computed, using the size distribution as determined for that particular material. The resistance of each material is then multiplied by the fractional part (by volume) that it occupies in the bed. The summation of the values for all the different kinds of materials is the resistance.

\section{EXAMPLE}

Prediction for run 226 (Table 9).-Predict the pressure drop under standard conditions, when $R=0.1$, per unit height of column in the specified mixture of materials, with the material finer than 14-mesh lifted, and formulate the general equation of flow for the system. 


\section{COMPOSITION}

Composition of bed.-One-third fine Provo ore, one-sixth medium Provo ore, one-sixth coarse Provo ore, one-third Provo coke (by weight).

From Table 10: Specific gravity of Provo ore $=3.60$

Specific gravity of Provo coke $=0.90$.

Composition of bed then is: One-sixth fine Provo ore, one-twelfth medium Provo ore, one-twelfth coarse Provo ore, two-thirds Provo coke (by volume). (Decimal fractions or percentages are usually more convenient to use but not in. this case.)

Specific resistances.-

From Table 10, $F / V_{n}$ for Provo ore $=1.61$, and

F. $/ V_{n}$ for Provo coke $=1.56$.

$$
\begin{aligned}
& K_{1 \infty}= \Delta P_{S_{\infty}} . \\
& R=0.1 \\
& V=.50 \\
& d=1.00
\end{aligned}
$$

From equation (32) or Figure 39, for Provo ore

$$
\log _{10} K_{1 \infty}=3.7843-3.4414 \times 1.61+0.6177 \times 1.61^{2}=-0.265 \text {. }
$$

This figure is for voids $=0.50$.

The normal voids of Provo ore are 0.575. (See Table 10.) The specific resistance then will be less than given by the above equation.

From equation (8) or Figure 30,

$$
\begin{gathered}
\Delta \log _{10} A=\Delta \log _{10} \Delta P=\left[4.2 \times 0.575-8.9 \times 0.575^{+2}\right]-\left[4.2 \times 0.50-8.9 \times 0.50^{+2}\right] \\
=-0.403 . \\
\log _{10} \Delta P_{S_{\infty}}=-0.265+(-0.403)=-0.668 . \\
R=0.1 \\
d=1.0 \\
V=\text { normal } \\
\Delta P_{S_{\infty}}=0.215 \\
R=0.1 \\
d=1.0 \\
V=\text { normal } \\
\Delta P_{S_{\infty}}=\frac{K}{d^{J}}=\frac{0.215}{d^{J}} \\
R=0.1 \\
V=\text { normal } \\
V_{n}=1.68-0.58=1.10 .
\end{gathered}
$$

\begin{tabular}{|c|c|c|c|c|c|c|c|c|}
\hline Screen size & $\begin{array}{l}\text { A verage } \\
\text { screen } \\
\text { opening, } \\
\text { centi- } \\
\text { meter }\end{array}$ & $d^{1}$ & $\begin{array}{c}\text { Per cent } \\
\text { by } \\
\text { weight } 2\end{array}$ & $\begin{array}{c}\text { Per cent } \\
\text { by } \\
\text { weight, } \\
\text { neglect- } \\
\text { ing fines }\end{array}$ & $d^{1.1}$ & $\begin{array}{c}\text { Unit } \\
\Delta P_{s_{\infty}}\end{array}$ & $\begin{array}{l}\text { Frac- } \\
\text { tional } \\
\Delta F_{S_{\infty}}\end{array}$ & $\begin{array}{l}\text { Frac- } \\
\text { tional }\end{array}$ \\
\hline 1 & 2 & 3 & 4 & 5 & 6 & 7 & 8 & $d$ \\
\hline $\begin{array}{l}0.525 \text {-inch to } 3 \text {-mesh } \\
3 \text { to } 8 \text { mesh } \\
8 \text { to } 14 \text { mesh. }\end{array}$ & $\begin{array}{r}1.000 \\
.450 \\
.177 \\
\end{array}$ & $\begin{array}{r}0.930 \\
.420 \\
.165 \\
\end{array}$ & $\begin{array}{l}42.5 \\
13.2 \\
11.7 \\
\end{array}$ & $\begin{array}{l}63.0 \\
19.6 \\
17.4 \\
\end{array}$ & $\begin{array}{r}0.923 \\
.385 \\
.138 \\
\end{array}$ & $\begin{array}{r}0.233 \\
.559 \\
1.558 \\
\end{array}$ & $\begin{array}{r}0.147 \\
.110 \\
.271 \\
\end{array}$ & $\begin{array}{l}0.59 \\
.08 \\
.03 \\
\end{array}$ \\
\hline Total & & $\ldots$ & 67.4 & 100.0 & 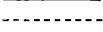 & - - & .528 & .70 \\
\hline
\end{tabular}

Therefore,

$$
\Delta P_{S_{\infty}}=\frac{0.215}{\begin{array}{c}
d^{1.1} \\
R=0.1
\end{array}}
$$

Resistance of unit column of fine ore (with material finer than 14-mesh lifted).Data of Provo fine ore from Tables 10 and 11

1 Shajpe factor $=0.93$.

Note. $-\Delta P_{\mathbf{S}_{\infty}}$ for fine Provo ore $=0.528$.

${ }^{2}$ In this case per cent by weight $=$ per cent by volume. 


\section{RESISTANCE OF UNIT COLUMN OF OTHER SIZES OF ORE}

The resistances of a unit column of the medium and coarse Provo ores were computed in exactly the same manner. The only variation was in the screen analysis. (See Table 11.)

By these computations,

$$
\begin{aligned}
\Delta P_{S_{\infty}} \text { for medium Provo ore } & =0.085, \text { and } \\
\Delta P_{S_{\infty}} \text { for coarse Provo ore } & =0.052, \text { while } \\
\text { medium ore, average } d & =2.31, \text { and } \\
\text { coarse ore, average } d & =3.94 .
\end{aligned}
$$

RESISTANCE OF UNIT COLUMN OF COKE

Using the data of Table 10 and the method as outlined above: For Provo coke,

$$
\begin{gathered}
\Delta P_{S_{\infty}}=0.162, \\
R=0.1 \\
d=1.0 \\
V=\text { normal } \\
\Delta P_{S_{\infty}}=\frac{0.162}{d^{1.08}}, \text { and } \\
R=0.1 \\
V=\text { normal } \\
\Delta P_{S_{\infty}}=0.058, \\
\text { average } d=3.33 .
\end{gathered}
$$

\section{RESISTANCE OF MIXED BED}

The resistance of the mixed bed of three sizes of ore and of coke is:

$\Delta P_{S_{\infty}}=\frac{1}{6} \times 0.528+\frac{1}{12} \times 0.085+\frac{1}{12} \times 0.052+\frac{2}{3} \times 0.058=0.138$ centimeter of water
per centimeter of height.

The above figure is for a bed in a container of infinite diameter.

Average $d=\frac{1}{6} \times 0.70+\frac{1}{12} \times 2.31+\frac{1}{12} \times 3.94+\frac{2}{3} \times 3.33=2.85$ centimeters.

Diameter of container $=38.1$ centimeters.

From Figure 36,

$$
d / D=\frac{2.85}{3.81}=0.075 \text {. }
$$

Wall-effect factor $=0.80$.

Predicted $\Delta P_{S}$ (in 38.1-centimeter container) $=0.138 \times 0.8=0.110$.

Observed $\Delta P_{S}$ (Table 9$)=0.142$ centimeter of water per centimeter of height. $R=0.1$

$$
\text { Error }=\frac{0.142-0.110}{0.142}=22.5 \text { per cent. }
$$


FORMULATION OF GENERAL EQUATION

The foregoing computations apply to a flow of 0.1 liter per second per square centimeter. The general equation of variation of pressure drop with flow is

$$
\Delta P_{S}=A R^{B} \text {. }
$$

$B$ may be taken as 2.0. (See p. 90.)

From above predicted $\Delta P_{S}=0.110$,

$$
R=0.1 \quad A=\frac{0.110}{0.1^{2}}=11.0 .
$$

Predicted equation

$$
\Delta P_{S}=11.0 R^{2.0} \text {. }
$$

From Table 9, observed $\Delta P_{S}=0.142$, and $B=1.90$.

$$
R=0.1
$$

$$
\text { Observed } A=\frac{0.142}{0.1^{1.00}}=\frac{0.142}{0.1259}=11.3 \text {. }
$$

General equation for observed data,

$$
\Delta P_{S}=11.3 R^{1.9} \text {. }
$$

Error in prediction of $A=\frac{0.3}{11.3}=2.7$ per cent.

Error in prediction of $B=\frac{0.1}{1.9}=5.3$ per cent.

These tedious computations may be lessened somewhat by tabulating the resistance factor, which is defined as

$$
\Sigma\left(\frac{\text { per cent }}{\sqrt{d_{1} d_{2}}}\right)^{J}
$$

as a first approximation, resistance factor

$$
=\frac{1}{d_{1}}+\frac{1}{d_{2}}+\frac{1}{d_{3}}-\cdots-\frac{1}{d_{n}} \text {. }
$$

Multiply the computed resistance of a bed of particles of unit diameter by this summation.

This plot of the resistance factor against pressure drop at $R=0.1$ is given in Figure 64. For these computations $J$ was taken $=1: 2$, an average value for most material. Although this prediction is somewhat complicated because of the presence of four different materials, the results are quite satisfactory.

\section{DEGREE OF RELIABILITY OF PREDICTIONS}

Comparison of columns 15 and 16 of Table 9 shows that in the systems studied when the fine material was lifted from the bed the maximum error in predicting the pressure drop at $R=0.1$ was 50 per cent. The systems investigated represent a wide range in kind and size of materials, and the author feels that the rule as given is reliable for predictions in systems of many sizes with an accuracy of 50 per cent, provided the ratio of the extreme sizes is not greater than 50 to 1 . 
Several predictions were also made for the systems in which the fines were not lifted. (Column 7.) The size ratios in some cases were as much as 500 to 1 . In most cases the degree of accuracy of prediction was about the same as when the fines were lifted, but in one case (fine Provo ore, run 222) the error was 75 per cent.

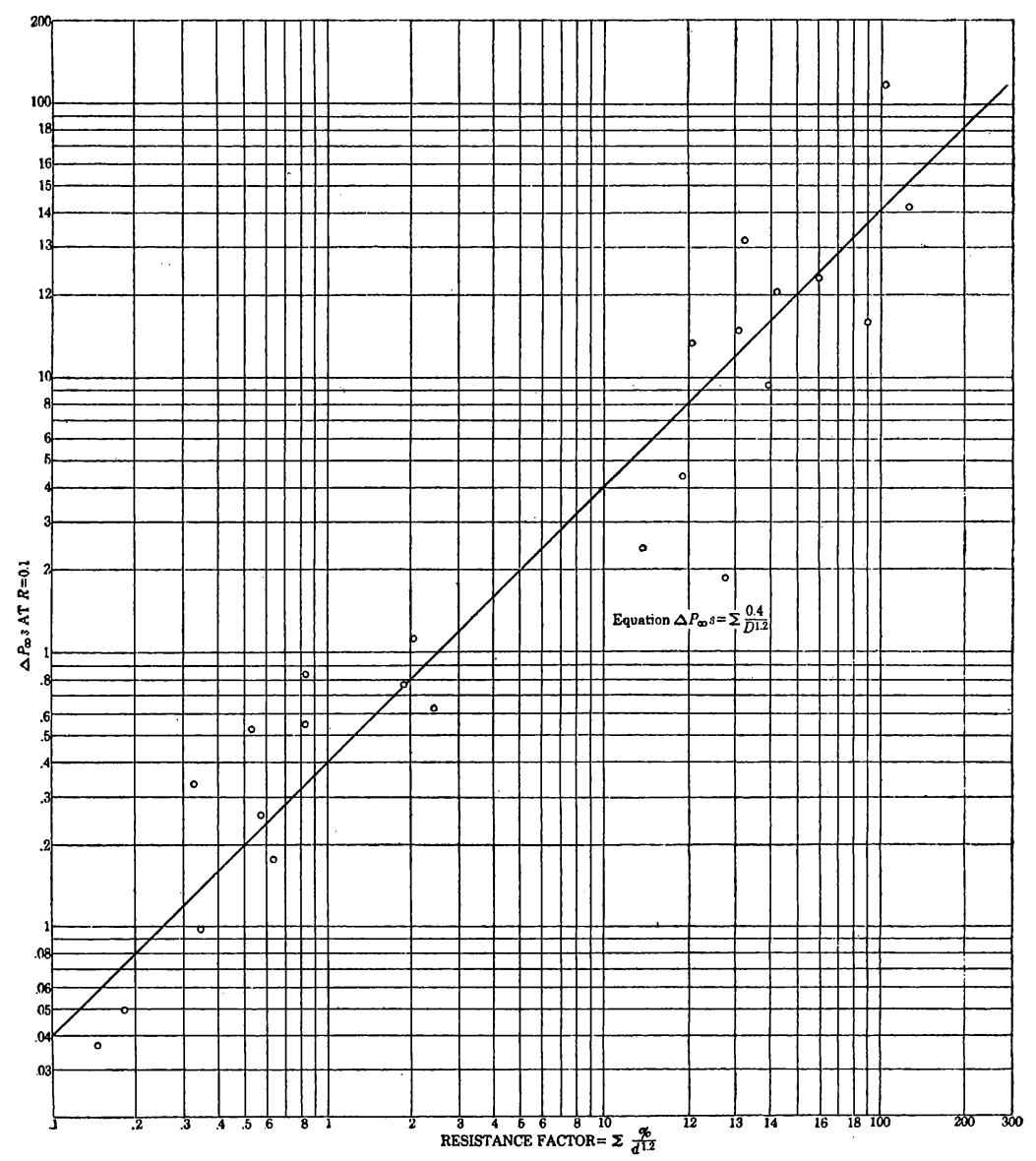

Figure 64.-Relation between resistance factor in systems of many sizes and pressure drop at a constant rate of flow of 0.1 liter per second per square centimeter

In general, the method of prediction of pressure drop in systems of many components by considering the resistance as an additive property of the composition gives results that may always be relied upon, if the size distribution is fairly uniform, to give the order of the pressure drop, and if the ratio of extreme sizes is not greater than 50 to 1 the prediction will be within 50 per cent of the true value. If the size ratio is less than 50 to 1 the error of the prediction may be expected to be smaller. 


\section{METHOD OF PREDICTION FOR SPECIAL CASE}

The foregoing arguments have been based upon the assumption that the particles are distributed fairly evenly over the size range. This is true for most natural materials; and the author has not found any variations from it that would require any special considerations, but such a case might arise. Thus, if there were two dominant size divisions in the system it might be necessary to treat it as a twocomponent system. The question is, when will it be necessary to do this?

Suppose a screen analysis is -made of a material wherein the ratio between screen sizes is 2:1. From the general consideration of the curves for binary systems (figs. $45,46,47$ ) if two of these screen divisions each contains as much as 40 per cent of the total weight of the material and if these two screen divisions are removed from each other by a size ratio of at least $4: 1$ it will be more accurate to consider it a binary system composed of the two dominant sizes in their own relative proportions. It will be seen that such an example is unlikely in natural systems.

\section{EFFECT OF MOISTURE}

All of the foregoing data have concerned dry materials. No extensive study has been made of the effect of moisture, for this item is not particularly important in blast-furnace considerations. In the blast furnace the stock is usually soaked with water before charging, but it is soon dried in the heat of the gas stream, and the water plays only a minor rôle in the resistance to the passage of the gas. However, there may be instances in which the influence of water is important.

To get an idea of the extent of this influence, a run was made on Vermilion ore, saturated with water (run 204, compare with run 199). In this particular example the bed contained 12.7 per cent of material finer than 28-mesh. When wet, this fine material clung to the large pieces, left larger openings in the bed, and lowered the resistance very markedly-from 12 to 1.8 , a drop of 85 per cent. When the air flow was increased to a point at which the fines had been lifted from the dry bed, the fine material in the wet bed still clung to the large pieces and there was no lifting. Because the fine pieces were not lifted out of the wet bed the passageways were somewhat smaller than for the dry bed at the same rate of flow, and the pressure drop was somewhat higher-1.8 as compared to 1 for the dry bed.

The following generalizations may safely be made from these experiments:

1. The presence of water in so far as it affects only the surface of the particles of the bed does not affect the resistance to the flow of gases.

2. If there is sufficient large material in the bed to offer enough clinging surface to hold all of the wetted fine particles (of the order 
of 28 -mesh or finer), the resistance will be decreased if the rate of flow is less than lifting velocity and will be increased somewhat if the gas velocity is sufficiently great to lift the fine particles from the dry bed.

Probably there are materials whose interfacial tension with water is such that the small pieces will not cling to the large ones, and the above rule will not hold.

3. If the major portion of the bed is made up of fine particles (28-mesh or under), there will be no surfaces for the fine wet particles to cling to, a continuous water film will be formed between adjoining small particles throughout the bed, and the resistance to the passage of gas will be increased.

A thorough quantitative study of these effects will be necessary for complete and accurate understanding of the flow of gases through

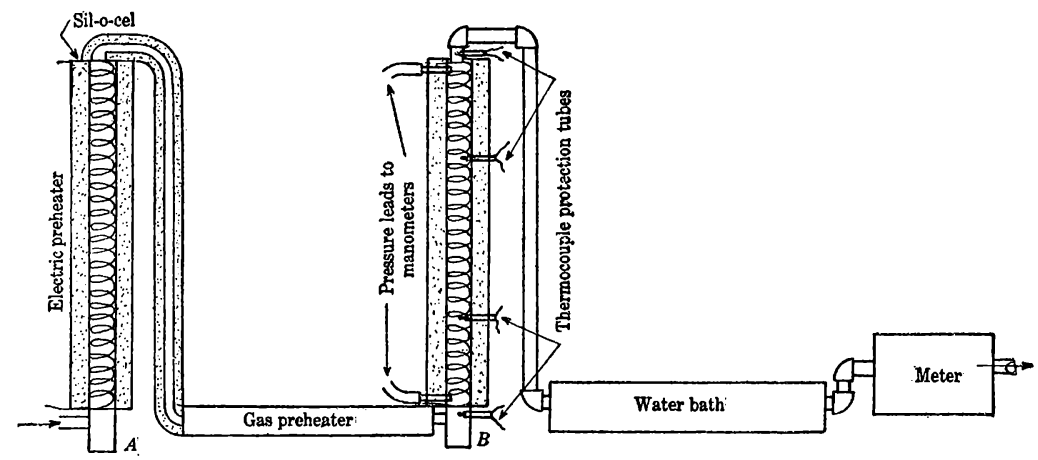

FIGURE 65.-Apparatus for study of gas flow at elevated temperatures

wetted fuel beds, especially if the wetting causes caking, and of still columns when there is a constant countercurrent stream of liquid.

\section{EFFECT OF TEMPERATURE}

\section{APPARATUS}

The apparatus used for the investigation at higher temperatures is shown diagrammatically in Figure 65. A photograph of the set-up is given in Figure 66.

The essential parts of the apparatus were the upright tubes marked $A$ and $B$ in Figure 65 . These tubes were 122 centimeters long and were made of standard 3-inch pipe threaded at both. ends, fitted with flange unions at the top. A nichrome screen (4-mesh) rested on bars welded across the bottom of each tube. Pressure-drop leads fastened to piezometer rings of four openings led off from the top and bottom of each tube to manometers.

Each tube was surrounded by a heating element made of a coiled helix of No. 16 nichrome IV wire, wound on a hollow cylinder of refractory material with walls 2 centimeters thick. The refractory tubes were made large enough to slip over the 3-inch pipe which con- 


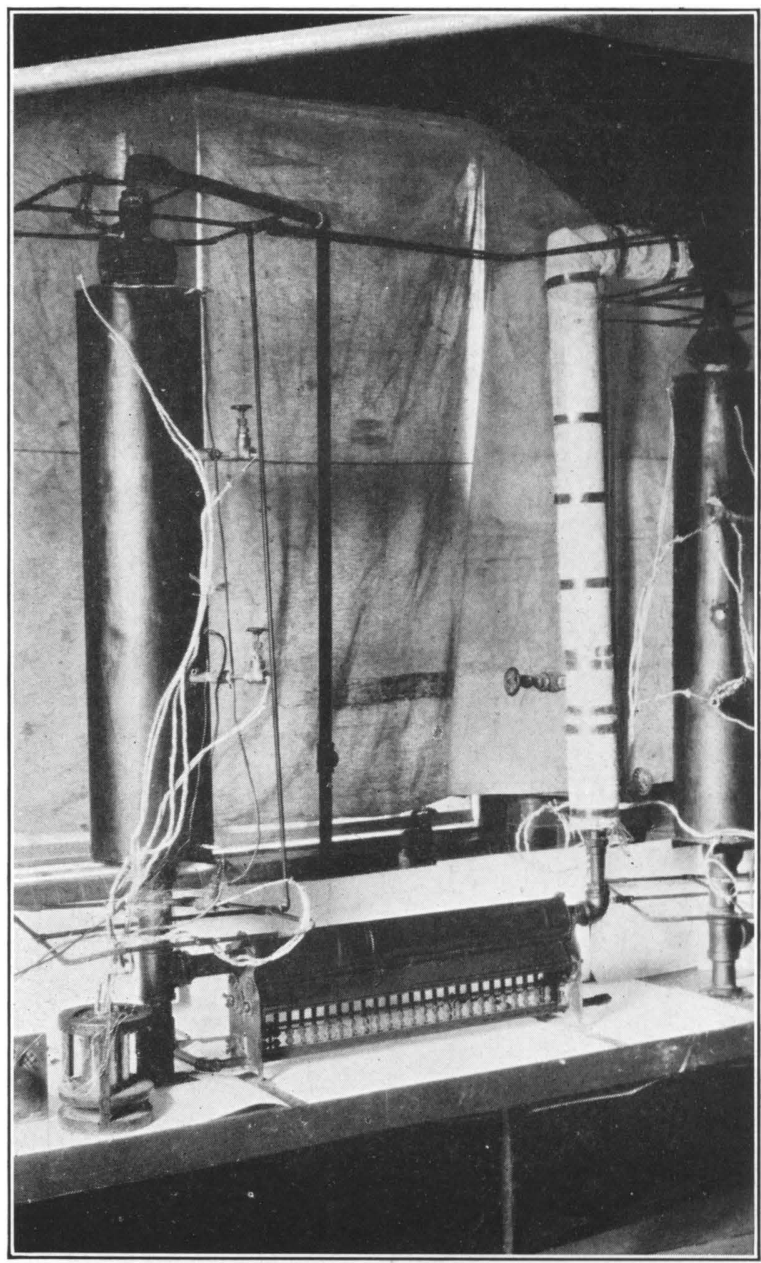

FIGURe 66.-View of apparatus for determining pressure drop at elevated temperatures 

tained the column of broken material. The refractory for tube $B$ was made in two sections of carbofrax cement, which is largely silicon carbide. This material was found to be unsatisfactory as an insulator at temperatures above $800^{\circ} \mathrm{C}$., for at elevated temperatures the silicon carbide became a relatively good conductor and persisted in short-circuiting the heating element on the grounded iron pipe. However, the tube was satisfactory for operations up to the specified temperature. The refractory tubes were insulated with powdered sil-o-cel, and the whole was surrounded by a sheet-metal tube 25 centimeters in diameter.

Tube $A$ was built to withstand higher temperatures. The refractory cylinder was made in three sections of a 50-50 mixture of alundum cement and fused alumina bonded with molasses and baked hard $\left(1,400^{\circ}\right.$ C. $)$ for three hours. The tubes were heated with alternating current, 110 or 220 volts as desired.

The temperatures were measured by means of chromel-alumel thermocouples in iron protection tubes made of $1 / 4$-inch pipe welded shut at one end. The temperatures were read by means of a Leeds $\&$ Northrup portable potentiometer. There were four thermocouples in each tube; their positions are indicated in Figure 65.

In order that the true temperature of the gas might be measured by the couples, the protection tubes were made with holes 0.15 centimeter in diameter drilled through the end, so that when gas was flowing it would flow out through the protection tube directly onto the bead of the thermocouple. ${ }^{23}$ Obviously such a device shunted part of the gas out of the column of broken material, producing errors in determinations of rate of flow and pressure drop; therefore data on temperatures and pressure drops could not be taken simultaneously. The experiments were run when the temperatures of the apparatus were steady, so that temperature readings could be taken, the couples removed, a valve on the protection tube closed, and pressure-drop and flow readings taken at the same temperature.

Tube $A$ was filled with a bed of broken solids and served as a preheater for the gas. The gas was further heated by a horizontal gas heater made of a 2 -inch pipe filled with crushed fire brick heated by a series of Bunsen burners. Tube $B$ was the testing tube, and the power input was regulated to suit the conditions desired. An auxiliary cold-air line was tapped into the end of the gas heater next to tube $B$. The flow of air through this line was regulated by a valve to give desired gas temperatures.

After leaving tube $B$ the gas was cooled by passing through a 4-inch pipe 3 meters long in a water bath and from there through a wet gas meter. The apparatus had a gas capacity of about 5 liters per second.

${ }^{23}$ For the necossity of such an arrangement see Haslam, R. T., and Chappell, E. L., The Measurement of the Temperature of a Flowing Gas: Jour. Ind. Eng. Chem., vol. 17, 1925, p. 402. 


\section{OPERATION}

The charge whose resistance was to be measured was placed in tube $B$. The current was turned on in both tubes $A$ and $B$. One of the couples in tube $B$ was attached to a Leeds \& Northrup recording potentiometer. The apparatus was heated until the temperature was steady. This required 24 to 36 hours. Before a run was made the gas heater was turned on for about an hour to heat the charge; then air was forced through the apparatus until the temperature of the incoming gas, as indicated by couple at the bottom of column $B$, was approximately that of the temperature of the charge with no gas flowing, as indicated by couples in the bed in column $B$. When the flow and the temperatures were uniform, couples in the bed were pulled from their protection tubes and the valves of the tubes closed. Readings were then taken on the rate of flow as indicated by the gas meter and on the pressures at the two ends of the column and the pressure differences. The three manometers were mounted on one board and graduated in tenths of an inch. The pressures were indicated by mercury manometers, the pressure differences by water.

After the necessary data were recorded the valves of the protection tubes were opened, the couples were replaced, and a check reading of the temperatures was taken. The process was repeated for each rate of flow. Data were taken at five or six different rates. Before obtaining data at different temperatures it was necessary to heat or cool tube $B$ and its contents the desired amount.

\section{DATA OBTAINED}

The charge in the tube consisted of 60 per cent 0.525 -inch to 3 -mesh Mesabi iron ore plus 40 per cent 3 to 4 mesh Mesabi iron ore. It was left in place and was not disturbed throughout the temperature experiments. Data were taken at six different temperatures- $-26^{\circ}, 216^{\circ}$, $330^{\circ}, 445^{\circ}, 550^{\circ}$, and $660^{\circ} \mathrm{C}$.

\section{GENERAL DISCUSSION OF RESULTS}

Temperature regulation throughout the apparatus was not good. There were longitudinal variations of $10^{\circ}$ to $20^{\circ}$ in the tube of material, despite the even winding of the heating coil. It was not always possible to regulate the temperature of the incoming gas to be exactly the same as that of the solid charge. This error was largely compensated for by the fact that the gas coming into the bottom of the column was heated to the temperature of the solids within a few centimeters. The exact data on this item will not be known until the proposed work on heat transfer in beds of broken solids has been completed. The temperatures as recorded are average values. Individual variations amounted to $10^{\circ}$ to $25^{\circ} \mathrm{C}$. Pressure-drop readings were accurate to within 5 per cent, as were the readings on rates of flow.

The inaccuracies in temperature control precluded the possibility of obtaining really accurate data. To make an accurate study of the 
effect of temperature, it will be necessary to construct a much more delicate apparatus. However, these data are sufficiently accurate for the formulation of general laws, and their accuracy far transcends the field of nonvariation in the study of the blast furnace, to which these

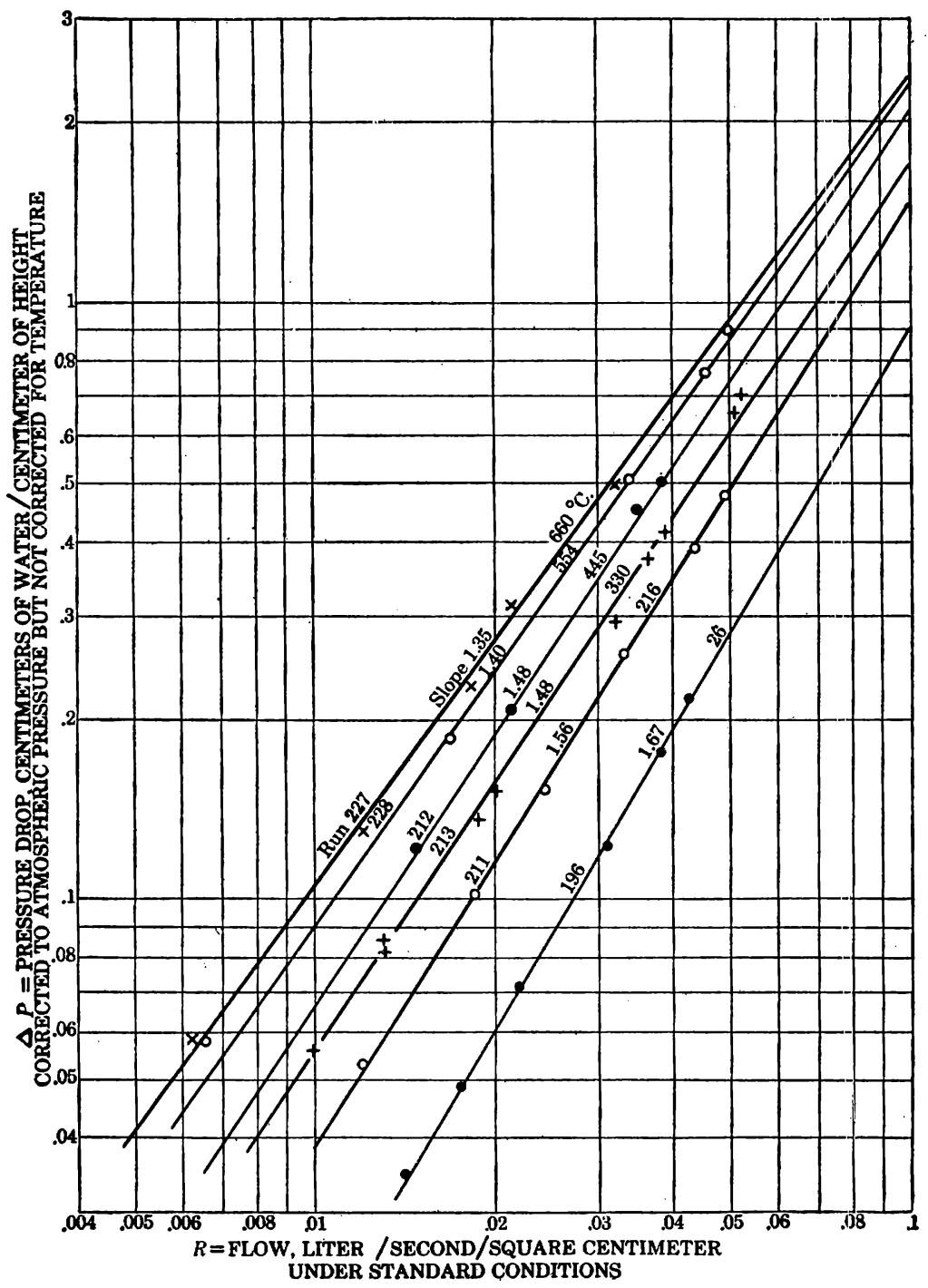

Figure 67.-Pressure drop for air at various temperatures. Material: 6,000 grams of 0.625-inch to 3 -mesh plus 4,000 grams of 4 to 6 mesh Mesabi ore

data are to be applied. The acquisition of more accurate data is left to some investigator with more time at his disposal.

The observed data of the temperature runs are graphically presented in Figure 67. As in all former tests, when the logarithm of the pres 
sure drop is plotted against the logarithm of the rate of flow the curve is a straight line. There are some discrepancies in the sets of data caused by temperature variations. On the whole, the data are accurate and consistent enough to convey the necessary information concerning the effect of temperature.

The pressure drops recorded in Figure 67 are not standard. The data are computed to the standard pressure of 76 centimeters of mercury, but no correction has been made for temperature, the latter being as indicated on the curves. It will be observed that as temperature increases the pressure drop for a given flow increases, but the slope of the line decreases. This is the same general effect as observed with change of size of particles. As in all other cases the study of the effect of temperature consists of a study of its effect on the values of $A$ and $B$ in equation (1).

\section{EFFECT OF VARYING DENSITY AND VISCOSITY OF GAS}

\section{GENERAL DISCUSSION}

The flow of fluids through a uniform circular conduit is well represented by Fanning's equation,

$$
\Delta P=\frac{4 f P L u^{2}}{2 g d},
$$

where $f$ is a friction factor,

$P$ is the density of the gas,

$L$ is the length of the conduit,

$u$ is the linear velocity,

$g$ is acceleration due to gravity, and

$d$ is the diameter of the passage.

Dimensional analysis ${ }^{24}$ has shown that the friction factor $f$ for flow through conduits must vary as some function of $\left(\frac{z}{d u s}\right)$,

where $z$ is the viscosity of the fluid,

$d$ is the diameter of the passage,

$u$ is the linear velocity, and

$s$ is the specific gravity.

This means that all of these variables must enter into the equation to the same degree, that is, to the same power.

More recent compilation of data ${ }^{25}$ has shown that for various fluids $f$ varies directly as $\left(\frac{z}{d u s}\right)^{n}$ for flow through uniform conduits. If

\footnotetext{
24 Reynolds, Osborne, Trans. Roy. Soc. London, 1883, p. 935, and “Scientific Papers" of Reynolds, Osborne, Cambridge University Press, vol. 1, 1900, On Certain Dimensional Properties of Matter in the Gaseous State, pp. 257-390; and vol. 2, 1901, The Law of Resistance in Parallel Channels, pp. 51-105.

${ }_{25}$ Wilson, R. E., McAdams, W. H., and Seltzer, M., The Flow of Fluids Through Commercial Pipe Lines: Jour. Ind. and Eng. Chem., vol. 14, No, 2, 1922, pp. 105-119.
} 
this fact is applied to Fanning's equation (47), the equation for the flow of fluids through a conduit may be written

$$
\Delta P=K\left(\frac{2}{d u s}\right)^{n} \frac{s u^{2}}{d}=\frac{K z^{n} s^{1-n} u^{2-n}}{d^{1+n}},
$$

where $K$ is the general expression for any constant. It is not unreasonable to suppose that this equation may apply in a generall way to the flow of gas through beds of broken solids.

\section{EVIDENCE OF APPLICABILITY OF FANNING'S EQUATION}

Two facts have been presented in the report thus far offering evidence that the friction factor for beds of broken solids is a function of $\left(\frac{z}{d u s}\right)^{n}$.

1. The pressure drop for a given rate of flow (measured in volume of gas flowing per second at standard conditions or as a given weight of a given gas) varies inversely as the over-all pressure or density of the gas, since the density of a gas is approximately proportional to the pressure.

If equation (48) is applied to this phenomenon al! of the variables except $s$ and $u$ are constant, and the equation becomes

$$
\Delta P=K s^{1-n} u^{2-n} .
$$

$u$ refers to the linear velocity of the gas, and if the rate of flow is held constant at a given weight or volume under standard conditions passing a given plane per unit of time $u$ will vary inversely as the specific gravity of the gas; therefore for this case

$$
u=\frac{K}{8},
$$

where $K$ is the general term for any constant:

$$
\text { or } \Delta P=\frac{K s^{1-n}}{s^{2-n}}=\frac{K}{s},
$$

which is the equation for the statement that the pressure drop varies inversely as the pressure.

This proof was general and is applicable whatever the value of $2-n$, which in this case corresponds to $B$ of equation (1). Ample proof of the validity of this relation is given in Figures 25 to 27 .

2. From Figures 36 and 37 and equations (30) and (31) it will be seen that the pressure drop varies as $\frac{1}{d^{J}}$, where $J$ has been found to be greater than 1 in all cases in practice. According to equation (48) the pressure drop should vary as $\frac{1}{d^{1+n}}$, which is in agreement with the foregoing statement. This only serves as qualitative evidence.

It would seem, then, as if equation (48) might be applicable to flow through beds of broken solids. The situation, however, is not as simple as for uniform conduits. In the case of conduits the same values of the modulus $\frac{z}{d u s}$ always gave the same friction factor and 
the same value of $n$. With broken solids it was found that no such simple correlation exists and that different factors of the modulus affect the value of the friction factor and of $n$ differently.

The effect of $d$ on the friction factor and upon $n$ (in the nomenclature of this bulletin, upon $A$ and $B$ ) has been studied and evaluated (figs. 21, 36, and 37), and since $d$ is not a variable in the systems studied it may now be left out of consideration. In the case about to be studied the gaseous velocity will not be a variable, as comparisons of resistance will be made at some fixed rate of flow. However, since $B$ of equation (1) is a constant $n$ apparently does not vary with $u$.

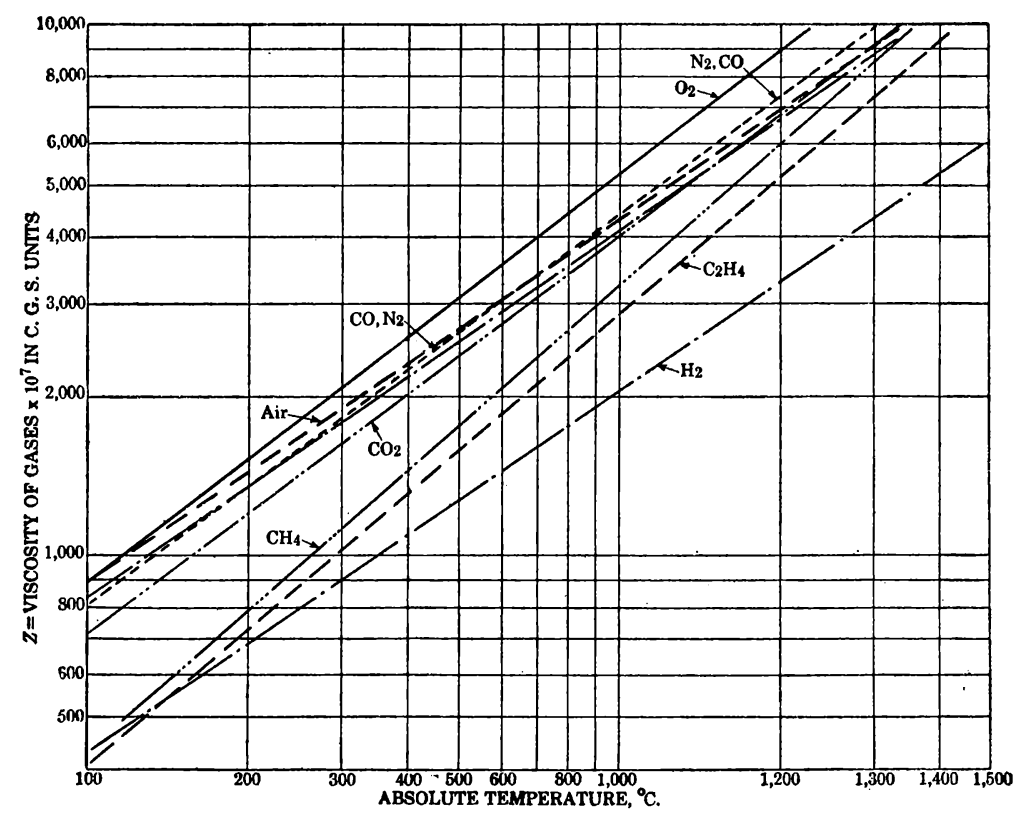

Figure 68.-Variation of viscosities of gases with temperature. Data from various sources

Making these quantities constant, Fanning's equation becomes

$$
\Delta P=K z^{n} \mathcal{S}^{1-n} .
$$

There is no assurance that this equation will express the relations found in systems of tortuous flow, but it is fajrly certain that $z$ and $s$ are necessary and sufficient to determine the conditions. The discussion of this phase of the work from now on necessarily must be empirical.

$$
\text { VARIATION OF } B \text { WITH } \frac{s}{z}
$$

The viscosity of gases increases with temperature. The data that the author used for the values of viscosity of various gases at various 
temperatures are given in Figure 68. These curves represent the best available data in the literature. The specific gravity of air was taken as 0.001293 at $0^{\circ} \mathrm{C}$. and 76 centimeters of mercury.

The data relating $s, z, B$, and $A$ are compiled in Table $14 . \quad n$ is taken as the exponent of the factor $\left(\frac{z}{d u s}\right)^{n}$ of equation (48). It is arbitrarily taken as equal to $2-B$. The value of $n$ has been found to vary $\operatorname{with} \cdot \frac{s}{z}$.

If the values of $\frac{s}{z}$ in Table 14 are plotted as abscissas on a loga-

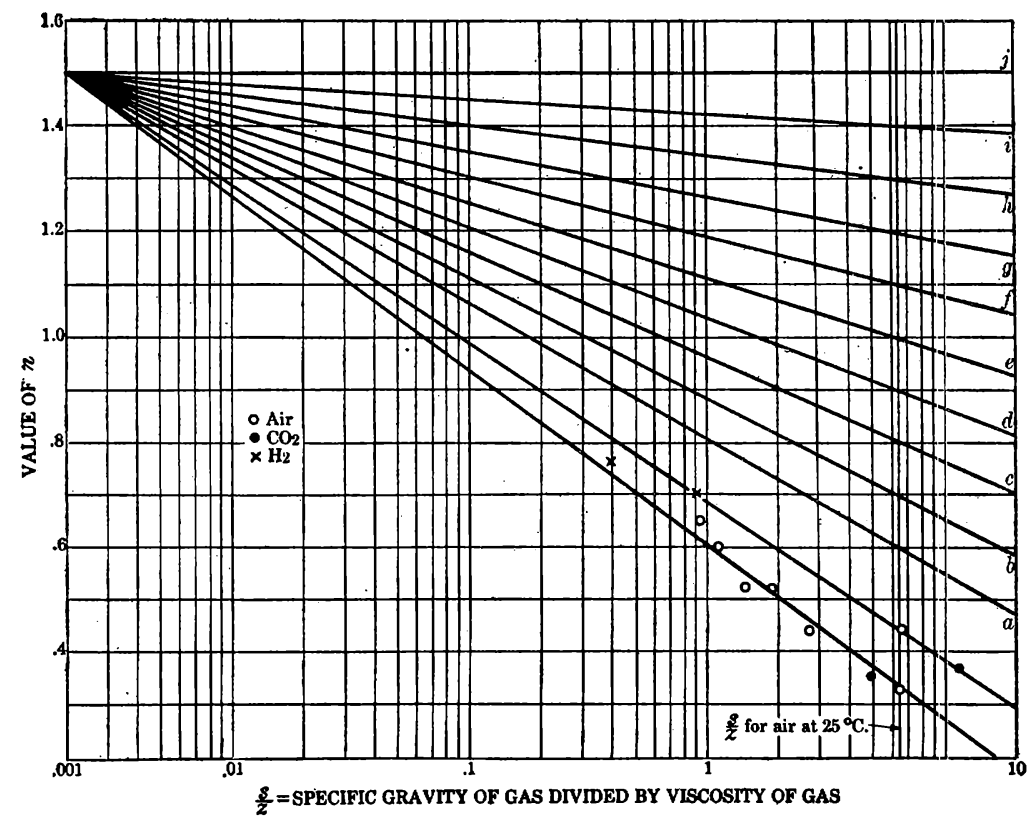

Figure 69.-Relation between $n$, specific gravity, and viscosity of gas for various initial values of $n$

rithmic scale against values of $n$ as ordinates on a linear scale the data are well represented by two straight lines intersecting at an abscissa of 0.002 and an ordinate of 1.5. (See fig. 69.) The lower line is for the variation with temperature; the upper line is for the variation with gas composition.

Although these data are not all-inclusive or very accurate the author feels that the intersection of the two lines at a value of $n=1.5$ has a particular significance. If $n=1.5$, then $B=2-1.5=0.5$.

If the curve of Figure 21 ( $B$ plotted against size of particle) is extrapolated to an abscissa of 0.0 , the value of $B$ is very close to 0.5 . This is not true if $d=0.0$ is substituted in equation (7), but equation (7) does not represent the relation very well at low values of $d$. 
This would be the value of $B$ of equation (1) for a bed of particles of infinitely small diameter and may represent the lower limit that $B$ could have in any system. If this is assumed to be true and the variation of $n$ with the logarithm of $\frac{s}{z}$ is a straight line for any system, then the data of Figure 69 may be generalized to determine the variation of $n$ (or $B$ ) with $\frac{s}{z}$ in any system.

The reference value of $\frac{s}{z}$ is 6.41 , as this is the value for air at $25^{\circ} \mathrm{C}$. and 76 centimeters of mercury. If the value of $n$ for any system is known for this standard condition, the variation is shown by drawing a straight line on the plot of Figure 69 from the point $6.41, n$, to the point $0.002,1.5$. Such a series of lines has been drawn in the figure (lines $a-j$ ).

TABLE 14.-Data showing effect of temperature and gas composition

\begin{tabular}{|c|c|c|c|c|c|c|c|c|c|c|}
\hline Run & Gas & $\begin{array}{l}\text { Compo- } \\
\text { sition } \\
\text { of bed }\end{array}$ & $\begin{array}{l}\text { Average } \\
\text { tempera- } \\
\text { ture, }{ }^{\circ} \mathrm{C} .\end{array}$ & $S^{1} \times 10^{3}$ & $z^{2} \times 10^{7}$ & $\frac{s}{z}$ & $B^{3}$ & $n^{4}$ & $A_{t}{ }^{\circ}$ & $A^{6}$ \\
\hline $\begin{array}{l}196 \\
211, \ldots \\
213,214 \\
212 \\
228 \\
227 \\
256 \\
257 \\
253 \\
252,253 \\
254 \\
255\end{array}$ & 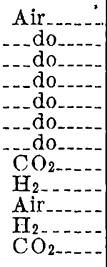 & $\begin{array}{l}a \\
a \\
a \\
a \\
a \\
a \\
a \\
a \\
a \\
b \\
b \\
b\end{array}$ & $\begin{array}{r}26 \\
216 \\
330 \\
445 \\
554 \\
660 \\
215 \\
215 \\
215 \\
23 \\
23 \\
22\end{array}$ & $\begin{array}{r}1.183 \\
.722 \\
.586 \\
.492 \\
.422 \\
.379 \\
.722 \\
1.100 \\
.050 \\
1.190 \\
.082 \\
1.830\end{array}$ & $\begin{array}{r}1,840 \\
2,680 \\
3,090 \\
3,450 \\
3,800 \\
4,100 \\
2,680 \\
2,320 \\
1,250 \\
1,840 \\
900 \\
1,600\end{array}$ & $\begin{array}{r}6.44 \\
2.70 \\
1.90 \\
1.43 \\
1.11 \\
.93 \\
2.70 \\
4.75 \\
.40 \\
6.47 \\
.91 \\
11.4\end{array}$ & $\begin{array}{l}1.67 \\
1.56 \\
1.48 \\
1.48 \\
1.40 \\
1.35 \\
1.56 \\
1.65 \\
1.24 \\
1.56 \\
1.30 \\
1.63\end{array}$ & $\begin{array}{l}0.33 \\
.44 \\
.52 \\
.52 \\
.60 \\
.65 \\
.44 \\
.35 \\
.76 \\
.44 \\
.70 \\
.37\end{array}$ & $\begin{array}{r}41.4 \\
53.7 \\
51.5 \\
62.4 \\
59.0 \\
54.0 \\
\end{array}$ & $\begin{array}{c}37.9 \\
30.0 \\
23.3 \\
23.7 \\
19.3 \\
15.8 \\
31.5 \\
71.0 \\
2.52 \\
123 \\
12.8 \\
200\end{array}$ \\
\hline
\end{tabular}

Note.-Bed $a$ was a uniform mixture of 60 per cent 0.525 to 0.371 inch Mesabi iron ore plus 40 per cent 3 to 4 mesh Mesabi ore. Bed $b$ was a uniform mixture of 47.6 per cent No. 000 lead shot plus 22.4 per cent No. $B$ shot plus 30 per cent No. 12 shot.

1 Specific gravity.

2 Viscosity in C. G. S. units.

a Defined by equation (1).

${ }_{4}^{4}$ Defined by equation (48). Arbitrarily fixed as $2-B$.

5 Value $n f A$ for specified temperature and 76 oentimeters of mercury.

${ }^{\circ}$ Defined by equation (1). Value for standard conditions.

Qualitatively interpreted these lines mean that the larger the initial value of $n$ the smaller the variation with temperature or gas composition.

Probably the curves are not true straight lines but tend to approach the ordinate 1.5 asymptotically. However, it will never be possible fully to investigate this curve, for the point of intersection represents a temperature of approximately $36,000^{\circ}$ C. for air. From experimental data it seems that $n$ may assume negative values as a number of cases have been found in which $B$ was greater than 2.0 .

These data may be interpreted in terms of $B$ instead of $n$. Figure 70 is a plot of $B$ against $\frac{s}{z}$ for various initial values of $B$. "Initial" 
values of $B$ are those at $25^{\circ} \mathrm{C}$. for air or at a value of $\frac{s}{z}=6.41$. These curves are perfectly general, applicable to any system.

The general equation of these lines is:

$$
B=m \log _{10} \frac{s}{z}+b
$$

where

$$
m=\frac{B_{25}-0.5}{3.51},
$$

$B_{25}=$ value of $B$ at $25^{\circ} \mathrm{C}$. for air.

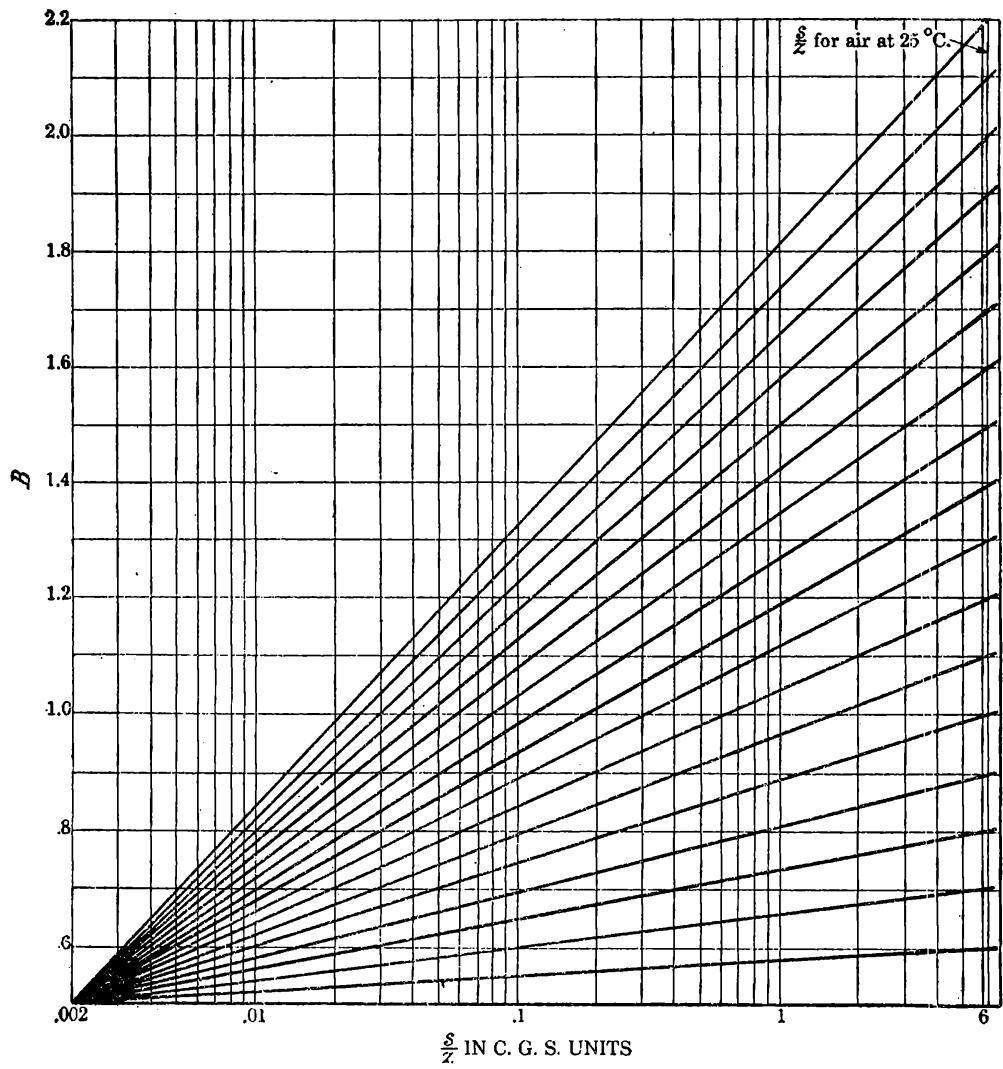

FIGURE 70.- Relation between $B$, gaseous viscosity, and specific gravity for various initial values of $B$

Therefore

$$
\begin{gathered}
\Delta B=\frac{B_{25}-0.5}{3.51} \Delta \log _{10} \frac{s}{z}, \text { and } \\
\Delta B=\frac{B_{25}-0.5}{3.51}\left(\log _{10} \frac{s}{z}-0.807\right) .
\end{gathered}
$$

$\Delta B$ refers to the change of $B$ from the value for $25^{\circ} \mathrm{C}$. and 76 centimeters of mercury. This equation is applicable to any system. $B$ may be directly correlated with the absolute temperature. 
From Figure 68 it will be seen that for air

From the gas laws,

$$
z=K T^{0.68} \text {. }
$$

$$
s=\frac{K}{T}
$$

Therefore for air

$$
\frac{s}{z}=\frac{K}{T^{1.68}}
$$

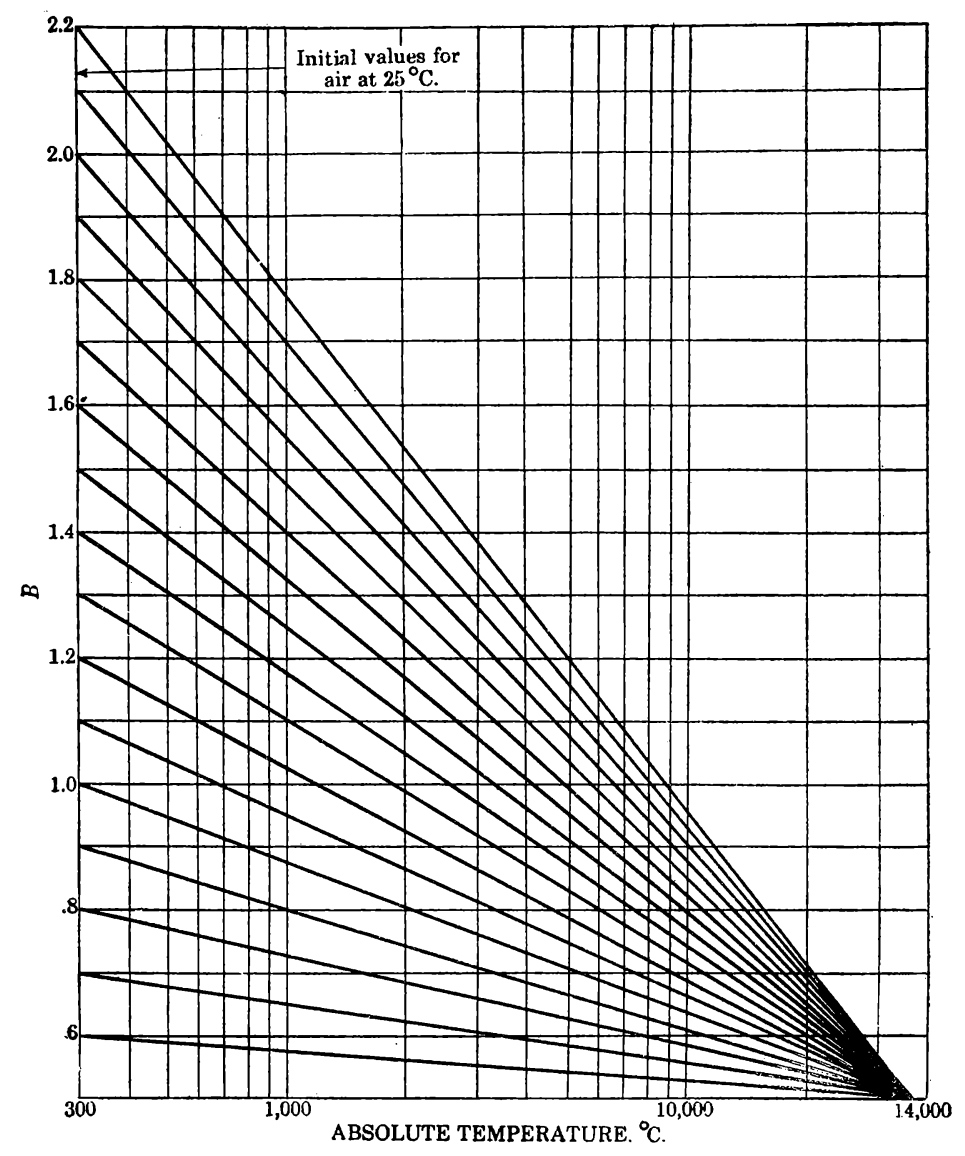

Figurf, 71.-Relation between $B$ and temperature for air at various initial values of $B$

From equations (50) and (51),

$$
B=-\left(B_{25}-0.5\right) 0.479 \log _{10} T+\left(B_{25}-0.5\right) 0.479 K+b .
$$

For any particular initial value of $B$-that is, $B_{25}$ - the last two terms of the equation are constant and the curve of $B$ is a straight line when plotted against the logarithm of $T$, the slope of the line being $-\left(B_{25}-0.5\right) 0.479$. The lines for various values of $B_{25}$ are plotted in Figure 71 . 
EFFECT OF SPECIFIC GRAVITY AND VISCOSITY OF GAS ON VALIUES OF A

TEMPERATURE EFFECT ON AIR

Although there is a definite correlation between the variables, temperature and gas composition and their effect on values of exponent $B$ of equation (1), there seems to be no such correlation in

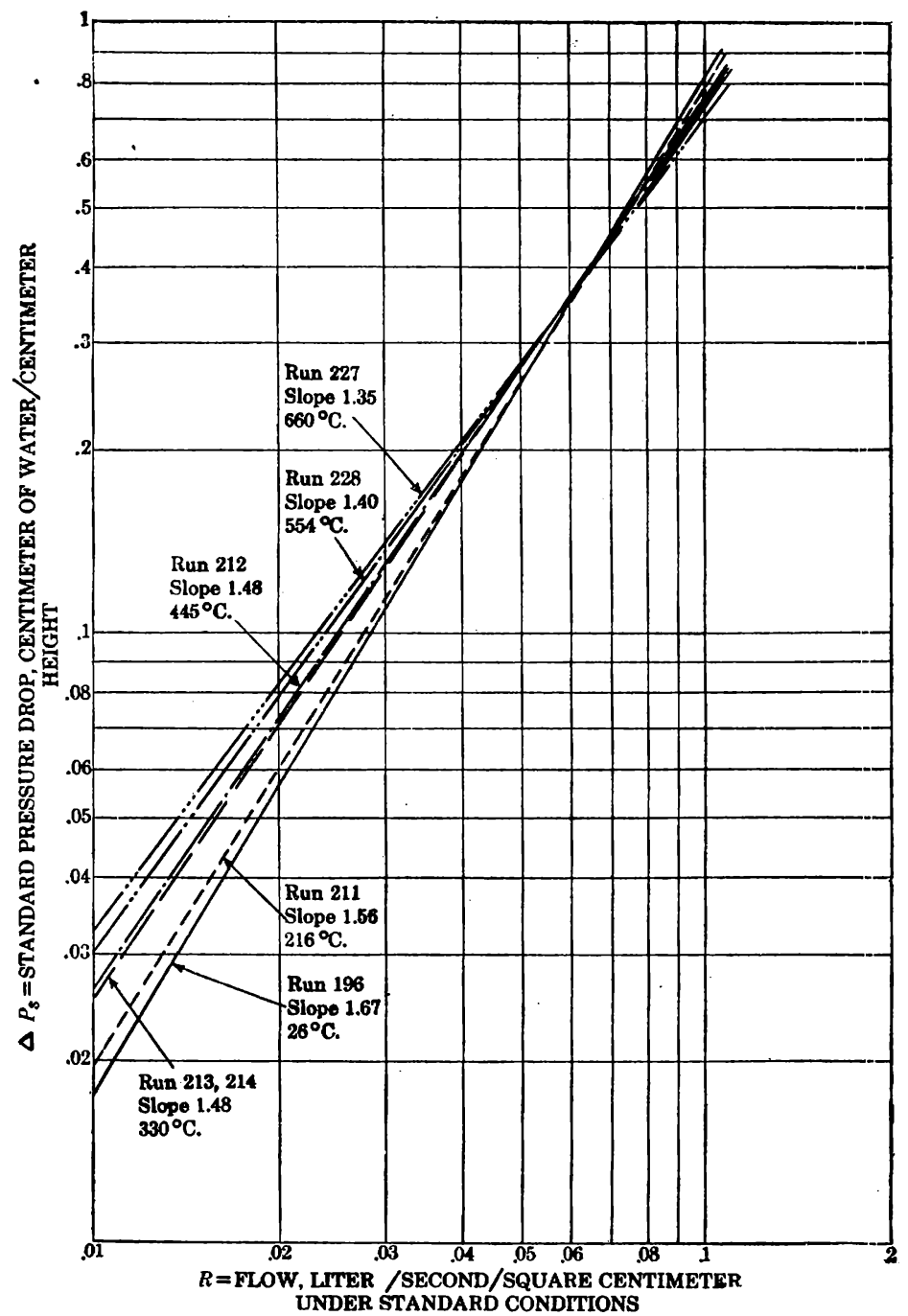

Figure 72.-Standard pressure drop against rate of flow for various temperatures. Material: 6,000 grams of 0.525-inch to 3-mesh plus 4,000 grams of 4 to 6 mesh Mesabi ore

the effect upon the value of coefficient $A$. Gas density and viscosity are the determining variables in each case, but if a change in these variables is brought about by changing the temperature of the gas a different law applies than if the change is produced by varying gas composition. 
The effect of temperature upon air will be considered first. If the curves of the temperature runs as given in Figure 67 are corrected to a standard temperature of $0^{\circ} \mathrm{C}$. (pressure drops computed to standard conditions of temperature and pressure), the curves tend to have a common point of intersection as shown in Figure 72.

By observation the point of intersection has been chosen at a value $R=0.065$

$$
\log _{10} 0.065=-1.187 \text {. }
$$

The general equation of the lines of Figure 67 is

or

$$
\Delta P=A R^{B},
$$

$$
\log _{10} \Delta P=\log _{10} A+B \log _{10} R \text {. }
$$

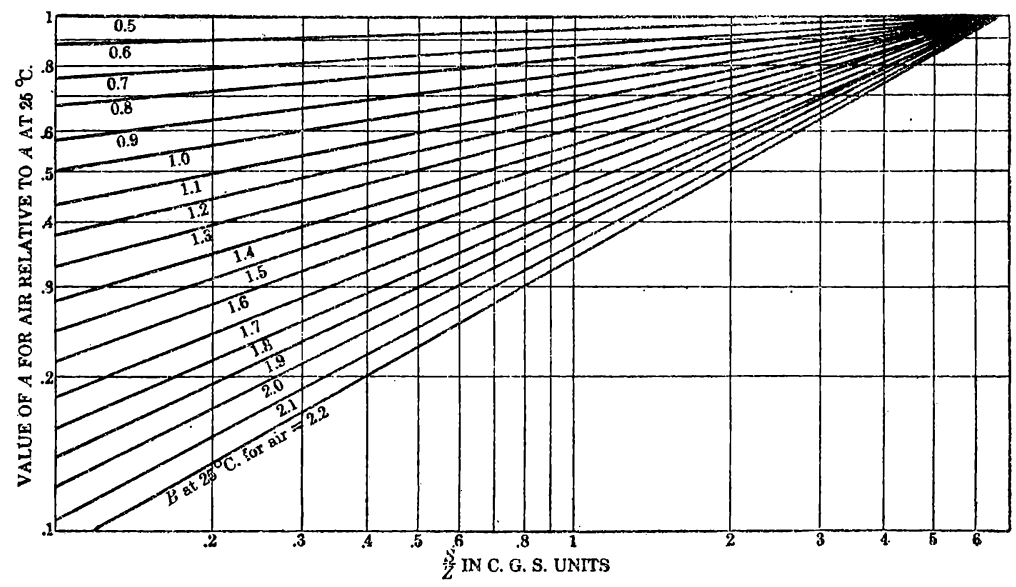

Figure 73.---Relation between relative $A$ and $\frac{s}{z}$ for air; all values relative to value of $A$ at $25^{\circ} \mathrm{C}$; values of $A$ corrected to standard conditions of temperature and pressure

At the common point of intersection values of $\log _{10} \Delta P$ for all the curves are equal and $\log _{10} R=-1.187$.

As an equation,

$$
\begin{gathered}
K=\log _{10} A-1.187 B, \text { and } \\
\log _{10} A=K+1.187 B,
\end{gathered}
$$

where $K$ is a general constant.

This, then, is a general equation giving $A$ in terms of $B$ for systems in which temperature alone is varied.

From equations (50) and (51),

$$
\begin{gathered}
\log _{10} A=K+\frac{1.187}{3.51}\left(B_{25}-0.5\right) \log _{10} \frac{s}{z}, \text { and } \\
\log _{10} A=K+0.338\left(B_{25}-0.5\right) \log _{10} \frac{s}{z},
\end{gathered}
$$


or

$$
A=K\left(\frac{s}{z}\right)^{0.338\left(B_{25}-0.5\right)},
$$

where $K$ is a general constant depending on initial $A$.

From equation (54),

$$
\Delta \log _{10} A=0.338\left(B_{25}-0.5\right)\left(\log _{10} \frac{s}{z}-0.807\right)
$$

These equations apply only to air. $\Delta$ refers to the change of $\log _{10} A$ from the reference state, air at $25^{\circ} \mathrm{C}$, 76 centimeters of mercury. Equation (55) is graphically represented in Figure 73 for a number

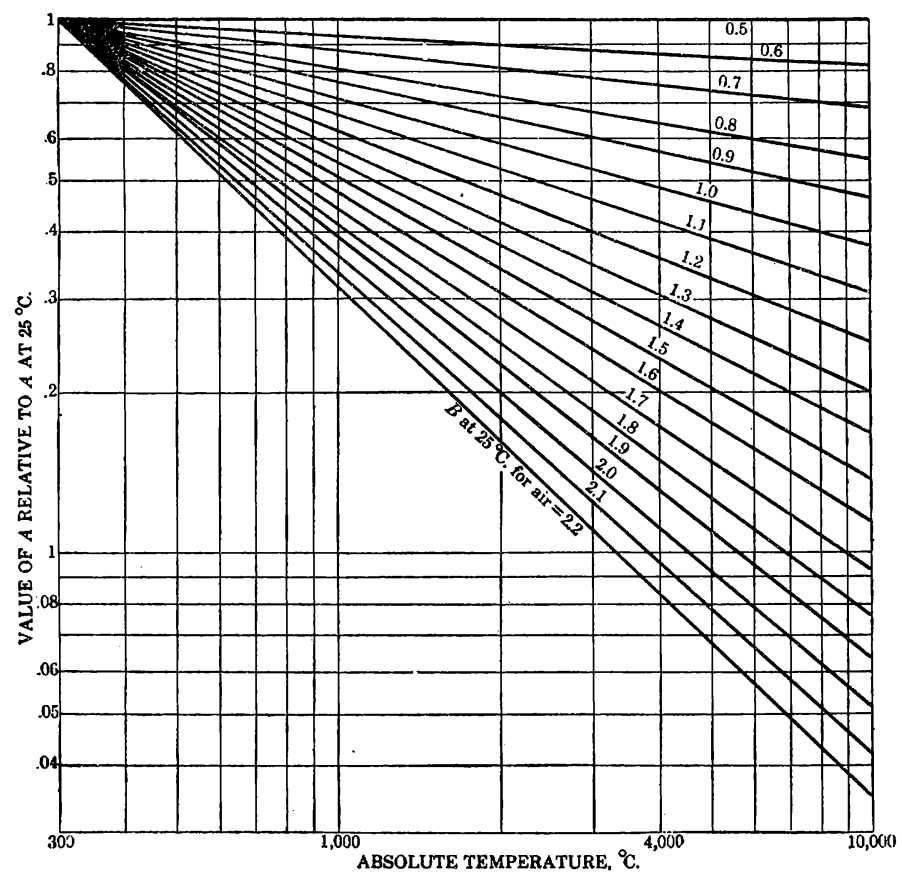

FigURE 74.- Relation between relative $A$ and $T$ for air; all values relative to value of $A$ at $25^{\circ} \mathrm{C}$.; all values for standard conditions of temperature and pressure

of values of $B_{25}$. The ordinate is graduated into fractional values of 1.0 , by which the values of $A$ for air at $25^{\circ} \mathrm{C}$. are to be multiplied to obtain the value of $A$ at the desired value of $\frac{s}{z}$, as on page 124 .

Therefore, for air

$$
\frac{s}{z}=\frac{K}{T^{1.68}}
$$

Substituting in equation (55),

$$
A=K\left(\frac{1}{T}\right)^{1.68 \times 0.338\left(B_{25}-0.5\right)}=K T^{-0.568\left(B_{25}-0.5\right)}
$$


The graph of this equation for a number of different values of $B$ is given in Figure 74. The factor for $A$ for any given temperature may be read directly from this figure. $A$ in this case, as in all others, refers to the standard conditions of temperature and pressure.

Since pressure drop at all rates of flow varies inversely as the density of the gas and since density of a gas varies inversely as the absolute temperature,

$$
A_{T}=\frac{T}{273} A
$$

where $A_{T}$ is the value for $A$ at the specified temperature and $T$ is the absolute temperature.

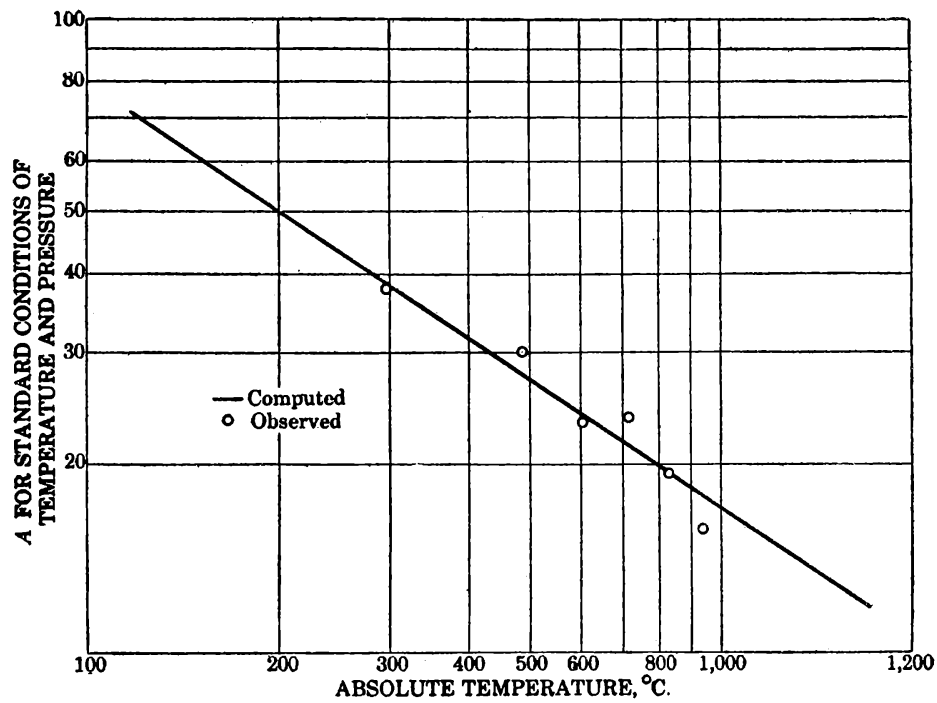

FIgURE 75.-Relation between $A$ and $T$ for air for a particular system; computed and observed values. Material: 6,000 grams of 0.525 -inch to 3-mesh plus 4,000 grams of 4 to 6 mesh Mesabi ore

A comparison of computed and observed $A$ 's with changing temperature is shown in Figure 75.

For the particular system that was studied for the effect of temperature $B_{25}=1.67$. According to equation (55c) then

$$
A=K T^{-0.568(1.67-0.5)}=\frac{K}{T^{0.665}} .
$$

In Figure 70, $T$ is plotted against $A$, both axes graduated in the logarithmic scale. The slope of the predicted line as drawn is -0.665 , and it passes through the datum point for $A$ at $25^{\circ} \mathrm{C}$. The other observed data points are indicated on the graph. The agreement is quite satisfactory. 


\section{VARIATION OF A WITH GAS COMPOSITION}

If $s$ and $z$ are changed by altering the gas composition, the variation of $A$ follows the general law represented by equation (54) or (55), but the constants in the exponent assume a different value. To obtain data on this variation, runs on three different gases, air, hydrogen, and carbon dioxide, were made at two different temperatures, $23^{\circ}$ and $215^{\circ} \mathrm{C}$. The data are given in Table 14. The data

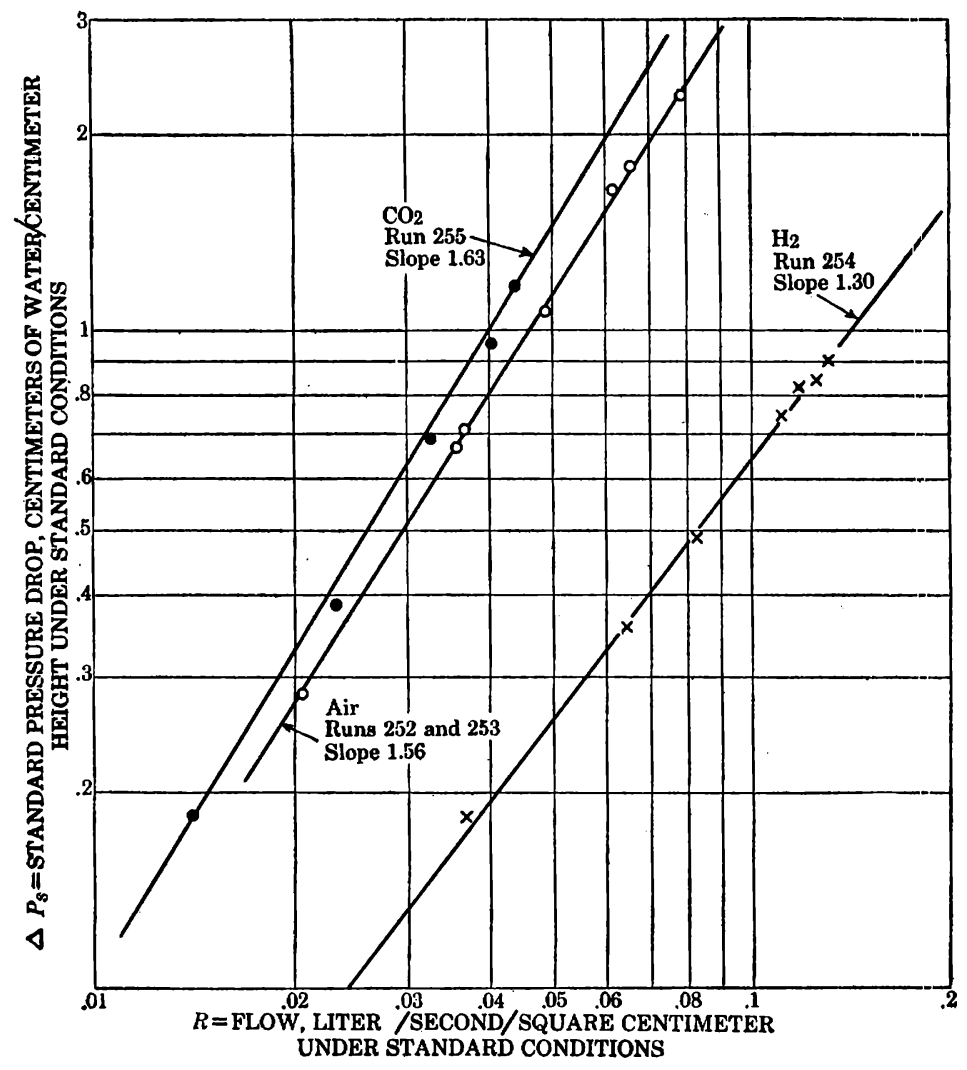

Figdre 76,-Pressure drop for various rates of flow for different gases. Material: 5,000 grams of No. 000 shot plus 3,150 grams of No. 12 shot

of standard pressure drop against rates of flow are plotted in Figures 76 at $23^{\circ} \mathrm{C}$. and 77 at $215^{\circ} \mathrm{C}$. The two sets of curves can not be compared directly, as they were taken on two entirely different beds of materials. Both sets tend to converge to a common point, which would be somewhere beyond the left margin of the figure. It is evident that the common point of intersection has a much different value than for the runs made on a single gas at various temperatures. (See fig. 72.) 
The point of intersection is so far out of the range of observed values that extrapolation for its determination would not be feasible, but the value of $R$ at the point of intersection for any two lines can easily be computed and the average of all such values be taken as the common point.

The results of such computations are given in Table 15. The values of $A$ and $B$ used were taken from Table 14 . It will be noted

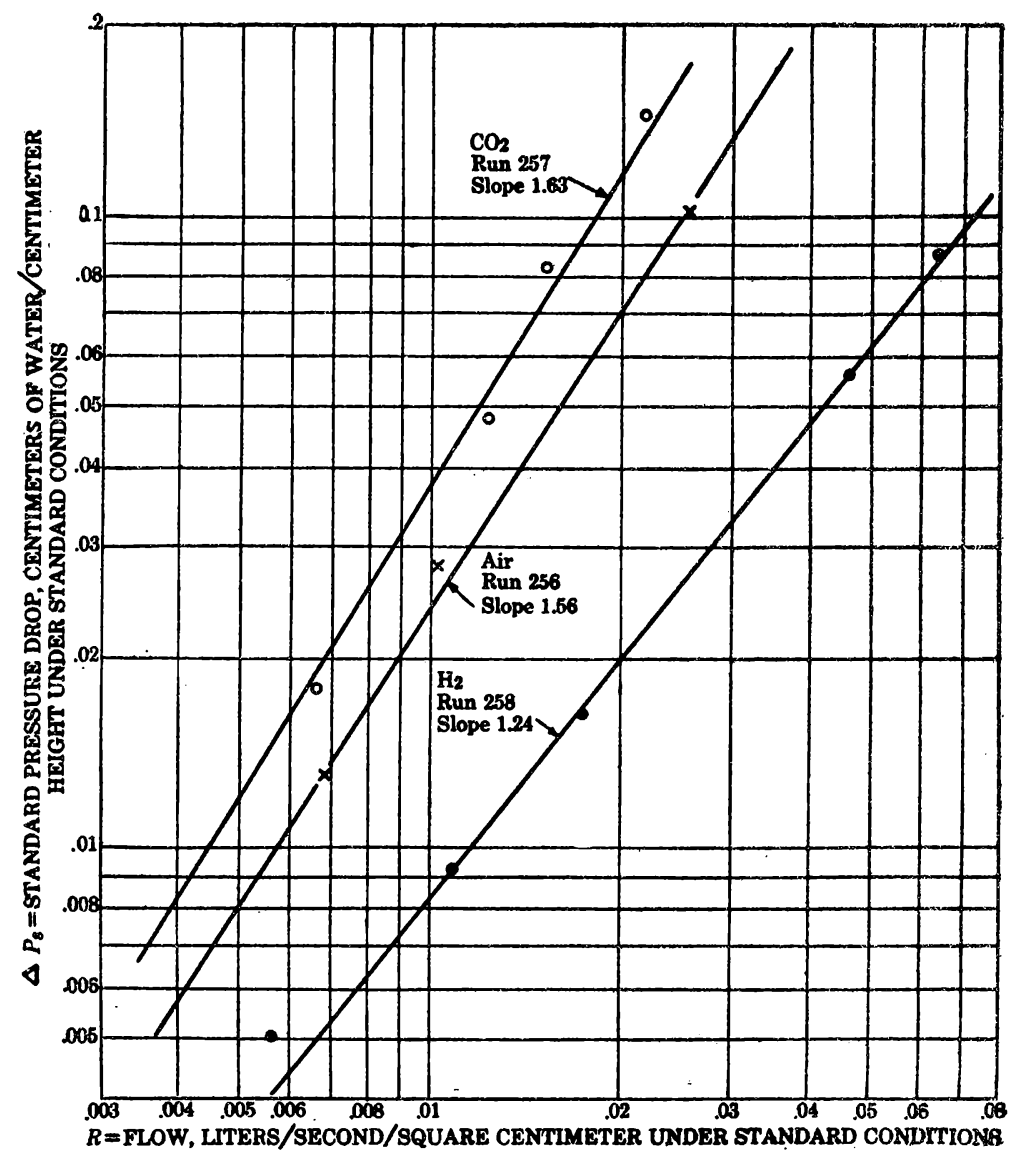

Figure 77.-Pressure drop for various rates of flow for different gases; average temperature, $215^{\circ} \mathrm{C}$. Material: 6,000 grams of 0.525 -inch to 3-mesh plus 4,000 grams of 4 to 6 mesh Mesabi ore

in Table 15 that the logarithms of the values of $R$ at the point of intersection are fairly constant and independent of temperature. This means that if the standard pressure drops through a given system are plotted against rates of flow for a number of different gases at any constant temperature the curves will all pass through a common point where $\log _{10} R=-3.51$, or $R=0.000309$ liter per second per square centimeter, and the value of this point is independent of 
temperature. In the equations that follow the logarithms of the numbers only are of importance.

Since the curves for different gases pass through a common point, an equation for the variation of $A$ with changing $\frac{s}{z}$ effected by changing gas composition at any constant temperature can be derived in exactly the same manner as was done for change of temperature with constant gas composition.

TABLE 15.-Points of intersection for constant temperature and varying gas composition

\begin{tabular}{|c|c|c|c|c|c|}
\hline $\begin{array}{l}\text { A verage temperature, } \\
{ }^{\circ} \mathrm{C} \text {. }\end{array}$ & $\begin{array}{l}\text { Gases consid- } \\
\text { ered }\end{array}$ & $\begin{array}{l}\log _{10} R \\
\text { at point } \\
\text { of inter- } \\
\text { section }\end{array}$ & $\begin{array}{l}\text { A verage temparature, } \\
{ }^{\circ} \mathrm{C} \text {. }\end{array}$ & $\begin{array}{l}\text { Gases consid- } \\
\text { ered }\end{array}$ & $\begin{array}{l}\log _{10} R \\
\text { at point } \\
\text { of inter- } \\
\text { section }\end{array}$ \\
\hline $\begin{array}{l}23 \\
23 \\
23\end{array}$ & $\begin{array}{l}\mathrm{Air}-\mathrm{COO}_{2} \ldots \\
\mathrm{H}_{2}-\mathrm{air} \\
\mathrm{H}_{2}-\mathrm{CO}_{2} \\
\mathrm{Air}-\mathrm{CO}_{2} \ldots\end{array}$ & $\begin{array}{l}-3.015 \\
-3.778 \\
-3.617 \\
-3.917\end{array}$ & Average & $\begin{array}{l}\mathrm{H}_{2}-\mathrm{air}_{\mathrm{H}} \\
\mathrm{H}_{2}-\mathrm{CO}_{2}\end{array}$ & $\begin{array}{l}-3.428 \\
-3.325 \\
-3.51\end{array}$ \\
\hline
\end{tabular}

The elementary form of the equation for the latter condition is given as equation (54). In equation (54) the expression $\frac{\left(B_{25}-0.5\right)}{3.51}$ is the slope of the straight-line curve of the variation of $B$ with $\log _{10} \frac{s}{z}$, as shown by Figure 70 .

The standard of comparison for temperature runs for air was chosen as $25^{\circ} \mathrm{C}$. The value of $\frac{s}{z}$ for air at $25^{\circ} \mathrm{C}$. is 6.41 . The point of intersection for all the curves of Figures 70 and 71 is at $\frac{s}{z}=0.002$. The figure 3.51 is the logarithm of this increment of the abscissa. The fact that its value is the same as the point of intersection for changing composition as shown in Table 14 is purely a coincidence and no significance should be attached thereto. $B_{25}-0.5$ is the corresponding increment of the ordinate and the quotient of the two is the slope of the curve. In exactly the same manner the equation that relates changes in $A$ with changes in $\frac{s}{z}$ caused by varying composition of the gas must have a term that is the slope of the $B$ curve.

The change of $B$ with $\frac{s}{z}$ is insensible to the origin of the change of $\frac{s}{z}$; that is, it does not depend on whether $s$ and $z$ are changed through the medium of temperature or of gas composition. The expression for the slope of the curve then depends entirely upon the point that is chosen for reference. 
The logical reference point is $B_{\text {alr }}$, that is, the value of $B$ for the system at the particular temperature under consideration. Only when the system considered is at $25^{\circ} \mathrm{C}$. will the value of the reference $\frac{s}{z}$ be 6.41. The general expression for the slope to be used in the equation for changing gases then is

$$
\frac{B_{\mathrm{a} 1 \mathrm{r}}-0.5}{\left(\frac{s}{z}\right)_{\mathrm{a} 1 \mathrm{r}}}
$$

The development of the equation requires that this slope be multiplied by the value of $\log _{10} R$ at the common point for all the curves of $\Delta P$ plotted against $R$. With constant gas composition and changing temperature this value of $\log _{10} R$ was -1.187 . With constant temperature and changing gas composition $\log _{10} R$ for the common point is -3.51 . Making these changes as indicated above in the elementary equation,

$$
\log _{10} A=K+\frac{3.51\left(B_{\mathrm{atr}}-0.5\right) \log _{10} \frac{s}{z}}{\left(\frac{s}{z}\right)_{\frac{\mathrm{atr}}{t}}}
$$

is the elementary equation for the variation of $A$ with $\frac{\mathcal{s}}{z}$, when the change in $\frac{s}{z}$ is produced by changing gas composition. In the exponential form

$$
\begin{aligned}
& \frac{3.51\left(B_{\mathrm{ain}}-0.50\right)}{\log \frac{s}{\frac{8}{z_{\mathrm{air}}}}} \\
& A=K\left(\frac{s}{z}\right) \quad \cdot \frac{t}{0.002}
\end{aligned}
$$

In these equations $K$ is a general constant, the value of which depends upon the initial value of $A$. According to the above equations, if $A$ is plotted against $\frac{s}{z}$ on paper graduated in the logarithmic scale on both axes the curves will be a straight line, the slope of which is given by the exponential expression.

The observed and computed curves for change of $A$ with $\frac{s}{z}$ for these gases is given in Figure 78 for the two different temperatures studied. The maximum error in the predicted curves is for hydrogen at $215^{\circ} \mathrm{C}$. 
The error is 25 per cent. The accuracy is commensurate with the rest of the quantitative theory as developed.

\section{EFFECT OF MOLECULAR WEIGHT OF GASES}

The reason that, although $\frac{s}{z}$ is the independent variable in both cases, different laws probably are necessary to evaluate $A$ if tempera-

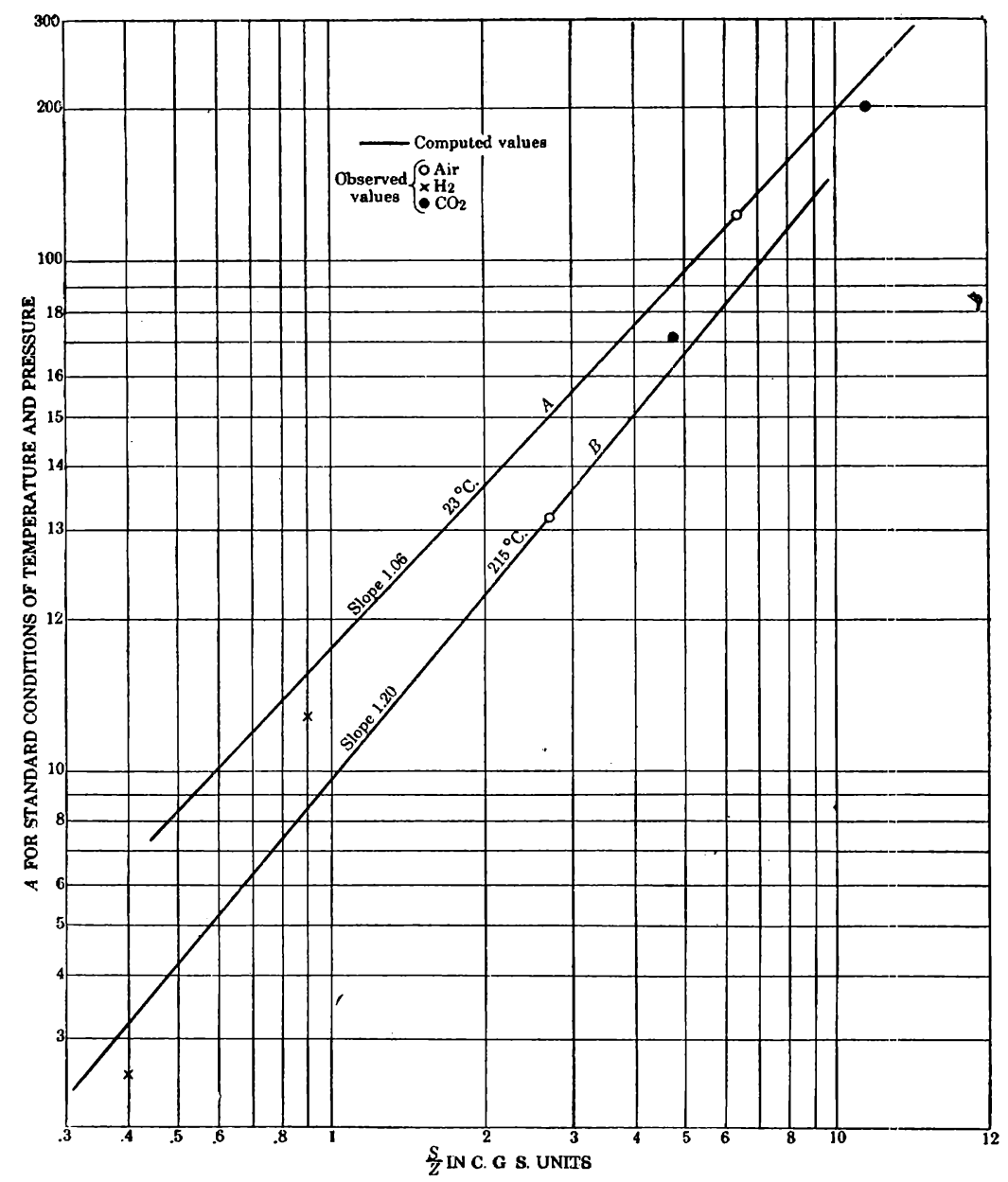

FigURe 78.-Observed and computed relations between $A$ and $\frac{s}{2}$ with changing gas composition for two different systems: $A, 5,000$ grams of No. 000 shot, 2,350 grams of No. B shot, and 3,150 grams of No. 12 shot; $B, 6,000$ grams of 0.525 -inch to 3 -mesh and 4,000 grams of 4 to 5 mesh Mesabi ore

ture is varied than if gas composition is changed lies in the two possibilities of changing the specific gravity of a gas.

The weight of a gas at a given pressure may be decreased by increasing the mobility of the molecules; that is, by raising the temperature. This increased random mobility makes it more difficult to force the $43318^{\circ}-29-9$ 
mass through a given tortuous path. On the other hand, the weight of a given volume may be decreased by decreasing the weight of the individual molecules, that is, by changing the composition of the gas. The lighter molecules possess less inertia, hence turn corners more easily and are more easily pushed through a tortuous passage. Change in specific gravity of the gas has an opposite effect in the two conditions, hence the necessity for enunciating two laws.

\section{MIXTURES OF GASES}

The values of $A$ and $B$ can be computed for a mixture of gases if $s$ and $z$ are known for the mixture. Gases form practically perfect solutions; hence the specific gravity $s$ is an additive property of the composition. The viscosity of a mixture of gases does not always vary in any such simple manner. The data on this subject are very fragmentary. The data of one investigator ${ }^{26}$ are presented in Figure 79. It will be observed that mixtures containing hydrogen are the ones that deviate most from an additive function. From the observation of these data the author suggests that the viscosities of mixtures of most of the common industrial gases except hydrogen be considered an additive property of the composition. If considerable quantities of hydrogen are in the mixture, the curves of Figure 79 should be used.

There are no data on the variation of the viscosities of gas mixtures with temperature. It is known, however, that viscosities vary according to the equation

$$
z=K T^{q},
$$

where $q$ is a constant for any given gas and has a value between 0.5 and 1 . The value for a given gas mixture can be estimated from the slopes of the various lines of Figure 68, the line being selected that is nearest in composition and value to the initial viscosity of the given mixture.

\section{SAMPLE COMPUTATION OF EFFECT OF CHANGING TEMPERATURE AND GAS COMPOSITION}

Problem.-Compute the pressure drop in centimeters of water per centimeter of column when hydrogen at $1,000^{\circ} \mathrm{C}$. flows through a bed of material of the composition of run 226 (see Table 9) in the specified container, 38.1 centimeters in diameter, if the material finer than 14-mesh is lifted from the bed and $R=0.10$ liter per second per square centimeter.

Composition of bed (volume fraction): One-sixth fine Provo ore, one-twelfth medium Provo ore, one-twelfth coarse Provo ore, and two-thirds Provo coke.

${ }^{80}$ Hofsăss, M., Über die Zăhigkeit von Gasen: Jour. Gasbel, vol. 62, 1919, p. 776; Chem. Abs., vol. 14, 1920, p. 2111. 
Predicted equation for air at $25^{\circ}$ C. (see p. 99),

$$
\Delta P_{s}=11.0 R^{2.0} \text {, }
$$

where $\Delta P_{s}$ is the pressure drop for gas at $0^{\circ} \mathrm{C}$. and 76 centimeters of mercury.

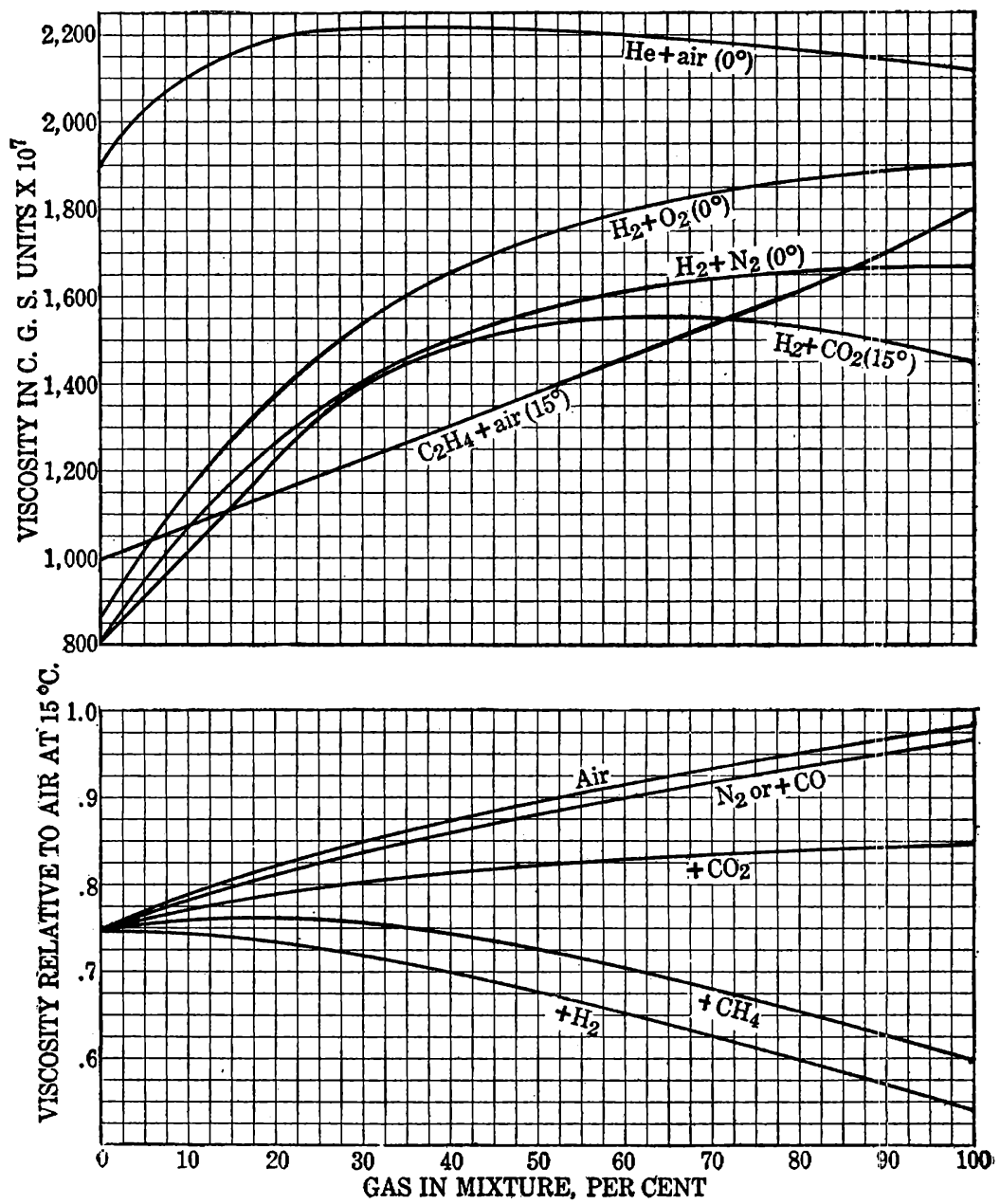

Figure 79.-Viscosity of gaseous mixtures. Data from Hofsäss, M., Jour. Gasbeliguchtung, Jahrg. 62,1919 , p. 776. Lower half of figure shows coal-gas compositionl to be 43.6 per: cent $\mathrm{H}_{2}$, 21.2 per cent $\mathrm{CH}_{4}, 7.4$ per cent $\mathrm{CO}, 3.6$ centimeters $\mathrm{HC}, 5.2$ per cent $\mathrm{CO}_{3}, 0.4$ per cent $\mathrm{O}_{2}, 18.6$ per cent $\mathrm{N}_{2}$

Specific gravity of hydrogen at $1,000^{\circ}$ C. $=\frac{2.016}{22,400} \times \frac{273}{1,000+273}=$ 0.0000192 .

$z$ from Figure $68=2,420 \times 10^{-7}$

$$
\frac{s}{z}=\frac{192 \times 10^{-7}}{2,420 \times 10^{-7}}=0.0694 \text {. }
$$


Evaluating $B$ : From equation (60) the value of $B$ for air at $25^{\circ} \mathrm{C}$. is 2.0 .

From Figure $71 B$ for $\mathrm{H}_{2}$ at $1,000^{\circ} \mathrm{C} .\left(\frac{s}{z}=0.0694\right)$ with initial $B=2.0$ is 1.15 .

Evaluating $A$ : In evaluating $A$ for the given condition the gas may be considered as being changed from air in the reference state, $25^{\circ} \mathrm{C}$., to air at $1,000^{\circ} \mathrm{C}$, then changed from air at $1,000^{\circ} \mathrm{C}$. to hydrogen at $1,000^{\circ} \mathrm{C}$.

From Figure 74 the $A$ factor for air at $1,000^{\circ} \mathrm{C}$. is 0.25 .

From equation (61), $A$ for air at $1,000^{\circ} \mathrm{C} .=4.4$.

$$
\begin{gathered}
\frac{s}{z} \text { for air at } 1,000^{\circ} \mathrm{C} .=\frac{0.277 \times 10^{-3}}{5,100 \times 10^{-7}}=0.544 . \\
\frac{s}{z} \text { for hydrogen at } 1,000^{\circ} \mathrm{C} .=0.0694 .
\end{gathered}
$$

From equation (59) and Figure 71,

$$
A=K\left(\frac{s}{z}\right)^{\frac{3.51(1.55-0.50)}{\log _{10} \frac{0.544}{0.002}}}=12\left(\frac{s}{z}\right)^{1.47} .
$$

Conversion factor for $A$ from air to $\mathrm{H}_{2}$ at $1,000^{\circ} \mathrm{C}$. is given by

$$
\text { Factor }=\left(\frac{0.0694}{0.544}\right)^{1.47}=0.0483 \text {. }
$$

$A$ for $\mathrm{H}_{2}$ at $1,000^{\circ}$ C. $=4.4 \times 0.0483=0.213$, and

$$
\Delta P_{s}=0.213 R^{1.15} \text {. }
$$

This is the equation for the pressure drop corrected to standard conditions of temperature and pressure. The actual pressure drop at $1,000^{\circ} \mathrm{C}$. is inversely proportional to the density of the gas or directly proportional to the absolute temperature.

$$
\text { Factor }=\frac{1,273}{273}=4.66 \text {. }
$$

Therefore in the specified system, with hydrogen at $1,000^{\circ} \mathrm{C}$,

Therefore, $\Delta P=0.993 R^{1.15}$

$$
A=4.66 \times 0.213=0.993 \text {. }
$$

when $R=0.1$

$$
R^{1.15}=0.0708
$$

$\Delta P=0.993 \times 0.0708=0.0704$ centimeter of water per centimeter of height. This is the answer sought.

This figure is for the specified mixed bed of Provo ore and coke in the designated circular container 38.1 centimeters in diameter. For comparison it should be noted (p. 99) that the predicted pressure 
drop for $R=0.1$ for air at $25^{\circ}$ C. was 0.11 centimeter of water per centimeter of height. The change in temperature has largely compensated for the change in molecular weight of the two gases.

\section{DOWN DRAFT}

Since the density of gas at 1 or 2 atmospheres pressure is so small the effect of gravity on the pressure drop is negligible, and it is immaterial whether the gas is forced up or down relative to gravity.

If a bed contains a great deal of very fine material down draft will tend to pack it together and thus increase its resistance, just as up draft tends to lift the fines and decrease the resistance.

\section{EFFECTIVE TEMPERATURE OF A SYSTEM}

The foregoing development has concerned itself only with isothermal systems. In most industrial applications it will be found that there. is a temperature gradient throughout the apparatus studied. In such cases there will be a difference between the temperature of the solid material of the bed and the gas stream. The question arises: What temperature determines the characteristics of the system? The answer is: The temperature of the gas. The temperature of the solids has no effect on the resistance except indirectly as it changes the temperature of the gases.

If there is a temperature gradient along the gas stream, the column may be divided into small sections and the resistance computed for each portion on the basis of the average gas temperature over that region.

Data are not available as yet on heat transfer between gas and solids in beds of broken solids, but the author's next task is to work on this problem. When these data are available, it should be possible to predict the temperature gradient in a given gas stream as well as the pressure drop.

\section{PRESSURE DROP IN LONG COLUMNS}

It was shown (p. 26) that the rate of pressure drop with change of height is inversely proportional to the total pressure on the gas. Hence, if a column of material is long the pressure drop between the two ends will be sufficient to affect the rate of pressure drop. As a first approximation it is permissible to take the average total pressure as the arithmetical mean of the two ends of the column and compute the pressure drop per unit of height for that pressure and consider it constant for the length of the column. This was the procedure used by the author in standardizing the pressure drops (see p. 30), but the experimental work was all done on short columns. 
Wherever the pressure drop becomes a large fraction of the total pressure-in the blast furnace, for instance-more exact means of evaluation must be employed.

The development is quite simple. In general,

$$
\frac{d P}{d h}=\frac{K P_{\mathrm{o}}}{P} .
$$

Equation (65) is simply the statement of the law that the pressure drop per unit height of column varies inversely as the total pressure.

and

$$
P d P=P_{\mathrm{o}} K d h
$$

$$
\frac{P^{2}}{2}=P_{0} K h+\frac{P_{0}^{2}}{2}
$$

where $P_{\mathrm{o}}$ is the total pressure at the exit end of the column and $P$ is the total pressure at the entrance.

$P-P_{\mathrm{o}}=$ total pressure drop.

$h$ is the total height of the column.

$K$ is the pressure drop per unit of height at the temperature of the system and at pressure $P_{\mathrm{o}}$.

$$
\begin{gathered}
P=\sqrt{P_{\mathrm{o}}\left(2 K h+P_{\mathrm{o}}\right)}, \\
\text { or pressure drop }=\Delta P=\sqrt{P_{\mathrm{o}}\left(2 K h+P_{\mathrm{o}}\right)}-P_{\mathrm{o}} .
\end{gathered}
$$

It is necessary, of course, to have $K h$ and $P_{\mathrm{o}}$ in consistent units.

In many cases, notably the blast furnace, $K$ is not constant but varies with different values of $h$ because of temperature or gas composition variations.

In such a case $\int P_{\mathrm{o}} K d h$ is no longer $P_{\mathrm{o}} K h$ but some unknown function of $h$. In this general case then equation (69) becomes

$$
\Delta P=\sqrt{P_{\mathrm{o}}\left(2 \int K d h+P_{\mathrm{o}}\right)}-P_{\mathrm{o}},
$$

where $K$ is a variable but by definition is still the value for pressure drop per unit of height if the pressure $=P_{\mathrm{o}}$. If $K$ can not be expressed as a function of $h$ the integration can be performed graphically.

\section{EXAMPLE}

Gas is flowing through a bed of broken solids 20 meters high. The bed is of uniform temperature throughout. The resistance of the bed and the flow of gas are such that at the top, where the pressure is 10 centimeters of water, the pressure drop per centimeter of height $=1.5$ centimeters of water. The atmospheric pressure is 75.0 centimeters of mercury. What is the pressure at the bottom of the column? 
Solution:

Atmospheric pressure $=75.0 \times 13.6=1,020$ centimeterss of water, $P_{\text {o }}$ (at top of column) $=1,020+10=1,030$ centimeters of water, $K=1.5$ centimeters of water per centimeter of height, and $h=2,000$ centimeters.

Using equation (68),

$P=\sqrt{1,030(6,000+1,030)}=2,691$ centimeters of water, $=2.6$ atmospheres.

If the effect of total pressure had been neglected, the computed pressure drop would have been $K h=3,000$ centimeters of water and the total pressure 4,030 centimeters of water, or 3.9 atmospheres, an error of 50 per cent in total pressure and of 80 per cent in pressure drop.

\section{MAGNITUDE OF ERROR FOR SMALIER PRESSURE DROPS}

If a pressure drop were computed to be 100 centimeters of water above atmospheric pressure without applying the pressure formula the true pressure drop would be found to be 96 centimeters of water, an error of 4.2 per cent.

If the pressure drop were computed to be 10 centimeters of water without applying the pressure formula the true pressure drop would be found to be 9.95 centimeters of water, an error of only 0.5 per cent.

\section{CONCLUSIONS}

When gas passes through a bed of broken solids it follows a very circuitous path. The passage may well be characterized as "tortuous" flow. The laws for fluid flow through conduits are very much altered by the presence of expansions, contractions, or bends, but if the system is disturbed by a great number of these there is an over-all effect that can be formulated into a definite and simple law of fluid flow. Such is the case with bẹds of broken solids. The simple law that apparently always applies when gas flows through beds of broken solids is expressed by the equation

$$
\Delta P=A R^{B},
$$

where $A$ and $B$ are constants for any particular condition, $R$ is the rate of flow, and $\Delta P$ is the pressure drop per unit of length. This report has concerned itself with the study of the variation of $A$ and $B$ with different conditions.

The foregoing material covers, in a more or less cursory manner, the influence of every variable, except one, that has a major effect in determining the character of flow of gases through beds of broken solids. The one exception is the effect of wetting the particles, and even it was not neglected entirely. 
This field is a very large one, and the data in many cases are necessarily incomplete, for the exhaustive study of the interrelations of the nine variables involved would be a stupendous task. These variables are: (1) Density of gas, (2) size of particles in the bed, (3) degree of packing, (4) size of container, (5) shape of particles, (6) size composition of beds of mixed sizes, (7) viscosity of gas, (8) molecular weight of gas, and (9) wetting of the particles.

The gases studied have been air, hydrogen, and carbon dioxide. The character of the surface of the solid particles has a neglible effect, if any, on the resistance to gaseous flow.

The equations to be used in determining or predicting gas flow and pressure drop are summarized in Appendix I. Temperatures studied have been from $25^{\circ}$ to $660^{\circ} \mathrm{C}$. Sizes of particles studied have ranged from 0.01 to 20 centimeters in diameter.

The accuracy of the data and methods of prediction leave much to be desired in some cases, but since this work was undertaken primarily as a study of the characteristics of an iron blast furnace, extreme accuracy is unnecessary because of the internal variability of that device.

The characteristics of fluid flow through a bed determine the amount of contact between the fluid and the solid, and all processes that involve an exchange of energy or substance between two such phases is vitally concerned with work of this character.

\section{FUTURE WORK}

Material is being compiled correlating the information in this report with information concerning gas flows, temperatures, and gas compositions as found in typical commercial blast furnaces. When completed, this work will reveal, at least in a general way, the characteristics of the gas flow throughout the stock of the average iron blast furnace. Considerable attention will be given to the prediction of pressure drops and characteristics of flow for different arrangements and compositions of materials which might be used in blast furnaces.

\section{APPENDIX I. SUMMARY OF EQUATIONS}

SIZED MATERIAL

The function for the resistance of sized materials may be summarized in one equation. The general form of the equation is

$$
\Delta P=A R^{B} .
$$


In detail (in C. G. S. units):

$$
\begin{aligned}
& \Delta P_{\infty}=\frac{82.8 \times 10^{B_{\mathrm{air}}+3.9093-3.4414} \frac{F}{V_{n}}+4.2 V+0.6177\left(\frac{F}{V_{n}}\right)^{2}-8.9 \mathrm{~V}-V_{\mathrm{n}}}{25}
\end{aligned}
$$

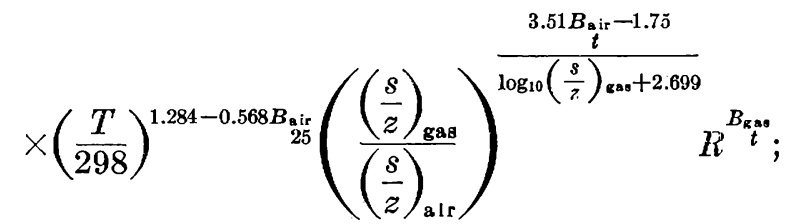

as a first approximation for air or similar gases,

$$
\Delta P_{\infty}=\frac{1,390 T^{0.15} R^{B_{\mathrm{air}}}}{P d^{1.2}}
$$

where

$$
B_{\substack{\mathrm{alr} \\ 25}}=\frac{0.006+d}{0.036+0.51 d}
$$

$$
B_{t} B_{t}=2.185 B_{25}^{a_{21}}-0.593-0.479\left(B_{25}-0.5\right) \log _{10} T ;(7.2)(\text { fig. } 71)
$$

as a first approximation,

$$
\begin{aligned}
& B_{\mathrm{atr}}=3.78-0.721 \log _{10} T,
\end{aligned}
$$

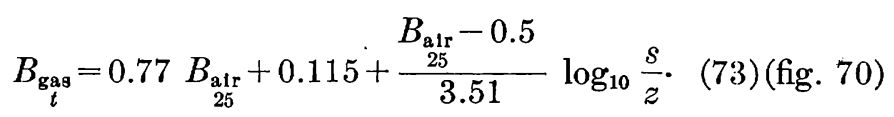

For explanation of nomenclature, see Appendix II.

The above equation is for containers of infinitely large diameter. Unless the diameter of the container is at least fifty times that of particles, the computed pressure drop should be multiplied by a factor. The value of this factor is given by Figures 33 and 34 .

Possible error of prediction with equation (71), 25 per cent.

For rough computation:

Average value of $V$ for irregular solids $=0.55$.

Average value of $\frac{F}{V_{n}}$ for irregular solids $=1.65$.

\section{TWO COMPONENT SIZES}

If computations are made for two component sizes, equation (71) is still applicable with the following changes:

(1) $d$ is the diameter of the small constituent.

(2) The values of $B_{\frac{a}{25}}$ for substitution in equation (7l) are no longer determined by equation (7) but by Figure 49 . 
(3) The computed pressure drop must be multiplied by a factor depending on the size composition. The relative pressure drops in Figures 45 to 47 are for a flow of 0.1 liter per second per square centimeter. Therefore, equation (71) must be multiplied by

$$
\text { Factor }=\Delta P_{\tau} 0.1^{B_{2}-B_{1}},
$$

where $\Delta P_{r}$ is the relative pressure drop indicated in Figures 45 to 47 , $B_{2}=$ the value of $B$ for the two component system.

$B_{1}=$ the value of $B$ for the small constituent.

Possible error of prediction, 25 per cent.

\section{SYSTEMS OF MANY COMPONENT SIZES}

Equation (71) is applicable to systems of many sizes if the term $d^{1.68-V_{n}}$ is displaced by the term

$$
\Sigma \text { per cent }\left(\sqrt{d_{1} d_{2}}\right)^{1.68-V_{n}},
$$

where $d_{1}$ and $\dot{a}_{2}$ represent the limits of spherical diameter in each screen-size fraction.

Per cent represents the fraction (by volume) of the bed in the size limit under consideration.

Symbol $\Sigma$ represents the sum of these various terms.

The values of $B_{\frac{a 1 r}{25}}$ may be computed with sufficient accuracy by means of Figure 63.

The resistance factor, as plotted on the abscissa,

$$
=\Sigma\left(\frac{\text { per cent }}{\sqrt{d_{1}}}\right)^{J}
$$

as a first approximation resistance factor

$$
=\frac{1}{d_{1}}+\frac{1}{d_{2}}+\frac{1}{d_{3}} \cdots-\frac{1}{d_{n}} .
$$

Estimated possible error of prediction, 50 per cent.

\section{MEANS OF APPROXIMATION}

To make an estimate of the value of the resistance the following approximations may be made:

1. The equivalent spherical diameter $d$ may be considered equal to the geometrical mean of the screen diameter.

2. The exponent of $d$, instead of being $1.68-V_{n}$, may be given as average value of 1.2 .

Estimated possible error of prediction, 75 per cent.

The wall-effect factor should be determined (figs. 33 and 34) for polycomponent sizes using the geometrical mean size. 


\section{CHANGE OF UNITS}

The constants of equation (71) were evaluated for C. C. S. units throughout. The transformation to other systems of units is simple though somewhat tedious.

Thus for the English system:

$$
\begin{aligned}
& \Delta P_{\infty}=\frac{391.2 \times 10^{B_{\mathrm{air}}+3.9093-3.4414} \frac{F}{V_{n}}+4.2 V+0.6177\left(\frac{F}{V_{n}}\right)^{2}-8.9 V^{2}}{P(d \times 2.54)^{1.68-V_{n}}} \\
& \times\left(\frac{T_{F}}{536}\right)^{1.284-0.568 B_{\mathrm{air}}}\left(\frac{\left(\frac{s}{z}\right)_{\mathrm{gas}}}{\left(\frac{s}{z}\right)_{\mathrm{a} 1 \mathrm{r}}}\right)^{\frac{3.51 B_{\mathrm{air}}-1.75}{\log _{10}\left(\frac{s}{2}\right)_{\mathrm{gaes}}+1.526}}(0.0305 R)^{B_{\mathrm{z} n \mathrm{~ns}}} ;
\end{aligned}
$$

as a first approximation for air or similar gases,

$$
\Delta P_{\infty}=\frac{1,965 T^{0.15}(0.0305 R)^{B_{\mathrm{air}}}}{P d^{1.2}},
$$

where $\Delta P$ is the pressure drop in inches of water per foot of height of column,

$P$ is the total pressure on the system in inches of mercury,

$d$ is the diameter of particles in inches,

$T_{F}$ is the absolute temperature in degrees Fahrenheit;

$S$ is the specific gravity of the gas compared to water,

$Z$ is the viscosity of the gas in English units (pounds per second-foot),

Noте.-C. G. S. viscosity unit (poise) $=0.0672$ English units.

$R$ is the rate of gas flow in cubic feet per square foot per second (under standard conditions),

$$
\begin{aligned}
& B_{\mathrm{alr}}=\frac{0.0024+d}{0.014+0.51 d} \\
& B_{i}=2.185 B_{77} B_{71 \mathrm{I}}-0.593-0.479\left(B_{77}-0.5\right)\left(\log _{10} T_{F}-0.255\right),
\end{aligned}
$$

as a first approximation,

$$
\begin{gathered}
B_{\mathrm{Ras}}=0.77 B_{\substack{\mathrm{a} 1 \mathrm{r} \\
77}}+0.115+\frac{B_{\mathrm{agr}}-0.5}{3.51}\left(\log _{10} \frac{s}{z}-1.173\right) ; \\
B_{\substack{\mathrm{alr} \\
t}}=3.96-0.72 \log _{10} T .
\end{gathered}
$$


If the gas flow is measured in pounds of air per square foot per hour, the term involving $R$ becomes $(0.000105 R)^{B_{\text {gas }}}$.

If, as is frequently the case, the pressure drops and the rate of flow are measured in the English system but the viscosity is measured in the C. G. S. system, the constants of equation (74) apply except that the factor involving $\frac{s}{z}$ is the same as equation (71) and equation (73) is used instead of equation (76).

\section{PRESSURE DROP IN COLUMNS OF MORE THAN UNIT LENGTH}

All of the preceding summary has dealt with columns of material of unit length. If the column is short, the total pressure drop may be computed by multiplying unit pressure drop by the total length.

\section{PRESSURE DROP IN LONG COLUMNS}

If the column is long enough so that the computed pressure drop is greater than 10 per cent of the total pressure, a different method of computation must be employed.

The equation is:

$$
\Delta P=\sqrt{P_{\mathrm{o}}\left(2 K h+P_{\mathrm{o}}\right)}-P_{\mathrm{o}} .
$$

Where $K$ is the pressure drop per unit of height at a pressure of $P_{0}, P_{\mathrm{o}}$ is the pressure at the exit end of the column of solids.

If $h$ is in centimeters and $K$ in centimeters of water per centimeter of height $P_{\mathrm{o}}$ must be expressed in centimeters of water.

1 atmosphere $=1,033$ centimeters of water.

\section{TOTAL PRESSURE DROP IF TEMPERATURE OR GAS COMPOSITION VARIES IN THE COLUMN}

If $K$, the pressure drop per unit of height at a pressure of $P_{0}$, varies because of temperature or gas composition changes throughout the column,

$$
\Delta P=\sqrt{P_{\mathrm{o}}\left(2 \mathcal{S} K d h+P_{\mathrm{o}}\right)}-P_{\mathrm{o}} .
$$

If $K$ is some unknown function of $h, \mathcal{S} K d h$ must be evaluated graphically from detailed data.

\section{EXAMPLES OF USE OF EQUATIONS AND CURVES}

\section{PROBLEM 1}

A certain Mesabi iron ore is sized to pass a square screen opening of 2.667 centimeters and to stay on a screen of 1.885 centimeters. The average true specific gravity of this ore was found to be 3.98. One hundred pieces picked at random out of a pile of the screened material weighed 2.047 grams. Ten kilograms was dropped into a round container 20.3 centimeters in diameter, so each piece fell into place individually in the bed and the average height of the bed was 16.25 centimeters. One hundred kilograms of the material is 
placed in a container 25.9 centimeters in diameter and packed until the bed is 95 centimeters high. A mixture of 27 per cent $\mathrm{H}_{2}, 43$ per cent $\mathrm{N}_{2}$, and 30 per cent $\mathrm{CO}$, at an average temperature of $800^{\circ} \mathrm{C}$., is passed through a.t a rate of flow of 0.2 liters per second per square centimeter under standard conditions. The outlet is at a pressure of 76 centimeters of mercury. What is the pressure drop through the system?

Solution:

\section{Shape factor}

The arithmetical mean of the screen opening $=\frac{2.667+1.885}{2}=2.276$ centimeters.

The average volume of the solid pieces $\frac{2,047}{3.98 \times 100}=5.143$ cubic centimeters.

The average equivalent spherical diameter $=\sqrt[3]{\frac{5.143}{0.524}}=2.143$ centimeters.

Shape factor (definition, p. 18) $=V_{n}=\frac{2.143}{2.276}=0.942$.

\section{Normal voids}

Definition, page 18 .

Apparent gravity in test cylinder $=\frac{10,000}{\pi \times 10.15^{2} \times 16.25}=1.902$.

From equation (6):

$$
\begin{gathered}
V_{n}=\left(1-\frac{1.90}{3.98}\right)=0.523 \\
\frac{F}{V_{n}}=\frac{0.942}{0.523}=1.801
\end{gathered}
$$

Voids in charge

Apparent gravity in column $=\frac{100,000}{\pi \times 12.95^{2} \times 95}=1.998$.

$$
V=\left(1-\frac{1.998}{3.98}\right)=0.502 \text {. }
$$

From equation (7),

$$
B_{\mathrm{sir}}=\frac{0.006+2.14}{0.036+0.51 \times 2.14}=1.90 \text {. }
$$

From Figure 71 , at $800^{\circ} \mathrm{C}$,

$$
B_{\mathrm{air}}=1.53 \text {. }
$$

Specific gravity of the gas is given by

$$
S=\left(0.27 \times \frac{2}{28.8}+0.43 \times \frac{28}{28.8}+0.30 \times \frac{28}{28.8}\right) \frac{273}{1,073} \times 0.001293=0.000239
$$


It can be seen from Figure 68 that the function of the variation of viscosity with temperature is the same for $\mathrm{N}_{2}$ as it is for CO. Therefore, while dealing with viscosity the gas may be considered as 27 per cent $\mathrm{H}_{2}$ and 73 per cent $\mathrm{N}_{2}$. From Figure 79 it will be scen that the viscosity at $0^{\circ} \mathrm{C}$. at this composition is $\frac{1,650}{10^{7}}$ C. G. S. units.

By drawing a straight line between the two extremities of this curve in Figure 79 it will be seen that at this composition the additive vissosity would be $\frac{1,440}{10^{7}}$ C. G. S. units.

Therefore, the viscosity of the mixed gases is 1.15 times as great as the additive viscosity.

Assume that this relation holds at the elevated temperatures.

From Figure 68 the additive viscosity at $800^{\circ} \mathrm{C}$. of the gas is

$$
(0.27 \times 2,150+0.73 \times 4,700) \times \frac{1}{10^{7}}=\frac{4,000}{10^{7}} \text { C. G. S. units. }
$$

Applying the factor; viscosity of mixture $=\frac{4,600}{10^{7}}$ C. G. S. units,

From Figure 68, for air

$$
\frac{s}{z}=\frac{0.000239}{0.0004600}=0.52 \text {. }
$$

From Figure 70 , at $800^{\circ} \mathrm{C}$,

$$
\frac{s}{z}(800)=0.730
$$

$$
B_{\mathrm{gas}}=1.46 .
$$

Substituting in equation (71),

$$
\begin{gathered}
\Delta P_{\infty}=\frac{82.8}{76.0 \times 2.14^{1.16}} \times 10^{1.80+3.8093-3.4414 \times 1.801+4.2 \times 0.502+0.6177 \times 3.244-8.0 \times .262} \times \\
\left(\frac{1,073}{298}\right)^{1.284-0.588 \times 1.80}\left(\frac{0.52}{0.730}\right)^{\frac{3.51 \times 1.53-1.75}{\log _{10} 0.62+2.699}} 0.2^{1.48}=1.02 .
\end{gathered}
$$

This value for $\Delta P$ is for an infinitely large container.

The ratio of size of particles to size of container is $\frac{2.14}{25.9}=0.083$.

In this case the upper half of Figure 34 is used for the determination of the wall-effect factor.

Interpolating between the curves, for $B=1.25$ and $B=1.50$,

Factor $=0.80$.

Therefore: $\Delta P=0.82$.

This is the pressure drop per unit of length (centimeters).

Neglecting the cumulative pressure effect, total pressure drop $=95.0 \times 0.82$ $=78$ centimeters of water.

\section{PROBLEM 2}

Assume that the column of material is 10 meters high instead of 95 centimeters (problem 1) but that all other conditions are the same. What is the pressure drop through the system?

In this case the cumulative effect of pressure is significant.

Atmospheric pressure is $76.0 \times 13.6=1,034$ centimeters of water. 
From equation (69),

$$
\begin{aligned}
\Delta P & =\sqrt{1,034(2 \times 0.82 \times 1,000+1,034)}-1,034, \\
& =629 \text { centimeters of water. }
\end{aligned}
$$

If the pressure effect had been disregarded, the computed pressure drop would have been 820 centimeters of water.

\section{PROBLEM 3}

One-half of the material of problem 1 is crushed to an equivalent spherical diameter of 0.1 centimeter. The two sizes are uniformly mixed and slowly dropped into the same tube with no additional packing. What is the pressure drop through the bed when air at $25^{\circ} \mathrm{C}$. is flowing at a rate of 0.05 liter per second?

It is necessary first to compute the value of $A$ for the general equation (1). If the last factor of equation (71) is unity, the computed pressure drop is the value of $A$.

For large constituent,

$$
B_{25}=1.90 \text {. }
$$

For small constituent,

$$
B_{25}=1.21 \text {. }
$$

The normal voids for each constituent $=0.523$. There is no additional packing.

For large constituent, $d=2.14$,

$$
\begin{aligned}
\frac{F}{V_{n}} & =1.801, \\
B & =1.90, \text { and } \\
V & =0.523 .
\end{aligned}
$$

Substituting in equation (71), $T=298$,

$$
A_{\infty}=10.4 \times 1 \times 1 \times 1=10.4 \text {. }
$$

For small constituent,

Substituting in equation (71),

$$
\begin{aligned}
& d=0.1 \\
& B=1.21
\end{aligned}
$$

For large constituent,

$$
A_{\infty}=74 \text {. }
$$

at $R=0.1$,

For small constituent,

$$
\Delta P_{\infty}=10.4 \times 0.1^{1.00}=0.131 \text { centimeter of water. }
$$

$$
\begin{aligned}
& \text { at } R=0.1 \\
& \Delta P_{\infty}=74 \times 0.1^{1.21}=4.58 \text { centimeters of water. }
\end{aligned}
$$

The ratio of $\Delta P_{\infty}$ for the two sizes at $R=0.1$ is $\frac{0.131}{4.58}=0.0286$.

Interpolating between Figures 46 and 47 for a 50-50 mixture of the two components, it is found that the $\Delta P_{\infty}$ for the mixed system is 2.90 times as great as for the small constituent

Therefore at $R=0.1$,

$$
\Delta P_{\infty}=2.90 \times 4.58=13.3 .
$$


For the mixed system, from Figure 49,

$$
B=1.90 \times 0.735=1.40 \text {. }
$$

For the mixed system

$$
A_{\infty}=\frac{13.3}{0.1^{1.40}}=335
$$

In the mixed system the average equivalent spherical diameter $=\sqrt{0.1 \times 2.14}$ $=0.46$ centimeter.

Since the container is 25.9 centimeters in diameter,

$$
\frac{d}{D}=0.02 \text {. }
$$

From the lower half of Figure 29 the wall-effect factor is 0.95 .

Therefore, $A=318$.

For a flow of 0.05 liter per second per square centimeter, $\Delta P=318 \times 0.05^{1.40}=4.8$.

This is the pressure drop per unit of height. Interpolating between Figures 52 and 53 , it is found that upon mixing the two constituent sizes the voids in the bed are decreased from 0.52 to 0.38 .

The height of the column (see problem 1) then becomes

$$
95 \times\left(\frac{1-0.52}{1-0.38}\right)=73.5 \text { centimeters. }
$$

If there were no cumulative pressure effect for the entire column,

$$
\Delta P=4.8 \times 73.5=353 \text { centimeters of water. }
$$

Actual total pressure drop (equation 69),

$$
\begin{aligned}
\Delta P & =\sqrt{1,034(2 \times 353+1,034)}-1,034 \\
& =307 \text { centimeters of water. (Ans.) }
\end{aligned}
$$

\section{PROBLEM 4}

\begin{tabular}{|c|c|c|c|c|c|c|c|c|c|c|c|}
\hline \multirow[b]{2}{*}{ I'hrough....... } & \multicolumn{10}{|c|}{ Screen size } & \multirow{3}{*}{ Total } \\
\hline & $\begin{array}{l}5.35 \\
\mathrm{~cm} .\end{array}$ & $\begin{array}{l}2.67 \\
\mathrm{~cm} \text {. }\end{array}$ & $\begin{array}{l}1.33 \\
\mathrm{~cm} .\end{array}$ & 3-mesh & 8 & 14 & 28 & 48 & 65 & 100 & \\
\hline (1) & $\begin{array}{l}2.67 \\
\mathrm{~cm} .\end{array}$ & $\begin{array}{l}1.33 \\
\mathrm{~cm} .\end{array}$ & 3-mesh & 8-mesh & 14 & 28 & 48 & 65 & 100 & 200 & \\
\hline $\begin{array}{l}\text { (2) G e o metrical } \\
\text { mean } \operatorname{size}=\sqrt{d_{1} d_{2}}\end{array}$ & 3. 79 & 1.88 & 0.942 & 0.397 & 0.165 & 0.083 & 0.042 & 0.025 & 0.0175 & 0.010 & \\
\hline (4) $d_{m}: 16$ & $\begin{array}{l}9.9 \\
4.69\end{array}$ & $\begin{array}{c}12.4 \\
2.08\end{array}$ & $\begin{array}{l}12.6 \\
.931\end{array}$ & \begin{tabular}{|l}
13.4 \\
.342
\end{tabular} & $\begin{array}{l}6.4 \\
.124\end{array}$ & $\begin{array}{l}8.2 \\
.0557\end{array}$ & $\begin{array}{l}20.4 \\
.0253\end{array}$ & $\begin{array}{l}5.0 \\
.0139\end{array}$ & $\begin{array}{l}4.6 \\
.00916\end{array}$ & $\begin{array}{l}7.0 \\
.00474\end{array}$ & $\begin{array}{r}99.9 \\
\hdashline \ldots\end{array}$ \\
\hline (5)Resistance factor $\frac{(3)}{(4)}$ & .02 & .06 & .135 & .392 & .515 & 1.47 & 8.05 & 3.60 & 5.01 & 14.60 & 33.9 \\
\hline
\end{tabular}

The material of problems 1, 2, and 3 was obtained from a run-of-mine Mesabi ore having the screen analysis given in Table 1, following. The shape factor and voids of normal packing are practically the same for all constituent sizes. What is the pressure drop in a column of this material 100 centimeters high when air at $25^{\circ} \mathrm{C}$. is passing through at a rate of 0.03 liter per second per centimeter?

TABLE 1.-Screen analysis of run-of-mine Mesabi ore

Note.-The figure 33.9 is the "resistance factor" of the entire mixed bed. From Figure 63 it can be seen that the probable value of $B$ is 1.10 . 
The reciprocal of $33.9(1 / 33.9=0.0295)$ may be substituted for $d^{1.68-V_{n}}$ in equation (71).

The following values are substituted in equation (71).

Solving equation (71),

$$
\begin{aligned}
B_{25} & =1.10, \\
d^{1.16} & =0.0295, \\
T & =298, \text { and } \\
R & =0.03 .
\end{aligned}
$$

$$
\Delta P_{\infty}=237 \times 1 \times 1 \times 0.03^{1.10}=5 \text { centimeters of water } .
$$

The wall-effect factor may be neglected in this case. Substituting in equation (69),

$$
\begin{aligned}
\Delta P & =\sqrt{1,034(2 \times 5 \times 100+1,034}-1,034 \\
& =416 \text { centimeters of water (Ans.). }
\end{aligned}
$$

\section{APPROXIMATE EQUATIONS}

For approximate results the very simple equations (71a) and (72a) (or (76a) and (77a)) may be used. The equations are self-explanatory.

\section{APPENDIX II.-TABLE OF NOMENCLATURE}

Explanation of subscripts

1, 2, 3 designate particular values of constants.

10 refers to the logarithm to the base 10 .

25 refers to $25^{\circ} \mathrm{C}$.

77 refers to $77^{\circ} \mathrm{F}$.

$\infty$ refers to a container of infinite size.

Air refers to air.

$C$ refers to container.

$d$ refers to displacement diameter.

$n$ refers to normal voids.

$p$ refers to solid particles.

$S$ refers to standard conditions.

$t$ refers to a specified constant temperature.

$w$ refers to wall of the container.

Explanation of symbols

$A=$ pressure drop at standard conditions in centimeter of water per centimeter of height at a rate of gas flow of 1 liter per second per square centimeter under standard conditions of temperature and pressure.

$a=$ area in square centimeters.

$43318^{\circ}-29-10$ 
$B=$ a constant exponent for a paríicular system as defined by equation (1). No units.

$b=$ a general constant.

$d=$ equivalent spherical diameter of particles in centimeters.

$D=$ diameter of container in centimeters.

$e=$ base of natural logarithms $=2.71828$.

$f=$ friction factor. No units.

$F=$ shape factor. Equivalent spherical diameter divided by the average screen size. No units.

$g=$ acceleration due to gravity; C. G. S. units.

$G=$ standard pressure drop for the small component of a two component mixture measured in centimeters of water per centimeter of height at a flow of 0.1 liter per second per square centimeter under standard conditions.

$h=$ maximum standard pressure drop in two component systems. Measured in centimeters of water per centimeter of height at a flow of 0.1 liter per second per square centimeter under standard conditions.

$J=$ exponent in equation for variation of pressure drop with particle size. Constant for given conditions. No units.

$K=$ a general symbol for any constant, used in developing an equation.

$K_{1 \infty}=$ a definite constant termed the "specific resistance." It is the standard pressure drop at $25^{\circ} \mathrm{C}$. in centimeters of water per centimeter of height for a column of a specified material when the rate of flow of air is 0.1 liter per second per square centimeter under standard conditions, average equivalent spherical diameter of the particles is 1 centimeter and the voids in the bed are 0.50 .

$L=$ standard pressure drop measured in centimeters of water per centimeter of height for the large constituent in a two component system when the rate of flow is 0.1 liter per second per square centimeter under standard conditions. $M=$ a constant used in the equations of wall effect. No units. $m=$ a general constant used to designate the slope of a straight line.

$n=$ an exponent used with the modulus $\frac{z}{d u s}$ to designate the changes in friction factor of resistance. No units.

$P=$ pressure in units designated.

$\Delta P=$ pressure drop; unless otherwise designated, in centimeters of water per centimeter of height of column.

$q=$ an exponent in the equation for the variation of gaseous viscosity with temperature. 
$R=$ rate of flow of gas; unless otherwise designated, measured in liters per second per square centimeter of area under standard conditions.

$\boldsymbol{r}=$ radius of a particle in centimeters.

$s=$ specific gravity. No units.

$T={ }^{\circ} \mathrm{C}$. absolute temperature, unless otherwise designated.

$u=$ linear gas velocity in centimeters per second.

$V=$ voids in bed measured in fractional part of the total volume. No units.

$W=$ weight of a specified substance in grams.

$x=a$ general variable used in the development of equations, denoting the quantities plotted as abscissas.

$y=a$ general variable used in the development of equations, denoting the quantities plotted as ordinates.

$z=$ viscosity of gases. Measured in C. G. S. units or "poises." 



\section{N DE X}

Accuracy, of readings, statement of

Page

Air, flowing through sized materials, sum-

mary of data on

Anthracite, effect of packing, curves showing 34,36 relation between average normal voids and exponent of equation, curvesshowingrelation between pressure drop and size of particle for, curve showing. summary of dats on air flowing through

Audibert, M. E., work cited .............

Augustine, C. E., work cited.. $4,20,31,48,52,59,61$ curves illustrating $34,36,49$

Bed, depth of, effect on pressure drop. curve showing.

Binary systems. See Two-component systems.

Blake, F. C., work cited

Blast-furnace ore charge, constants for determining resistance to gas flow of ...... pressure-drop data for, curves showing . . . size analyses of

Borelius, G., work cited. W., work cited ...- 4, 20,31,48,52,59,61 curves illustrating $34,36,49$

Burke, S. P., work cited.

Cadiz ore, screen analyses of

Chappell, E. L., work cited

Coke, bed of, cross section of, view of constants for determining resistance to gas flow of.

physical constants of

resistance data on.

screen analyses of

size analyses of

Or-

curves showing.

summary of data on air flowing through

Columns, long, pressure drop in, study of ....

Conclusions, on investigation

Container surface, effect of, on pressure drop

Cotton, A., work cited

Curves, use of, examples of

Cuyuna iron ore, beds of, cross sections of views of

broken, bed of, resistance of, curve showing constants for determining resistance to gas flow of

data on. ing

variation of pressure drop in, curves showing

voids in, curves showing

physical constants of

prediction of value of exponent for
Cuyuna iron ore, pressure-drop tests, with curves showing ..................... 24, 27, 28, 29

quantitative effect of packing os . ......... 30 curves showing ...................... 32, 33, 34

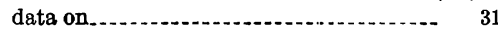

relation between normal voids and exponent of equation, curve shıwing ..... 50

relation between shape factor and normal voids in curve showing

resistance data on.

54

52

screen analyses of ............................ 94

size analyses of ........................... 91,92

curve showing

specific resistance of, curve showing ....... 53

summary of data on air flowing through ... $\quad 58$

used in tests, variation in .................. 53

wall-effect studies with, curves showing _. _ $\quad 41$

data on......................................... 42

Cuyuna iron ore and water, mixture of, theoretical specific volume of, curve show. ing

Down draft, in blast furnace, effect of

Equations, approximate, list of

summary of . . . . .

use of, examples of....................... 132

Equivalent spherical diameter, data on ...... 3

definition of ............................. 17

Expansion chamber, length of, efiect of, on pressure drop............................

diagram showing .................... 11

Fanning's equation, use of

Flow, approximate law of _................. 17

tortuous, experimental analysis of . ........ 10

explanation of

general law for, equation expressing ....- 6

explanation of .......................... 12

objection to . ......................... 13

turbulent, in conduits, equation for ......- 5

Flue dust, screen analysis of ............... 94

Free area, effective, deflnition of.............. $\quad 20$

for beds of broken solids, table showing.- 22

Friction factor, explanation of ........... 5

qualitative relations of, curve showing-..-- $\quad 5$

Fuel bed, synthetic, description of...-_.... 10

diagram of . . . .

variation of exponent $B$ with cross section of passages, diagram showing ....... 13

Furnas, C. C., work cited ................

Gaseous flow, resistance to, effect of wall surface on . . . . . . curves illustrating ..................... 41, 43, 44

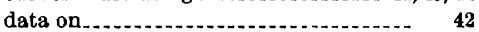




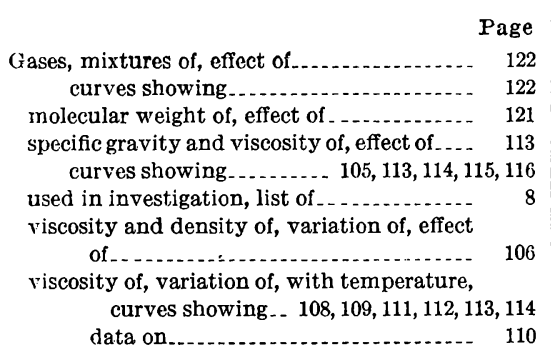

Hartgen, F. A., work cited

Haslam, R. T., work cited . . . . . . . . . . . 103

Hersey, M. D., acknowledgment to.........

Hofsïss, $M$.

Holbrook, W. F., acknowledgment to .......

Johnson, F. M. G., work cited -

Joseph, T. L., acknowledgment to

Judd, Horace, work cited.

Kinney, S. P., acknowledgment to

Kossonogov, I. I., work cited.

Kreisinger, Henry, work cited curves illustrating

Jarose, P., work cited.

Lead shot, beds of, cross sections of, vien resistance of, curve showing

data on ........................................ effect of packing, curves showing

of two sizes, pressure drop of, curves show-

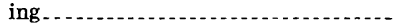
variation of pressure drop in, curves showing -

voids in, curves showing

physical constants of pressure-drop studies with, curves show-

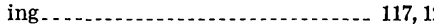

relation between average normal voids and exponent of equation, curve showing.

resistance data on ........................... specific resistance of, curve showing........summary of data on air flowing through ... wall-effect studies with, curve showing ... data on.

Lead shot and Cuyuna iron ore, pressure drop of, curve showing

specific volume relations in, curve showing variation of pressure drop in, curves showing.

voids in, curves showing

Lead-shot systems, specific volume relations of, curves showing

Lewis, G. N., work cited.

Lifting velocity, definition of ...............

Limestone, beds of, cross sections of, views of. constants for determining resistance to gas flow of

physical constants of

prediction of pressure drop for ..............

curve showing

properties of, data on.
Limestone, relation between shape facto: and normal voids in, curve showing. . resistance data on size analyses of . . . . . . . . . . . . . . . specific resistance of, curve showing ........ $\quad 53$ summary of data on air flowing through ... $\quad 58$ Lindblom, S., work cited.................. 13

Maier, C. G., acknowledgment to......... 4

Material, sized, equations for ............... 128 experimental work on ................... 19

Maximum, law of the, curve illustrating .... $\quad 66$ explanation of . . ...................... 66

McAdams, W. H., work cited .......... 12, 84, 102

Mesabi iron ore, beds of, cross sections of, view of constants for determining resistance to gas

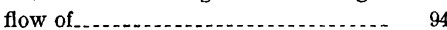

physical constants of ..................... 3

prediction of values of exponent for ......... 95

pressure-drop studies with, curves showing .............................. 118, 121

relation between average normal voids and exponent of equation, curve showing-

relation between pressure drop and size of particle for, curve showing.

relation between shape factor and normal voids in, curve showing

resistance data on ........................ 52

screen analyses of ......................... 94

size analyses of ......................... 91,92

curves showing ........................ 89

specific resistance of, curve showing ....... summary of data on air flowing through . . $\quad 58$ temperature tests with, results of, curves showing ...................... 105, 113

tests of, sample computations for . . . . . . 132

used in tests, variation in ........... 53

Mixtures, rule of ......................... 68

Moisture, effect of

Nicholls, P., work cited........ . 4, 20,31, 48, 52, 59, 61 curves illustrating .................. $34,36,49$

Nomenclature, table of . ................... 137

Normal packing, definition of . . . . . . ..... 18

per cent voids in, data on

North Central Experiment Station, work of ..

Orr, M. L., work cited . . ..... . 4, 20, 31, 48, 52, 59, 61 curves illustrating ...................... $34,36,49$

Packing, quantitative effect of .............. 30 curves showing ........................ $32,33,34$ data on ............................. 31

Passage, size of, effect on exponent $B$....... $\quad 12$

Plummer, W. B., acknowledgment to ...... 4 work cited

Pressure drop, apparatus for determining air supply in details of . . . . . diagram of .............................. 8 manometers for........................ 8 meter for, calibration of ................ 9 procedure with ...................... 9

views of . .

change of, with size of particle............ 23 curve jllustrating........................ 23

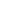

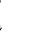

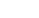

1

(3)

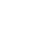

5

21

50

49

4

4

9

8

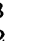

8

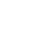


Pressure drops, effect of container surface on curve showing

effect of depth of bed on

curve showing

effect of size composition on, at specified flow rate

equations for

in long columns, study of -

predicition of, for sized materials curves showing.

relat:on to size of particle, curves showingstandardization of

through layered beds, curves showing . .... discussion of

variation of, in two-component systems. curves showing

with average cross-sectional areas of part.cles, curve showing .............. with gas composition curves showing. $117,118,121,123$ data on $\ldots 119$

with rate of gas flow, curve showing _.... $\quad 24$ with total pressure. curves showing.

Provo coke, sample pressure-drop computation with

curve illustrating. ing.

Provo ore, constants for determining res:stance to gas flow of

prediction of value of exponent for ........ pressure drop in, sample computation for - sample pressure-drop computation with

curve illustrating

screen ańalyses of

size analyses of

Ralston, O. C., acknowledgwent to .......

Randall, Merle, work cited.................

Ray, W. 'T., work cited

- 4,31,59

curves illustrating _................. 34, 36, 48

Resistance, components of, diagram illustrating -

concept of . - . -

lowering, by using more than two com-

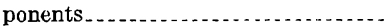

maximum, highest value of

of bed of broken material, with particle size, study of curves illustrating ........... _ 4 47, 48, 49,50

specific, siguificance of.

variation of, with shape of particle data on

Resistance factor, relation of, to exponent $B$, for systems of mixed sizes, diagram showing :

Resistance maxima, positions of curves illustrating

Reynolds, Osborne, work cited .............

Roll scale, bed of, cross section of, view of .-.-

physical constants of

prediction of pressure drop for curve showing

sample computation for
Roll scale, properties of, data on relation between shape factor and normal voids in, curve showing............. 54 screen analyses of .................... E4 summary of data on air flowing through _... 58 Royster, P. H., work cited .................

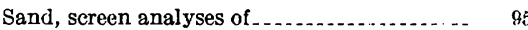

size analyses of _......... 91,92

Scope of work, statement of ............... 2

Screen size, data on .................................

Screen-size openings, average, data on .....

Seltzer, M., work cited ................... 106

Shape factor, data on ................... 3

definition of

relation to normal voids.

curve showing .......................... 54

Shot. See Lead shot.

Sinter, screen analyses of . . . . . . . .

Size, concept of .

Soil, dry, screen analysis of . . . . . . . ....... 95 size analysis of

Solids, broken, hypothetical systems of, resistance in . . curves showing

Specific gravity, data on.....................

Specific volumes, of two-component mixtures, law for

Specific volume relations, curves showing ... 78,79

study of $\ldots \ldots \ldots$.

Stone dust, screen analyses of ............. 95

size analysis of ......................... 91,92

Storrow, J. T., screen-analysis data of ...... 95 work cited

Subscripts, explanation of . _............ 137

Summary, presentation of . . .

Symbols, explanation of ................... 137

Systems involving a liquid, specific volume of curve showing

Systems of mixed sizes, equations for . . . . . . 130

flow of gases through, curves illustrating ... 86, 87

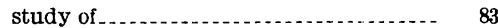

apparatus for, description of . ......... 83 diagram of view of 84

prediction of pressure drop in $\ldots \ldots \ldots . . .95$

curve illustrating ........................ 100

specific volumes in

Temperature, changing, effect of, sample computation for . . . 122

effect of, study of .

apparatus for, description of ....... 102 diagram of 102 view of 102

data obtained by ................ 104

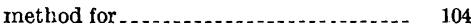

results obtained by

curves showing. 105

of a system, effective

Transition stage, variability of .............. 88

Two-component systems, data on .......... 62

equations for

resistance of, lowering 68

rule of 67

separation of constituent sizes in, effect of. - 72 


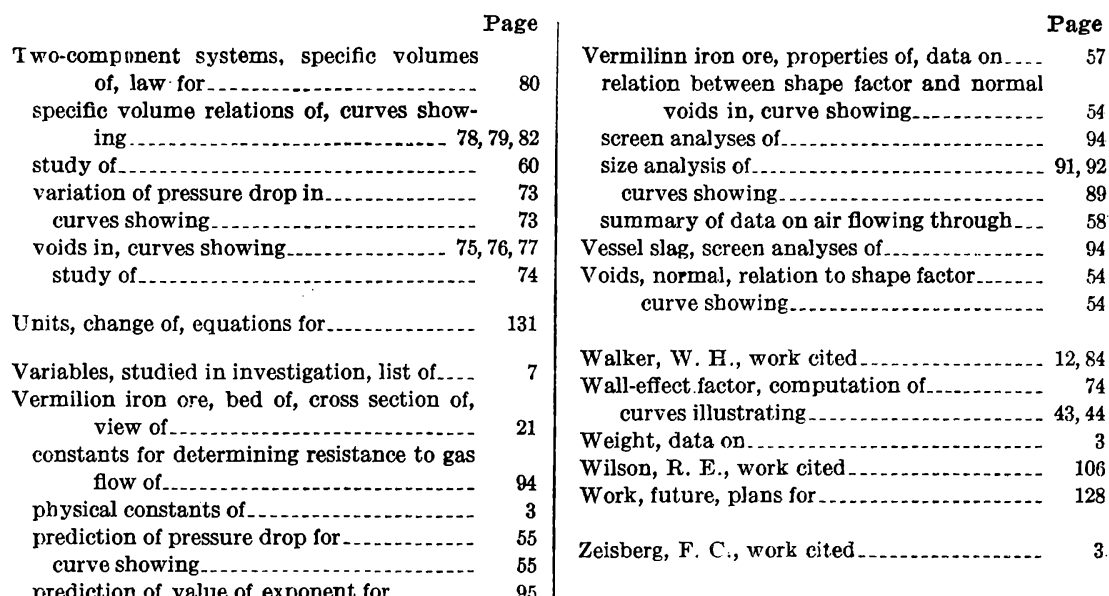

